\title{
Comparative Safety Analysis of LNG Storage Tanks
}

\author{
B. A. Fecht \\ T. E. Gates \\ K. O. Nelson \\ G. D. Marr
}

July 1982

Prepared for the U.S. Department of Energy under Contract DE-AC06-76RLO 1830

Pacific Northwest Laboratory Operated for the U.S. Department of Energy by Battelle Memorial Institute 


\title{
DISCLAIMER
}

This report was prepared as an account of work sponsored by an agency of the United States Government. Neither the United States Government nor any agency thereof, nor any of their employees, makes any warranty, express or implied, or assumes any legal liability or responsibility for the accuracy, completeness, or usefulness of any information, apparatus, product, or process disclosed, or represents that its use would not infringe privately owned rights. Reference herein to any specific commercial product, process, or service by trade name, trademark, manufacturer, or otherwise, does not necessarily constitute or imply its endorsement, recommendation, or favoring by the United States Government or any agency thereof. The views and opinions of authors expressed herein do not necessarily state or reflect those of the United States Government or any agency thereof.

\author{
PACIFIC NORTHWEST LABORATORY \\ operated by \\ BATTELLE \\ for the \\ UNITED STATES DEPARTMENT OF ENERGY \\ under Contract DE-AC06-76RLO 1830
}

\begin{tabular}{|c|c|}
\hline Printed in the & of America \\
\hline & 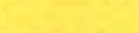 \\
\hline National Tech & tion Service \\
\hline United States & f Commerce \\
\hline 5285 & od \\
\hline Springf & 22151 \\
\hline & \\
\hline & \\
\hline & \\
\hline & Price \\
\hline Pages & Codes \\
\hline 001-025 & $\mathrm{A} 02$ \\
\hline $026-050$ & $\mathrm{~A} 03$ \\
\hline 051-075 & A04 \\
\hline $076-100$ & A05 \\
\hline $10:-125$ & A06 \\
\hline $126-150$ & A07 \\
\hline $151-175$ & $\mathrm{~A} 0 \mathrm{~B}$ \\
\hline $176-200$ & A09 \\
\hline $201-225$ & A010 \\
\hline $226-250$ & A011 \\
\hline $251-275$ & A012 \\
\hline $276-300$ & A013 \\
\hline
\end{tabular}




\section{4}

PNL-4399

UC-11

COMPARATIVE SAFETY ANALYSIS OF LNG STORAGE TANKS
B. A. Fecht
T. E. Gates
K. 0. Nelson
G. D. Marr

July 1982

Prepared for

the U.S. Department of Energy Office of

Environmental Protection, Safety and Emergency Preparedness Under Contract DE-AC06-76RLO 1830

Pac ific Northwest Laboratory

Richland, Washington 99352 



\section{FOREWORD}

This report is one of a series prepared by Pacific Northwest Laboratory (PNL) to communicate results of the Liquefied Gaseous Fuels (LGF) Safety Studies Project, being performed for the U.S. Department of Energy, Office of Environmental Protection, Safety and Emergency Preparedness (DOE/EP). The DOE/EP Office of Operational Safety, Environmental and Safety Engineering Division (ESED), is conducting the DOE Liquefied Gaseous Fuels Safety and Environmental Control Assessment Program. The LGF Safety Studies project contributes research, technical surveillance and program development information in support of the ESED Assessment Program. Th is comparative safety analysis of LNG storage tanks benefited from the technical direction and guidance provided by Dr. John M. Cece and Dr. Henry F. Walter of ESED. Completed effort in other tasks of the PNL project are reported in:

1. Assessment of Research and Development (R\&D) Needs in LPG Safety and Environmental Control (PNL-3991)

2. Assessment of Research and Development (R\&D) Needs in Ammonia Safety and Environmental Control (PNL-4006)

3. An Overview Study of LNG Release Prevention and Control Systems (PNL-4014)

4. Analysis of LNG Import Terminal Release Prevention Systems (PNL-4152)

5. Analys is of LNG Peakshaving Facility Release Prevention Systems (PNL-4153)

6. LNG Fire and Vapor Control System Technologies (PNL-4398)

7. Applications of Human Factors Engineering to LNG Release Prevention and Control (PNL-4090) 


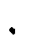




\section{ACKNOWLEDGEMENTS}

Th is comparative safety analys is of LNG storage tanks benefited from several plant visits undertaken by the authors and other members of the project team. The authors wish to acknowledge and thank contributing representatives from the natural gas industry and several tank manufacturing firms who made technical staff available for consultation with members of the project team. This report contains the authors' interpretation of all such information received.

The authors also gratefully acknowledge the assistance provided by individuals at Pacific Northwest Laboratory (PNL) during the course of this study and preparation of the final report. J. G. DeSteese, Manager of the Liquefied Gaseous Fuels Safety Studies Project at PNL, provided support and guidance throughout the study. P. J. Pelto provided technical insights about the LNG facilities and also provided a technical review of the entire study. The editorial review of the final report prior to publication was contributed by Karen Yasutake and Cary Counts. Finally, Marlene Hale and Annette Taylor contributed their word processing skills in the preparation of the final manuscript. 
. 


\section{CONTENTS}

FOREWORD

ACKNOWLEDGEMENTS

1.0 SUMMARY

1.1

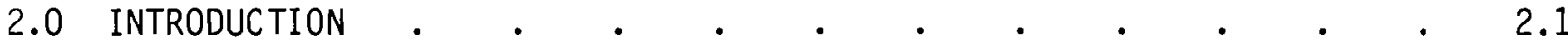

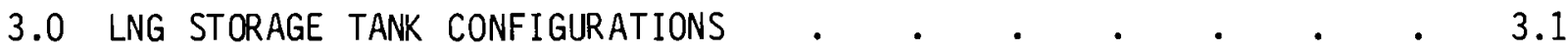

3.1 TANK TYPES $\quad . \quad \ldots \quad$.

3.1 .1 Double Wall Metal Tanks . . . . . . . 3.2

3.1.2 Prestressed Concrete Tanks . . . . . . . 3.6

3.1.3 In-ground Storage Tanks $\quad . \quad . \quad . \quad . \quad . \quad$. 3.12

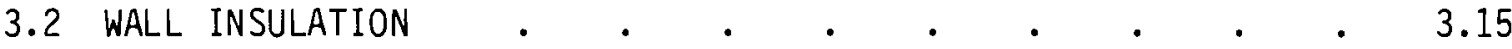

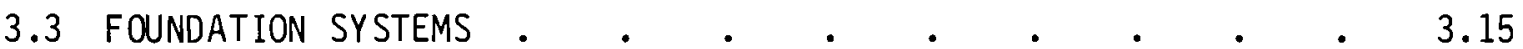

3.3.1 Concrete Ring Foundation . . . . . . . 3.16

3.3.2 Pilings With Concrete Cap . . . . . . . 3.16

3.3.3 Concrete Mat With Load Bearing Insulation . . . 3.17

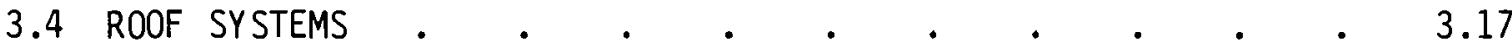

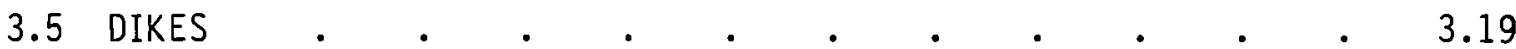

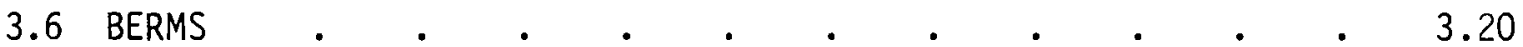

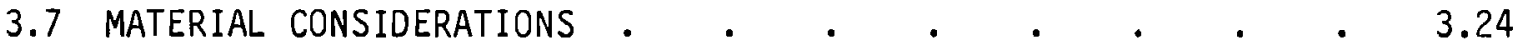

3.7 .1 Metals $. \quad . \quad . \quad . \quad . \quad . \quad . \quad . \quad . \quad . \quad 3.24$

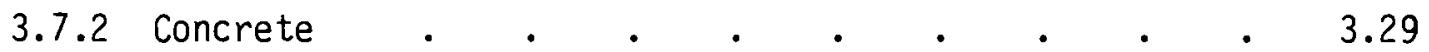

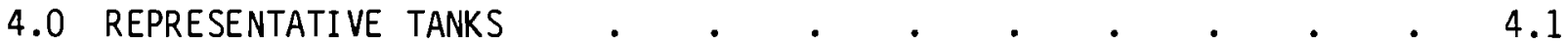

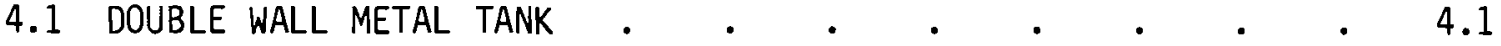

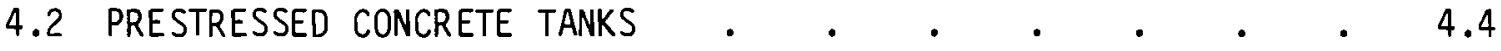

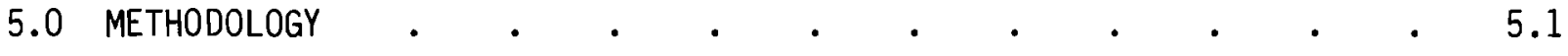




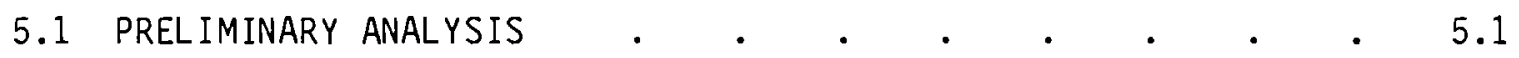

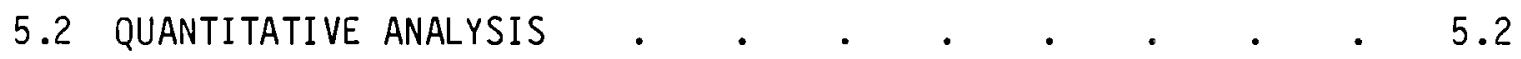

5.2.1 Overfil1 and Overflow . . . . . . . . . 5.3

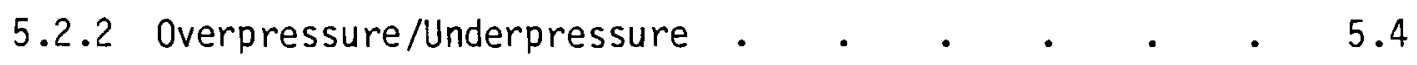

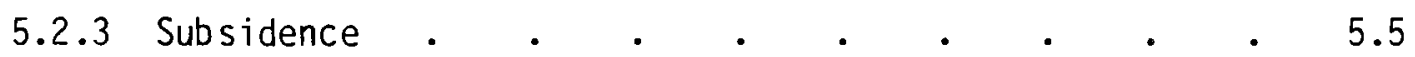

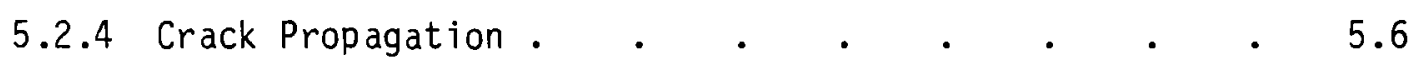

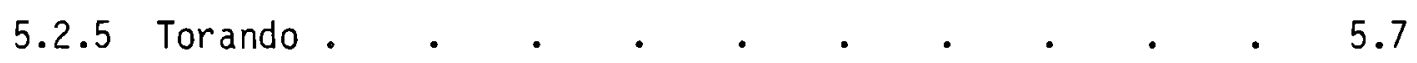

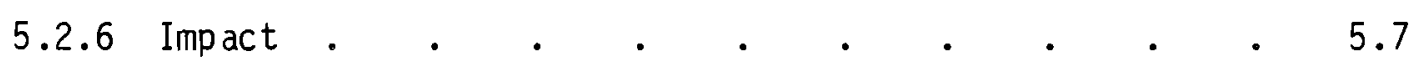

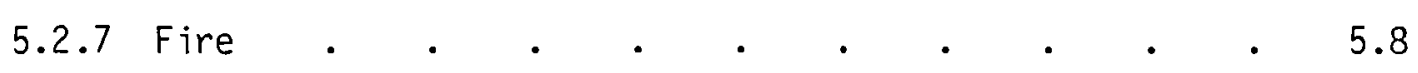

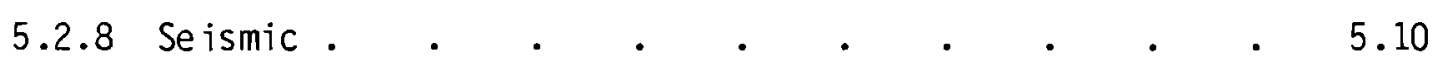

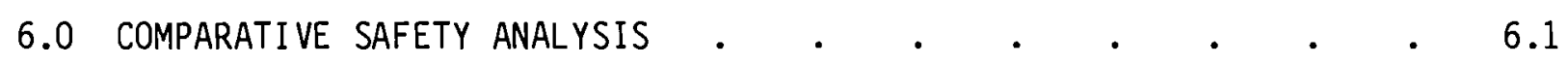

6.1 PRELIMINARY COMPARATIVE SAFETY ANALYSES • . . . . . 6.1

6.2 QUANTITATIVE COMPARATIVE SAFETY ANALYSIS $\quad . \quad \ldots \quad$ • $\quad$ • 6.2

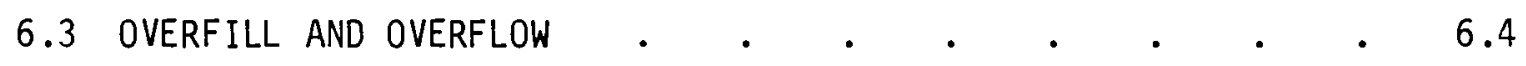

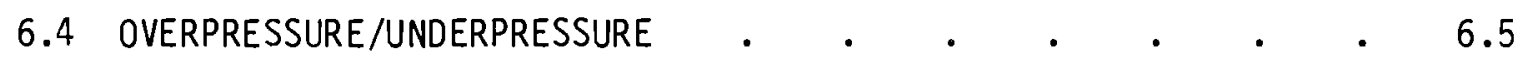

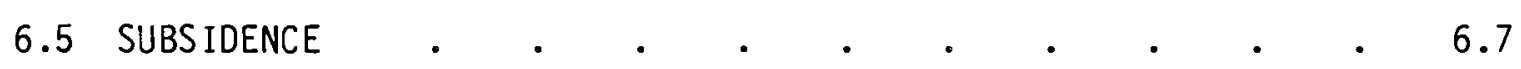

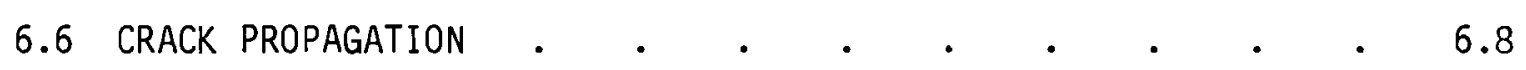

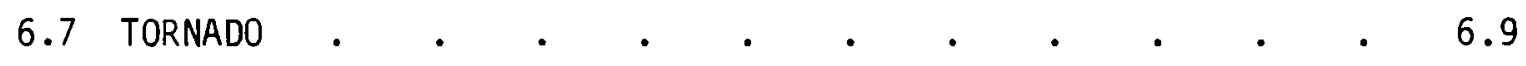

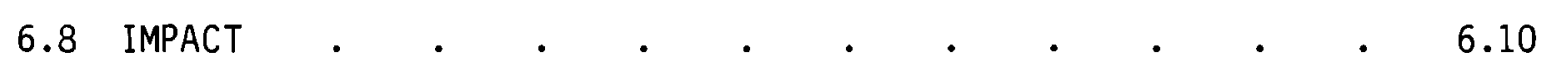

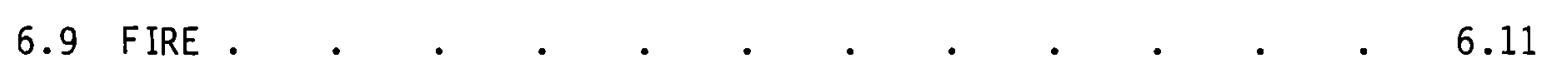

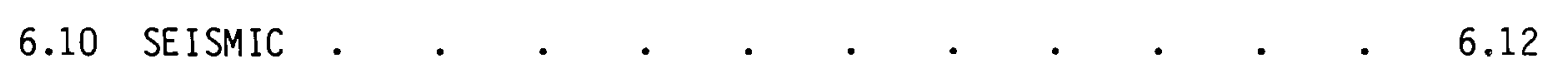

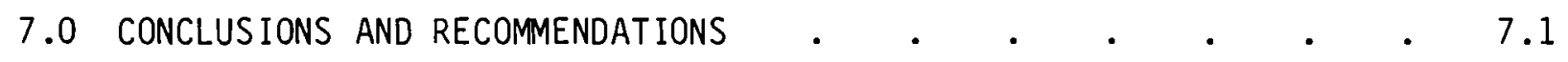

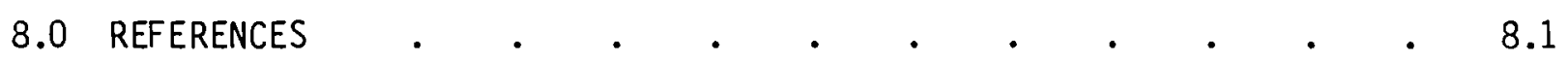

APPENDIX A - PRELIMINARY COMPARATIVE SAFETY ANALYSIS DETAILS • • • A.1

APPENDIX B - QUANTITATIVE COMPARATIVE SAFETY ANALYSIS DETAILS • • • B.1 


\section{FIGURES}

3.1 Double Wall Metal Tank With Double Roof and Piping Foundation . 3.3

3.2 Double Wall Metal Tank With Suspended Deck Roof and Concrete Ring Foundation $. \quad . \quad . \quad . \quad . \quad . \quad . \quad . \quad . \quad . \quad 3.4$

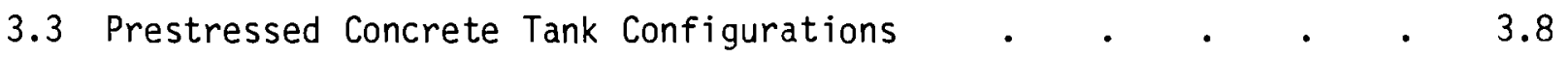

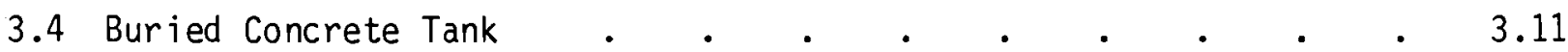

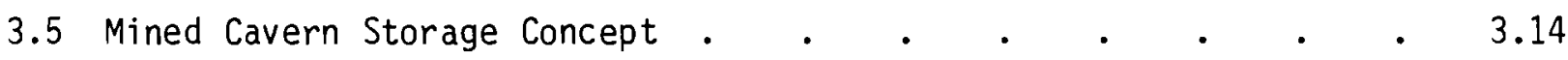

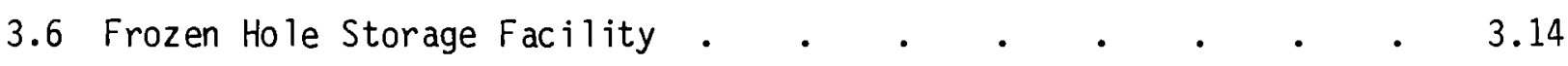

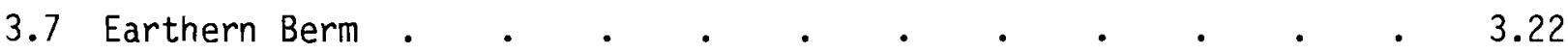

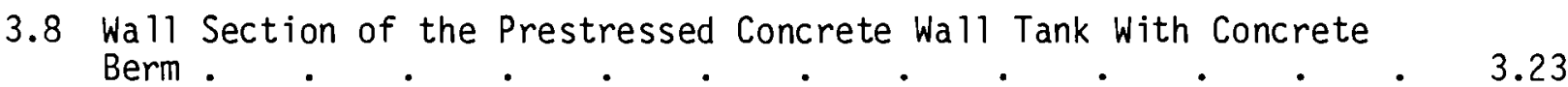

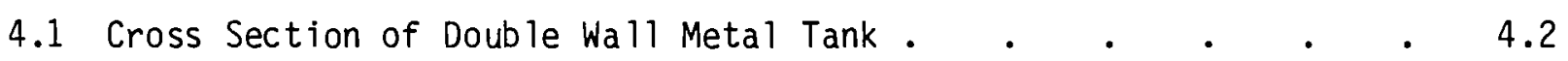

4.2 Cross Section of Prestressed Concrete Tank . . . . . . 4.5

\section{$\underline{\text { TABLES }}$}

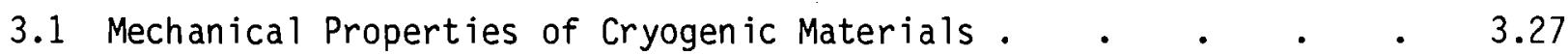

3.2 Critical Crack Sizes for Cryogenic Materials . . . . . . 3.27

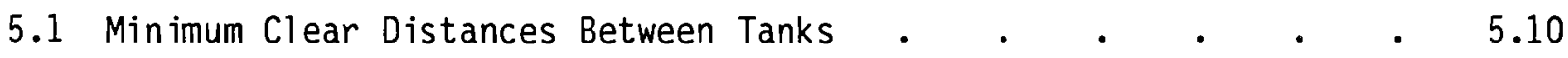

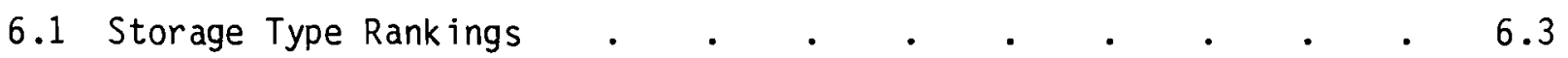

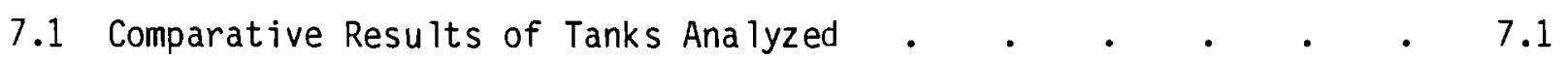





\subsection{SUMMARY}

As part of a larger LNG safety studies program to research LNG release prevention and control, this document seeks to investigate LNG storage tank response to selected release scenarios.

A preliminary safety analysis was performed on the different types of berms, dikes, roof systems, tanks and floor systems. This information was used to evaluate the performance of the structurally feasible combinations of system components. This analys is of evaluating the different types of LNG storage facilities was not an in-depth study, but it does give an indication as to which features of a storage facility contribute the most to the prevention of a release due to selected scenarios.

The preliminary analys is identified the need for site specific information as well as details pertaining to individual facilities in order to perform an effective safety comparison evaluation. Three basic storage facilities were selected as a foundation for the quantitative analysis. Although there are other storage facility designs with different characteristics this analysis provides a basis for performing comparative safety evaluations among different storage tank designs.

The following scenarios incorporated in the analysis were chosen based on an investigation of potential hazards as cited in the literature.

- overfill

- over/underpressure

- subsidence

- crack propagation

- tornado

- missile impact

- fire

- seismic activity

Several limitations become apparent in the review of this report. The storage tanks addressed are limited to three basic configurations and material types: the double-wall metal tank and the prestressed concrete tank (above 
and below ground types). Details with in even these tank types can differ widely and should be noted when viewing results. In addition, many of the analyses required the use of large, cost $1 y$, finite element models or simplified mathematical algorithms, where inclusion of structural detail was not feasible. In such cases, the assumptions made to acquire the approximate solutions are identified, and where possible, the consequences of omitting such detail are noted.

Based on the preliminary and final analyses, safety comparisons between the selected storage facilities are given in the results and comparison section with recommendations following. 


\subsection{INTRODUCTION}

Modern LNG storage $f$ acilities have a very good safety record. However, the growth of the LNG industry has increased the number of LNG storage facilities as well as the design options in areas of structural containment of stored LNG. The proliferation of storage system designs has necessitated an objective review of their relative merits from a safety standpoint, particularly in light of LNG storage in heavily populated areas and the trend towards increasing tank capacity.

As part of a large LNG safety studies project to research LNG release prevention and control, this document seeks to review LNG storage tank design practices and to investigate the LNG storage tank response to selected release scenarios. The selection of the scenarios was based on an investigation of potential hazards as cited in the literature. A review of the structure of specific LNG storage facilities is given in the following section. The storage tanks investigated in this report were selected in regard to current and future support for specific tank configurations.

In order to quantify storage tank response to adverse conditions, a specific set of failure scenarios was devised with these scenarios utilized in trial cases. The potential hazards were selected as a result of a literature survey conducted in conjunction with the LNG Safety Studies Program. Scenarios initially addressed included those that most likely emerge from the tank facility itself: conditions of overfill and overflow as related to liquid LNG content levels; over/underpressurization at respective tank vapor pressure boundaries; subsidence of bearing soil below tank foundations; and crack propagation in tank walls due to possible exposure of structural material to cryogenic temperatures. Additional scenarios addressed include those that result from external events: tornado induced winds and pressure drops; exterior tank missile impact with tornado winds and rotating machinery being the investigated mode of generation; thermal response due to adjacent fire conditions; and tank response due to intense seismic activity. Applicability of each scenario depended heavily on the specific tank configurations and material types selected. 
The "generic" tanks investigated included the above ground double wa 11 metal tank, the above ground prestressed concrete tank and the below ground prestressed concrete tank. The above ground tanks were selected because of the ir conventional configurations and material types. The below ground tank was investigated because of interest regarding its inherent safe design with respect to potential release of contents. In the comparative efforts at the conclusion of this report, primary consideration was given to the above ground tanks because of their established domination in this country.

This report is organized as follows. Section 3.0 presents a brief review and discussion of existing LNG storage tank design configurations. Section 4.0 describes the representative tanks used in the quantitative safety comparisons. Section 5.0 describes the methodology used in this study. The results are summarized in Section 6.0. 


\subsection{LNG STORAGE TANK CONFIGURATIONS}

The following list of LNG storage features is vital to the structural integrity of tank configurations under the selected release scenarios.

- tank walls

- wall insulation

- construction material

- floor systems

- roof systems

- ground level setting

- exterior structures (dikes and berms)

This section will survey the above list focusing on the characteristics that are responsible for the containment of $L N G$.

Tank walls, although listed as a tank feature, take on an added measure of significance when realizing that many tank features are dependent on the type of tank wall utilized. The tank wall may, in fact, designate the tank type under investigation, ie., double-wa 11 metal tank.

\subsection{TANK TYPES}

This section will discuss tank types, for the most part focusing on the wa $11 \mathrm{~s}$ of the tanks. The tank types discussed are:

- double-wa 11 metal tanks

- prestressed concrete tanks (above ground and below ground tanks)

- mined cavern

- frozen hole

The above ground double-wa 11 metal and prestressed concrete tanks are conventional types of tanks in the LNG industry. Though still a recent development in LNG storage, there is interest in below ground prestressed concrete tanks due to the ir inherent safe design with respect to a potential release of contents. The mined cavern and frozen hole types of storage are not standard forms of LNG storage. However, there are a few in existence, and 
like the below ground prestressed concrete tank, their design does have its merits with regard to the safe storage of LNG.

Whatever the type, tank walls must be designed to meet the following criteria:

- withstand the load of the contained LNG

- resist cracking due to liquid LNG temperatures (-165 F)

- protect the cryogenic liquid from atmospheric temperatures as well as extreme temperatures in the event of a fire

- resist damage as a result of impact

Although separate discussions are given to the other tank features, features characteristic to a tank type may be included in the tank type discussions below. (e.g., a particular roof used only with DW metal tanks may be discussed under DW metal tanks rather than with the tank roof section.)

\subsubsection{Double Wall Metal Tanks}

Double-wa 11 metal tanks are comprised of an inner LNG retaining wall constructed as a liquid containment barrier with appropriate cryogenic and structural properties. The outer wall has as its primary purpose the retention and protection of the insulation barrier. Either a carbon steel outer and a cryogenic metal inner roof (Figure 3.1), or a carbon steel outer roof with a suspended insulating inner roof (Figure 3.2) (see Roof Systems) are employed. Foundation design (see Floor Systems) is generally dictated by soil bearing capabilities, and is either a concrete ring or slab with load bearing insulation or pilings.

The cryogenic metal used for the inner tank is usually $9 \% \mathrm{Ni}$ steel, aluminum or stainless steel. Economic constraints have confined the use of stainless steels to smaller LNG containers (American Gas Association 1973), but whether $9 \% \mathrm{Ni}$ steel or aluminum is economically advantageous in large LNG tanks, has not been resolved. Maximum weld penetration depth and greater required thickness may prohibit the use of aluminum in extremely large tanks. Tank wa 11 thickness is dictated by API Standard 620, Appendix Q, under 


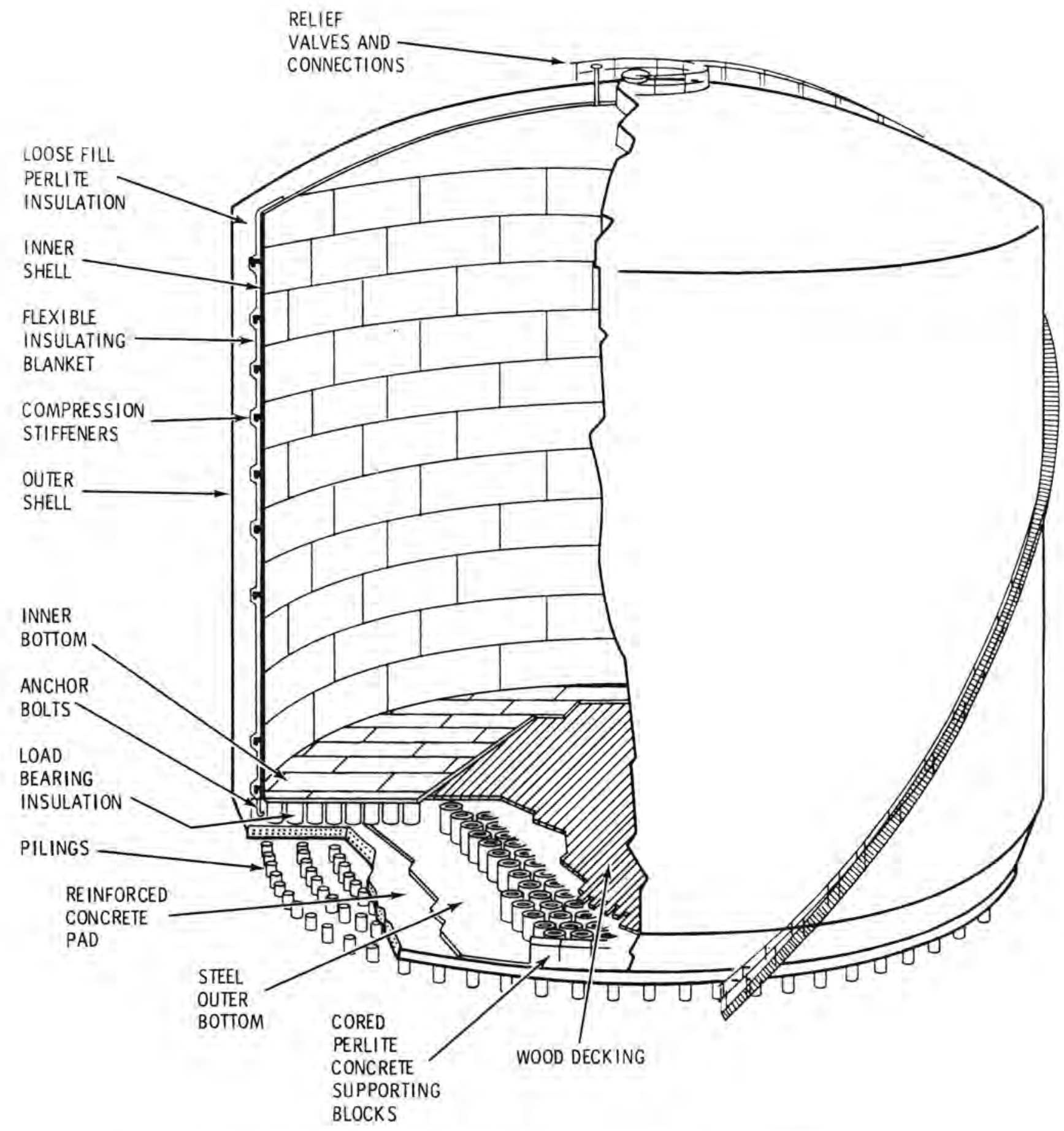

FIGURE 3.1. Double Wall Metal Tank With Double Roof and Piling Foundation (Hane 1966, p. 76-8) 


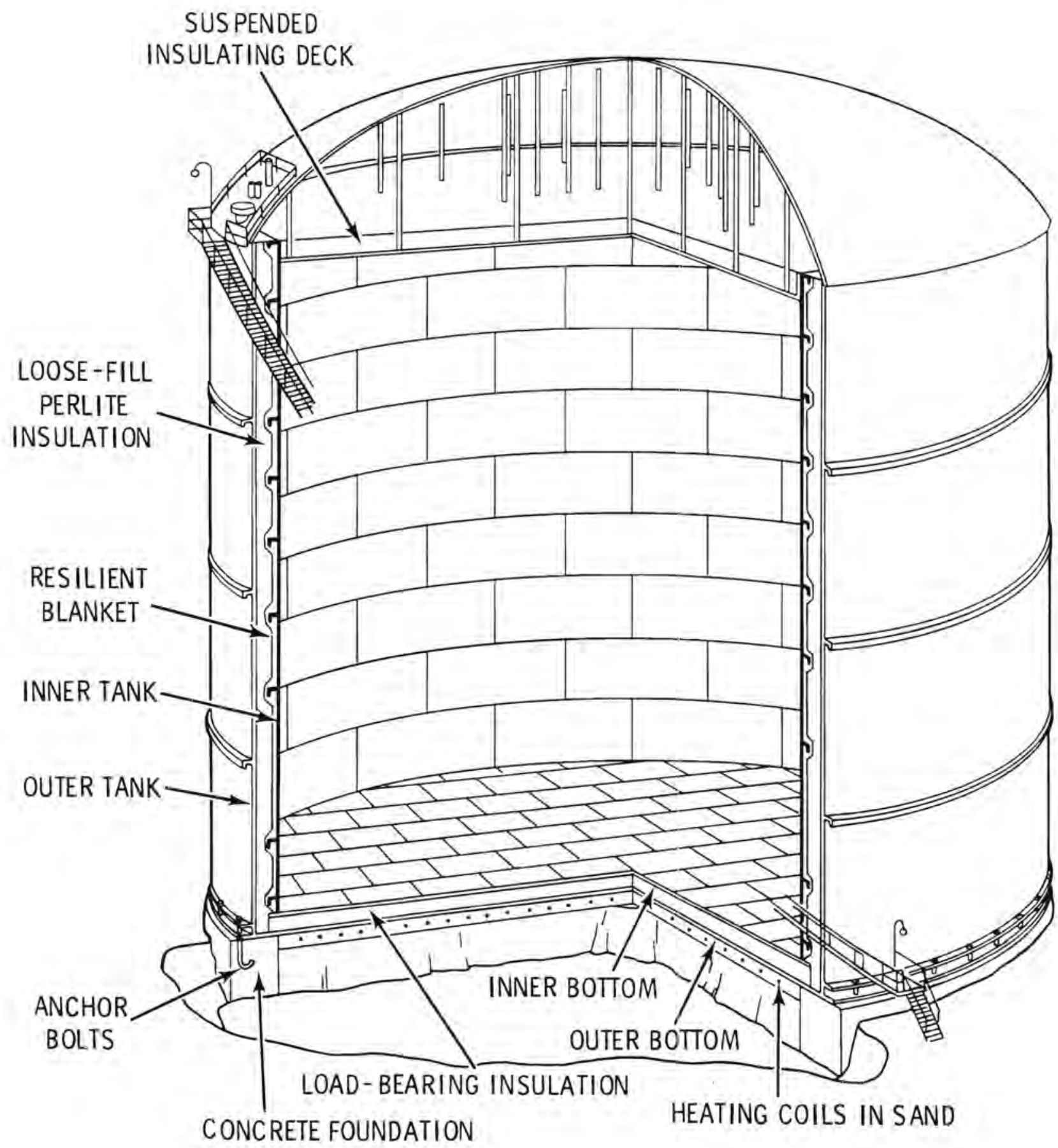

FIGURE 3.2. Double Wall Metal Tank With Suspended Deck Roof and Concrete Ring Foundation (American Gas Association 1973b) 
allowable stresses. ASTM alloy specifications are used (API Standard 620 1973), and allowable stresses are based on weld deposit metal strength.

Depending on the roof system, the inner tank may or may not be subject to internal pressure. In the design depicted in Figure 3.1, an inert, dry gas such as nitrogen is used as an interstitial gas in the perlite containing annulus. In the design illustrated in Figure 3.2, the boil off LNG is used as an interstitial gas with no pressure differential existing between the inner and outer tanks. In either design, the foundation anchor system must be designed to resist the uplift force at the roof due to pressure and/or external forces. Design guidelines are given in API Standard 620 (1974).

From a safety perspective, above-ground, double-wall metal LNG storage tanks have several advantages. One advantage is that the technology for their construction is well documented and has been extrapolated from successful methods used in containers for other types of storage. Heat influx is predictable, mitigating the possibility of hazards arising from thermal movement or overpressurization caused by excess vaporization. Material properties can be closely controlled thereby minimizing design unknowns. Metal requires no separate vapor barrier. Single material tanks largely eliminate differential thermal expansion stresses.

In spite of an excellent safety record, double-wall above-ground metal tanks have some inherent disadvantages. Greater coefficients of thermal expansion must be allowed, particularly if the material is aluminum. The exterior shell is incapable of supporting a protective berm or soil loading. Material thickness is limited by available welding technology (penetration). The relatively thin walls are susceptible to damage from external missiles.

If the roof is of the double-dome type, a separate purge gas system is required. Only the roof and vertical walls of the inner tanks are exposed to the necessary external positive pressure, causing the inner tank floor to bear an add itional load. The porosity required for good insulation properties means that a compromise must be made between load bearing capacity and thermal 
insulating ability. The net result is that the inner tank floor is vulnerable to ballooning when annular pressure rises to excessive levels, which can cause damage to the load bearing insulation.

The single roof suspended insulation deck arrangement also has some intrinsic problems. Although the outer metal shell is reasonably gas tight, it is not absolutely impermeable, and some vaporized LNG can leak to the atmosphere. Liquid sloshing due to earthquake or other external forces can cause cryogenic liquid to impinge on the carbon steel outer shell, possibly causing failure. A break in the outer shell will cause a methane gas release. In addition, both roof systems have a low margin of safety with respect to unforeseen loading because the metal shell has a low resistance to buck ling.

\subsubsection{Prestressed Concrete Tanks}

Prestressed concrete LNG tanks consist of two walls. One wall is generally metal. If the metal wall is an inner wall then it is generally a high grade metal that can withstand the extremely cold LNG temperatures. The other wall consists of prestressed concrete. The advantages of prestressed concrete walls over conventional metal walls are the higher buckling resistance, higher resistance to impact and added insulating protection in the event of fire. Generally, prestressed concrete tanks consist of an outer prestressed concrete wa11, and when metal is employed it is usually incorporated as the inner wa 11.

Both above and below ground prestressed concrete tanks are briefly discussed here.

Above Ground Prestressed Concrete Tanks

There are several kinds of above ground prestressed concrete tanks. An advantage of th is tank type over that of the DW metal tank are as discussed above. Among the consequences of such advantages is that most concrete tanks can support an earthen berm. 


\section{Inner and Outer Prestressed Concrete Walls}

This configuration (Figure 3.3a) utilizes prestressed concrete for both inner and outer tank walls with loose fill perlite in the annular space. The floor is usually $9 \% \mathrm{Ni}$ steel over load-bearing insulation. A soft metal or Teflon ${ }^{(a)}$ bearing is provided at the floor to inner wall junction to accomodate differential thermal movement. In some designs, the $9 \% \mathrm{Ni}$ stee 1 floor is joined with a vertical wall of the same material to form a vapor tight cladding around the inner concrete wall. This requires an expansion joint in the form of a toroidal ring in the steel floor to alleviate problems associated with thermal expansion.

This design has an advantage in that it incorporates cryogenic barriers in the primary container. Both walls have higher buckling resistances than are found in metal tanks, giving latitude for a variety of roof designs and the ability to withstand increased roof loading. The outer wall can withstand loading from exterior berms and has higher resistance to impact from external missiles. Concrete insulation properties would be of benefit in the event of a burnout. Foundation uplift due to over pressurization is no longer a problem.

The need for vapor and liquid containing liners necessitates complex junctions where the wall interfaces with the floor and roof, a variety of bearing surfaces and materials with different thermal expansion coefficients. This increases potential hazards due to differential thermal expansion or contraction problems at wall and roof interfaces. Greater tank weight may cause foundation difficulties.

\section{Inner Metal With Outer Prestressed Concrete Wall}

The chief difference between this inner tank design (Figure 3.3b) and the aforementioned membrane liner is that the inner tank is a "stand alone" structural member. Thermal movement is accommodated in the same manner as for a double-wall steel tank. The roof system is usually a carbon steel or prestressed outer roof supported by the outer concrete wall, with a suspended inner deck using boil-off methane as the interstitial annular gas.

(a) Trademark of DuPont. 

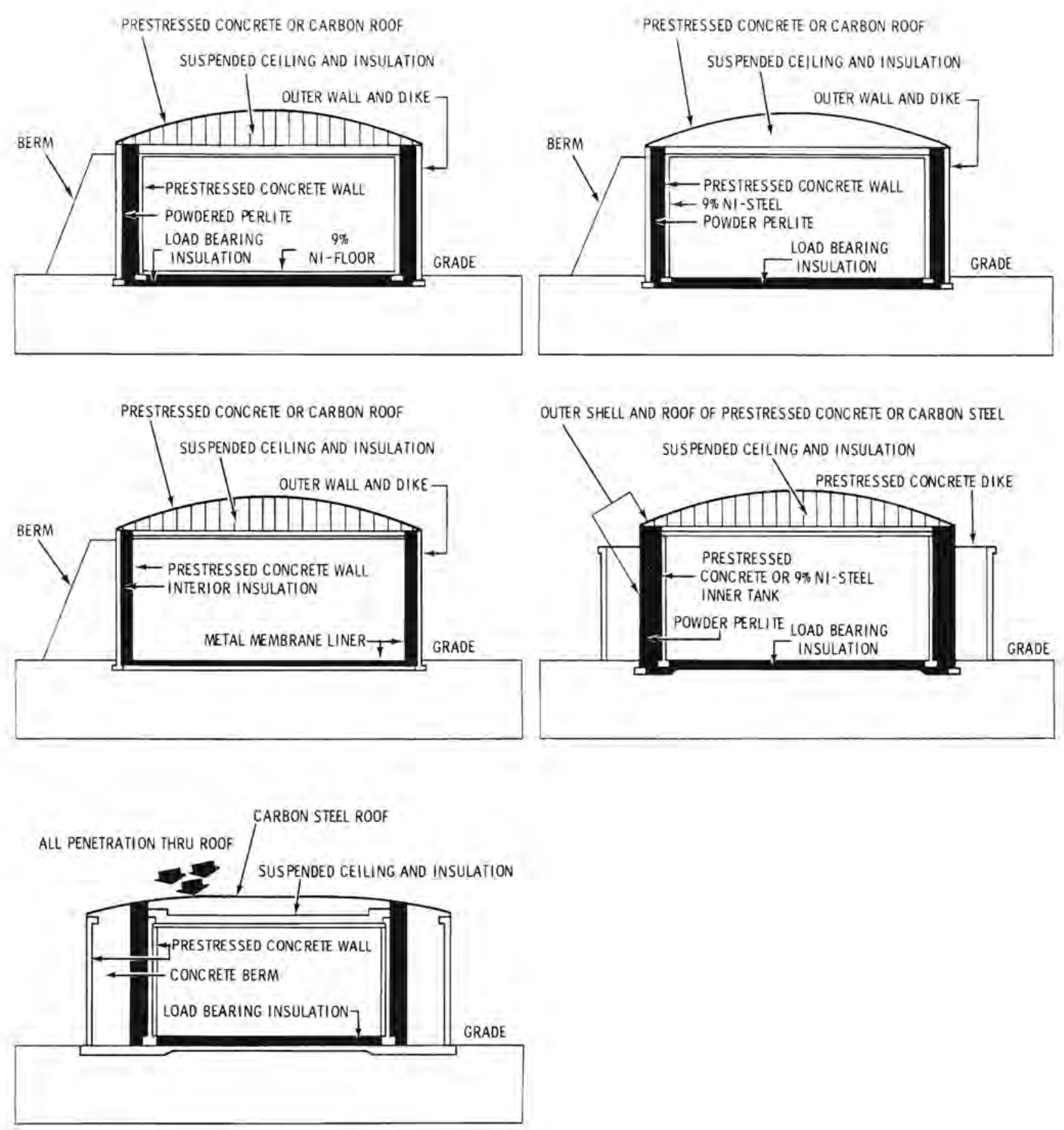

FIGURE 3.3. Prestressed Concrete Tank Configurations (AGA 1973) 
The outer prestressed concrete wa 11, as with other configurations using this outer wall material, has the capability of sustaining external soil bearing loads and heavier roof loads. It is easier to accommodate thermal movement with this design than with that incorporating a membrane liner. Insulation along a vertical height is required to support inner tank loads. In addition, the inner tank does not support pressure loads. In addition, resistance to impact from external missiles is reduced compared to designs incorporating the double wall prestressed concrete container systems.

\section{Prestressed Concrete Tanks With Membrane Liner}

The general tank configuration consists of an outer prestressed concrete wa 11, interior insulation on wa 11 and floor, and an inner metal membrane liner for liquid containment (Figure 3.3c). The outer prestressed concrete or metal roof has a suspended insulation deck. The floor insulation is supported on a concrete mat.

The exterior concrete wall possesses the same soil and roof loadings as a double prestressed concrete tank. Overall resistance to external impact should be greater for this design than for a metal tank. The internal insulation reduces transient thermal gradients in structural components.

Any breach of the interior liner would immediately compromise the insulation. Only the outer wall is capable of supporting structural loads. External missile resistance is reduced compared to that for the double-wall concrete designs. All insulation must absorb loads and thermal movement.

\section{Inner Concrete With Outer Carbon Stee 1 Tank}

The outer steel tank serves primarily as an insulation containment barrier also supporting the roof, which usually includes a suspended deck. The inner prestressed concrete tank is the cryogenic containment barrier. (Figure 3.3d). This tank can support structural loads. In addition, load-bearing insulation is not required in the annulus. 
The outer carbon steel tank is subject to failure by thermal shock should an inner tank failure occur. The outer tank cannot support soil loading from a berm and has additional load limits applicable to the roof. Foundation uplift due to over-pressurization must be considered.

Doub le-Wal1 Prestressed Concrete Tanks With Concrete Berm in Annulus

Th is tank design (Figure 3.3e) has been constructed in high population density areas. The inner prestressed concrete wall is the primary container with $9 \% \mathrm{Ni}$ steel serving as a liquid barrier on the floor and wall. Bearing material, usually soft metal, supports the wa 11 and allows thermal expansion. The annular space between the inner wall and the berm is filled with powdered perlite with a fiberglass or foam liner used to absorb differential thermal movement. The roof structurally joins the outer wall and typically supports a suspended insulation deck. Outer roof material can be carbon steel, prestressed concrete, or steel with a concrete overlay.

This configuration offers excellent resistance to external missiles. A high degree of structural redundancy offers exceptional resistance to any potential hazard.

The relatively large roof span with respect to inner tank diameter requires good structural integrity. The floating inner concrete wa 11 which must interface with a variety of material may portend thermal movement difficulties.

\section{Buried Concrete Tank With Membrane Liner}

The final prestressed concrete tank type considered is the buried concrete structure lined with an impervious membrane. Basically, the tank consists of a prestressed concrete she 11 with a layer of insulation on the inside surface and an impermeable membrane between the liquid contents and insulation (Figure 3.4). The tank is buried to the roof system.

Like other prestressed concrete tanks, the earth protects the tank walls from possible damage due to missiles, explosions, and high winds of tornados or hurricane force. However, flooding which could result from a hurricane is a disadvantage inherent to inground tanks. If the roof system is exposed to a wave pressure and a large amount of water is allowed to flow into the tank, 


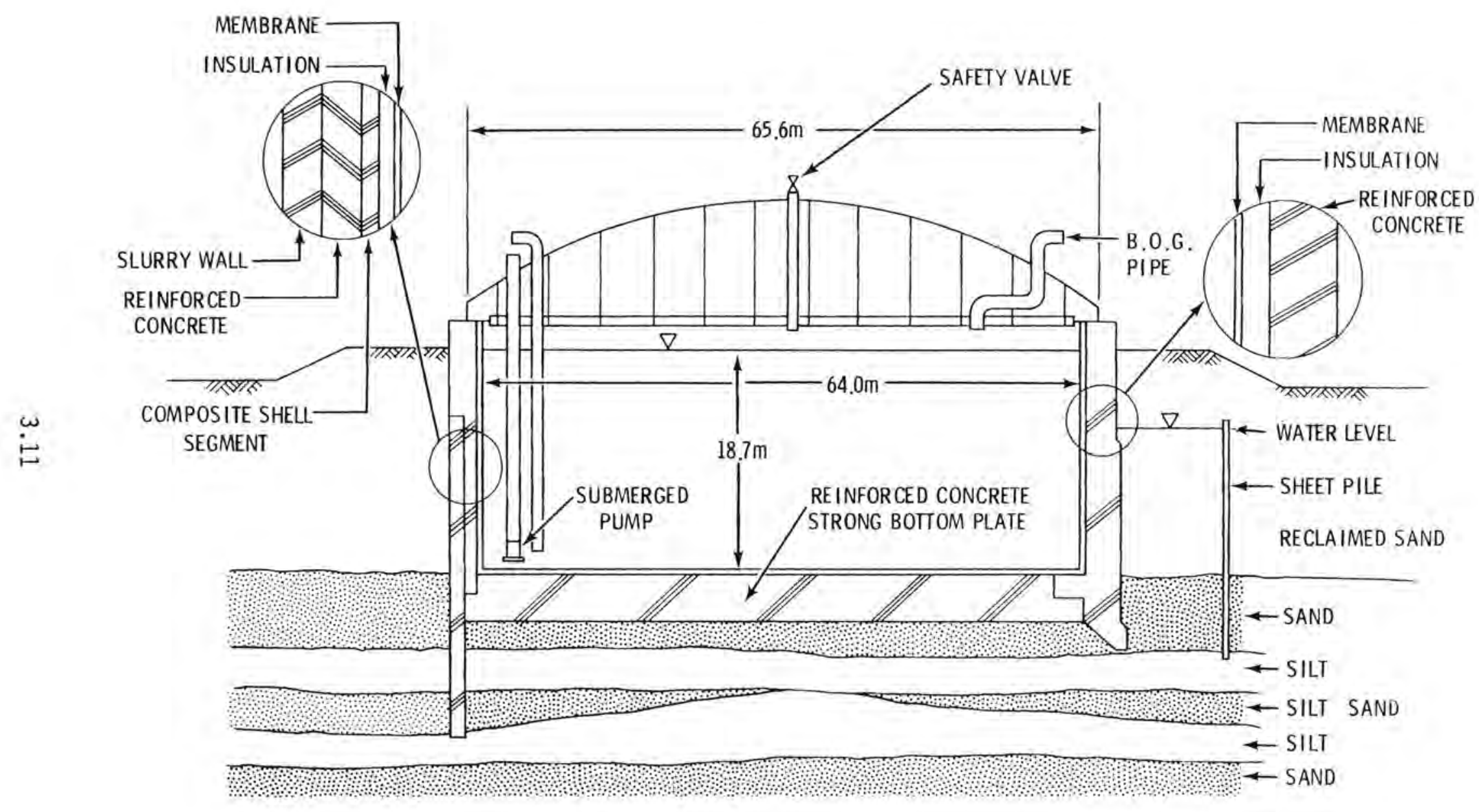

FIGURE 3.4. Buried Concrete Tank (Araft 1975) 
serious consequences could occur. The liquid LNG might be displaced by the denser water causing a spill above ground level. Also the danger from flamable LNG mixtures is very high due to LNG vaporization from pools of water. The low temperature of the LNG vapor and the condensation of steam in the surrounding air will combine to prevent dispersion of these LNG vapor clouds, thereby prolonging the existence of the flammable air/gas mixtures at the interface between gas clouds and air (Lom 1975).

Lastly, if the tank is in soil susceptible to frost heave, failure of the heating elements would allow the surrounding soil to freeze. The detection of a heating element failure would be necessary to prevent the possible formation of ice lenses, which could exert excessive stresses on the tank walls and bottom.

\subsubsection{In-ground Storage Tanks}

In-ground storage of LNG is basically storing the LNG in a dug-out hole in the ground. The storage systems discussed here include mined caverns and frozen holes. This type of storage is geographically specific in that the soil conditions and surrounding areas must satisfy unique conditions.

\section{Mined Cavern}

Mined cavern storage for liquefied petroleum gases at ambient temperature has been used for a number of years. These caverns were mined from various rock formations including limestone, shale, chalk, granite, and dolomite. The extension of techniques employed at ambient temperatures, to cryogenic temperatures, has been investigated by several groups (American Gas Association 1973b).

Gaz de France investigated large volume LNG storage in mined caverns for baseload operations. The Institute of Gas Technology (IGT) studied LNG storage in mined caverns for peakshaving operations. The basic difference between the two operations is that a depot for baseload operation can tolerate a greater rate of heat influx because the boil-off gas immediately goes toward baseload makeup. However, in a peakshaving operation, the boil-off rate must be minimized. 
A mined cavern as designed by IGT consists of an inclined entry way which provides access to the storage cavern. The excavation costs associated with this mining technique are low. Therefore, if the properties of the surrounding heterogeneous rock structure could be predicted accurately, th is type of LNG storage would be economically favorable for baseload operations. However, for peakshaving operations, IGT concluded that insulation and an impervious liner would be required to maintain an acceptably low vaporization rate. These necessities would increase the cost of storage substantially.

The mined cavern design offered by Gaz de France consists of a concrete lined vertical shaft which is connected via a lock with a manhole to horizontally excavated storage galleries (Figure 3.5). These storage galleries would be excavated in an impermeable strata. The concrete shaft allows access to the storage galleries during excavation.

During operation the shaft is filled with water to a level which would correspond to the desired operating pressure of the storage galleries. This pressure would be sufficient to restrict vaporization caused by heat influx from the surrounding rock (American Gas Association 1973b).

With respect to the release scenarios addressed, mined cavern storage is the safest type of storage because the LNG is isolated completely underground. Therefore, the LNG is inherently safe from adjacent fires, missiles, explosions, and high winds. However, potential flooding could be a problem if the depot was located in a flood basin or near large bodies of water.

\section{Frozen Hole}

Frozen hole storage consists of an excavated earthen cavity with no liner, no insulation, and with a dome roof over the opening (Figure 3.6). A concrete ring 10 to 20 feet high is poured around the opening to provide support for the roof system. The excavated cavity is shaped like a cylinder. The earth walls are allowed to freeze and would theoretically provide adequate insulation even for peakshaving operations.

Several LNG plants have opted for this type of storage. Two plants, one located in Algeria and one in England, were designed and constructed for use 


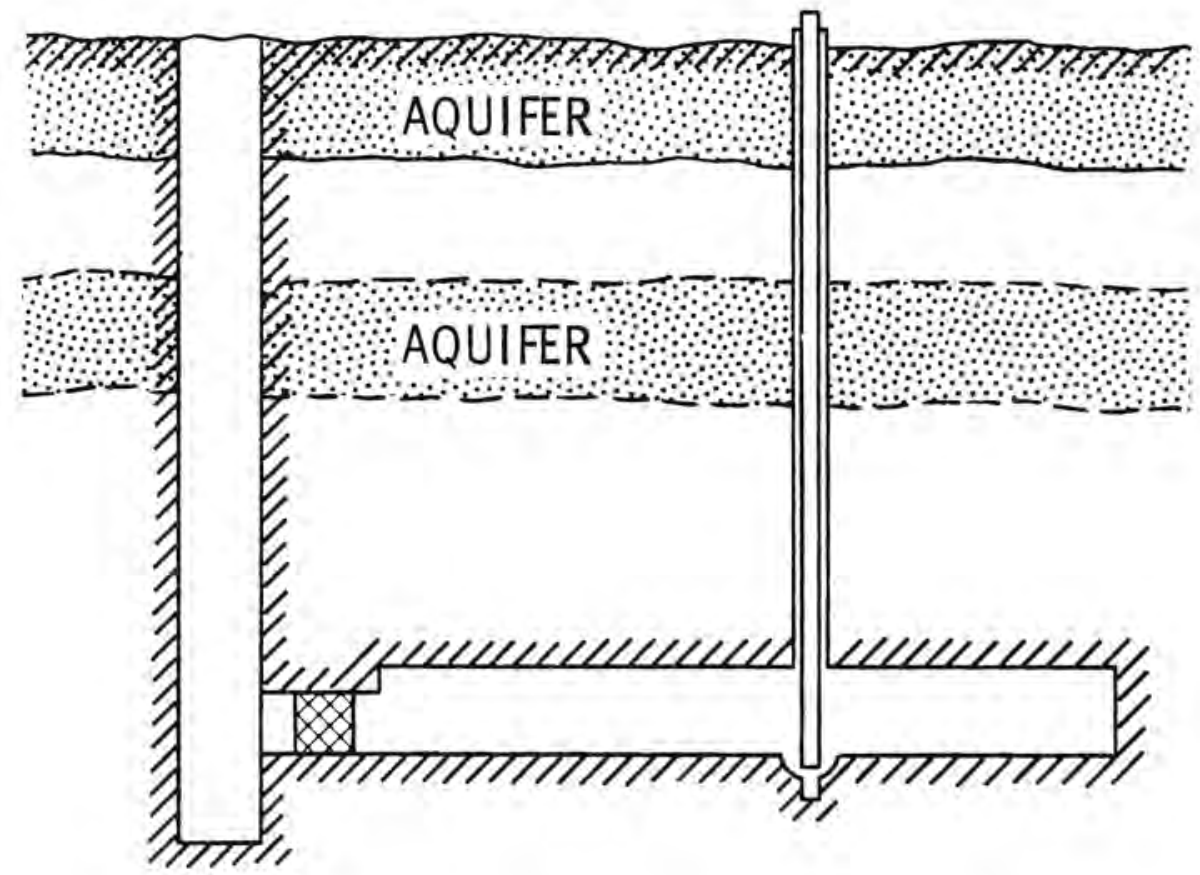

FIGURE 3.5. Mined Cavern Storage Concept

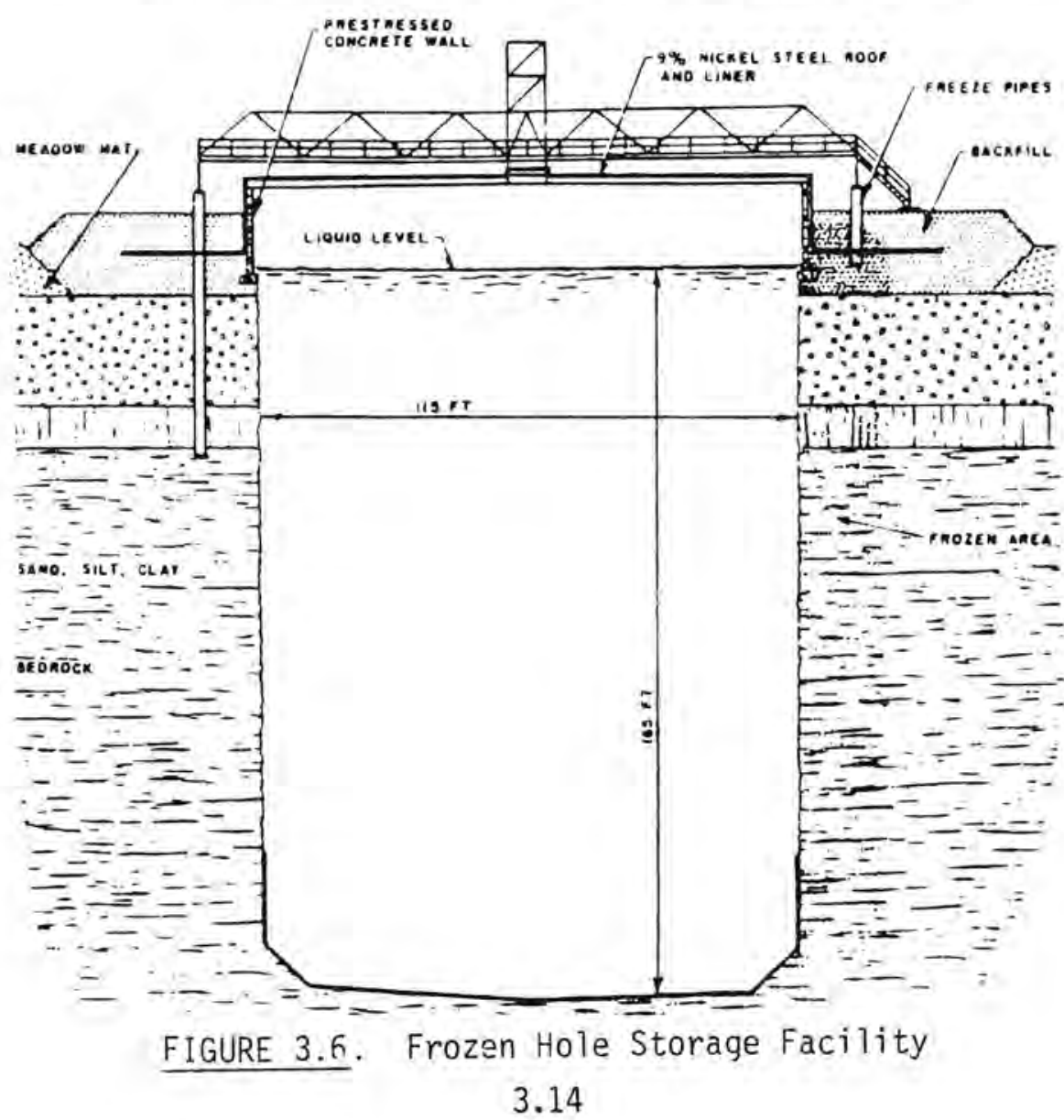


as baseload storage facilites and have performed satisfactorily. Two other frozen hole LNG storage units were built in the United States and were designed for peakshaving operation. Both of these units have been abandoned as a result of the high boil-off rates encountered during the first few months of operation. In one of these units the boil-off rate was about three times the predicted value. It was concluded that these high boil-off rates resulted from a higher heat influx from the surrounding soil than was predicted. Under these conditions, tanks were not economical and were abandoned (White and Penn 1969).

The frozen hole storage concept does not possess all the safety advantages found in the mined cavern concept. The hole is covered with a metal roof. Further study would be required to determine the resistance of this type roof to impact, adjacent fire conditions, etc. relative to that resistance exhibited by rock. Also, there is no assurance that the response of the earthen wall in the frozen hole can be predicted during earthquake activity.

\subsection{WALL INSULATION}

Perlite is the most commonly used insulation material in double-wall LNG tanks. It is inorganic, light, inexpensive, fire resistant and, most importantly, an excellent insulator. It does, however, have a few drawbacks associated with being a granular material. It flows into voids and compacts, thus building up pressure inside spaces enclosed by moving walls.

In the event of a tank wall rupture, the perlite is most likely to flow out with the liquified natural gas. Perlite floating on the ground and on the spilled LNG will make it hard to identify the quantity of LNG released. Also, perlite floating on LNG can effect the evaporation and dispersion of natural gas. This phenomenon needs further investigation.

\subsection{FOUNDATION SYSTEMS}

The following section discusses floor systems for above ground tanks. Floor conditions for other tank types are given within the tank wall discussion. 
The floor system design of above ground tanks is primarily designed to resist subsidence. Therefore, the design is strongly dependent on the soil bearing capabilities.

\subsubsection{Concrete Ring Foundation}

In areas where soil load bearing capabilities are sufficient to support load bearing insulation, a concrete ring is used to support vertical tank walls (Figure 3.2). In the case of prestressed concrete tanks, it takes the form of a footing with a concrete mat bearing against the soil beneath the tank bottom. Tank height and diameter can be adjusted to accommodate soil conditions, but it is desirable to have soil bearing load limits equivalent to the load bearing insulation load limits so that tank height vs. diameter may be optimized.

Contact with the soil by the load bearing insulation requires that a heating system be installed in the soil beneath the tank to prevent soil freezing and subsequent frost heave. Some designs have circumvented this need by excavation and filling with soil free from to frost heave prior to construction.

The primary advantage of the concrete ring beam system is economic. The cost is roughly two-thirds that required for the installation of pilings. From a safety aspect, some drawbacks exist. Inconsistent soil bearing capabilities can cause uneven, unpredictable tank settling that may compromise the load bearing insulation by cracking it vertically and increasing heat influx. Local membrane stresses in the tank bottom may also increase. Resistance to earthquake is lower with this foundation type as compared to pilings. Impairment of the heating system could cause local frost heave and repair could be extremely difficult.

\subsubsection{Pilings with Concrete Cap}

Because of expense, pilings are generally employed on ly when tank site requirements dictate location on soils with poor bearing capabilities (Figure 3.1). Several safety advantages are inherent in this design. A heating system is not required as air space beneath the tank precludes ground 
freezing. Tank height vs. diameter for a given capacity can be optimized and uneven soil bearing problems are removed. Resistance to earthquakes, flooding, and other hazards affecting local soil is increased as compared with the other foundation designs discussed.

\subsubsection{Concrete Mat With Load Bearing Insulation}

Prestressed concrete mats (Figure 3.3e) are often employed beneath prestressed concrete tanks. A heating system is required to prevent frost heave as in the concrete $r$ ing beam foundation. Load bearing insulation is located above the mat and may support either a membrane liner or an inner tank bottom. This floor system is able to nullify variable soil bearing effects and has thermal movement characteristics compatible with the vertical tank walls. A complete secondary containment barrier is formed with the outer concrete wa 11 .

\subsection{ROOF SYSTEMS}

There are three types of roof systems which have been used in conjunction with the previously discussed representative tank types. The first two types of roof systems differ in how they are incorporated into a double-wall tank configuration. The first roof system design consists of a roof structure attached to both the inner and outer tanks. The second roof system design consists of a similar structure attached only to the outer tank with an insulation deck suspended above the inner tank. The third type of roof system differs from the second type in that there is a concete layer several feet thick located on top of the stee 1 plate structure (Figure 3.3). It is reinforced and supports itself. This last type of roof system can only be used in conjunction with a concrete outer tank or berm. The first two roof systems may be used with any tank configuration, and the double metal roof is most often used with double-wa 11 metal tanks.

All three roof systems utilize a stiffened plate construction where structural stiffeners are welded to the roof plate to form a section. These sections are assembled to form a large thin plate structure which is designed 
to preclude failure by buckling and instability. Design loads incorporated are live snow loads and a partial internal vacuum (Riley and Plate 1974).

In the first roof type, the inner roof is pressurized as a result of LNG vapor and the outer roof is exposed to external loads and a slight internal pressure from a dry purge gas (Figure 3.1). The annulus between the tanks and the space between the roofs are filled with insulation. Nitrogen gas is used as the purge gas in the insulation space to prevent moisture migration from damaging the insulation.

Even though the internal gage pressure exerted by LNG vapor on the inner roof structure is relatively small (e.g., 0.5 to $2.0 \mathrm{psi}$ ) the net vertical upward force for large diameter tanks can be substantial. Therefore, anchor bolts have to be employed to hold down the inner tank. It is necessary to install these bolts in the annulus between tanks.

There are several inherent disadvantages associated with this type of roof system. Since the anchor bolts are exposed to cryogenic temperatures in the annulus, they have to be made of an expensive cryogenic material. In addition, the bolts cannot be inspected regularly for serviceability. Also, since the inner roof acts as a vapor barrier, thermal stresses and differential pressure induced stressed can form in the upper portion of the inner tank wall.

In the second type of roof system, the pressurized roof is connected to the outer tank. The suspended insulation deck above the inner tank allows LNG vapor to pass through it into the annulus (Figure 3.2). Therefore, the dry purge gas is provided by LNG vapor. This circulation of gas prevents thermal stresses and differential pressure induced stresses from forming in the upper portion of the inner tank wall. This precludes inner tank failure due to over-pressurization. Another advantage with this type of roof system is that anchor bolts can be installed outside the outer tank, thus reducing material costs and increasing availability to inspection.

A disadvantage with this suspended deck roof system as compared to the double roof configuration may exist during seismic activity. Liquid sloshing as a result of an earthquake could cause liquid to spill into the annulus with 
possible damage to the outer she11. Even so, this type of roof system has become the most popular design for use on LNG storage tanks today.

Hazards that are deemed most critical to the safety of roof systems for LNG storage tanks are adjacent fire, missiles, explosions, and earthquakes. The third roof sysem discussed would provide the most protection for the stored LNG with respect to the first three hazards cited. This is due to the additional thermal insulation and energy absorbing capabilities provided by concrete. A steel roof would not provide as much protection even when incorporating two layers of stee1. To determine the relative safety of these roof systems with respect to earthquake intensity more study is required.

\subsection{DIKES}

A dike is an earthen or a concrete wall designed to successfully contain the LNG in case of a major storage tank failure. A dike surrounds the storage tank and is designed to contain 115-125 percent of the tota 1 tank volume. There are two types of dikes in use today, low earthen dikes and high concrete wa 11 dikes. Both of these designs are engineered to contain a major spill without failure. However, the dynamic effects of a catastrophic spill have not been fully investigated. The LNG could slosh over a low earthen dike. Also, a dynamic surge of LNG could compromise the integrity of a high concrete dike wall if not designed for such a scenario.

The area of the pool formed by the spilled LNG and the height of the dike walls are the important factors when evaluating the degree of safety provided by these containment systems. These two factors are important for the dilution of LNG vapor into safe inflammable concentrations at ground level. Th is problem is directly dependent on the area of the pool and the controlled height of lateral dispersion of the vapor cloud (Closner and Parker 1978).

Consequently, the advantages of a concrete dike over an earthen dike are:

1. A high concrete wall dike is much closer to the storage tank than a low earthen dike. Consequently, a smaller pool is formed. 
2. The high concrete wall prevents the lateral dispersion of vapor up to maximum wall height.

3. The concrete wall would provide a greater degree of protection in case of impact from missiles, pressure waves from explosions and other external forces.

4. The concrete wa 11, because of its height, will offer more thermal insulation for protection from an adjacent fire and more protection in case of flooding.

5. The high concrete dike is more resistant to the hydrodynamic forces of sudden tank failure.

From a safety standpoint it can be concluded that a concrete dike is more desirable than an earthen dike.

\subsection{BERMS}

A berm is a structure that surrounds the storage tank in direct contact with the outer tank surface. A berm provides containment for a major sp 111 and also provides protection for the storage tanks from external hazards. A berm extends the full height of the tank. The advantages of a berm can be divided into two categories, the prevention of a major spill and the control of a major spill. For the prevention of a major spill, the advantages for including a berm around an above ground storage system are:

1. more than adequate insulation is provided against thermal radiation from adjacent fires;

2. protection of the storage tank from external forces produced by missiles, high winds, and explosions is provided.

In the control of a major spill, the advantages of a berm are:

1. the smallest possible pool size is achieved;

2. the heat influx is reduced to a minimum. Therefore, the rate of vaporization of LNG is also minimized; 
3. Should the vapor cloud become ignited, the base of the flame is projected at tank height rather than ground leve1; and

4. Even with inner tank rupture, vapor would not be released if the roof system remains intact.

There are two types of berms used today in conjunction with LNG storage: earthen and concrete.

An earthen berm consists of a huge backfill of earth which completely surrounds the storage tank and extends the full height of the tank (Figure 3.7). The earth is in direct contact with the outer tank shell and gradually slopes outward from the top of the tank. Since the earth is in contact with the outer tank, it must be supported by this wa11. This condition necessitates the use of prestressed concrete for structural support.

A concrete berm consists of a concrete wal1 3-10 ft thick completely surrounds the storage tank and extends the full height of the tank (Figure 3.8). The berm is again in direct contact with the outer storage tank wal1.

Compared with the concrete berm, the earthen berm has several disadvantages. There is difficulty in predicting the response of a buried structure to seismic intensities. Differential settiing between the tank and the backfill may occur since the load on the soil from the tank is about one-fourth of the soil load due to the backfill (Closner 1968a).

Impact studies have shown that in the event of an airplane crashing into the berm, the concrete berm provides more protection than the earthen berm (Closner 1968a). It has been shown that a concrete berm 10 feet wide can withstand the impact of a Boeing 727 jet aircraft traveling at 200 knots without permitting any damage to the storage tank (Closner 1971). Therefore, it seems reasonable to conclude that for safety considerations a concrete berm is superior to earthen backfi11. When one takes into account that construction time and costs are less for a concrete berm than for an earthen backfi11, the concrete berm becomes even more desirable. 


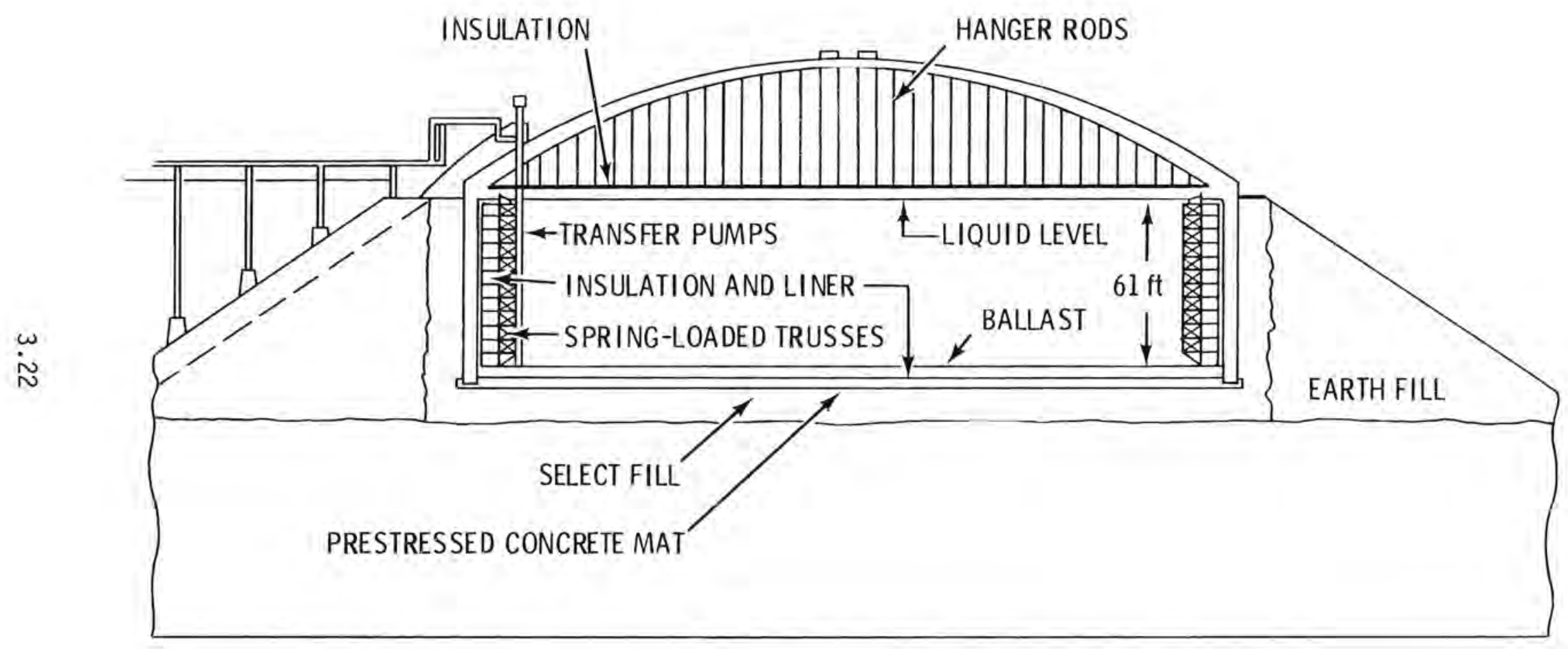

FIGURE 3.7. Earthen Berm (Ishima et al. 1977) 


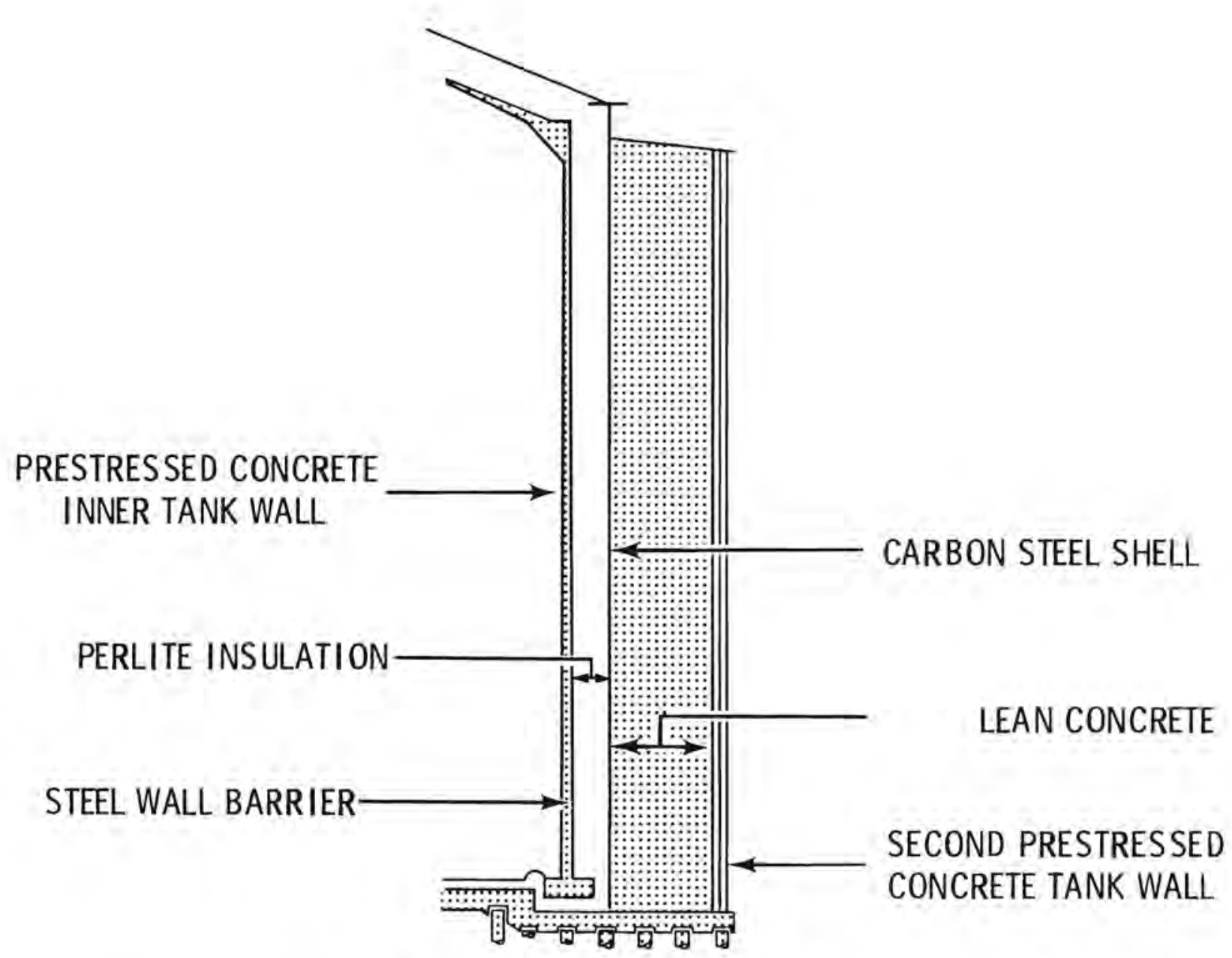

FIGURE 3.8. Wall Section of the Prestressed Concrete Wall Tank With Concrete Berm (Closner 1971) 


\subsection{MATERIAL CONSIDERATIONS}

This discussion of material considerations is primarily restricted to the walls, floor and roof of an LNG tank. The foundation is constructed of concrete with floors usually of concrete or metal. The most commonly used materials for constructing tank walls include aluminum alloys, nickel steels and prestressed concrete. In genera1, these materials should exhibit moderate strength and high toughness at low temperatures.

Over a constant bearing surface, the metal tank would have a smaller bearing load. Advantages associated with a concrete tank are related to increased buckling resistance and better insulation capabilities.

\subsubsection{Meta 1s}

Metal storage and transport systems for LNG require materials with moderate strength and high toughness at low temperatures. These systems have had an excellent safety records over the last 25 years; however, new fracture-prevention methods are being used to reevaluate the design of existing structures, and greater structural demands are being required of new construction.

Fracture-prevention methods include improvements in the transition-temperature approach and the addition of the fracture mechanics approach to failure contro1. Greater structural demands are required because of shortages of critical materials and the need for improved efficiencies. Two materials are used for most applications involving exposure to LNG temperatures: $9 \%$ nicke1 stee 1 and 5083-0 aluminum. Although these materials have successfully been used in many applications, it is economically desirable to push design stresses as high as possible and to find materials which are less expensive to use.

Fracture control was, until recentiy, based on the transition-temperature approach. The basic test methods used today were invented in the early part of this century, but did not come into widespread use until it was recognized that cracks in the hulls of American Liberty Ships occurred most frequently during cold weather (Pellini 1967). It became apparent that toughness tests 
should be performed over a range of temperatures to evaluate the fracture behavior of a given material (Lange 1976). Common steels were found to lose most of their toughness over a narrow temperature band; the midpoint of this band is called the transition temperature. Much effort has been directed toward reducing the transition temperature and elevating toughness at the service temperatures in materials intended for cold temperature service.

The science of fracture mechanics has greatly increased the ability to predict conditions under which fracture will occur. This has enabled the design of existing structures to be reevaluated, and has assisted in selection of new materials and designs to meet greater structural demands. The fracture mechanics approach to fracture control is based on the concept of cracking stress intensity factors. This parameter is a combination of stress and stress concentration. A structural flaw, such as a crack or welding defect, produces a higher stress intensity at the top of the flaw. Stress intensity increases with crack length, stress, and flaw acuity. The stress intensity at which a material fractures without deformation is known as the fracture toughness of the material. Given the fracture toughness of a material at a specific temperature, one can determine allowable flaw sizes at various stresses, or allowable stresses given specific flaw sizes. Fracture toughness is an important design parameter for cryogenic applications, because many materials become brittle at low temperatures.

Another advantage of the fracture mechanics approach in design is the leak-before-break concept. The stress intensity at the tip of a surface flaw is calculated under design stresses. If the flaw can grow through the thickness of the vesse 1 without producing a stress intensity greater than the material's fracture toughness, the leak-before-break criterion is satisfied and a growing flaw would produce a detectable leak before catastrophic failure of the vessel.

The concepts of stress intensity and fracture toughness are we 11 established by many smal1- and large-scale experiments; however, the leak-before-break method for fracture control assumes that the crack grows at some fixed aspect ratio characteristic of a homogenerous, isotropic material affected only by imposed stresses. In practice, cracks sometimes grow to much 
larger aspect ratios due to anisotropy or residual stresses. It is not currently possible to evaluate these factors without performing full-scale tests of vesse 1 material with intentionally initiated cracks.

Welding may affect the safety of vessels by changing the metallurigical quality of the vessel material, or by imposing stresses on the structure. The metallurgical quality of the metal may be reduced by the introduction of hydrogen or other impurities, by causing a temperature-induced transformation to occur, resulting in brittleness, or by softening the material surrounding the weld. Flaws such as porosity, inclusions, lack of fusion, or hotcracking present likely initiation points for cracking. Stresses from the welding process are both parallel and perpendicular to the weld direction. These residual stresses must be added to the applied stresses in determining structural stability. In some material the combination of residual stresses, flaws, and impurities from welding has caused delayed cracking to occur before the structures were put into service.

Much work has been done to evaluate the low-temperature fracture characteristics of 5083 aluminum and $9 \% \mathrm{Ni}$ steel. Both of these materials have been shown to have high toughness at LNG temperatures, and this is substantiated by the excellent safety record of metal LNG piping and tankage systems.

Critical crack size for a given geometry is determined from the relation:

$$
a_{c}=\left[K_{c} / T Y(a)\right]^{2}
$$

where

$$
\begin{aligned}
a_{c} & =\text { critical crack size } \\
K_{c} & =\text { fracture toughness } \\
T & =\text { stress }
\end{aligned}
$$

and

$$
Y(a)=\text { dimension less geometry parameter for surface flaws (Irwin 1964). }
$$


Using this relationship one can find the crack length which will cause failure of a vessel, or the maximum tolerable stress given a specific crack length. A sumary of fracture toughness and yield strength data for cryogenic materials at various temperatures is given in Table 3.1. This data has been used to calculate critical crack sizes at various stresses, as shown in Table 3.2. The design stresses of $28.5 \mathrm{ksi}$ for $\mathrm{A} 553$ ( $9 \% \mathrm{Ni}$ ) steel and $12.0 \mathrm{ksi}$ for 5083-0 aluminum are included in these calculations. The steel alloy at $-323^{\circ} \mathrm{F}$ has a critical crack length of 10.9 inches at its design stress, and the aluminum alloy has a critical crack length of 3.4 inches at th is temperature. Leak-before-break approaches to fracture control have concluded that critical crack length should be at least twice the wall thickness at design stress, to ensure that a growing flaw will grow through the wall before catastropic failure can occur (Tada 1973). This is based on a typical crack aspect ratio and may vary if high anisotropy or residual stresses exist.

TABLE 3.1. Mechanical Properties of Cryogen ic Materials

\begin{tabular}{|c|c|c|c|c|}
\hline Temp. F & Material & $\begin{array}{l}\text { Yield } \\
\text { Strength } \\
\text { (ksi) }\end{array}$ & $\begin{array}{l}\text { Tensile } \\
\text { Strength } \\
\text { (ksi) }\end{array}$ & $\begin{array}{c}\text { Fracture } \\
\text { Toughness } \\
\text { (ksi } \sqrt{7 n .})\end{array}$ \\
\hline 70 & $9 \%$ Ni Steel & 99.9 & 109.1 & 187.0 \\
\hline-323 & $9 \% \mathrm{Ni}$ Steel & 121.0 & -- & 167.0 \\
\hline 70 & 5083-0 Aluminum & 20.6 & 44.2 & 24.3 \\
\hline-323 & 5083-0 A luminum & 21.7 & 58.6 & 39.1 \\
\hline
\end{tabular}

TABLE 3.2. Critical Crack Sizes for Cryogenic Materials

\begin{tabular}{|c|c|c|c|c|c|c|}
\hline \multirow[b]{2}{*}{ Temp. F } & \multirow[b]{2}{*}{ Material } & \multicolumn{5}{|c|}{ Critical Crack Size, in. } \\
\hline & & & & $\frac{s s, k s}{20}$ & $\begin{array}{l}= \\
28.5\end{array}$ & 40 \\
\hline 70 & $9 \% \mathrm{Ni}$ Stee 1 & 111.3 & -- & 27.8 & 13.7 & 4.5 \\
\hline-323 & $9 \% \mathrm{Ni}$ Steel & 88.8 & -- & 22.2 & 10.9 & 5.6 \\
\hline 70 & 5083-0 Alumi num & 1.88 & 1.3 & 0.5 & -- & -- \\
\hline-323 & 5083-0 Aluminum & 4.9 & 3.4 & 1.22 & -- & -- \\
\hline
\end{tabular}


By th is criteria, vessels made of $9 \% \mathrm{Ni}$ steel should be no thicker than 5.4 inches, and vessels made of 5083-0 aluminum should be no thicker than 1.7 inches. The toughness of both materials is insensitive to temperature over the LNG temperature range (Tobler and Reed 1977) and 5083-0 aluminum is not sensitive to impact loading (Lake 1975). The 9\% Ni alloy, however, may experience a toughness transition at very low temperatures. Dynamic testing (fracturing specimens at a high loading rate) may be needed to determine the effects of impact loading on material toughness. . It is possible that the dynamic toughness transition occurs at a higher temperature than the static toughness transition. This could result in an inability to predict catastrophic failure under dynamic loading conditions.

Thermal cycling and pressure cycling do not affect the metallurgical quality of LNG materials; however, cyclic loading does provide the possibility for subcritical crack growth due to cyclic stress intensity. The fatigue-crack-growth rates of common LNG material have been studied over a wide range of cyclic stress intensities (Tobler et al. 1975; Tobler and Reed 1977). The metals exhibit about the same crack-growth rate at $4 \mathrm{~K}$ as at ambient temperature, and give no cause for concern as long as thermal and pressure cycling are taken into design considerations.

Thermal and pressure loading cycles for an LNG storage tank can result from filling and emptying a tank. Stress induced by pressure loads result from hydrostatic and vapor pressures exerted by LNG stored in the tank. Thermal stresses are produced during the cooldown of a tank to the temperature of LNG.

In evaluating cyclic effects, pressure stress levels can conservatively be assumed to be the allowable design stress for the material. API standard 620 gives the allowable design stresses for $9 \% \mathrm{Ni}$ steel as 31,700 psi and for AL-5083-0 as $12,000 \mathrm{psi}$. The fatigue curves for these materials indicate that over $10^{6}$ cycles of pressure could be experienced by the tank before fatigue failure (Battelle Columbus Laboratories 1974).

Thermal stresses produced during loading of LNG are found to be typically 70,000 psi for $9 \% \mathrm{Ni}$ steel tanks and 35,000 psi for Al 5083-0 tanks (Lom 1975). In calculating these stresses it was assumed that the temperature 
changes from $21^{\circ} \mathrm{C}$ to $-161^{\circ} \mathrm{C}$ and the tank walls were assumed to be complete ly constrained during cooldown. Both of these assumptions are conservative, especially the former in conjunction with import-export storage facilities. Import-export storage tanks experience a loading cycle about 100 times a year, the most frequent of all LNG storage facilities. These tanks probably would not warm up to ambient temperature between loadings. However, assuming they did, the fatigue curves for $9 \% \mathrm{Ni}$ stee 1 construction could withstand about 6000 loading cycles. Therefore, on this basis an import/export $9 \% \mathrm{Ni}$ stee 1 storage tank has an expected life of 60 years. Tanks of A1 5083-0 could withstand up to 3600 thermal loading cycles. Consequently, the expected life of A1-5083-0 import/export storage tanks is 36 years.

It should be noted that the above estimate is based on a very simplified model and does not take into account welds or other discontinuities in storage tank construction. Currently, Factor Mutual Research Corporation is conducting research in this area and their results will be reviewed in future work.

\subsubsection{Concrete}

The use of prestressed concrete for cryogenic storage was first investigated in 1951 by the Linde Company of East Chicago, in cooperation with the Preload Company. They found that the properties of the material were suitable, and a tank for the storage of liquid oxygen was built in 1953 (Turner 1972).

Since that time there has been an increasing emphasis placed on the use of prestressed concrete for cryogenic use. In 1966, the Institute of Gas Technology thoroughly investigated and reported the properties of concrete and prestressing steel at cryogenic temperatures (Closner 1970). In 1968, Gaz de France built and tested a small prestressed concrete tank at Nantes. The test to which this tank was subjected included pouring liquid nitrogen onto the unlined, uninsulated floor and walls of the warm tank, thereby exposing it to an instantaneous thermal shock resulting from a temperature difference of $400^{\circ} \mathrm{F}$. The only effect on the tank was a crack that developed in the base of the tank, which subsequently closed when the thermal gradient became less extreme (Turner 1972). 
Generally, it has been found that at cryogenic temperatures the tensile and compressive strengths of prestressed concrete increase. The tensile and compressive strengths of dry concrete increase by 10 percent. Dry concrete is a test sample that has been oven dried before testing. Young's Modulus for dry concrete remains unchanged, but for wet concrete it increases by about 50 percent (Turner 1972).

Another concrete property that should be discussed is thermal conductivity. It has been shown that for wet concrete, thermal conductivity increases by about 50 percent from $75^{\circ} \mathrm{F}$ to $-250^{\circ} \mathrm{F}$. Whereas therma 1 conductivity for dry concrete increases only by about 15 percent over the same temperature range (Lentz and Monfore 1965).

In evaluating Thermal and Pressure Cycling loads for concrete tanks, it is found that prestressed concrete storage tanks are constructed of concrete with an ultimate stress of 4000 to 5000 psi (American Gas Association 1973). The maximum allowable design stress, assumed to be the cyclic pressure stress, was found to be 2000 psi (Closner 1979). The fatigue characteristics of concrete indicate that a concrete storage tank could withstand in excess of $10^{7}$ cycles of pressure stresses (American Society for Testing and Materials 1975).

The thermal stress experienced when loading LNG would be significant on ly in a concrete tank with an uninsulated interior surface. In such a tank, because of a very slow cooldown procedure, thermal stresses would result from the maximum thermal gradient in the tank wa 11 . Consequently, thermal stresses assuming worst case conditions, were calculated at 3400 psi (Closner 1968b). Therefore, the fatigue curve for concrete indicates that an uninsulated concrete tank could withstand about 15,000 cooldown cycles. Th is translates to a 150 year lifetime for an import/export concrete storage tank.

As a result of the many investigations addressing the suitability of prestressed concrete as a material for cryogenic use, many prestressed concrete tanks have been built for storage of LNG including several in Phildelphia, PA; Staten Island, NY, and Barcelona, Spain. 


\subsection{REPRESENTATIVE TANKS}

The reference tanks to be investigated are the above ground double wa 11 meta 1 tank (Figure 3.2), the above ground prestressed concrete tank (Figure 3.3) and the below ground prestressed concrete tank (Figure 3.4).

The above ground tanks were selected because of their conventional configurations and material types. The below ground tank was investigated because of interest regarding its inherent safe design with respect to potential release of contents. In the comparative efforts at the conclusion of this report, primary consideration was given to the above ground tanks because of their established domination in this country.

The excellent safety record for these plants can, in a large way, be attributed to the ongoing research and development as well as the periodic evaluations of existing systems. Most cryogenic tanks in existence with in the U.S. today have followed ASME, Section 8 or API 620, Appendix Q, specifications at least as guidelines (American Gas Association 1973). Many facilities have been built to exceed these specificiations.

\subsection{DOUBLE WALL METAL TANK}

Figure 3.2 illustrates the flat bottom metal LNG storage tank selected for analysis, with several tank specifications included in the cross-sectional view of Figure 4.1. This conventional double wall tank functions at a relatively low internal pressure $(2.0 \mathrm{psig})$ and has a liquid storage capacity of approximately $2.93 \times 10^{6} \mathrm{cu}$. $\mathrm{ft}$. of LNG.

The double wa 11 tank configuration is constructed such that the inner tank functions as the liquid containment barrier. The outer tank serves as a pressure barrier eliminating the differential gas pressure between tanks, as a containment structure for insulation located in the annulus between tanks, and as an additional barrier to moisture, external missiles, fire, etc. This is accomplished through a single roof design, the roof being attached at the outer tank wall and serving to support a suspended insulating deck. 


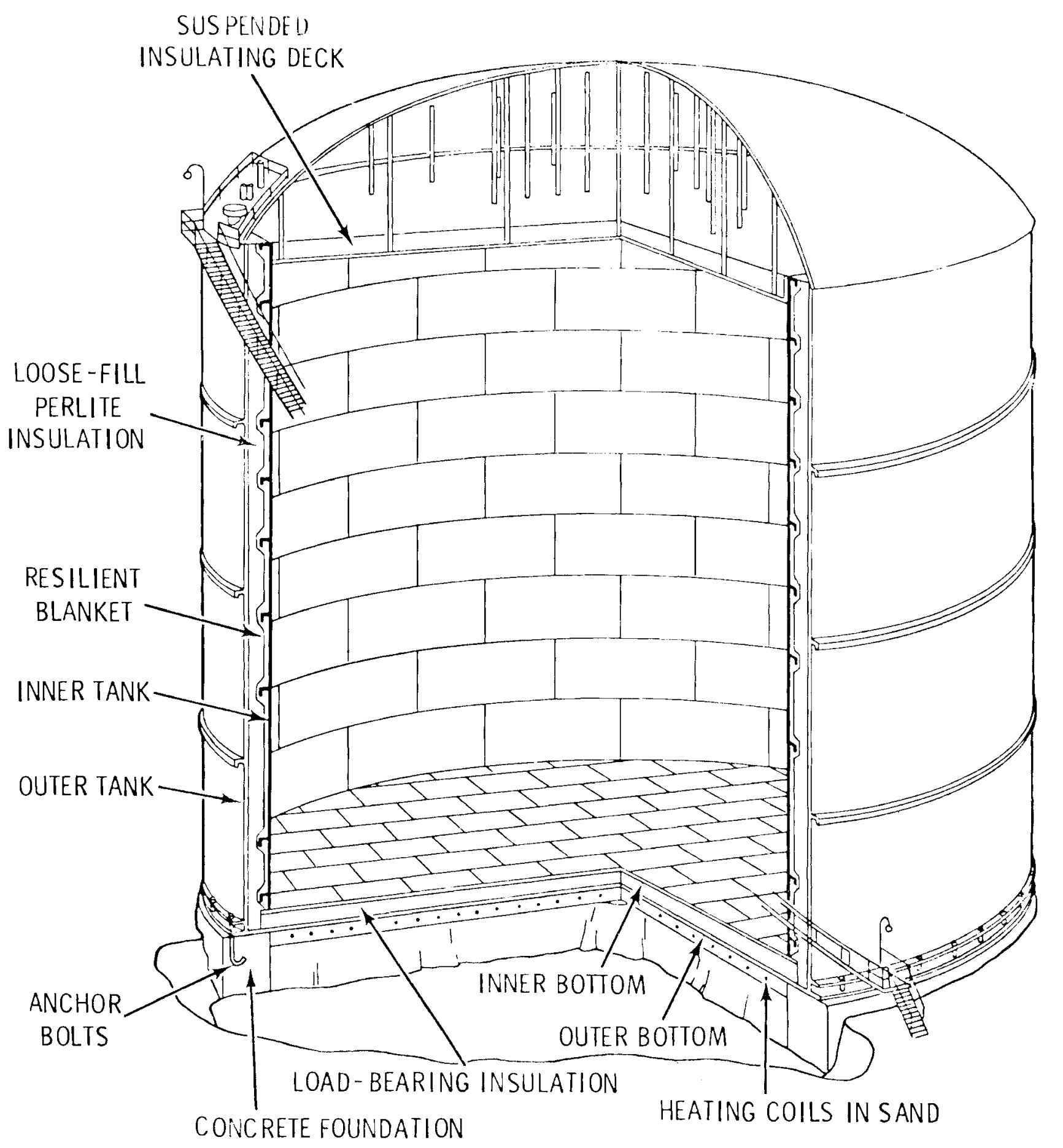

FIGURE 4.1. Cross Section of Double Wall Metal Tank 
The inner tank containing the cryogen ic liquid is constructed from $9 \%$ nickel steel. The API 620 Standard, Appendix Q lists acceptable plate and structural materials based on ASTM specifications. Inner tank shell plates are approximately 9.85 feet high and vary in thickness from .795 inch at the tank bottom to .3125 in, at the tank top. Each is welded and usual procedure specifies extensive radiography to allow a higher design joint efficiency (American Gas Association 1973). Eight tank ring stiffeners are included along the outer tank surface with an additional gusset stiffener located at the tank top.

The outer tank wall is constructed from a mild carbon steel (e.g., A131 GR C) with plates $9.33 \mathrm{ft}$ high and external wind stiffeners located every 25 ft vertically. The shell plates vary in thickness from $9 / 16$ in. for the first 6 courses to $1 / 2$ in. plate for the seven remaining courses. Additional stiffening in the form of rim girders is introduced at the wall-dome junction. The dome is constructed from $1 / 4$ in. plate stiffened by an internal umbrella frame network and, in turn, supports a suspended insulating deck with approximately $3 \mathrm{ft}$ of perlite insulation.

The annulus between tanks is approximately $3.67 \mathrm{ft}$. This region contains a fiberglass resilient blanket which lines one or both tank surfaces and acts to maintain a uniform perlite compaction during differential movement between tanks. The remainder of the annular space contains the inert, noncombustible, expanded volcanic material, perlite, which has a density of between 3 and 4 $\mathrm{lb} / \mathrm{cu}$. ft. The insulating material between the tank floor plates is of $a$ load-bearing capability, in this case Foamglas sheets approximately 4 in. thick.

The outer and inner tank sit on a common foundation ring wall with the outer tank anchored to prevent uplift due to the pressure boundary at the dome. The ring wall is normally heavy enough to balance a maximum uplift under empty tank conditions. The remainder of the tank is supported by soil yielding design bearing values of 4500 psf. A uniform selected grade is required to prevent tank settlement, which could cause additional tank 
stresses or initiate insulation cracks leading to heat leakage into the LNG. Operating temperature controls are maintained in this area through the installation of heating coils beneath the tanks. These prevent soil freezing and subsequent frost heave conditions.

The particular tank described here appears to typify tank configurations in existence and has a proven excellent safety record. Therefore, this "generic" tank type has been selected for subjection to various release scenarios and to which comparisons with other tanks will be made.

\subsection{PRESTRESSED CONCRETE TANKS}

The basic design for both prestressed concrete tanks. (Figure 4.2), consists of a concrete foundation on a preloaded sand $f i l l$ and an insulated base covered by a $3 / 16$ inch, $9 \%$ nickel steel floor system. The interior tank with a radius of $68.78 \mathrm{ft}$ consists of $3 / 16$ inch $A 553$ Type $19 \%$ nickel steel.

The exterior core wall with a radius of $75.17 \mathrm{ft}$ is $95 \mathrm{ft} 7$ inches $\mathrm{high}$, 16 inches thick and is prestressed both vertically and circumferentially. A $3 / 16$ inch thick carbon steel (A131, Grade C) tank liner is integral with the exterior face of the prestressed concrete core wall. The circumferential prestressing wires are applied around the steel liner and a 2 inch shotcrete cover placed over the wires. The core wall rests on 2 inch A537 bearing and side plates to permit movement of the wall during prestressing and cooldown.

The spherical tank dome consists of a 3/16 inch A516 Grade 70 carbon stee 1 roof plate with a concrete overlay of 8 inches. The tank's ceiling is suspended from the dome. The $1.2 \mathrm{ft} \times 1.9 \mathrm{ft}$ dome ring is prestressed to induce sufficient compressive stresses to counteract the tensile stresses set up in the ring under the maximum load conditions.

The annular space between the two walls and between the roof and dome is filled with powdered perlite as the insulation medium for the walls and roof. The perlite insulation space is blanketed with dry methane, and the pressure is equalized between the inner tank and the insulation space. 


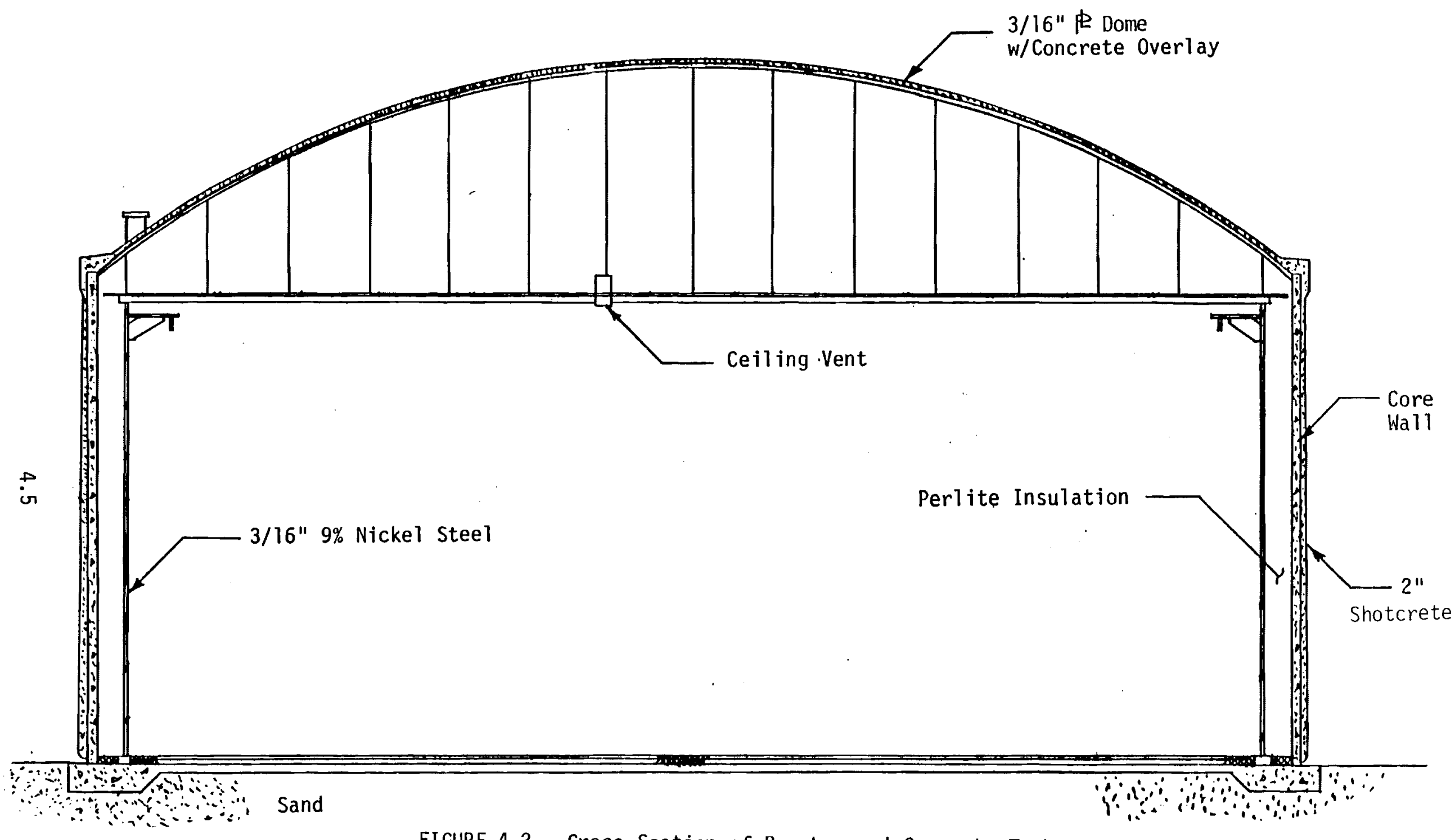

FIGURE 4.2. Cross Section of Prestressed Concrete Tank 



\subsection{METHODOLOGY}

The storage tank assessment is performed in two stages, a qualitative preliminary analysis and then a more detailed quantitative analysis. The intent of the preliminary analys is is to develop a method of comparing the safety aspects of different types of LNG storage facilities which does not require site specific or operating conditions information.

Following this preliminary analysis a more involved and quantitative analysis is performed. In order to attempt to attain quantitative results, several assumptions were required in the mathematical models used. Although these assumptions keep the complexity of this evaluation within the scope of this study it can also limit the number of details needed to fully describe the accident or situation being analyzed. The merit of the quantitative analysis is that it does consider in detail the parameters that affect the performance of a tank, whereas in other studies, including the preliminary evaluation, much is based on generalities.

In th is methodology discussion, the preliminary and quant itative evaluations are outlined, introducing the scenarios to be considered and discussing how they affect the performance of an LNG storage tank.

\subsection{PREL IMINARY ANALYSIS}

In an initial attempt to assess storage tanks a preliminary comparative evaluation was performed. This analys is examined the following tank components individually:

- walls

- floor

- roof

- dikes

- berms.

The hazards which were applied to the tank included: earthquake, adjacent fire, overpressurization, missile impact, explosions, tornadoes, hurricanes, crack propagation, floods, failure, overfill and underpressurization. 
Given a specific scenario, the different types of tank components are ranked in relation to the relative chance of failing to contain the LNG. The ranking given to these results is defined as its ranking index. The higher the ranking index, the more protection provided by that type of component against possible damage done by the selected hazard. Then, an LNG tank is assembled with various types of components (i.e, double-wall metal tank, with suspended roof, concrete floor and earthen dike). The sum of the ranking indices of these types of components becomes the total rarking index for that particular system.

Several assumptions were made in the process of setting up this analysis. The most important assumption was that a 11 hazards were treated equally. That is, all the hazards were assumed to pose the same potential danger to the stored LNG. In order to assign a relative weight of importance to the hazards, one has to evaluate the potential degree of damage done to the LNG storage system by each hazard, as well as the probability of occurrence for each hazard. This is beyond the scope of this preliminary evaluation and is its major drawback. But this evaluation still provides insight to the effectiveness of various types of storage tank components to selected hazards.

\subsection{QUANTITATIVE ANALYSIS}

It is the intent of this safety study to perform a quantitative analysis on the resistance of LNG storage facilities to failure due to internal instabilities or external events.

In order to quantify storage tank response to adverse conditions, a specific set of failure scenarios was devised with these scenarios utilized in trial cases. The potential hazards were selected as a result of a literature survey conducted in conjunction with the LNG Safety Studies Program (Bampton et a1. 1980). Scenarios initially addressed included those that most likely emerge from the tank facility itself (these are only applied to DW metal tanks). 
- overfill and overflow

- over-underpressurization

- subsidence

- crack propagation

Additional scenarios addressed include those that result from external events:

- tornado

- exterior tank missile

- fire

- seismic

Applicability of each scenario depends heavily on the specific tank configuration and material types selected.

For scenarios that emerge from within the tank facility itself (except crack propagation), the analysis initially begins by assessing the in-service or steady-state conditions quantitatively. Then the effect of the scenaro is assessed by calculating the difference in stress, load or pressure between the normal operating state and the state the tank would be in due to the occurrence of abnormal performance within the tank.

When possible, in the assessment of the external events, (including crack propagation) the frequency of occurrence of these external events is studied before determining whether a certain storage tank can retain its integrity by withstanding the damaging effects of the specific scenario.

\subsubsection{Overfill and Overflow}

Overfill conditions in which the normal liquid filling level is exceeded would most likely occur because of human error or misoperation. Most systems are equipped with three alarm systems; one for normal liquid levels, one for overfill levels and one for extreme overfill levels. The latter often operates simultaneously with an automatic shut off valve to prevent overflow, defined as spillage of liquid into the annular space between the double walls of the tank. 
Overfil1 can result in additional stresses in the inner tank wall due to the increased hydrostatic head. Overflow may result in increased hydrostatic pressures in the annulus as well as thermal stresses due to contact between the liquid at cryogenic temperatures and the outer tank wall. This latter case is addressed assuming minimal vaporization and total containment of the spilled LNG. In reality, LNG liquid spilled into the annulus will result in leakage initially along the inner tank and through the fibrous blanket and insulation. In small quantities, this leakage would most likely vaporize. Large quantities, however, could result in contact between the cryogenic fluid and the mild carbon steel outer shell with subsequent cracking due to temperature exposures below the transition temperature. In th is case, vapor releases to the atmosphere could also occur. However, assuming early detection the cracks would be small due to the arresting features of the adjacent higher wall temperatures and reduced stresses.

Stress calculations are performed on the inner and outer tank walls during operating, overfill and overflow conditions.

\subsubsection{Overpressure/Underpressure}

Over/underpressure conditions potentially result from various postulated failure scenarios (e.g., adjacent fire, operator error, tornado conditions). It is the intent here to assume an over/underpressure situation without strict regard to its initiation. Several consequences of over/underpressures as related to the pressure boundary (outer tank/dome) are analyzed beginning with an investigation of steady state relationships under typical operative conditions. This is followed by a determination of changes in boil-off rate as a function of sudden pressure drop (e.g., from tornado conditions), critical buckling and bursting pressure, increased stresses at the dome-wall interface due to overpressurization (e.g., from operator error), and the potential for rollover to occur.

LNG is stored as a saturated liquid in a state of thermodynamic equilibrium. Heat is transferred from the surrounding environment to the liquid LNG through conduction, convection and radiation. Any disturbance such 
as pressure changes in the vapor space will cause reestablishment of this equilibrium state through alterations in evaporative cooling at the liquid surface. In addition, saturation temperatures will change as a function of absolute pressure. The efficiency of the system requires control of these mechanisms to assure minimum heat influx and, thus, controllable boil-off rates and tank pressures.

Perhaps one of the most important advantages to the storage of LNG as a cryogenic fluid is that liquefaction results in a volume contraction of about 600 to 1 . This however, requires low temperature maintenance for which low conducting insulations play a major role. In addition to the low conduction thermal properties, the cellular structure of such insulations trap gases, helping to eliminate gaseous circulation through the annular space between the inner and outer tanks. A resultant low convective path occurs. The annular space is further exposed to the vaporized LNG. Not only does th is equalize the pressure between the two tanks allowing for less material to structurally support the system, but the moisture content in the insulation space is kept to a minimum. The importance of this is to limit the buildup of ice, thus eliminating possible loss of insulating capabilities.

\subsubsection{Subsidence}

The foundations for LNG storage tanks are designed and constructed to meet the requirements of the specific site selected. Under the shells a ring wall is often used and installed with such a weight as to counteract the uplift forces due to pressures on the dome. In some cases where differential settling or seismic activity may occur, slab foundations are used. On poor soils, the tank can be decreased in height and increased in diameter to create smaller bearing forces per unit area. However, this tends to decrease the economical advantages present when an optimum height to diameter ratio is used. In other situations, soil conditions may require pile foundations. In all cases soil freezing and subsequent frost heaving must be prevented. This is usually accomplished through the installation of heating coils and use of selected fill. In addition, some foundations of the pile type allow for circulation of air between the ground and pile caps. 
Before in-service operation commences, a hydrostatic proof test is conducted. This establishes tank performance during exposure to a resultant bearing load ranging from 1 to 1.25 times the load at maximum LNG storage capacity. In addition, this test tends to mechanically stress relieve the welded structure. Should settlement occur, whether during proof test or in-service operation, it will most likely fall under one of four categories; uniform settling, tilted settlings, dishing, or differential settling around the tank perimeter. Excessive dishing, and thus possible leakage due to damaged Foamglas, is unlikely if a crowned bottom is used. Differential settling is also unlikely if uniform compaction is initially established. Under these conditions, however, it is possible that elastic buckling could occur during a slow differential settling situation and that reconstruction of the foundation would allow a return to original specifications.

The effects of subsidence on the metal DW tank itself is assessed by developing a 3-D finite element model of the tank and applying various degrees of total subsidence to it.

\subsubsection{Crack Propagation}

Catastropic failure due to brittle fracture does not often occur, and in fact, in over 20 years of in-service experience using $9 \% \mathrm{Ni}$ in LNG storage tanks, there has been no record of catastropic brittle fracture of the primary containment vesse 1 (Clark and Upit is 1980). However, through history there have been large structures that have failed in this manner, thus, the continued investigation that parallels the growth of the field of fracture mechanics. Many factors can contribute to the brittle fracture of a structure (temperatures, material toughness, exposure to fatigue, geometric configuration, etc.) but the three primary variables are identified as flaw size, material toughness, and the stress field (Rolfe and Barsom 1977). Both the inner and outer tank walls are investigated using developed interrelationships among these variables. In addition, some experimental results are presented along with crack existence probability calculations. 


\subsubsection{Tornado}

A tornado is a localized, intense storm of short duration. The destructive forces can be attributed to rotating winds of high speed in conjunction with large decreases in atmospheric pressure. Wind speeds and pressure drops have been estimated at $250 \mathrm{mph}$ and $1.10 \mathrm{psi}$ (Arthur D. Little 1971) to $360 \mathrm{mph}$ maximum wind speed and $290 \mathrm{mph}$ rotation speed with a pressure drop of 3.0 psi (U.S. NRC 1974). The rate of pressure drop is rapid, perhaps up to $2 \mathrm{psi} / \mathrm{sec}$, and the radius of maximum rotational speed can be $150 \mathrm{ft}$ from the tornado center (U.S. NRC 1974).

Designing structures to resist wind loading is a complex engineering problem. Currently, NFPA 50A (NFPA 1979) does not specifically consider wind pressure in its standards but references the wind design requirements in API 620 (API 1973).

In the analysis the probability of the occurrence of a tornado is discussed. Following this, severe tornado wind velocities are assigned to the representative tanks. These velocities are transformed into an effective pressure applied to the exposed surfaces of the tank structure. These results give an indication as to how well these tanks will hold up under tornado conditions.

\subsubsection{Impact}

The impact impact scenario will only address site generated missiles. Aircraft or military type missile are not considered due to the remote probability of occurrence. (a)

Missiles may be generated by an event that is not related to plant operations or by failure of plant equipment. Debris transported by tornado

(a) Calculations based on the number of fatal crashes, the area of the U.S. and the area of a typical LNG tank yield an expected number of airplane crashes at any random site as $5 \times 10^{-11}$ per hour. For LNG sites located near airports, the risk is greater and should perhaps be investigated (American Gas Association 1973). 
winds and falling objects generated by activities near the site are the most common type in the first category. The second type of missile usually results from forces released accidently from pressurized systems or rotating machinery.

The analysis will subject the tank to missiles at some selected velocity and determine the wall thickness that such a missile will perforate. For the tornado generated missiles, velocities were based on the velocity attained if carried by a typical tornado wind.

\subsubsection{Fire}

A major potential hazard of an LNG facility is a fire and its consequences. Gas fires generally fall into two categories: a low-pressure type where the flame is localized and high-pressure type in which a burning gas jet may impinge on other equipment. A high velocity gas jet could be produced by a crack in a gas treatment vessel or a failure in gas piping. If such a jet ignites, the length of the burning jet depends primarily on the size of the opening. The flame jet length (feet) for methane is about 16 times the hole diameter (inches). Rapid heating and secondary failure may occur if such a jet impinges on other equipment and exposures are not cooled with water. This type of gas fire poses less of a hazard than the low pressure type and is not analyzed further.

A large LNG pool fire is normally a low-pressure type with the fire about three times higher than its base dimension. Objects around the fire absorb the radiated heat from the visible burning zone. The thermal radiation intensity can be estimated as a function of location and distance from the fire for a specified burning LNG pool size and known weather conditions. Failure of steel structures, machinery, fatality or serious burns to people from doses of thermal radiation have been fairly well defined. This combination of information, along with specific site details, allows hazard sever ity estimates to be made. 
Some of the safety concerns in the transportation and storage of LNG were highlighted in a report issued on July 31, 1978, by the General Accounting Office entitled, "Liquefied Energy Gases". Foremost among these concerns were:

1. the protection of persons and property near an LNG facility from thermal radiation (heat) caused by ignition of a major spill of LNG,

2. protection of persons and property near an LNG facility from dispersion and delayed ignition of a natural gas cloud arising from a major spill of LNG, and

3. reduction of the potential for a catastrophic spill of LNG.

The study of the effect of fire on the tank consists of two parts and will focus on points 1 ) and 3) above. Part one of the study will investigate the temperature distribution in the wall due to a flux radiation, Q, of 4755 $B t u / \mathrm{ft}^{2}-\mathrm{hr}$. (a) The basic assumption for this analysis considers the roof to no longer be intact and the fire to be concentrated within the tank's boundaries. The heat flux radiation rate on the tank due to a fire in an adjacent tank $525 \mathrm{ft}$ away (C.L. - C. L.) will be determined in part two of the study. The clear distance between tanks is we 11 above the minimum clear distances specified by NFPA 59A-1979 (NFPA 1979) as listed in Table 5.1. Some state codes, however, are double the NFPA 59A requirements and probably reflect an increasing concern regarding LNG hazards.

An analysis to determine if the two types of tanks, DW metal and prestressed concrete, can withstand the effects of a fire is performed in the analysis section. For both tanks, temperature distribution in the wall due to a flux radiation of $4755 \mathrm{Btu} / \mathrm{ft}^{2}-\mathrm{hr}(\mathrm{a})$ and the heat flux radiation rate on the tank due to an adjacent tank fire are determined. For the DW metal tank, a time-temperature history at varying locations through the perlite insulation region and the thermal strains with resulting bending stresses and deflection are also determined.

(a) Marchaj, T. J., July 10, 1981, personal communication, the Preload Company, Inc., Garden City, NY. 
TABLE 5.1. Minimum Clear Distances Between Tanks

\begin{tabular}{|c|c|c|}
\hline \multirow[b]{2}{*}{ Water Capac ity Per Conta iner } & \multicolumn{2}{|c|}{ Minimum Clear Distances } \\
\hline & $\begin{array}{l}\text { From Container } \\
\text { To Property } \\
\text { Line Which } \\
\text { May Be } \\
\text { Built Upon } \\
\end{array}$ & $\begin{array}{l}\text { Between } \\
\text { Any Two } \\
\text { Adjacent } \\
\text { Containers }\end{array}$ \\
\hline Less than 125 gal $(473 \mathrm{~L})^{(\mathrm{a})}$ & None & None \\
\hline 125 to $250 \mathrm{gal}(473$ to $946 \mathrm{~L})$ & $10 \mathrm{ft} \cdot(3 \mathrm{~m})$ & None \\
\hline 251 to $500 \mathrm{gal}(950$ to $1892 \mathrm{~L}$ ) & $10 \mathrm{ft} \cdot(3 \mathrm{~m})$ & $3 \mathrm{ft} \cdot(1 \mathrm{~m})$ \\
\hline $\begin{array}{l}501 \text { to } 2,000 \mathrm{gal}(1.9 \text { to } \\
\left.7.6 \mathrm{~m}^{3}\right)\end{array}$ & $25 \mathrm{ft} .(7.6 \mathrm{~m})$ & $3 \mathrm{ft} .(1 \mathrm{~m})$ \\
\hline $\begin{array}{l}2,001 \text { to } 3 q, 000 \mathrm{gal}(7.6+ \\
\left.\quad \text { to } 113 \mathrm{~m}^{3}\right)\end{array}$ & $50 \mathrm{ft} \cdot(15 \mathrm{~m})$ & $5 \mathrm{ft} .(1.5 \mathrm{~m})$ \\
\hline $\begin{array}{l}30,001 \text { to } 30,000 \mathrm{gal}(113+ \\
\left.\text { to } 265 \mathrm{~m}^{3}\right)\end{array}$ & $75 \mathrm{ft} \cdot(23 \mathrm{~m})$ & $10 \mathrm{ft} \cdot(3 \mathrm{~m})$ \\
\hline Above $70,000 \mathrm{gal}\left(265 \mathrm{~m}^{3}\right)$ & $\begin{array}{l}0.7 \text { times the con- } \\
\text { tainer diameter but } \\
\text { not less than } 100 \\
\mathrm{ft}(30 \mathrm{~m}) \text {. }\end{array}$ & $\begin{array}{l}1 / 4 \text { of sum of dia- } \\
\text { meters of the two } \\
\text { adjacent containers } \\
\text { but not less than } \\
25 \mathrm{ft} .(7.6 \mathrm{~m}) .\end{array}$ \\
\hline
\end{tabular}

(a) If the aggregate water capac ity of a multicontainer installation is 501 gal $\left(1.9 \mathrm{~m}^{3}\right)$ or greater, the minimum distance shall comply with the appropriate portion of this table, applying the aggregate capacity rather than the capacity per container. If more than one installation is made, each installation shall be separated from another installation by at least $25 \mathrm{ft}$. $(7.6 \mathrm{~m})$. Do not apply the minimum distances between adjacent containers to such installations.

\subsubsection{Se ismic}

Wozniak and Mitchell (1971) summarize and categorize the damage which has been done to flat bottom welded steel storage tanks during major earthquake occurrences. Four categories are included. Buckling has occurred at the tank bottom resulting in the "elephant foot" configuration. This has usually been found in unanchored tanks having 10 to 100 foot diameters, and has been caused by meridional compressive stresses resulting from large overturning moments. sloshing of the liquid has damaged internal roof supports and upper portions 
of the tank she11. Differential movements between the tanks and connecting systems (e.g., piping), and failure of the supporting ground have caused damage in isolated instances.

Several approximate methods of determining the response of cylindrical tanks containing liquids have been suggested. A widely used procedure developed by Housner was utilized, (Lockheed Aircraft Corporation et al. 1973) followed by suggested alterations to that method. In the following analysis section it was assumed that the 2 tanks (inner and outer tanks) act independently of one another and that the analys is was directed at the primary liquid containment barrier. 


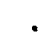




\subsection{COMPARATIVE SAFETY ANALYSIS}

In the methodology section, the outline of the preliminary and final analyzes were given. In this section detail of the analyses are presented, with calculations presented in the appendices.

Following the final analysis, safety comparisons between the selected tank configurations are made. Although tank responses to the selected scenarios may be very different thus making comparisons among tank types difficult, several comparative results are provided.

\subsection{PRELIMINARY COMPARATIVE SAFETY ANALYSES}

In Section 3.0 the various structural components that make up an LNG storage system were discussed. The advantages and disadvantages associated with each component in relation to their design and to their responses to the outlined hazards were discussed. The preliminary analys is will discuss combinations of these components into complete LNG storage systems and will attempt to assess their relative merits.

In order to evaluate all structurally feasible combinations of system components an evaluating technique was devised. This technique involved ranking the various system components, within their own component group, in relation to each hazard. A total ranking index for each spec ific component was derived by adding the individual rankings for each hazard together. These total ranking indices were sumed as the components would be assembled to compose an LNG storage system. Before summing, these indices were multiplied by a weighting coefficient. The weighting coefficient reflects the components' relative contribution to the overall safety of the complete LNG storage system. The number obtained by these operations was defined to be the safety rating of the given LNG storage system. The methodology of this technique is explained in greater detail in Appendix $A$.

A few assumptions were made in the process of setting up this analysis. The first one which was discussed in Section 5.1 is that all hazards are to be treated independent ly. 
The second assumption, not previously discussed, is that in the event two component designs present equal $r$ isk of damage by a particular hazard, they are given equal ranking indices. For example, buried concrete tanks and other in-ground storage provide the most and approximately the same protection when considering fatigue or crack growth problems. So, they shared first and second place and were assigned a ranking index of 4.5 each for this hazard.

The results of the analysis are shown in Table 6.1. See Appendix A.1 for calculations. Overall, below-ground storage of LNG achieved a higher safety rating than above-ground storage. The double walls of concrete tanks generally ranked higher than the double walls of metal tanks. Tanks with single steel roofs, suspended decks and concrete overlays scored high, but most likely because this roof is generally associated with the concrete tanks.

Unfortunate $7 y$, in an analysis of this type, subjectivity is inherently involved. The subjectivity arises when assigning the weighting coefficients to the components of the system and when assigning ranking indices.

This analys is is a start towards a comparative evaluation among different types of LNG storage tank designs. It has its limits in simplicity. In order to attain more accurate results the hazards need to be examined in greater depth for specific geographical locations. Consequently, the hazards could be assigned weighting coefficients according to their relative detraction from the overall safety of the LNG storage system. The weighting coefficients assigned to the components should be analyzed in a more objective light in order to contribute more validity to this technique and the results obtained with it.

\subsection{QUANTITATIVE COMPARATIVE SAFETY ANALYSIS}

In Section 4.0, the descriptions of the representative tanks for the quantitative analysis are described. Section 5.0 presented and discussed the list of scenarios that would affect the performance of a tank's operation. In this section a sumary of the comparative safety analyses of the chosen representative tanks is presented by scenario events. Detailed results are given in Appendix B. 
TABLE 6.1. Storage Type Rankings

\begin{tabular}{clc} 
Rank & \multicolumn{1}{c}{ Storage System } & Safety \\
1 & Mating \\
2 & DW concrete, concrete berm, concrete roof & 80.00 \\
3 & Buried concrete/frozen hole, concrete roof & 70.03 \\
4 & DW concrete, concrete berm, suspended roof & 68.25 \\
5 & DW concrete, earth berm, concrete roof & 65.65 \\
6 & In metal/out concrete, concrete berm, concrete roof & 65.53 \\
7 & Buried concrete/frozen hole, suspended roof & 64.53 \\
8 & DW concrete, earth berm, suspended roof & 62.00 \\
9 & In metal/out concrete, concrete berm, suspened roof & 61.15 \\
10 & DW concrete, concrete dike, concrete roof & 60.15 \\
11 & DW metal, concrete berm, concrete roof & 59.78 \\
12 & DW concrete, earth dike, concrete roof & 58.53 \\
13 & DW metal, concrete berm, double meal roof & 57.78 \\
14 & DW concrete, concrete dike, suspended roof & 55.55 \\
15 & DW metal, concrete berm, suspended roof & 55.40 \\
16 & DW concrete, earth dike, suspended roof & 54.15 \\
17 & In metal/out concrete, concrete dike, suspended roof & 49.90 \\
18 & In metal/out concrete, earth dike, suspended roof & 47.90 \\
19 & DW metal, concrete dike, double metal roof & 45.30 \\
20 & DW metal, concrete dike, suspended roof & 43.90 \\
21 & DW metal, earth dike, double metal roof & 43.30 \\
& DW metal, earth dike, suspended roof & 41.90
\end{tabular}

Note: All of the above assume a concrete ring or mat floor, for pilings subtract 0.15 from all ratings.

Many LNG storage tank configurations have been adopted in recent years. The tanks analyzed in th is report represent 3 configurations in use today. The conventional DW metal tank, with its primary containment system consisting of an inner liquid barrier and outer tank pressure barrier, is perhaps the 
tank from which the most experience has been gained. It is lower in cost than most other tank configurations (Gibson and Walters 1971, p. 65) requires less construction time and provides the best access to the pressure barrier for inspection and maintenance. It is a disadvantageous design in that it has limited protection from missiles and blast waves, and requires a large amount of land for inclusion of a secondary containment system, which in the event of a spil1 will result in a large pool. The above-ground prestressed concrete design results in higher costs and longer construction times with pressure boundaries not readily available for inspection and repair. The below-ground concrete tank will result in the smallest pool area, resulting in less required land area, and can be designed for protection against blasts and missiles. However, there is little experience with this configuration in this country, costs are high for this type of construction, the pressure boundary is not readily accessible for repairs, and wa 11 heating as we 11 as ground water control are usual1y required (Trame 11 and LaFave 1981, p. 3).

The following section is a sumary of the results from the previous sections. The scenarios performed for each tank configuration should provide limited information on the structural integrity of each tank type under given, specific conditions. Although tank responses may be very different, making comparisons among tank types difficult, several comparative results are provided in the following sections.

\subsection{OVERFILL AND OVERFLOW}

Overfill was studied by analyzing the stresses at normal liquid heights and a liquid height defined as maximum overfill for the given tank. For the metal tank the stresses at the floor-wall junction produced a strain of only $0.15 \%$. Since bending stresses are local in nature, and the strain is slight, these stresses due to overfil1 were considered to be secondary in nature.

The maximum hoop stresses of the DW metal tank increased from 31,700 psi to 32,800 psi from maximum liquid levels at normal operating conditions to maximum overfil1 conditions. However these values are less than the minimum yield of 75,000 psi as specified by API Standard 620 . 
In the event of overflow the LNG height of the inner tank exceeds $118 \mathrm{ft}$ and begins to spill into the annular space. Since bending stresses are of a local nature they were considered of secondary importance. The hoop membrane stress approaches yielding as the liquid height in the annulus reached $60 \mathrm{ft}$. but the primary concern in the event of an overflow is the propagation of cracks in the outer wall. The outer wall of the metal tank is generally not constructed from high toughness material as is the inner tank which contains the LNG. The outer tank, usually constructed from mild carbon steel, becomes brittle at the cryogenic temperatures in question and will propagate cracks readily. The inner tank constructed of $9 \% \mathrm{Ni}$ steel may, in fact, be a crack arresting material.

From the analysis the inner wall of the DW metal tank can accomodate the condition of overfill. But in the unlikely event of overflow the outer tank wa 11 is susceptible to crack propagation. Although the prestressed concrete tank was not addressed in the analysis, it is likely that it can accomodate overfill without any problem. In the event of overflow, however, the outer tank wa 11 is in serious jeopardy due to crack propagation.

It appears that both tanks are likely to accomodate overfill but as to which outer tank might fail first and to what extent, due to a combination of hydrostatic pressures and cryogenic temperatures, has not been determined.

In the event of an overflow in the prestressed concrete tank, crack propagation becomes as much or more of a concern than the hydrostatic pressure on the outer tank walls. From conclusions in the previous paragraph, it appears the most serious consequence of overfill/overflow to both types of tanks is crack propagation, at least with respect to a release of tank contents.

\subsection{OVERPRESSURE NNDERPRESSURE}

Overpressurization with in a tank applies stresses to the roof and walls such that bursting is a possibility. Underpressure within an LNG tank can induce buckling and cause a sudden rise in the boiloff rate.

In the DW metal tank, the critical buckling pressure $Q_{C R}$ for an assumed dome-internal stiffener configuration was determined to be 3,300 psi. 
Assuming the actual buckling value to be approximately $20 \%$ of th is theoretical value, the $Q_{C R}$ can be expected to be 660 psi. Buckling of the dome is not a plausible failure mode since yielding will occur well before the pressure required to buckle the dome.

The critical buckling pressure on the prestressed concrete dome was determined to be $21,040 \mathrm{psi}$. For the underpressure scenario it would take an unrealistic vacuum load to buckle this dome, hence, further analys is was not made.

The overpressurization scenario may be compared to the 3.0 psi pressure drop on the dome during the passage of a tornado. This pressure combined with the dead load was determined to be the most adverse condition for the above and underground concrete tank in investigating the tensile stresses in the dome. The resulting tensile stress of 390 psi was under the allowable tensile stress of $424 \mathrm{psi}$. Hence, the dome would be able to withstand an increase of 3.0 psi without any adverse effects. Further, indications preclude failure of either dome when exposed to an underpressure scenario resulting in net externa 1 pressures of 3 psi.

Due to wa 11 thickness and prestressed conditions, buckling of the cylindrical wall was not considered for the concrete configurations. A critical buckling pressure of 0.866 psi was obtained for the metal wall tank. Assuming opposing pressures due to internal vapor pressure and perlite insulation pressures, wh ich could range from approximate ly 5.5 psi at the tank bottom to approximately $2.3 \mathrm{psi}$ at the outer tank top, a net external pressure above 3 psi would be required for onset of any buckling in the upper tank region.

In a 11 three tanks analyzed, the seriousness of an increase in the boil-off rate is dependent on how the tanks' venting systems response to releasing excess gases. Their trend in boil-off decay through steady state boil-off rates, initial boil-off rates at pressure drop, and constants which determine the slope of the relationships should be determined in all cases. 


\subsection{SUBSIDENCE}

To carry the weight of the LNG liquid and tank, ringwall or pile supported foundations are used. For vertically prestressed concrete tanks, these foundations are also designed to withstand the uplift force caused by tensioning. When pile-supported foundations are used, they generally rest on bedrock or rely on the frictional resistance in the soil to carry the load.

A ringwall foundation for an LNG storage tank rests on soil that is generally backfill material. Soils used as backfill around and under structures are compacted so that their strength and stability will be increased, their permeability decreased, their resistance to frost action and erosion enhanced, and the ir compressibility decreased. The most sat isfactory backfill materials are relatively clean sand and gravel.

The amount of settlement which can be tolerated varies widely. It depends on the type of structure, its foundation, and its ridigity or flexibility. If the settlement is uniform, a structure can usually tolerate a fair amount of settlement, but differential settlement may cause substantial damage and should be held to a minimum.

For bearing capacity analyses, a factor of safety of 3 or more is normally used for permanent structures. This fact, along with the use of controlled backfill material and the foundation designed to withstand the uplift force of prestressing, makes detrimental settlement unlikely and further consideration was not given to th is scenario for the prestressed concrete tanks. The maximum allowable differential settlement for reinforced concrete structures is 1-3 in. and maximum allowable total settlement is $2-6$ in.

Extreme conditions of differential settling were investigated for the DW metal tank. Evidence shows tank wall stresses do not exceed yield for 10, 30, and 60 degrees subsidence under conditions of decreased soil stiffness ( $K=$ $\left.1 / 2 \mathrm{~K}_{0}\right)$. However, when 60 degrees total subsidence includes soil st iffness values of zero (total absence of supporting soil) deflections in the upper tank indicate possible conditions for instability. Assuming the bearing soil has been properly prepared, that a system for monitoring tank settlement is 
instigated and that there is a remote chance of onsite flooding, detection and correction of tank subsidence problems will occur before the above scenarios exist.

\subsection{CRACK PROPAGATION}

A fracture mechanics approach was utilized to address the possibility of crack propagation in the DW metal tank. From these results and those cited in current research it was concluded that propagating cracks in the $9 \% \mathrm{Ni}$ steel she 11 are highly unlikely at LNG temperatures due to its location on the upper toughness shelf. In fact, $9 \% \mathrm{Ni}$ stee 1 may very well function as a crack arrester for cracks initiating at welds or heat affected zones. The outer mild carbon steel she11, however, will propagate cracks readily when exposed to cryogenic temperatures. In this case, a large crack of approximately six inches, which would readily propagate at lower tank heights, will not have a sufficient stress field to propagate above a $20 \mathrm{ft}$ height under in-service conditions. Irreparable damage due to a crack of this nature is not likely.

The effect of cracking could be disastrous in conventional prestressed structures. If the structural member is cast as one piece, and if shrinkage and other cracks have not taken place, it will be able to take some tension before cracking. The direct tensile strength of concrete is variable and generally ranges from 0.06 to $0.10 \mathrm{f}^{\prime} \mathrm{c}$. Thus, the tensile strength may be from 300 to $500 \mathrm{psi}$ for a concrete of 5,000 psi which may provide a good margin of safety if the strength exists and has not been destroyed. However, once the concrete has cracked, the margin of safety is gone. Failure of the entire structure may result as soon as the concrete cracks, because at th is moment the tensile load carried by the concrete in tension is suddenly transferred to the stee 1. There may then be a sudden elongation of stee 1 which may have serious effects even though the ultimate strength of the steel is far from being reached.

It is important to note here that current methodology incorporates a $3 / 16$ in. steel plate as an integral part of the core wall and roof. The steel plate helps relieve the tensile stresses in the concrete as they develop; hence, provides an additional level of safety. 
Due to the remote probability of the allowable tensile limit for both steel and concrete being exceeded, further analys is was not performed.

\subsection{TORNADO}

Extreme tornado conditions were selected as the basis for investigating the adverse effects due to high winds and sudden atmospheric pressure drops on LNG storage tanks. In the case of the prestressed concrete tanks, the dome was considered the critical region and was analyzed assuming wind loads around a cylindrical structure for the above ground tank and a hemispherical roof for the below ground structure. The DW metal tank was analyzed as a cylindrical structure, assuming a flat, shallow dome, with investigations into the structural integrity of the tank wall and dome.

Wind loadings of $360 \mathrm{mph}$ and $311 \mathrm{mph}$ on the prestressed concrete and DW metal tanks, respectively, produced no adverse effects. This scenario constituted the greatest compressive hoop stresses in the concrete dome $(1,379 \mathrm{psi})$ but did not exceed allowable stresses of 2,250 psi. Meridional bending stresses were the largest stresses apparent in the DW metal tank. Again, these stresses were very localized and this case fell well below yield ( $1 / 2$ yield stress of the outer tank material). The maximum equivalent von Mises stresses were approximately $16,000 \mathrm{psi}$ and occurred at the dome-wall junction.

Tanks were exposed to isolated pressure loadings of $3.0 \mathrm{psi}$ for the prestressed concrete tank and 2.2 psi for the DW metal tank. For the sake of comparison, the 3.0 psi net internal dome pressure loading from the over/underpressure scenar io can be referenced for the DW metal tank. Under these isolated conditions, the prestressed concrete dome experienced tensile hoop stresses at $92 \%$ of the allowable tensile stress (424 psi). The maximum hoop stresses experienced by the DW metal tank were 15,000 psi in the dome and 54,000 psi at the junction under a net 3.0 internal pressure. This analysis excludes internal framing in the dome.

The above loading for the prestressed concrete dome were considered "worst" conditions under this scenario, whereas, superimposing $100 \%$ wind 
loading and a 50\% net external pressure drop was considered "worst" conditions for the DW metal tank. An investigation of hoop stresses shows yielding at the dome-wall junction and in the dome as well. Two critical factors which warrant further investigation are to be noted. Internal framing due to the roof plates are an integral, necessary portion of the structure. These were neglected in the simplistic model devised. In addition, wind loading on the dome was neglected due to its shallow, flat configuration.

\subsection{IMPACT}

Assumptions in the analyses for prestressed concrete and DW metal tanks were similar in that hard, nondeformable missiles with normal incidence at impact and missile axes following parallel to their line of flight were assumed. Missiles investigated ranged from sma 11 diameter stee 1 rods to large structura 1 columns.

Large mass and high velocity objects are the obvious missiles of concern with regard to tank perforation. However, the likelihood of such a missile is fairly remote. Nonetheless, objects such as cover plates with mass values in excess of $300 \mathrm{lbs}$ and velocities between 300 and $500 \mathrm{ft} / \mathrm{sec}$ require thicknesses greater than the tanks analyzed to preclude perforation. A cover plate weighing 850 lbs with a velocity of $300 \mathrm{ft} / \mathrm{sec}$ would perforate the outer stee 1 tank analyzed as we 11 (perforation thickness $=1.48$ in.).

of the missiles chosen $60 \%$ of them perforated the metal tank wall and $40 \%$ perforated the concrete wa 11. Keep in mind that these figures were derived from empirical formulas. What is important to note here is that it is possible to perforate both tanks with objects hurled by pressurized systems.

The domes on both tanks are highly susceptible to missile conditions examined due to their inherent lack of material thickness. The possibility of normal incidence as a missile contacts the domes of the above ground tanks is small unless one is considering sabotage. However, the possibility increases as the tank is placed inground, reducing the elevation of the projected dome area. It was found that $60 \%$ of the postulated missiles in the analysis of 
concrete domes would perforate the given thickness. For the metal domes, $93 \%$ of the postulated missiles would perforate the given thickness. It should be noted, however, that the total potential contact area for an inground tank as compared to an above ground tank is reduced from approximately 53,776 to $2,714 \mathrm{sq} f t$.

\subsection{FIRE}

Due to the nature of the tank configurations analyzed, the approaches to th is scenario were somewhat different for each tank. For instance, the prestressed concrete tank is able to support a radial temperature distribution, whereas the thermally thin steel outer she 11 of the DW metal tank has an insufficient internal thermal resistance to support a temperature gradient. Therefore, radial time-temperature distributions were determined for the concrete tank, and surface time-temperature profiles along with insulation time-temperature penetration depths were found for the DW metal tank. In addition, a radiation influx rate on both tanks due to a neighboring tank fire was calculated.

The heat influx due to radiation was $4,755 \mathrm{Btu} / \mathrm{sq} \mathrm{ft}-\mathrm{hr}$ for both tanks. the concrete tank surface temperature increased to $566^{\circ} \mathrm{F}$ after five hours whereas it was assumed the DW metal tank was exposed to an $810^{\circ} \mathrm{F}$ temperature immediately. Both methods considered radiation convection and conduction mechanisms. The concrete tank was not in danger of collapse until after a four hour duration. Th is is based on specified minimum design stresses and some possible loss of prestressing, but also based on temperatures we 11 below the critical $608^{\circ} \mathrm{F}$ temperature for complete loss of prestressing effects. The $810^{\circ} \mathrm{F}$ temperature for the DW metal tank will reduce the yield strength by approximately 8 percent, but this imposes no hazard under inservice conditions. Further investigation of time-temperature profiles through the insulation reveals a 15 hour period needed to increase the insulation temperature at a point next to the inner tank.

The heat interception rate on the above ground concrete tank wall downwind from an adjacent fire and $375 \mathrm{ft}$ away (outside to outside) was $986 \mathrm{Btu} / \mathrm{sq} \mathrm{ft-hr}$. At the closest point on the tank dome, the interception 
rate was $1,253 \mathrm{Btu} / \mathrm{sq} \mathrm{ft}-\mathrm{hr}$. For the below ground tank, the heat interception rate from an identical inclined flame due to a neighboring above ground tank fire was $961 \mathrm{Btu} / \mathrm{sq} \mathrm{ft}-\mathrm{hr}$. Reducing the clear distance to $250 \mathrm{ft}$ (outside to outside) increased the heat interception rates by $11 \%$ and $24 \%$ for wall and dome points, respectively. A similar scenario performed on the DW metal tank with a clear distance of $320 \mathrm{ft}$ resulted in radiation interception rates of $1,136 \mathrm{Btu} / \mathrm{sq} \mathrm{ft}-\mathrm{hr}$ and 1,572 Btu/sq ft/hr for a point on the wall and dome, respectively. The difference in values between the above ground tanks can largely be attributed to the increased view factor for the steel tank. In all cases, the calculated radiation interception rates for an adjacent tank fire accompanied by $30 \mathrm{mph}$ winds resulted in lower values than that used to determine tank surface temperatures during a possible fire scenario.

\subsection{SEISMIC}

The investigation of tank response to seismic activity was based on the El Centro, California, earthquake, where a zero period was assumed to correspond to a maximum ground acceleration of $0.33 \mathrm{~g}$. A two percent critical dampening factor was used for both structures as specified for the Operating Basis Earthquake. Both above ground tanks withstood this ground acceleration without failure. Although it is hypothesized that the below ground structure would withstand such a ground acceleration, further study involving soil-tank interactions is needed.

In general, the prestressed concrete configuration resulted in lower impulsive and convective tank forces by approximately $17 \%$ and $32 \%$, respectively. This can be attributed to the larger volume metal tank yielding a higher equivalent weight of fluid to produce the impulsive force and higher equivalent oscillating weight to produce the convective force. The liquid sloshing heights, calculated using various methods, did not in either case exceed the design freeboard heights. When excluding the vertical liquid loads and assuming anchor systems developing full tension before the liquid develops a downward blast, the overturning moments are adequately resisted by both above ground tank configurations. The DW metal tank shows signs of local yielding at the tank-floor junction due to high bending stresses in this 
region. This, however, is not an unusual phenomenon with regard to metal tanks, and in $f a c t$, shows strains of on $1 y 0.3 \%$. These results neglected the effects of the anchor strapping system as we 11.

The dome for the thick wall concrete structure has a natural frequency of $30 \mathrm{cps}$ and the liquid filled metal tank has a natural frequency of $36 \mathrm{cps}$. One would assume the liquid filled concrete tank would experience a natural frequency higher than that experienced by the metal tank due to its equivalent mass and rigid configuration. Within the bounds of this analysis, both tanks appear to withstand a $0.33 \mathrm{~g}$ ground acceleration adequately without loss of structural integrity. 


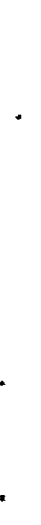

, 


\subsection{CONCLUSIONS AND RECOMMENDATIONS}

Table 7.1 presents comparative results among the tanks analyzed. The table incorporates the scenarios addressed. Under "tank type" the tanks addressed are ordered based on the results of this study, those being structurally more sound under a given scenario listed first. This does not necessarily indicate that one tank is superior for use as an LNG storage facility; in fact, both tanks may meet the structural requirements under selected scenarios. Thus, the ordering process may merely indicate where the greater margin of safety occurs under specific conditions.

In the case where only one tank type was analyzed for a specific scenario, the tank analyzed acquires a lower number. Comments included in the table may assist in identifying the relative position of other tank types.

In summary, all tank configurations exhibited strengths and weaknesses with respect to structural integrity under selected adverse conditions. However, all tanks appeared adequately designed to withstand the postulated scenarios.

TABLE 7.1. Comparative Results of Tanks Ana lyzed

Scenario

Overfill - Inner Tank
Tank Type

1. DW Meta l Tank
Comments

Calculations indicate that the DW metal tank can withstand maximum overfill conditions. Hoop stresses increase by 3\% compared to those under normal operating conditions and localized bending stresses at the wall-floor junction produce strains of $0.15 \%$.

2. Prestressed Contrete Tank
The prestressed concrete tank was not analyzed. 
TABLE 7.1. Contd

Scenario

Overflow - Outer Tank

Overpressure

Underpressure
Tank Type

1. DW Metal Tank

2. Prestressed Concrete Tank

1. Prestressed Concrete Tank

2. DW Metal Tank

1. DW Metal Tank

\section{Comments}

The DW Metal Tank will withstand a liquid height of approximately 60 feet due to an increased hydrostatic head on ly. When exposed to the cryogen ic temperatures of liquid $L N G$, however, it is expected that the mild carbon steel will

fracture immediately.

The prestressed concrete tank was not analyzed. However, it is anticipated that the secondary container could withstand the effects of sudden thermal shock due to release of liquid LNG from the primary container much better than a mild carbon steel tank.

The adverse conditions examined included a 3.0 psi pressure drop on the dome. Resulting tensile stresses were 390 psi compared to allowable tensile stresses of 424 psi.

A 3.0 psi pressure drop on the exterior dome face resulted in stresses approaching the allowable in the localized region at the dome-wall junction.

When incorporating a st iffener configuration, dome buckling was not a viable failure mode. 
TABLE 7.1. Contd

Scenario

Underpressure (contd)
Tank Type

1. DW Metal Tank (contd)
2. Prestressed Concrete Tank

Subsidence
1. DW Metal Tank
Comments

Localized yieldings at the dome-wall junction could occur under net external pressures of 3.0 psi, however. In addition, a net external pressure above 3.0 psi would be required to buck le the upper tank wall section.

Buck ling scenarios were not performed due to the unrealistic vacuums required to produce such phenomina in this tank. It is anticipated that th is tank would resist buck ling at higher external pressures than the DW metal tank.
Although subsidence is unlikely if controlled backfill materials are used and appropriate preparations are made, it is a potential problem. In addition, the problem is one that progresses slowly with early detection and correction possible. In the subsidence models investigated a 60 degree ring foundation subsidence model, with soil st iffnesses reduced linearly from normal stiffness values to zero, was required before tank deflections became critical. 
TABLE 7.1. Contd

Scenario

Sub sidence

Crack Propagation
Tank Type

2. Prestressed Concrete Tank

1. DW Metal Tank

2. Prestressed Concrete Tank
Comments

This tank was not analyzed. It is anticipated that the increased weight of concrete tanks might indicate increased potential for settlement under similar conditions.

Propagating cracks in $9 \%$ $\mathrm{Ni}$ steel at liquid LNG temperatures are highly unlikely. This

assumption is based on fracture toughness tests which indicate that quenched and tempered 9\% $\mathrm{Ni}$ steel is on the upper toughness she if at LNG temperatures.

The outer mild carbon steel tank will undoubtedly crack when in contact with liquid LNG. Damage due to cracking will be localized and is usually capable of being repaired.

Prestressed concrete tanks were not addressed in the analys is section but were discussed in the results section. The effects of cracking could be disastrous in conventional prestressed structures. However, a steel plate with in the concrete core wall and roof may assist in relieving the tensile stresses in the concrete as they develop from slight cracks. It was concluded that the probability was remote with regard to simultaneously exceeding 
TABLE 7.1. Contd

Scenario

Crack Propagation

Tornado
Missile Impact

\author{
1. BG Prestressed \\ Concrete Tank \\ 2. AG Prestressed \\ Concrete Tank
}

3. DW Metal Tank
2. Prestressed Concrete Tank (contd)
1. Prestressed Concrete Tank

Comments

allowable tensile limits in both the steel and concrete components of the prestressed concrete wa 11 .
Allowable stresses were determined from the prestressed concrete tanks and stresses under tornado induced loads were calculated. From these results, both concrete tanks withstood the occurrence of a tornado with the below- ground (BG) tank performing slightly better than the above- ground (AG) tank.

The DW metal tank is structurally more sensitive to the combined wind load and drop in atmospheric pressure. An examination of stresses at the dome-wall junction and in the dome region suggest possible yielding under these extreme conditions.
$40 \%$ of the missiles investigated perforated the $A G$ concrete tank wa 11. The BG tank was considered to be protected from missile impact to the wall region.
The dome region of the above ground tank would be less vulnerable to 
TABLE 7.1. Contd

Scenario

Missile Impact (contd)

Fire
Tank Type

1. Prestressed Concrete Tank (contd)

2. DW Metal Tank

1. DW Metal Tank

\section{Comments}

direct impact than in the below ground configurations. In addition, potential release of LNG vapors due to perforation of the dome at ground level would prove more hazardous.

$60 \%$ of the missiles investigated perforated the outer metal tank. This would indicate potential release of vapor but would not imply perforation of the inner tank and subsequent release of liquid into the annulus.

The metal dome is less resistant to perforation than the outer walls. However, there is an additional decrease in probability for direct impact to this area.

When exposed to a heat flux due to radiation of 4,755 Btu/ft2-hr the metal surface temperature at the point of exposure will assume a temperature of $810^{\circ} \mathrm{F}$ almost immed iately. This temperature will reduce the yield strength of mild carbon steel by an est imated $8 \%$. Th is has virtually no affect since outer tank stresses under in-service loading conditions only 
TABLE 7.1. Contd

Scenario

Fire

Earthquake
Tank Type

1. DW Meta 1 Tank (contd)

\section{Prestressed Concrete Tank}

No Order Given
Comments

experience stresses up to one half of the reduced value. Localized yielding is possible at tank discontinuities.

The tank wa 11 exposed to a fire radiation of 4,755 Btu/ft $2-\mathrm{hr}$ will cause increased surface temperatures over time. The tank could be in danger of collapse after a four hour exposure duration.

The heat interception rates for all tanks under conditions of adjacent fire were below the 4,755 Btu/ft $2-h r$ heat flux due to radiation used in tank wall temperature determinations.

In all tanks the design freeboard heights were not exceeded by sloshing liquid and all overturning moments were adequately resisted.

The prestressed concrete tank resulted in lower impulsive and convect ive tank forces by approximately $17 \%$ and $30 \%$ respectively. This is likely to be attributed to the smaller tank volume of the concrete tank studied. 
TABLE 7.1. Contd

\section{Scenario}

Earthquake
Tank Type

No Order Given
Comments

With in the bounds of this analys is both tanks appear to withstand a $0.33 \mathrm{~g}$ ground acceleration without loss of structural integrity.

It is hypothesized that the below ground concrete tank can withstand a ground acceleration of $0.33 \mathrm{~g}$ but further study involving soil-tank interactions is suggested.

The areas investigated in this report are continually researched by the gas industries and tank manufacturing firms as new materials are developed, new designs evolve and new research technologies become available. Suggestions for further study presented at this point are based on information from several sources. Some of these suggestions stem from questions formulated during the preceeding analyses, while others emanate from current literature surveys and contacts with tank manufacturing firms.

The final analysis of this report assesses LNG tanks to resist failure due to selected hazards associated with LNG tank failures. From this analysis, it was demonstrated how an assumed LNG tank response can be predicted or how weaknesses of an LNG tank can be determined. Th is was performed so as to be able to compare the safety of one type of tank to another.

In determining which tank would be better suited for a given site, the next step would be to take the information from Table 7.1 and incorporate with it the probability of occurrence of the scenario or other site specific information, which was specified in the analysis section but not included in detail. What should result from this extension is the magnitude of the possible damage and perhaps the unavailability of the tank due to damage during a scenario occurrence. 
To complete this analysis, the assessment of other types of tanks should be outlined. With this, one has guidelines as to performing safety assessments when deciding which type of LNG tank would be best suited to a specific facility.

The LNG industry is still growing and expanding with many of their storage facilities near highly populated areas. Though the installation of LNG facilities must meet the energy needs of the public at a cost they can afford, choosing a facility shouldn't be solely based on cost. Safety considerations between storage tank types will benefit the public by seeking to keep the LNG related accidents at its present low level of occurrence, even at the size that the LNG industry is growing presently. A comparative safety assessment is an invaluable consideration in assuring that the public will not be exposed to hazardous risk.

With storage tank locations often found near large industrial sites, it is suggested that the effects of a blast wave on the integrity of LNG storage tanks be investigated. The energy absorbing capabilities of insulating materials (e.g., perlite), steels, and concrete (fibrous and conventional) should be included in such an analysis also.

Current trends suggest a secondary containment system which could withstand consequences of a catastrophic rupture of the primary containment system, by retaining all spilled LNG in a confined and controlled area. The dynamics of such a scenario should be researched to conclude suitability of innovative secondary structures. On the other extreme, provisions for controlling small tank leaks should be investigated as well.

To enhance the information provided in th is report, several items warrant investigation. More sophisticated mathematical algorithms to predict boil-off rates and subsequent pressure control through use of relief and emergency valving systems would provide a more accurate indication of the hazards involved during tank overpressurization. Although single overpressurization events probably will not adversely affect tank integrity, the question regarding fatigue failures due to seismic occurrences and thermal or pressure cycling warrants close examination. Additional items of interest with regard 
to seismic events include the interaction between tanks, between the tank and accessory equipment (e.g., piping systems) and between the tank and bearing soil, an extremely challenging problem when addressing the below ground tank configuration. 


\subsection{REFERENCES}

American Gas Association (AGA). 1973. "Liquefied Natural Gas Committee," LNG Information Book, Arlington, VA.

American Petroleum Institute (API). 1974. Recommended Rules for Design and Construction of Large, Welded, Low-Pressure Storage Tanks. API Standard 620 , July, Washington, D.C.

American Soc iety for Testing and Materials. 1975. Significance of Tests and Properties of Concrete and Concrete-Making MateriaTs, Philadelphia, PA.

Araft, Mahmoud Z. 1975. "Design and Construction of Giant Precast Prestressed LNG Storage Tanks at Staten Island," Prestressed Concrete Inst itute Journa 1, Vo1. 20, No. 3, May-June, pp. 22-33.

Arthur D. Little, Inc. 1971. "A Report on LNG Safety Research," Vol. 1, AGA Project IU-2-1, Cambridge, MA.

Bampton, M. C. C., G. D. Marr, K. 0. Nelson, and S. G. Pitman. 1980. "Storage Tank Studies," Battelle Northwest Laboratories, SAM 80-9, September.

Battelle Columus Laboratories. 1974. Handbook Materials for Superconducting Machinery, Columbus, $\mathrm{OH}$.

Clark, C., E. Upitis, and R. Bruscato. 1980. "Refrigerated Storage of Liquefied Gas - A Success Story," presented at IGT Symposium on LNG Storage, January, Ch icago, IL.

Closner, J. J. 1979. "Economics of LNG Storage with Prestressed Concrete." Seminar on LNG Economic Commission for Europe United Nations, March, Washington, D.C.

Closner, J. J., and R. 0. Parker. 1978. "Careful Accident Assessment Key to LNG Storage Safety," 0 il and Gas Journal, February 6.

Closner, J. J. 1971. "Prestressed Concrete Dike Systems for LNG Storage Containers," Pipeline Gas Journal, September, Vol. 198, No. 11, pp. 63-69.

Closner, J. J. 1970. "Very Large Prestressed Concrete Tanks for LNG Storage." LNG Proceedings of the International Conference and Exhibition, Par is, October 19-23.

Closner, J. J. 1968a. "LNG Storage with Prestressed Concrete." Proceed ings of the International Conference on LNG, Institute of Gas Technology, April 7-17, Chicago IL.

Closner, J. J. 1968b. "Prestressed Concrete Storage Tanks for LNG," American Gas Association, Operating Section Conference. 
Drake, E., and R. C. Reid. 1977. "The Importance of Liquefied Natural Gas," Scientific American, Apri1, Vo 1. 236, No. 4.

Gibson, G. H., and W. J. Walters. 1971. "Consider Safety, Reliability, Cost in Selecting Type of LNG Storage," $0 i 1$ and Gas Journal, February 8, p. 65.

Hanke, C. C. 1966. "Above Ground Storage of LNG is Safe and Practical," Oil and Gas Journal, February 7.

Ishimasa, Yuzo, et a1. 1977. "Development and Operational Experiences of LNG In-Ground Storage Tanks in Japan," LNG 5 International Conference on LNG Gas, Duesse 1dorf, German, August 29-September 1.

Lake, R. L. 1975. "Toughness Variations Through the Thickness of Thick 5083-0 Aluminum Alloy Plate," Properties of Materials for Liquified Natural Gas Tankage, ASTM STP 579, American Society for Testing and Materials, 1975.

Lange, E. A. 1976. "Dynamic Fracture-Resistance Testing and Methods for Structural Analys is," NRL Report 7979, Apri1.

Lentz, A. E., and G. E. Monfore. 1965. "Thermal Conductivity of Concrete at Very Low Temperatures," Journal of the PCA Research Development Laboratories, May, pp. 39-46.

Lockheed Aircraft Corporation and Ho lmes Narver, Inc. 1963. Nuclear Reactors and Earthquakes. Chapter 6 and Appendix F, ERDA TID 7024, August, pp. 183-195 and 367-390.

Lom, W. L. 1975. Liquefied Natural Gas, Applied Science Publishers, London.

National Fire Protection Agency (NFPA). 1976. Standard for the Storage and Handling of Liquefied Petroleum Gases at Utility Gas Plants, NFPA No. 59 .

Pellini, W. S. 1967. "Evaluation of Engineering Principles for Fracture-Safe Design of Stee 1 Sturctures," NRL Report 6957, September.

Riley, G. E., and C. A. Plate. 1974. "Welded Tanks for Liquefied Gases," Metal Construction and British Welding Journal, Vol. 6, No. 2, February, pp. 52-54.

Ro lfe, S. T., and J. M. Barsom. 1977. Fracture and Fatigue Control in Structures - Applications to Fracture Mechanics, Prentice-Ha 11, Inc., Englewood, NJ.

Tada, H., P. C. Paris, and G. R. Irwin. 1973. The Stress Analysis of Cracks Handbook, June, Del Research Corp., Hellertown, PA.

Tobler, R. L., R. P. Mikese 11, R. L. Durcholz, and R. P. Reed. 1975. "Low Temperature Fracture Behavior of Iron Nickel Alloy Stee 1s," Properties of Materials for Liquified Natural Gas Tankage, ASTM STP 579, American Society for Testing and Materials. 
Tobler, R. L., and R. P. Reed. 1977. "Fracture Mechanics Parameters for a 5083-0 Aluminum Alloy at Low Temperatures," Journal of Engineering Materials and Technology, Trans. ASME $99 \mathrm{n}$ 4, October, pp. 306-312.

Trame11, J. H., and I. V. LaFave. 1981. "Large Scale Cryogenic Liquid Storage," Presented at Cryogenic Engineering Conference, August 10-14, San Diego, CA, p. 3.

Turner, F. H. 1972. "Prestressed Concrete LNG Storage Tanks, " Gas Journal, Vol. 349, No. 5651, March 15, pp. 189-190.

U.S. Nuc lear Regulatory Commission Regulatory Guide 1.76. 1974. "Design Bas is Tornado for Nuclear Power Plants," April.

Wozniak, R. S., and W. W. Mitche11. 1978. "Basis of Seismic Design

Provisions for Welded Steel $0 i 1$ Storage Tanks," presented at API Refining, 43rd Midyear Meeting, May, Toronto, Ontario.

White, G. W. and W. H. Penn. 1969. "Technical Problems With Inground Storage." In Proceedings of the 1969 AGA Operating Section Conference, American Gas Association, Washington, D.C. 


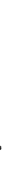




\section{APPENDIX A}

PRELIMINARY COMPARATIVE SAFETY ANALYSIS DETAILS 
APPENDIX A

\section{PRELIMINARY COMPARATIVE SAFETY ANALYSIS DETAILS}

The following is a detailed description of the preliminary comparative evaluation discussed in the main body of the text. Each design of a particular system component was ranked in relation to its relative chance of failing to contain the LNG in the event of a defined hazard. The ranking of a component is defined to be its ranking index. A high value of the ranking index indicates that more protection is provided by the component against possible damage done by the hazard in question. The sum of the ranking indices for each component for a 11 hazards is defined as the total ranking index for the particular system component.

These total ranking indices are combined in such a way as to rate the overall safety of an LNG system comprised of a specific combination of system components. This is done by multiplying the total ranking index by an assigned weighting coefficient. The weighting coefficient assigns a relative degree of contribution of the component to the overall safety of the storage system. These products are then added together according to the combination of components comprising the storage system being evaluated. This sum is the overall safety rating of the complete storage system.

The ranking indices for each component were chosen so that an average index would be three and the difference between the possible ranking indices would be the same. For example, for the component generic storage vessels possible ranking indices are $1,2,3,4$ and 5 . The average of these is three and the difference between them is one. For the component category of roof systems, possible ranking indices are 2, 3, and 4. Again, their average is three and the constant difference between them is one. For component categories consisting of two designs; floor systems, dikes, and berms, the possible ranking indices are 2.5 and 3.5. Assigning the same average to each of the component ranking indices assures that all the component categories are of equal importance before combining them. In other words, an "average representative storage vesse 1 would obta in a total ranking index of 36 , an "average" roof system would obtain a total ranking index of 36 , etc. This 
provides the opportunity to specifically assign weights of importance to each component in relation to its contribution to the safety of the overall LNG storage system.

These weighting coefficients are assigned as percentages. The total for the basic storage system is $100 \%$. For above ground tanks, the basic storage system consists of a tank configuration, roof system, and floor system. The tank configuration is the most critical component when considering the safety of the complete system. Almost all of the hazards could theoretically cause tank failure. Also, if tank failure occurs, grave consequences would result from a major spill of LNG. Hence, the assigned coefficient for the tank configuration was selected as 0.50 . The roof system is the second most critical component. If the roof fails a potentially dangerous LNG vapor cloud could be released. However, since the vapor cloud is not as dangerous as a major spill resulting from tank failure, the assigned coefficient for the roof system is 0.35 . Therefore, 0.15 remains for the coefficient of the floor system. In most cases the outlined hazards would not cause the floor system to fail before another part of the system. Hence, it is the least important component comprising the basic storage system.

Dikes and berms provide extra safety for the above-ground storage system. Accordingly, they are assigned weights which would make the total greater than 100 percent. Basically, a dike provides for containment of a spill. In the event of a failure of the basic storage sytem, a dike prevents the spilled LNG from causing catastrophic damage. This containment is a very important added safety feature. Therefore, a coefficient of 0.5 was assigned to dikes. In addition to containment, a berm provides a good deal of protection from external forces for the primary storage system. Consequently, a coefficient of 0.75 was assigned to berms.

The storage system in below-ground storage of LNG consists of the basic storage container and a roof system or the storage container only, depending on the type of underground storage. For buried concrete tanks and frozen holes, the coefficients assigned were 0.5 for the storage container and 0.5 for the roof system. Since the roof system is at ground level, a failure of the roof would create a vapor cloud right at ground level. Th is ground level 
vapor cloud is much more dangerous than an equivalent cloud formed by the failure of the roof in above-ground storage. Therefore, the roof system is given a higher coefficient in below-ground storage. For mined caverns the storage container represents the complete structural system. Consequently, the storage vessel was assigned a coefficient of 1.0 .

The ratings for below-ground storage of LNG obtained by using these we ighting coefficients account for 100 percent of the storage system. However, the above ground storage ratings were obtained by utilizing 150-175 percent total weighting coefficients. Therefore, an additional index was added to the ratings of below-ground storage systems to enable direct comparison to above ground storage system ratings. Since all the below-ground storage systems are surrounded by earth, it can be conservatively assumed that the earth is equivalent to an "average" berm. So an index of 27.0 , the product of 0.75 and 36 , was added to the ratings of the below-ground storage systems to account for an "average" berm. 
TABLE A.1. Ranking Tank Configurations

\begin{tabular}{|c|c|c|c|c|c|c|c|}
\hline \multirow[b]{2}{*}{ No. } & \multirow[b]{2}{*}{ Hazards } & \multicolumn{5}{|c|}{ Tank Types } & \multirow[b]{2}{*}{ Total } \\
\hline & & $\begin{array}{l}\text { Double Wall } \\
\text { Metal }\end{array}$ & $\begin{array}{l}\text { Combination of } \\
\text { Metal and Concrete }\end{array}$ & $\begin{array}{l}\text { Double Wa } 11 \\
\text { Concrete }\end{array}$ & $\begin{array}{l}\text { Buried Concrete/ } \\
\text { Frozen Hole } \\
\end{array}$ & $\begin{array}{l}\text { Mined } \\
\text { Caverns } \\
\end{array}$ & \\
\hline 1 & Earthquake & 1 & 2 & 3 & 4 & 5 & 15 \\
\hline 2 & Adjacent Fire & 1 & 2 & 3 & 4 & 5 & 15 \\
\hline 3 & Overpressurization & 1 & 2 & 3 & 4 & 5 & 15 \\
\hline 4 & Missiles & 1 & 2 & 3 & 4 & 5 & 15 \\
\hline 5 & Explosions & 1 & 2 & 3 & 4 & 5 & 15 \\
\hline 6 & Tornadoes & 1 & 2 & 3 & 4 & 5 & 15 \\
\hline 7 & Hurr icanes & 1 & 4 & 5 & 2 & 3 & 15 \\
\hline 8 & $\begin{array}{l}\text { Fatigue Crack } \\
\text { Growth }\end{array}$ & 1 & 2 & 3 & 4.5 & 4.5 & 1.5 \\
\hline 9 & Floods & 3 & 4 & 5 & 1 & 2 & 15 \\
\hline 10 & Failure & 3.5 & 3.5 & 3.5 & 1 & 3.5 & 15 \\
\hline 11 & Overfill & 1 & 2 & 3 & 4 & 5 & 15 \\
\hline 12 & Underpressure & 1 & 2 & 3 & 4 & 5 & 15 \\
\hline & Total & 17.5 & 29.5 & 40.5 & 39.5 & 53 & 180 \\
\hline
\end{tabular}


TABLE A.2. Ranking Roof Systems

\begin{tabular}{|c|c|}
\hline No. & Hazards \\
\hline 1 & Earthquake \\
\hline 2 & Adjacent Fire \\
\hline 3 & Overpressurization \\
\hline 4 & Missiles \\
\hline 5 & Explosions \\
\hline 6 & Tornadoes \\
\hline 7 & Hurr icanes \\
\hline 8 & $\begin{array}{l}\text { Fatigue Crack } \\
\text { Growth }\end{array}$ \\
\hline 9 & Floods \\
\hline 10 & Failure \\
\hline 11 & Overfill \\
\hline 12 & $\begin{array}{c}\text { Underpressure } \\
\text { Total }\end{array}$ \\
\hline
\end{tabular}

\begin{tabular}{|c|c|c|c|}
\hline \multicolumn{3}{|c|}{ Roof Systems } & \multirow[b]{2}{*}{ Total } \\
\hline $\begin{array}{c}\text { Double Metal } 1 \\
\text { Roof } \\
\end{array}$ & $\begin{array}{l}\text { Single Stee } 1 \text { with } \\
\text { Suspended Deck }\end{array}$ & $\begin{array}{c}\text { Single Stee } 1 \text { with Suspended } \\
\text { Deck Concrete Over lay } \\
\end{array}$ & \\
\hline 3 & 3 & 3 & 9 \\
\hline 3 & 2 & 4 & 9 \\
\hline 2 & 3.5 & 3.5 & 9 \\
\hline 3 & 2 & 4 & 9 \\
\hline 3 & 2 & 4 & 9 \\
\hline 2 & 3 & 4 & 9 \\
\hline 3 & 2 & 4 & 9 \\
\hline 2.5 & 2.5 & 4 & 9 \\
\hline 3 & 3 & 3 & 9 \\
\hline 3 & 3 & 3 & 9 \\
\hline 4 & 2.5 & 2.5 & 9 \\
\hline 3 & 2 & 4 & 9 \\
\hline 34.5 & 30.5 & 43.0 & 108 \\
\hline
\end{tabular}


TABLE A.3. Ranking Floor Systems

\begin{tabular}{|c|c|c|c|c|}
\hline \multirow[b]{2}{*}{ No. } & \multirow[b]{2}{*}{ Hazards } & \multicolumn{2}{|c|}{ Floor Systems } & \multirow[b]{2}{*}{ Tota 1} \\
\hline & & $\begin{array}{l}\text { In Ground Concrete } \\
\text { Mat or Ring } \\
\end{array}$ & $\begin{array}{l}\text { Concrete } \\
\text { Pilings } \\
\end{array}$ & \\
\hline 1 & Earthquake & 2.5 & 3.5 & 6 \\
\hline 2 & Adjacent Fire & 3 & 3 & 6 \\
\hline 3 & Overpressur ization & 3 & 3 & 6 \\
\hline 4 & Missiles & 3.5 & 2.5 & 6 \\
\hline 5 & Explosions & 3.5 & 3.5 & 6 \\
\hline 6 & Tornadoes & 3.5 & 2.5 & 6 \\
\hline 7 & Hurricanes & 3.5 & 2.5 & 6 \\
\hline 8 & $\begin{array}{l}\text { Fat igue Crack } \\
\text { Growth }\end{array}$ & 3 & 3 & 6 \\
\hline 9 & Floods & 2.5 & 3.5 & 7 \\
\hline 10 & Failure & 2.5 & 3.5 & 6 \\
\hline 11 & Overfi 11 & 3 & 3 & 6 \\
\hline 12 & Underpressure & 3 & 3 & 6 \\
\hline & Tota 1 & 36.5 & 35.5 & 72.0 \\
\hline
\end{tabular}


TABLE A.4. Ranking Dikes

\begin{tabular}{|c|c|c|c|c|}
\hline \multirow[b]{2}{*}{ No. } & \multirow[b]{2}{*}{ Hazards } & \multicolumn{2}{|c|}{ Dikes } & \multirow[b]{2}{*}{ Total } \\
\hline & & Low Earthern & $\begin{array}{c}\text { High } \\
\text { Concrete Walls }\end{array}$ & \\
\hline 1 & Earthquake & 3.5 & 2.5 & 6 \\
\hline 2 & Adjacent Fire & 2.5 & 3.5 & 6 \\
\hline 3 & Overpressurization & 3 & 3 & 6 \\
\hline 4 & Missiles & 2.5 & 3.5 & 6 \\
\hline 5 & Explosions & 2.5 & 3.5 & 6 \\
\hline 6 & Tornadoes & 3.5 & 2.5 & 6 \\
\hline 7 & Hurr icanes & 2.5 & 3.5 & 6 \\
\hline 8 & $\begin{array}{l}\text { Fat igue Crack } \\
\text { Growth }\end{array}$ & 3 & 3 & 6 \\
\hline 9 & Floods & 2.5 & 3.5 & 6 \\
\hline 10 & Failure & 3 & 3 & 6 \\
\hline 11 & Overfill & 2.5 & 3.5 & 6 \\
\hline 12 & Underpressure & 3 & 3 & 6 \\
\hline & Total & 34.0 & 38.0 & 72.0 \\
\hline
\end{tabular}


TABLE A.5. Ranking Berms

\begin{tabular}{|c|c|c|c|c|}
\hline \multirow[b]{2}{*}{ No. } & \multirow[b]{2}{*}{ Hazards } & \multicolumn{2}{|c|}{ Berms } & \multirow[b]{2}{*}{ Total } \\
\hline & & Earthern & Concrete & \\
\hline 1 & Earthquake & 2.5 & 3.5 & 6 \\
\hline 2 & Adjacent Fire & 3 & 3 & 6 \\
\hline 3 & Overpressurization & 3 & 3 & 6 \\
\hline 4 & Missiles & 2.5 & 3.5 & 6 \\
\hline 5 & Explosions & 2.5 & 3.5 & 6 \\
\hline 6 & Tornadoes & 3 & 3 & 6 \\
\hline 7 & Hurr icanes & 2.5 & 3.5 & 6 \\
\hline 8 & $\begin{array}{l}\text { Fatigue Crack } \\
\text { Growth }\end{array}$ & 3 & 3 & 6 \\
\hline 9 & Floods & 2.5 & 3.5 & 6 \\
\hline 10 & Failure & 2.5 & 3.5 & 6 \\
\hline 11 & Overfill & 3 & 3 & 6 \\
\hline 12 & Underpressure & 3 & 3 & 6 \\
\hline & otal 1 & 33 & 39 & 72 \\
\hline
\end{tabular}


TABLE A.6. Weighting Components

$\left.\begin{array}{l}\text { Tank }-50 \% \\ \text { Roof }-35 \% \\ \text { Floor }-15 \% \\ \text { Dike }-50 \% \\ \text { Berm }-75 \%\end{array}\right\} \begin{aligned} & \text { Tank }-50 \% \\ & \text { Roof }-50 \% \\ & \begin{array}{l}\text { For Above } \\ \text { Ground } \\ \text { Tanks } 1-3\end{array} \\ & \begin{array}{l}\text { Floor }-0 \\ \text { Berm }-(.75)(36)=27.0 \\ \text { points }\end{array} \\ & \begin{array}{l}\text { Tank }-100 \% \\ \text { Berm }-27.0 \\ \text { points }\end{array} \\ & \\ & \begin{array}{l}\text { For Mined } \\ \text { Caverns }\end{array}\end{aligned}$




\section{SAFETY RATING CALCULATIONS}

Double wa 11 metal tank with concrete ring floor, suspended deck roof and:

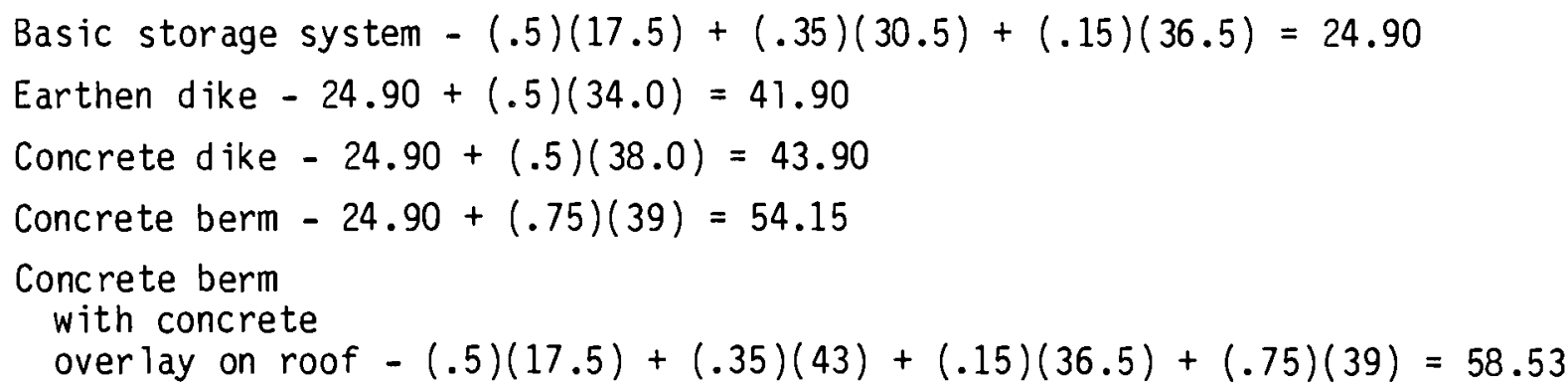

Double wall metal tank with concrete ring floor, double-metal roof and:

Basic storage system $-(.5)(17.5)+(.35)(34.5)+(.15)(36.5)=26.30$

Earthen dike $-26.30+(.5)(34.0)=43.30$

Concrete dike $-26.30+(.5)(38.0)=.45 .30$

Concrete berm $-24.90+(.75)(39)=54.15$

Concrete berm $-26.30+(.75)(39)=55.55$

Inner metal/outer concrete tank with concrete ring floor, suspended deck roof and:

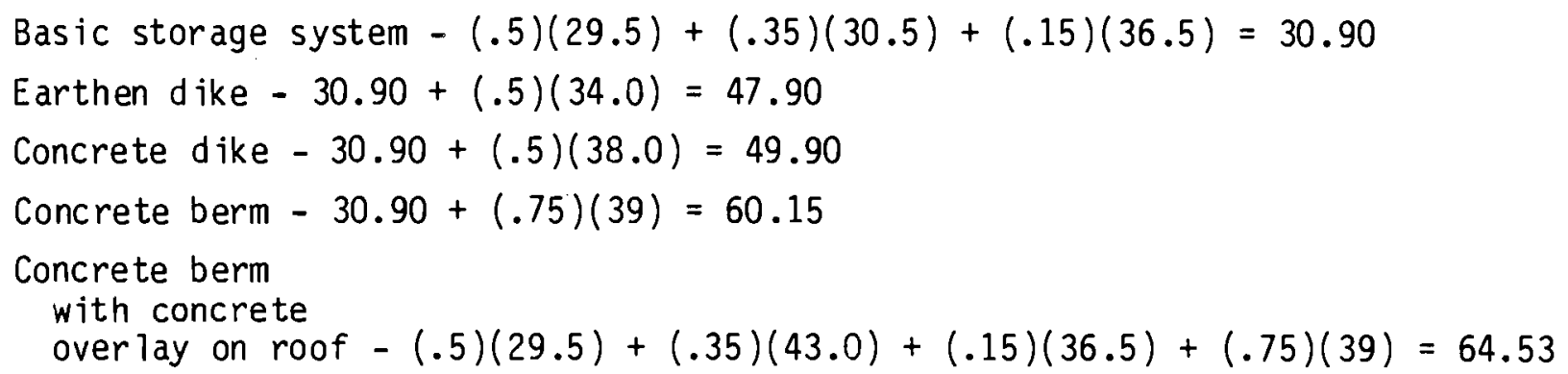

Double wall concrete tank with concrete ring floor, suspended deck roof and:

Basic storage system $-(.5)(40.5)+(.35)(30.5)+(.15)(36.5)=36.40$

Earthen dike $-36.40+(.5)(34.0)=53.40$

Concrete dike $-36.40+(.5)(38.0)=55.40$

Earthen berm $-36.40+(.75)(33)=61.15$

Concrete berm $-36.40+(.75)(39)=65.65$ 
Double wa 11 concrete tank with concrete ring floor, suspended deck roof with concrete overlay and:

$$
\begin{aligned}
& \text { Basic storage system }-(.5)(40.5)+(.35)(43.0)+(.15)(36.5)=40.78 \\
& \text { Earthen dike }-40.78+(.5)(34.0)=57.78 \\
& \text { Concrete dike }-40.78+(.5)(38.0)=59.78 \\
& \text { Earthen berm }-40.78+(.75)(33)=65.53 \\
& \text { Concrete berm }-40.78+(.75)(39)=70.03
\end{aligned}
$$

Buried concrete/frozen hole with suspended deck roof:

$$
(.5)(39.5)+(.5)(30.5)+27.0=62.0
$$

Buried concrete/frozen hole with suspended deck roof with concrete overlay:

$$
(.5)(39.5)+(.5)(43.0)+27.0=68.25
$$

Mined cavern:

$$
(1.0)(53)+27.0=80.0
$$



APPENDIX B

QUANTITATIVE COMPARATIVE SAFETY ANALYSIS DETAILS 


\section{APPENDIX B}

\section{QUANTITATIVE COMPARATIVE SAFETY ANALYSIS DETAILS}

This appendix contains the detailed calculations and results for the comparative safety analys is of the reference tanks described in Section 4.0 . 


\section{B.1. SPECIFIC SCENARIOS - DOUBLE WALL METAL TANK}

OVERFILL

Discussion

Overfill conditions in which the normal liquid filling level is exceeded would most likely occur because of human error or misoperation. Most systems are equipped with three alarm systems; one for normal liquid levels, one for overfill levels and one for extreme overfill levels. The latter often operates simultaneously with an automatic shut off valve to preclude overflow, defined as spillage of liquid into the annular space between tanks.

Overfill can result in additional stresses in the inner tank wall due to the increased hydrostatic head. Overflow may result in increased hydrostatic pressures in the annulus as well as thermal stresses due to contact between the liquid at cryogenic temperatures and the outer tank wall. This latter case is addressed assuming minimal vaporization and total containment of the spilled LNG. In reality, LNG liquid spilled into the annulus will result in leakage initially along the inner tank and through the fibrous blanket and insulation. If in small quantities, this leakage would most likely vaporize. Large quantities, however, could result in contact between the cryogenic fluid and the mild carbon steel outer shell with subsequent cracking due to temperature exposures below the transition temperature. In this case, vapor releases to the atmosphere could also occur. However, assuming early detection the cracks would be small due to the arresting features of the adjacent higher wall temperatures and reduced stresses.

Analyses

Stresses on Inner Tank: In-Service Operation

The wall stresses were calculated for the tank analyzed when exposed to liquid pressure under normal operating conditions. The procedure used was based on derivations by Timoshenko $(1)$ and was restricted to lower tank elevations. The deflection equation used was:

$$
\text { B. } 2
$$




$$
w=\frac{r a^{2} d}{E t}\left[1-\frac{x}{d}-\theta(\beta x)-\left(1-\frac{1}{\beta d}\right) \zeta(\beta x)\right]
$$

Hoop stresses were calculated from the force $\mathrm{N} \phi$ in the circumferential direction:

$$
\sigma_{\phi}=\frac{N \phi}{t}
$$

where

$$
N_{\phi}=\operatorname{rad}\left[1-\frac{x}{d}-\theta(\beta x)-\left(1-\frac{1}{\beta d}\right) \zeta(\beta x)\right]
$$

and meridional bending stresses were calculated from the bending moment, $M_{x}$ :

$$
\sigma_{M B}=\frac{6 M_{x}}{t^{2}}
$$

where

$$
M_{x}=\frac{\gamma \text { adt }}{\sqrt{12\left(1-\nu^{2}\right)}}\left[-\zeta(\beta x)+\left(1-\frac{1}{\beta d}\right) \theta(\beta x)\right]
$$

The moment and shear force at the base assuming a fixed bottom are:

$$
\begin{aligned}
& M_{0}=\left(1-\frac{1}{\beta d}\right) \frac{\text { radt }}{\sqrt{12\left(1-v^{2}\right)}} \\
& Q_{0}=-\frac{\gamma a d t}{\sqrt{12\left(1-v^{2}\right)}}\left(2 \beta \frac{1}{d}\right)
\end{aligned}
$$

where

$$
\begin{aligned}
\sigma_{\phi} & =\text { hoop stress } \\
\sigma_{M B} & =\text { meridional bending stress } \\
\gamma & =\text { density of liquid } \\
E & =\text { elastic modulus } \\
\nu & =\text { Poisson's ratio }
\end{aligned}
$$




$$
\begin{aligned}
D & =\text { flexural rigidity }=\frac{E t^{3}}{12\left(1-v^{2}\right)} \\
B^{4} & =\frac{3\left(1-v^{2}\right)}{a^{2} t^{2}} \\
a & =\text { tank radius } \\
d & =\text { tank height } \\
t & =\text { wal1 thickness } \\
e(\beta x) & =e^{-\beta x} \cos \beta x \\
\zeta(B x) & =e^{-\beta x} \sin \beta x
\end{aligned}
$$

Figure 6 illustrates the meridional bending and hoop stresses in the tank analyzed after some modifications to include variable wall thickness. This approach assumes conservative results due to the neglect of tank wall stiffeners and opposing lateral pressures from the perlite insulation.

\section{Stresses on Inner Tank: Overfil1 Conditions}

In the event of alarm system failures at maximum fill levels and failure of automatic shut off systems during overfill, the inner tank will begin to see increased stresses. The critical area for investigation centers at the wal1-floor junction. Because these hydrostatic forces exceed that of inservice operation, this area was investigated more thoroughly for overfill conditions. The stresses in this region were investigated for conditions under normal operating situations (1iquid height $=114.2 \mathrm{ft}$ ) and under a maximum liquid height for the inner tank of $118.25 \mathrm{ft}$.

The procedure used to calculate the stresses at the wall-floor junction (2) was based on shel1 and beam theory provided by Timoshenko. If one considers a tank subjected to a hydrostatic pressure and having a wall thickness, $t$, which is small compared to the radius $R$ and depth $H$, the radial expansion can be expressed as: (1) 

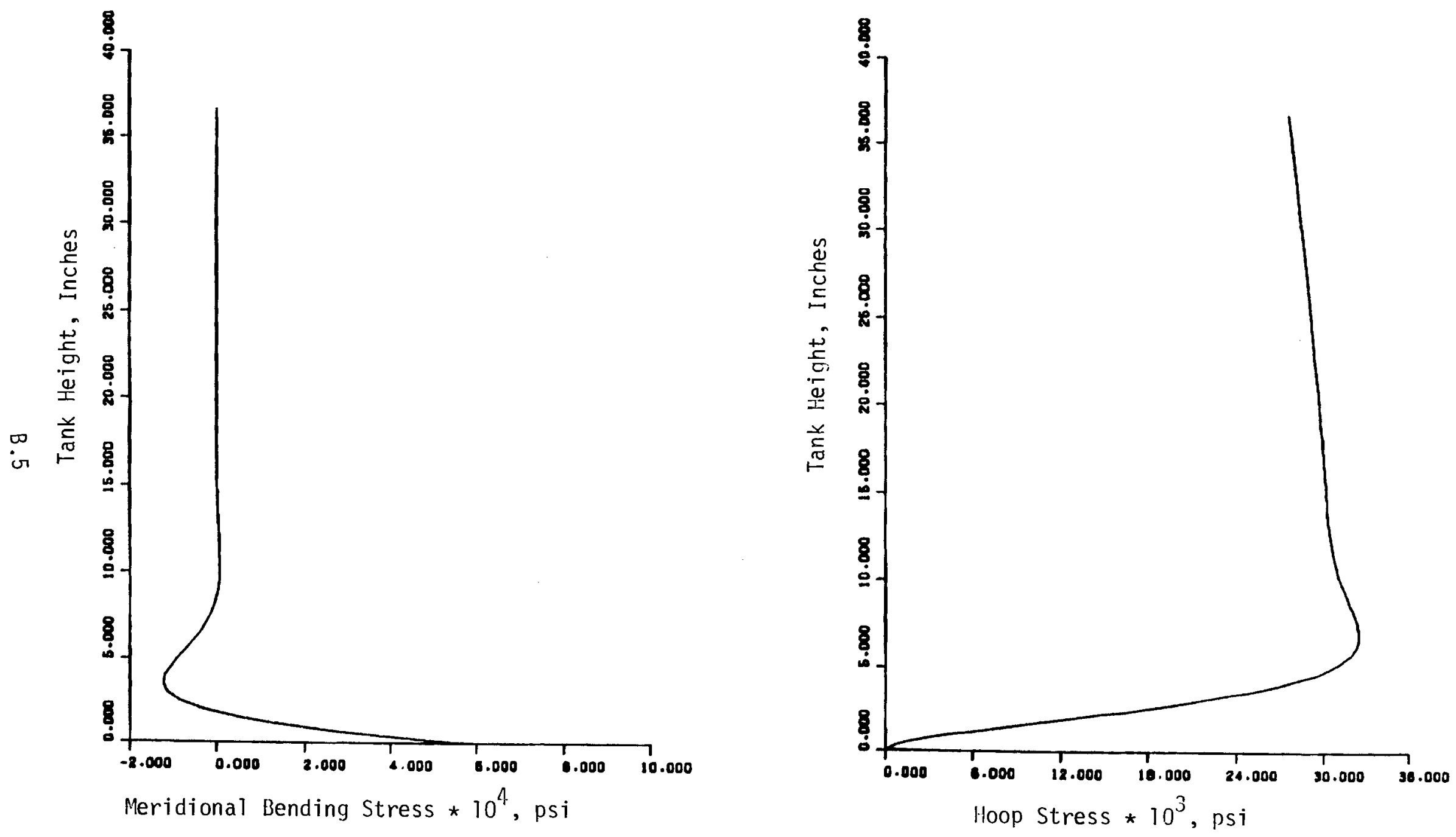

FIGURE 6. Meridional Bending and Hoop Stresses for the Lower Inner Tank Under In-Service Conditions 


$$
w=e^{-\beta x}\left(C_{3} \cos \beta x+C_{4} \sin \beta x\right) \frac{\gamma(H-x) R^{2}}{E t}
$$

where

$$
\begin{aligned}
\beta^{4} & =\frac{3\left(1-v^{2}\right)}{R^{2} t^{2}} \\
Y & =1 \text { iquid density } \\
E & =\text { elastic modulus } \\
t & =\text { wal1 thickness } \\
R & =\text { tank radius } \\
H & =\text { liquid depth }
\end{aligned}
$$

Incorporating the appropriate boundary conditions, solving for constants $C_{3}$ and $C_{4}$ and differentiating yields an equation for determining the slope of the tank wall:

$$
\theta_{0}=\frac{\gamma R^{2}}{E t}(1-\beta H)+\frac{M_{0}}{2 \beta D}
$$

The floor is considered a beam of length $L$ supported at points $A$ and $B$ (see Figure 7 ). It is loaded at point 0 by a moment $M_{0}$ and $a$ vertical load $G$ with a distributed load along the beam length $b$. The resulting deflection, moment and slope equations are:

$$
\begin{aligned}
& R_{B}=\frac{G a}{L}+\frac{P(L-a) \frac{(L+a)}{2}}{L}-\frac{M_{O}}{L} \\
& M_{0}=\frac{\left(L^{2}-a^{2}\right)}{L^{2}-3 a^{2}}\left[\frac{P}{4}\left(L^{2}-a^{2}\right)+G a\right] \\
& \frac{d y}{d x}=\frac{(L-a)^{2}}{2 E I}\left(R_{B}-\frac{P(L-a)}{3}\right)
\end{aligned}
$$

A value of $L$ was found such that the above equations were mutually satisfied and rotation of the floor beam $\frac{d y}{d x}$ equaled the rotation in the tank wall $\theta$. (3) These results were then used to calculate stresses in the wall and floor about the wall-floor junction under normal loading conditions: ${ }^{(2)}$ 


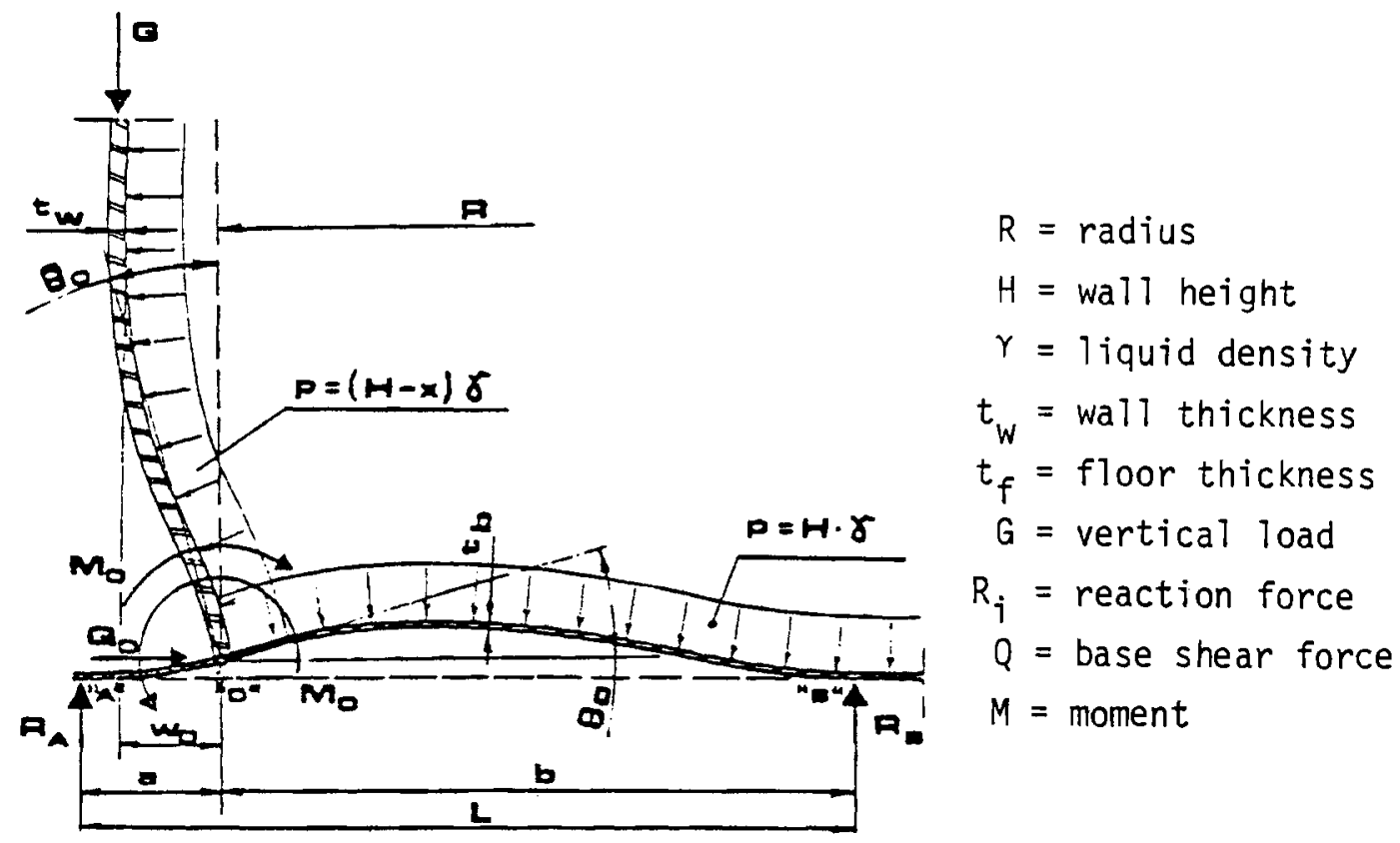

FIGURE 7. Floor-Wall Junction (Inner Tank) With Representative Loading (2) 
Bending stress in the floor plate at $x=a=2$ in. (junction of wall and floor):

$$
\sigma_{b f}=E I \frac{d^{2} y}{d x^{2}} \times \frac{6}{t^{2}}=\left[-R_{B}\left(L-x_{1}\right)+\frac{P\left(L-x_{1}\right)^{2}}{2}\right] \frac{6}{t^{2}}=33,707 \text { psi }
$$

Bending stress in wall due to $M_{0}$ :

$\sigma_{b w}=\frac{6 M_{0}}{t^{2}}=45,394 p s i$

Shear stress at base:

$$
\sigma_{S}=\frac{Q_{0}}{t_{f}}=598 \mathrm{psi}
$$

where

$$
Q_{0}=\frac{\gamma H R^{2}}{E t} \times 2 \beta^{3} D+\beta M_{0}=475.791 \mathrm{~b} / \mathrm{in} .
$$

When the inner tank was exposed to an overfill condition where the 1iquid LNG level was increased to $118.25 \mathrm{ft}$, the following stresses resulted:

$$
\begin{aligned}
\sigma_{b f} & =34,923 \mathrm{psi} \\
\sigma_{b w} & =46,910 \mathrm{psi} \\
\sigma_{s} & =618 \mathrm{psi}
\end{aligned}
$$

Since the bending stresses are local in nature and only produce strains of approximately 0.15 percent, the focus of attention was directed toward the membrane stresses in the tank wall. The maximum hoop stresses, these being the larger of the membrane stresses, were found to increase from approximately 31,700 psi for maximum liquid levels under normal operating conditions to 32,800 psi for maximum overfill conditions. These values do not approach the yield for $9 \%$ Nickel steel, which is approximately 100,000 psi for tensile test yields ${ }^{(4)}$ and given as 75,000 psi for specified minimum yield in API Standard 620. (5) 


\section{Stresses on Outer Tank - Overflow Conditions}

Under conditions of overflow where large amounts of LNG liquid flow into the annular region between tanks, increased stresses develop in the outer tank as a function of increased liquid height. A plot of equivalent von Mises stress versus outer tank height is shown in Figure 8 . These results were calculated from longitudinal, bending and hoop stresses for cylindrical tanks with rigid foundations, dome deadweight loading and perlite pressures. Again, bending stresses were considered to be of secondary importance due to their local nature. Membrane stresses in the hoop direction approached yielding as the liquid height was increased to $60 \mathrm{ft}$. The primary concern, however, is the decrease in ductility of the metal as it is exposed to cryogenic temperatures, and the resulting presence of propagating cracks with subsequent release of LNG vapor to the atmosphere. Crack propagation is addressed in a subsequent analysis.

\section{REFERENCES}

1. Timoshenko, S.P. and S. Woinowsky-Krieger, Theory of Plates and Shells, McGraw-Hill Book Co., New York, 1968, pp. 485-488.

2. Marchaj, T.J., "Importance of Vertical Acceleration in the Design of Liquid Containing Tanks", Proceedings of the 2nd U.S. National Conference on Earthquake Engineering, Stanford, CA, August 1979, p. 153.

3. Fecht, B.A., "Results in Support of LNG Storage Tank Analysis", Battelle Northwest Laboratories, Richland, WA, November 1981.

4. Bruscato, Robert, "The Measurement of Crack Arrest Fracture Toughness in Welded 9\% Nickel Steels Used in Cryogenic Storage Tanks", Chicago Bridge and Iron Co., January 1981, p. 10.

5. API Standard 620, Appendix Q: Recommended Rules for Design and Construction of Large, Welded, Low-Pressure Storage Tanks, American Petroleum Institute, Washington, D.C., 1974, p. 107. 


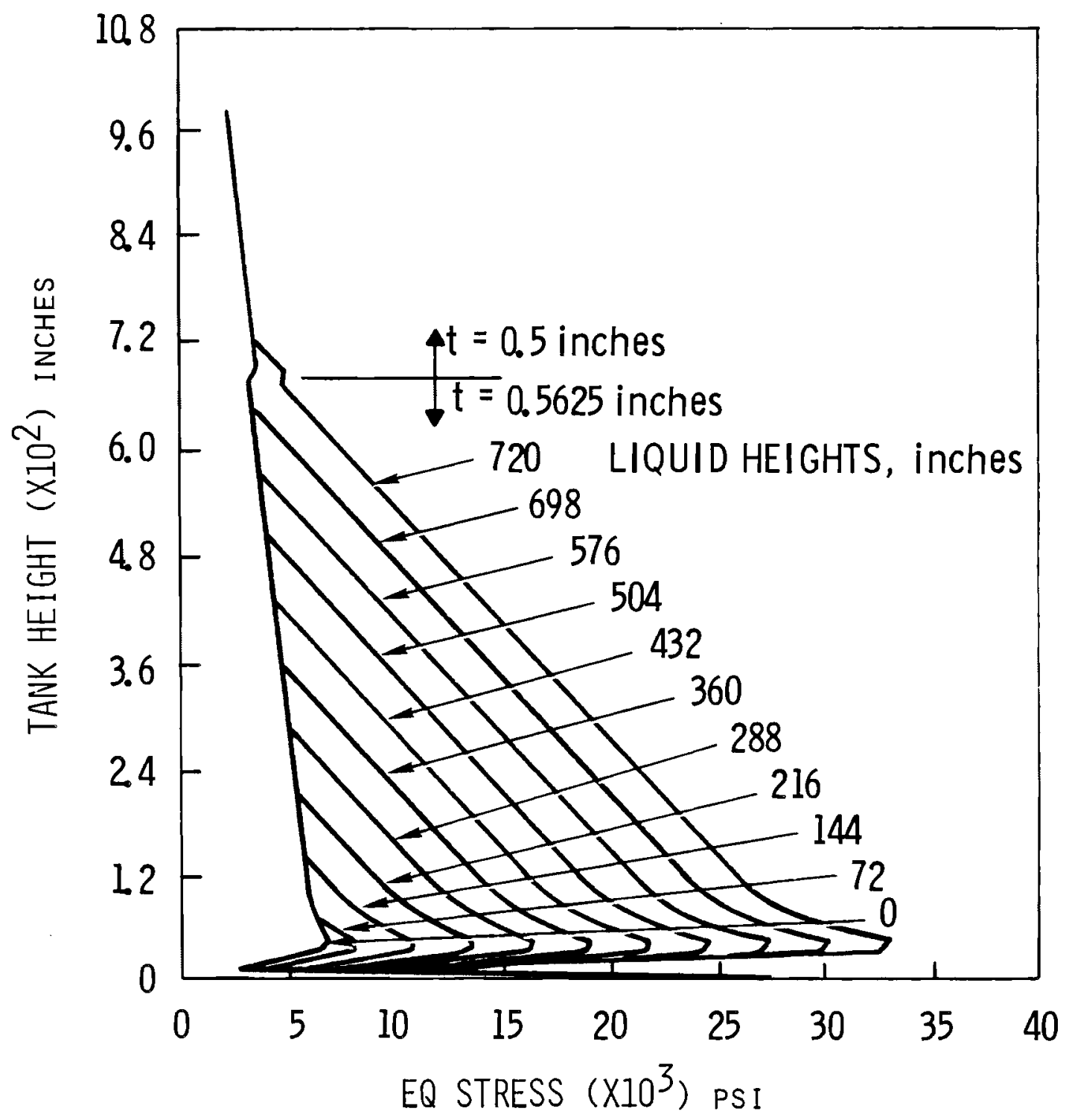

FIGURE 8. Equivalent von Mises Stresses in Outer Tank Versus Tank Height in Conjunction With Exposure to Increasing Liquid Heights in the Annulus Between Tanks 


\section{OVER/UNDERPRESSURE}

\section{Discussion}

Over/underpressure conditions potentially result from various postulated failure scenarios (e.g., adjacent fire, operator error, tornado conditions). It is the intent here to assume an over/underpressure situation without strict regard to its initiation. Several consequences of over/underpressure as related to the pressure boundary (outer tank/dome) are analyzed beginning with an investigation of steady state relationships under typical operative conditions. This is followed by a determination of changes in boil-off rate as a function of sudden pressure drop (e.g., from tornado conditions), critical buckling and bursting pressure, increased stresses at the dome-wall interface due to overpressurization (e.g., from operator error), and the potential for roll-over to occur.

LNG is stored as a saturated liquid in a state of thermodynamic equilibrium. Heat is transferred from the surrounding environment to the liquid LNG through conduction, convection and radiation. Any disturbance such as pressure changes in the vapor space will cause reestablishment of this equilibrium state through alterations in evaporative cooling at the liquid surface. In addition, saturation temperatures will change as a function of absolute pressure. The efficiency of the system requires control of these mechanisms to assure minimum heat influx and, thus, controllable boil-off rates and tank pressures.

Perhaps one of the most important advantages to the storage of LNG as a cryogenic fluid is that liquefaction results in a volume contraction of about 600 to 1. This, however, requires low temperature maintenance for which low conducting insulations play a major role. In addition to the low conduction thermal properties, the cellular structure of such insulations trap gases, helping to eliminate gaseous circulation through the annular space between the inner and outer tanks. A resultant low convective path occurs. The annular space is further exposed to the vaporized LNG. Not only does this equalize the pressure between the two tanks allowing for less material to structurally support the system, but the moisture content in the insulation space is kept to a minimum. The importance of this is to limit the buildup of ice, thus eliminating possible loss of insulating capabilities.

$$
\text { B.11 }
$$




\section{Analyses}

\section{Steady State Conditions: In-Service Operation}

Heat transferred to a storage tank is controlled by dissipation through evaporation at the liquid surface. To maintain a steady state evaporation rate there must be a temperature difference between the surface and subsurface layers with the surface temperature close to the saturation temperature of the vapor phase. (1) A resulting boil-off of typical magnitudes for large storage tanks (e.g., 300,000 bbl) in this steady state condition is between $0.06 \%$ and $0.08 \%$ of the tank capacity per day. (2) by: $(3)$

A simplified approach to estimating maximum boil-off rate is given

$$
\dot{m}=\frac{K_{p}}{\zeta_{p}}\left(T_{0}-T_{L}\right) A / \lambda
$$

where

$$
\begin{aligned}
\dot{m}= & \text { maximum boil-off rate assuming a full tank } \\
K_{p}= & \text { thermal conductivity of perlite } \\
\zeta_{p}= & \text { perlite thickness } \\
& \text { (the ratio, } K_{p} / \zeta_{p}, \text { determines a coefficient of heat transfer } \\
& \text { based on the assumption that thernal conductivity through } \\
& \text { the insulation is dominant over conductivities through the } \\
& \text { tank walls) } \\
T_{0}= & \text { ambient outside temperature } \\
T_{L}= & \text { liquid temperature } \\
A= & \text { total area for heat transfer } \\
\lambda= & \text { heat of vaporization for } L N G .
\end{aligned}
$$


With a heat transfer coefficient of $0.00619 \mathrm{BTU} / \mathrm{ft}^{2}-\mathrm{hr}-{ }^{\circ} \mathrm{F}$, outside temperature of $530^{\circ} \mathrm{R}$, LNG liquid temperature of $196^{\circ} \mathrm{R}$ and $\lambda$ of $220 \mathrm{BTU} / \mathrm{lb}$, a maximum boil-off rate for the given tank configuration is approximately $0.04 \%$ of the tank capacity per day. This boil-off rate is likely to be low due to the neglect of the radiant heat transfer into the vapor space. An iterative scheme incorporating conventional convective, conductive and radiant heat transfer calculations is used by Neill, et al., (3) to more accurately determine boil-off rates as well as wall temperatures.

Typical displacements and stresses for the outer tank wall were obtained using the finite element code, ANSYS. The 2-D model of a circumferential tank wall section incorporated tank stiffeners, a ring foundation and the stiffener configuration at the dome-wall interface. Loading conditions included wall pressures resulting from insulation, LNG vapor and dome deadweight. Resultant hoop and meridional bending stresses are plotted versus tank height in Figure 9 . It should be noted that absolute maximum and minimum meridional bending stresses versus outer tank height are not necessarily shown as element shell size would be necessarily small to assure inclusion of such extremes.

\section{Sudden Pressure Drop}

This scenario might result from high 1 iquid or vapor withdrawal rates, introduction of subcooled LNG at the surface layer or increases in barometric pressure. (4) It is assumed here that a sudden drop in gage pressure results in an instantaneous decrease in temperature at the 1 iquid LNG surface layer. Consequently, the boiling point of the LNG decreases resulting in an increased boil-off rate. This is relative to an unchanging liquid bulk temperature. To achieve equilibrium the temperature of the bulk liquid drops assuming the above lower pressure and surface layer boiling point remains constant. The boil-off is then a function of the rate of change of temperature in the liquid. The differential equation necessary to express this relationship will decay to the equilibrium state as the liquid bulk temperature drops. 

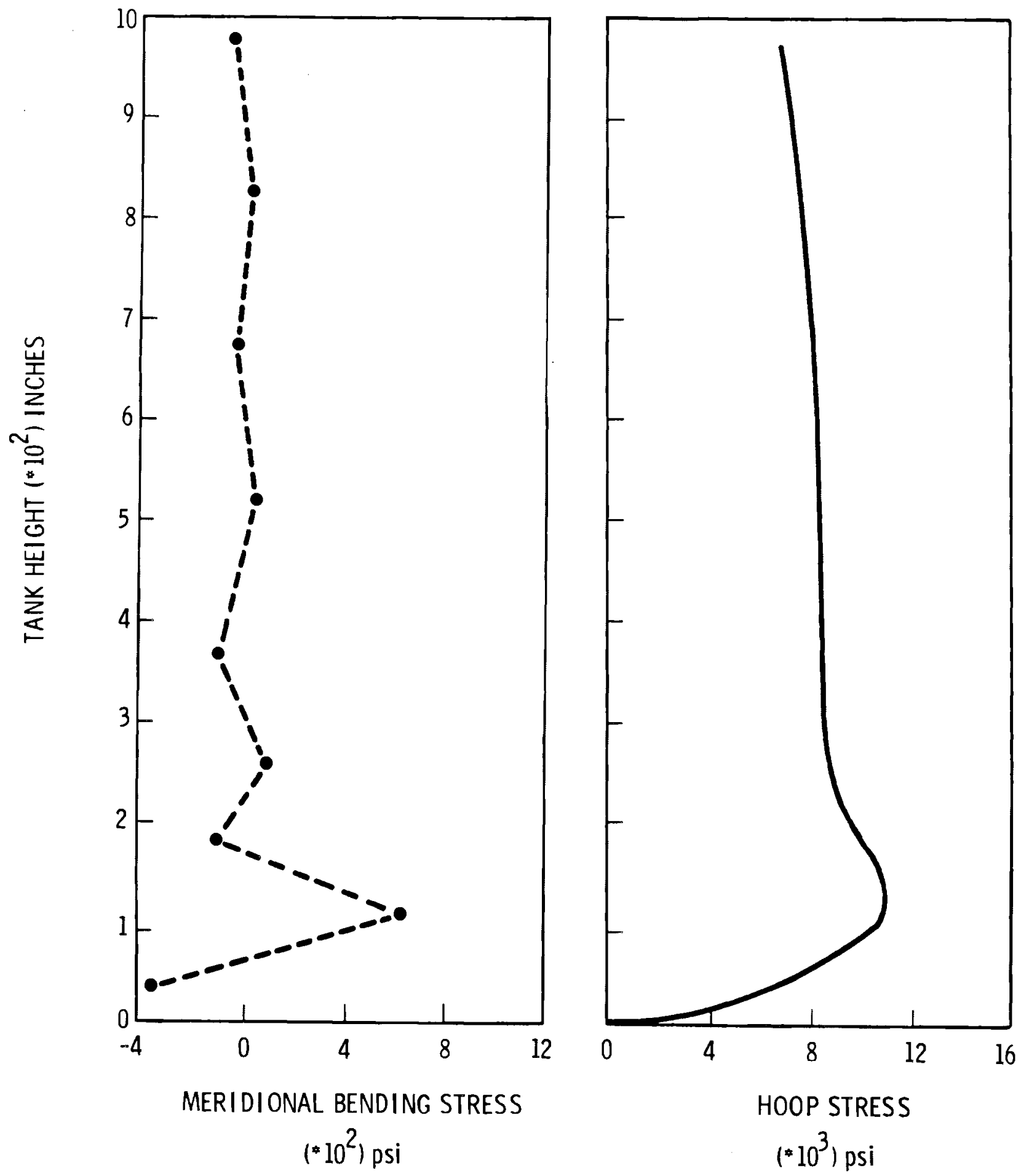

FIGURE 9. Meridional Bending and Hoop Stresses in Lower Outer Tank Under In-Service

Conditions

B. 14 
The procedure used to determine the change in boil-off rate, based on Hashemi and Wesson ${ }^{(1)}$, makes several assumptions. Among these are that the liquid is at a uniform temperature, $T_{b}$; the surface layer is at the boiling point of $L N G, T_{S}$, and is a function of the vapor pressure in the tank; $T_{b}$ is greater than $T_{S}$; the only heat transferred from the liquid is through boil-off; and the boiling point, $T_{S}$, is a linear function of pressure. Evaporation rate is given by

$$
\dot{\mathrm{m}}=(0.0082) \Delta \mathrm{P}_{\mathrm{s}}^{4 / 3} 1 \mathrm{bs} / \mathrm{hr}-\mathrm{sq} \mathrm{ft}
$$

where

$$
\begin{aligned}
& \Delta \mathrm{P}_{\mathrm{S}} \text { is the difference in vapor pressure and super- } \\
& \text { saturation pressure of the liquid. }
\end{aligned}
$$

This relationship assumes no agitation of tank contents, no filling and "normal" vapor withdrawal rates.

Also,

$$
\Delta P_{S}=\left(\frac{d T_{S}}{d P}\right)^{-1} \Delta T_{B}
$$

where

$$
\left(\frac{d T_{S}}{d P}\right)^{-1}=19.34 \text { in. of } H_{2} 0 /{ }^{\circ} \mathrm{F} \text { for } L N G \text { at } 14.7 \mathrm{psia} \text {. }
$$

To determine the number of BTUs/day required to change the 1 iquid temperature, several constants are necessary. First, it takes 0.5139 BTUs to raise one pound of LNG one degree fahrenheit. There are $23.6 \mathrm{cu} \mathrm{ft}$ of gas per 1 iquid pound of LNG which reduces to $585 \mathrm{cu} f \mathrm{ft}$ gas/24.8 $1 \mathrm{bs}$ LNG liquid or $585 \mathrm{cu} \mathrm{ft}$ gas/cu ft liquid, and the latent heat of vaporization for LNG is 220 BTUs/1b. The following relationship yields the number of pounds evaporated in one day, $N$ :

$$
N=\dot{m}\left(\pi r^{2}\right) 24 \frac{h r}{d a y}
$$


This vaporization rate causes a temperature drop in the tank equal to:

$$
\Delta T_{B}=\frac{220}{0.5139}\left(\frac{1}{\pi r^{2} h}\right) \frac{\dot{m}}{585}
$$

or

$$
\frac{d T_{B}}{d t}=C_{1} \dot{M}
$$

where

$$
\begin{aligned}
\dot{M} & =\text { boil off in MMscfd } \\
c_{1} & =0.7318 / \pi r^{2} h
\end{aligned}
$$

If one assumes that the heat supplied from external tank sources is at such a rate to maintain constant boil-off, the equilibrium ODE is:

$$
\frac{d T_{B}}{d t}=\frac{B T U_{\text {ext }}}{0.5139\left(\pi r^{2} h\right)(24.8)}-C_{1} \dot{M}_{\infty}=0
$$

Assuming the only heat loss is due to boil-off and that the boil-off temperature of the liquid does not change when the pressure is held constant, the following dynamic ODE results:

$$
\begin{aligned}
& \frac{d\left(\Delta T_{B}\right)}{d t}=\frac{d T_{b}}{d t}=-c_{1} \dot{M}_{(t)}+c_{1} \dot{M}_{\infty} \\
& \frac{d T_{b}}{d t}=-c_{1}\left[\dot{M}_{(t)}-\dot{M}_{\infty}\right]
\end{aligned}
$$

but,

$$
\begin{aligned}
& \Delta T_{b}=\frac{1}{19.34} \Delta P_{S}=\frac{1}{19.34}\left(\frac{\dot{M}}{a(0.0082)}\right)^{3 / 4} \\
& \frac{d}{d t} \Delta T_{b}=\frac{1}{19.34}\left(\frac{1}{a(0.0082)}\right)^{3 / 4}(\dot{M})^{-1 / 4} \frac{d \dot{M}}{d t}
\end{aligned}
$$

therefore,

$$
\frac{d \dot{M}}{d t}=-C_{1}(19.34)(0.0082 \alpha)^{3 / 4}(\dot{M})^{1 / 4}\left[\dot{M}-M_{\infty}\right]
$$

B. 16 
or

$$
\frac{d \dot{M}}{d t}=-C(\dot{M})^{1 / 4}\left(\dot{M}-\dot{M}_{\infty}\right)
$$

Solving for constants:

$$
c_{1}=\frac{220}{0.5139 \pi r^{2} h(585)}=2.498 \times 10^{-7}
$$

where

$$
\begin{aligned}
& r=90.333 \mathrm{ft} \\
& h=114.250 \mathrm{ft} \\
& C=C_{1}(19.34)(0.0082)^{3 / 4} \alpha^{3 / 4}=0.03097
\end{aligned}
$$

where

$$
\alpha=\pi r^{2}(24)(23.6)=14.520 \times 10^{6}
$$

Assuming the steady state boil-off is a typical $0.06 \%$ per day or

$1.028 \mathrm{MMscfd}$, the equilibrium boil-off at $t=0^{-}$(before sudden pressure drop) is:

$$
\begin{aligned}
\dot{m} & =\frac{1.028 \times 10^{6}}{\pi r^{2}(24)(23.6)}=0.0708 \\
\Delta P_{S} & =\left(\frac{\dot{m}}{(0.0082)}\right)^{3 / 4}=5.036 \text { in } \mathrm{H}_{2} \mathrm{O}
\end{aligned}
$$

The total boil-off after a sudden pressure drop of $2 \mathrm{in.} \mathrm{Hg}$ :

$$
\pi r^{2}(0.0082)(27.09+5.036)^{4 / 3}=21,4691 \mathrm{~b} / \mathrm{hr}
$$

or

$$
\dot{M}_{t=0^{+}}=12.16 \mathrm{MMscfd}
$$


One would expect the boil-off to be substantially less than that found by Hashemi due to the smaller surface area attributable to the tank considered here. Solving the ODE with the above constants yielded the boil-off rate versus time relationship for a sudden pressure drop of $2 \mathrm{in.} \mathrm{Hg}$ in a full tank. The results are found in Figure 10. Included are the results from an identical analysis for a tank with half the liquid volume (i.e., $C \rightarrow 2 C$ ). The boil-off rate versus time for full and half filled tanks during a sudden pressure drop of $1 \mathrm{in.} \mathrm{Hg}$ is also shown. The same procedure yields an initial boil-off (at $t=0^{+}$) of 5,857 MMscfd. Reference 5 presents tabulated boil-off rates versus time for the sudden pressure drops investigated.

In such an actual occurrence of underpressure as illustrated above, one would expect corrective measures to be taken immediately to increase the internal tank pressure. In the event that this does not occur, it is important to note that boil-off rates will gradually decrease thus reducing potential problems.

Further, one would expect the increase in boil-off as suggested in the above scenario to be handled by the systems designed to cope with problems of overpressurization (e.g., liquefaction, flaring, safety and emergency relief valves). The number of vents varies but is usually between 2 and 7 . Using available systems, the above scenario should be adequately handled without resultant tank overpressurization. Equivalent stresses near the critical dome-wall junction region for a pressure drop of $2 \mathrm{in} . \mathrm{Hg}$ (approximately equivalent to 1 psi) are presented in Figure 15.

\section{Critical Buckling and Bursting Pressures}

Buckling of the dome and cylinder were considered separately in this section with symmetrical buckling of the dome investigated first. It is important to note that reliable critical buckling loads are not easily obtainable. Often buckling will occur at lower pressures than that predicted by classical theory. This may be due to the dependence of buckling loads 


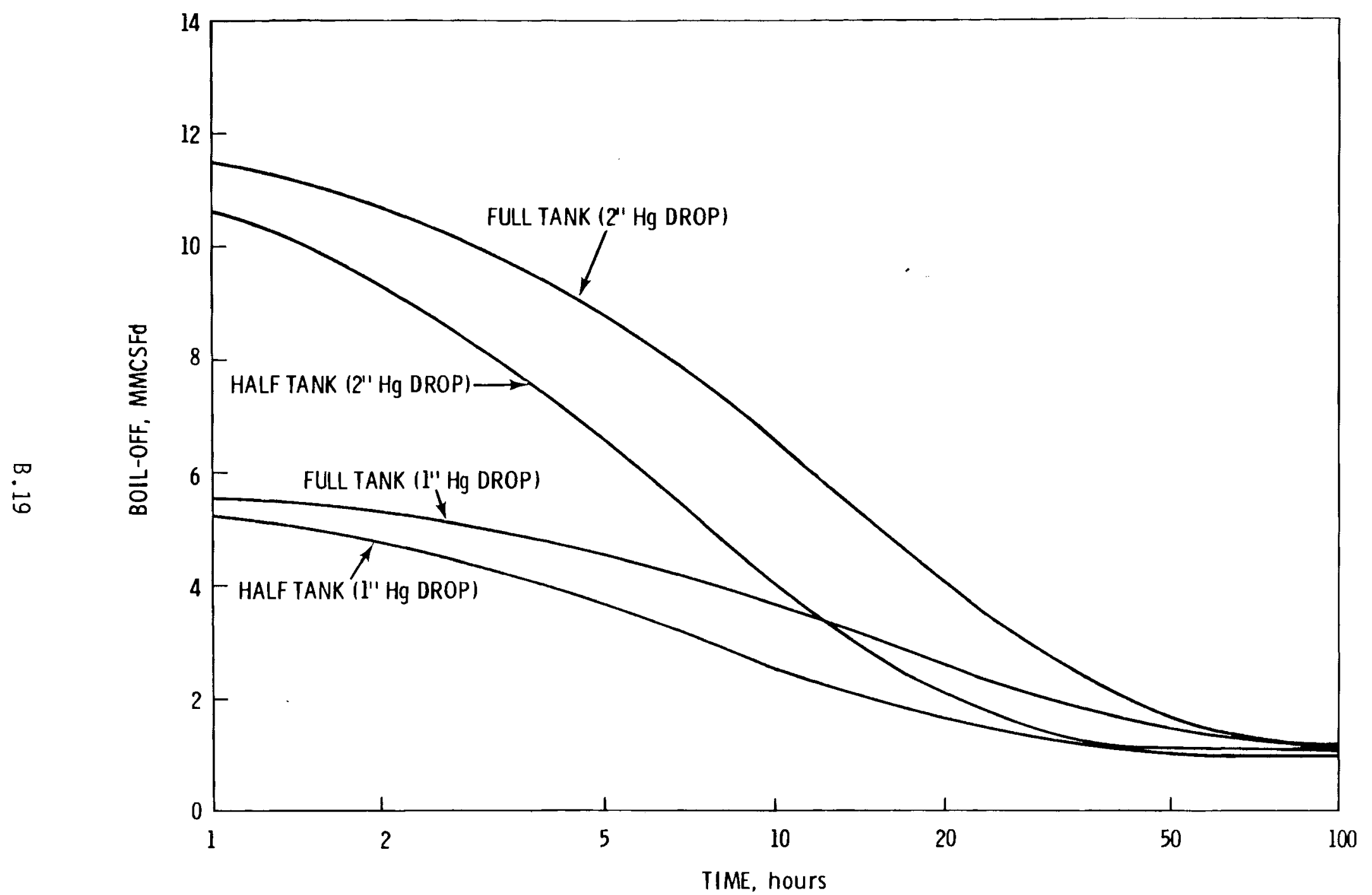

FIGURE 10. Boil-0ff Rate Versus Time Under Conditions of Sudden Pressure Drop 
on smal1 disturbances during loading, deviations in symmetrical shapes, nonhomogeneity of material or local edge conditions.

Dome. A spherical shell undergoing uniform external pressure will experience a uniform compressive stress and eventually become geometrically unstable and buckle. If one considers small displacement theory with respect to a compressed sphere, the following relationship approaches the critical pressure at which buckling occurs.

$$
q_{C R}=\frac{2 E h}{a\left(1-v^{2}\right)}\left(\sqrt{\frac{1-v^{2}}{3}} \frac{h}{a}-\frac{v h^{2}}{2 a^{2}}\right)
$$

or, by neglecting the smaller right-hand term inside the parentheses:

where

$$
q_{C R}=\frac{2 E h^{2}}{a^{2} \sqrt{3\left(1-v^{2}\right)}}
$$

$$
\begin{aligned}
& h=\text { she11 thickness } \\
& a=\text { she11 radius } \\
& E=\text { elastic modulus } \\
& \nu=\text { Poisson's ratio. }
\end{aligned}
$$

For the dome analyzed:

$$
q_{C R}=\frac{2\left(30 \times 10^{6}\right)(0.25)^{2}}{(1806)^{2} \sqrt{3\left(1-.33^{2}\right)}}=0.703 \mathrm{psi}
$$

In addition, a linear buckling analysis was performed using the finite difference energy code, BOSOR, ${ }^{14)}$ in which an eigenvalue procedure was used where eigenvalues represented the buckling loads for axisymmetric systems loaded axisymmetrically. The lowest eigenvalue, designated as the incipient point of buckling, was used to calculate the critical load, $\mathrm{P}_{\mathrm{CR}}$. 


$$
\begin{aligned}
P_{C R} & =L+\lambda \Delta L \\
L & =\text { applied load } \\
\lambda & =\text { eigenvalue } \\
\Delta L & =\text { increasing incremental load. }
\end{aligned}
$$

The critical pressure, 0.7028 psi, compared favorably with the previous results. In addition, the corresponding circumferential wave number was also generated. Figure 11 represents a plot of P-critical versus number of circumferential waves using linear buckling theory with an externally applied uniform pressure on the shell surface which represents the dome analyzed.

Because this particular thin shell dome represents a flat, shallow configuration, the decision was made to investigate deadweight loading in addition to a normal pressure loading. One would expect critical buckling loads to converge for the two configurations as the dome approximates a flat surface. The BOSOR analysis indicated a critical pressure of 0.723 psi as indicated in Figure 11.

A critical collapse load incorporating large deflections of the dome was determined using BOSOR and using an empirical method. BOSOR results indicate a $P_{C R}$ of 0.0932 psi. The empirical method for determining $P_{C R}$ for the snap through of a shallow spherical shell is presented below. (7) The available data for clamped shells provides a relationship between the ratio of buckling pressure, $P_{C R}$, to classical buckling pressure for a complete spherical she11, $\mathrm{P}_{C L}$, with respect to a geometric parameter, $\lambda$, where:

$$
\begin{aligned}
P_{C L} & =\frac{2}{\left[3\left(1-\mu^{2}\right]^{1 / 2}\right.} E\left(\frac{t}{R}\right)^{2} \\
\lambda & =\left[12\left(1-\mu^{2}\right)\right]^{1 / 4}\left(\frac{R}{t}\right)^{1 / 2} 2 \sin \frac{\phi}{2}
\end{aligned}
$$

and where

$$
\begin{aligned}
& \mu=\text { Poisson's ratio } \\
& E=\text { elastic modulus } \\
& t=\text { dome thickness } \\
& R=\text { dome radius } \\
& \phi=1 / 2 \text { included angle of dome. }
\end{aligned}
$$




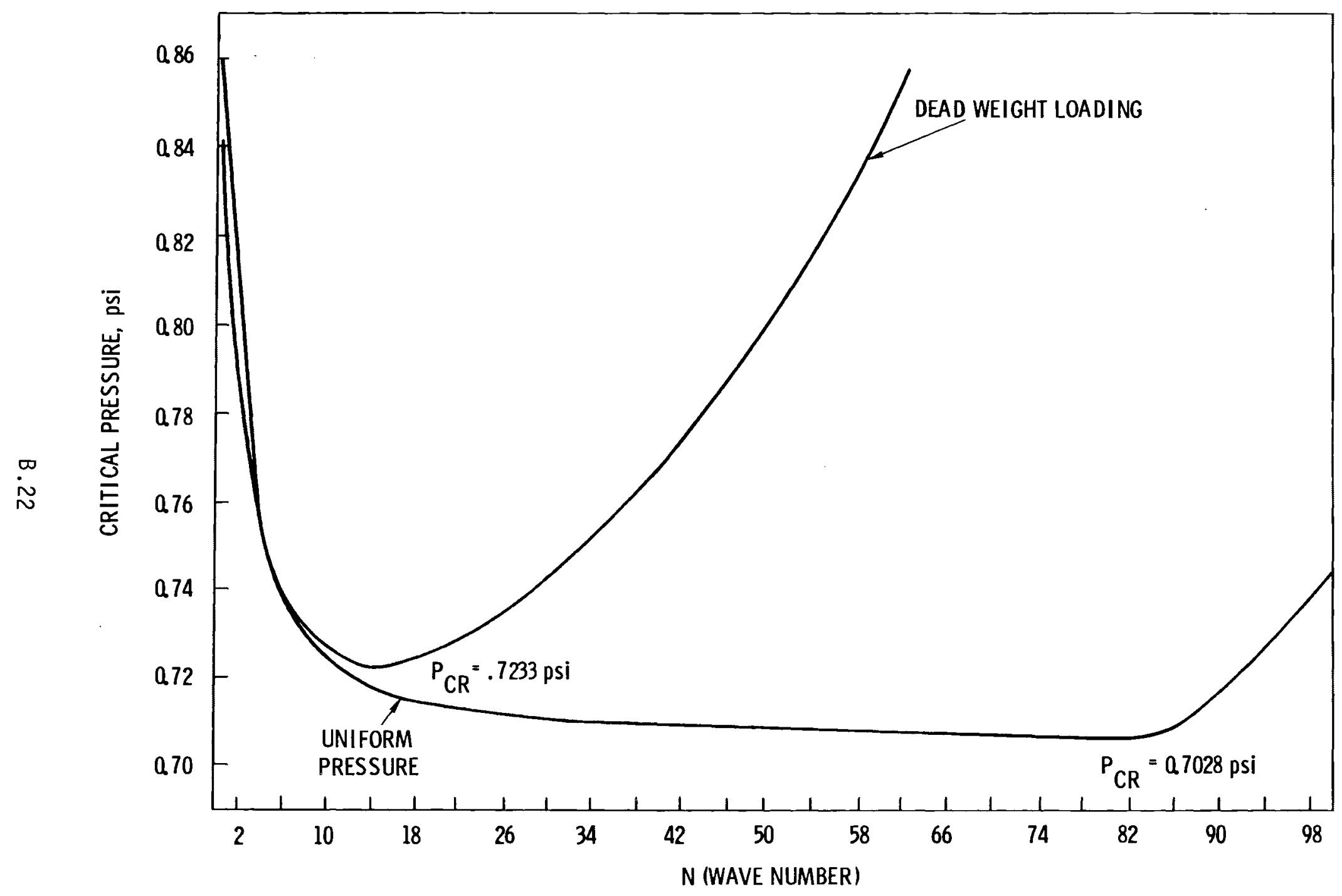

FIGURE 11. Critical Buck1ing Pressure Versus Number of Circumferential Waves for Dome Under Dead Weight and External Pressures 
The empirical relationship indicates: ${ }^{(7)}$

$$
\frac{{ }^{P} \mathrm{CR}}{{ }^{P} \mathrm{CL}}=\left[0.14+\frac{3.2}{\lambda^{2}}\right] \text { where } \lambda>2
$$

For the dome in question:

$$
\begin{aligned}
P_{C L} & =\frac{2}{\left[3\left(1-.33^{2}\right)\right]^{1 / 2}} \times 30 \times 10^{6}\left(\frac{0.25}{1806}\right)^{2}=0.70319 \mathrm{psi} \\
\lambda & =\left[12\left(1-.33^{2}\right)\right]^{1 / 4}\left(\frac{1806}{0.25}\right)^{1 / 2} 2 \sin \frac{36.89}{2}=627.06 \\
P_{C R} & =0.70319\left[0.14+\frac{3.2}{(627.06)^{2}}\right]=.099 \mathrm{psi}
\end{aligned}
$$

Again, this compared favorably with the BOSOR results given previously.

Since the weight per unit area of the dome (shell only) is approximately 0.071 psi, one might expect possible collapse failure during construction or with a decreased pressure in the vapor space in combination with live loads during service operation. Upon further investigation it was discovered that with a flat shallow spherical dome of this diameter an umbrella stiffener configuration is used such that a safety factor of at least 2 is obtained after considering additive applications of shell deadweight and live loads. An additional safety factor is obtained during operation with an opposing 2 psi internal tank pressure. To more closely approximate the critical buckling pressure, ${ }^{q} C R$, the flexural rigidity and equivalent dome thickness were determined for a plate-stiffener configuration, assuming the internal frame system to consist of $15^{\prime \prime}$ I beams on eight foot centers. Utilizing the elastic buckling equation ${ }^{(6)}$ and assuming ${ }{ }_{C R}$ is directly proportional to flexural rigidity and inversely proportional to thickness, the ratio $q_{C R}$ (including shell plates only) to ${ }^{q_{C R}}$ ' (including shell plates and stiffeners) was .00021. This produced a $\mathrm{q}_{C R}$ ' of approximately $3300 \mathrm{psi}$. Assuming $\mathrm{q}_{\mathrm{CR}}{ }^{\prime}$ to be as 1 ow as $20 \%$ of this value, recalling that buckling occurs at pressures much smaller than that predicted by classical theory, buckling was not considered a plausible failure mode since yielding would occur well before the pressure required to buckle the dome. 
Tank. To accurately determine the critical buckling pressure of the outer tank wall one must consider the simultaneous action of an axial compressive pressure due to dome weight (prior to tank pressurization) and a uniform lateral pressure due possibly to increased atmospheric pressure. This combination results in the worst case scenario for investigating buckling of the outer tank wall.

A procedure for determining the critical values of combined axial and circumferential pressures to cause buckling is given by Timoshenko. ${ }^{(8)}$ The procedure used was applicable to a circumferentially stiffened cylindrical shell where the rings were replaced by an equivalent flexural rigidity and wa11 thickness. The procedure assumed that the stiffener cross section was symmetric with respect to the middle of the shell. An equation for determining critical pressure was derived from the equations of equilibrium for determining small displacements from the cylindrical shape. For the stiffened cylinder this resulting equation is:

$$
c_{1}+c_{2^{\alpha}}+c_{3^{\alpha} 1}=c_{4} \phi_{1}+c_{5} \phi_{2}
$$

where

$$
\begin{aligned}
& c_{1}=s \lambda^{4} \\
& c_{2}=\lambda^{6}\left(\lambda^{2}+2 n^{2}\right)+s \lambda^{2} n^{2}\left[2\left(\lambda^{2}-1\right)^{2}+2\left(n^{2}-1\right)^{2}+5 \lambda^{2} n^{2}-2\right] \\
& c_{3}=\left(n^{2}-1\right)^{2}\left[\lambda^{4}+s\left(2 \lambda^{2}+n^{2}\right) n^{2}\right] \\
& C_{4}=\lambda^{4} n^{2}+s\left(2 \lambda^{2}+n^{2}\right) n^{4}-s\left(3 \lambda^{2}+n^{2}\right) n^{2} \\
& C_{5}=\lambda^{6}+s \lambda^{2} n^{2}\left(2 \lambda^{2}+n^{2}+1\right) \\
& \alpha_{1}=\frac{I_{y}\left(1-\nu^{2}\right)}{b h a^{2}}
\end{aligned}
$$


where

$$
\begin{aligned}
I_{y} & =\text { moment of inertia } \\
v & =\text { Poisson's ratio } \\
b & =\text { distance between rings } \\
h & =\text { cylinder thickness } \\
a & =\text { cylinder radius } \\
\alpha & =\frac{h^{2}}{12 a^{2}} \\
s & =\frac{h_{y}\left(1-v^{2}\right)}{h}
\end{aligned}
$$

where

$$
\begin{aligned}
h_{y} & =c y l i n d e r \text { equivalent thickness } \\
\lambda & =\frac{m \pi a}{1}
\end{aligned}
$$

where

$$
\begin{aligned}
m & =\text { number of half waves in the axial direction } \\
1 & =\text { cylinder length } \\
\phi_{1} & =\frac{\text { qa }\left(1-v^{2}\right)}{E h}
\end{aligned}
$$

where

$$
\begin{aligned}
q & =\text { lateral pressure } \\
E & =\text { elastic modulus } \\
\phi_{2} & =-\frac{N_{x}\left(1-v^{2}\right)}{E h}
\end{aligned}
$$

where

$$
\begin{aligned}
& N_{x}=\text { compression in the axial direction } \\
& 2 n=\text { number of half waves in the circumferential direction. }
\end{aligned}
$$


When $m$ is fixed, a system of linear relationships between $\phi_{1}$ and $\phi_{2}$ is found for increasing values of $n$. These lines intersect such that broken lines are formed from which critical values for axial and circumferential pressures can be calculated. Figure 12 illustrates a representative plot using this procedure for the "generic" tank analyzed. Several relationships can be seen. For instance, as $\lambda$ increases for the case where there is no axial pressure, the critical lateral pressure increases; as the cylinder length is decreased, the number of circumferential waves is increased; and increasing or decreasing axial pressures produce decreasing or increasing lateral pressures, respectively.

The same cylindrical buckling problem was investigated utilizing BOSOR. A linear buckling procedure incorporating ring beams for the wind load stiffeners, plus axial and uniform lateral pressures, resulted in a critical buckling pressure of 0.866 psi with 18 circumferential waves and no meridional waves. As one approaches zero the critical pressure obtained in the Timoshenko procedure would approach this value at a much lower circumferential wave number. It is apparent that as waves in the meridional direction increase, the resulting lateral pressure will increase substantially (at $m=1, q \simeq 12 \mathrm{psi}$ ). Again, it must be emphasized that lateral pressures on the outer wall will be opposed by pressure from the perlite insulation and the LNG vapor, both present in the annular region between tanks. This will assure a resultant positive internal pressure on the outer tank wall.

Svensson ${ }^{(9)}$ derived an expression for the bursting pressure of cylindrical and spherical vessels manufactured from materials having a stress-strain curve of the form $\sigma=\sigma_{0} \varepsilon^{n}$. As material work hardens, one can expect the octahedral shear stress to increase as the shear strain increases. The bursting of the vessel may not occur until after the entire wall enters the plastic region of the stress-strain curve. Using assumptions made, Svensson derives a relationship between internal tank pressure and change in radial dimension of the internal tank surface. A plot of internal pressure versus effective strain at the internal bore for several values of $K$ and $n$ reveals a maximum pressure to strain the vessel followed by a decrease in pressure as the strain continues to increase. This maximum depends on the rate of work hardening and the reduction in wall thickness, the maximum also indicating a point after which bursting, crack forming, or localized bulging may occur. 


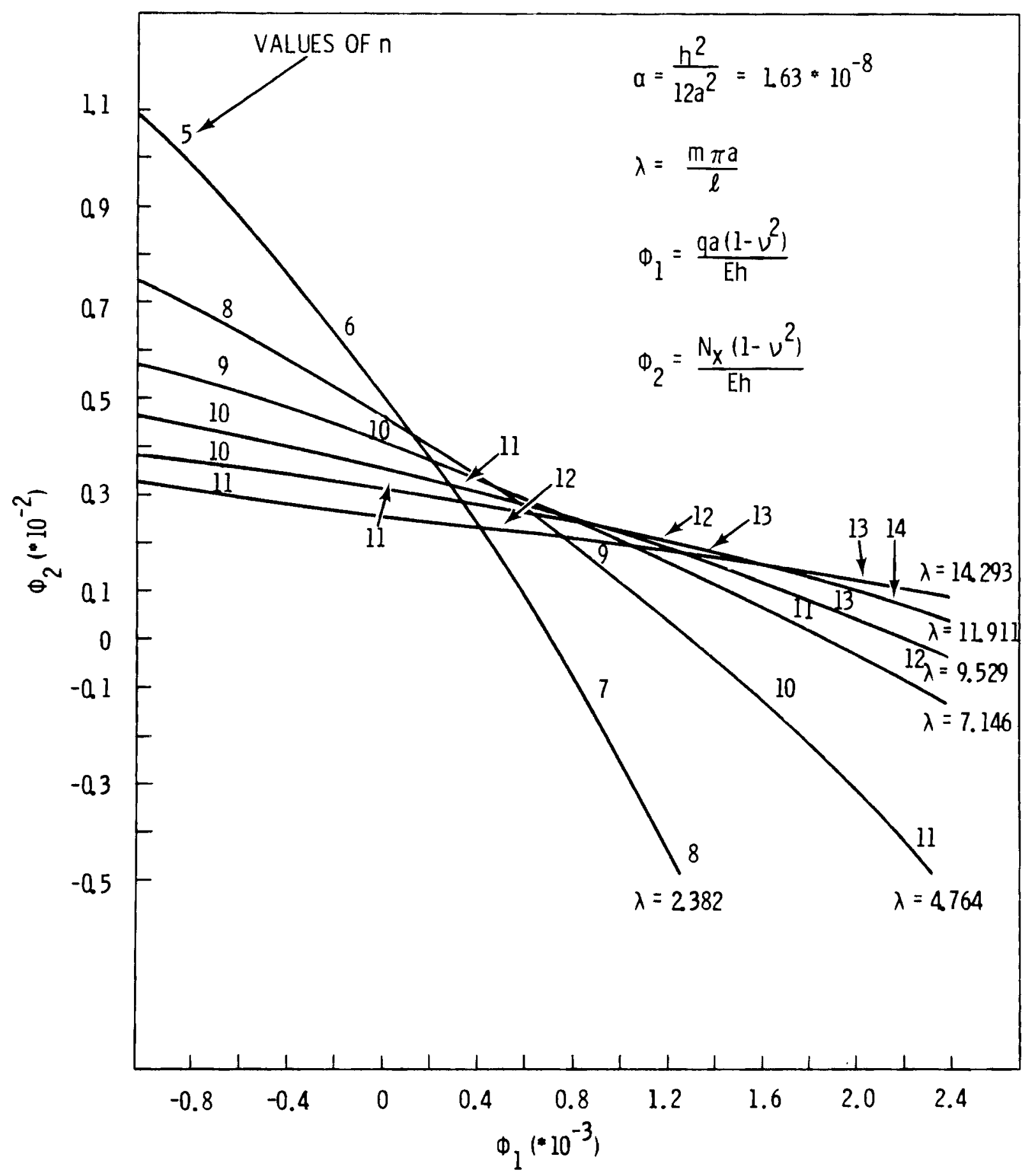

FIGURE 12. Critical Values for Determining Axial and Circumferential Pressures of Stiffened Cylinder 
The bursting pressure for a thin-walled cylindrical vessel is:

$$
\frac{\tilde{p}}{\sigma_{0}}=\frac{t_{i}}{R_{i}}\left(\frac{n}{e}\right)^{n} \frac{2}{(\sqrt{3})^{n+2}}
$$

where

$$
\begin{aligned}
\tilde{p} & =\text { bursting pressure } \\
\sigma_{0} & =\left(\frac{e}{n}\right)^{n} \sigma_{\mu}{ }^{\prime} \\
t_{i} & =\text { initial wall thickness } \\
R_{i} & =\text { initial cylinder radius } \\
n & =\varepsilon_{\mu}=\log _{e}\left(1+\varepsilon_{\mu}{ }^{\prime}\right) \\
\sigma_{\mu}{ }^{\prime} & =u l t i m a t e \text { nominal stress } \\
\varepsilon_{\mu}{ }^{\prime} & =\text { nominal strain at ultimate stress }
\end{aligned}
$$

Using a stress-strain relationship for mild steel to approximate that of $A 131$, the resultant bursting pressure for the outer tank is approximately $43 \mathrm{psi}$. Because of the typical construction, allowing for pressure equilization between the annular region and the inner tank, the above investigation was not considered applicable to the inner tank.

\section{Stresses at the Dome-Wall Junction}

Forces in the dome area, particularly edge forces, are of concern in the over/underpressure scenario. Using the finite element code, ANSYS, (15) a two dimensional model of the dome and cylinder wall, which incorporated a series of axisymmetric conic shell elements with membrane and bending capabilities, was developed. Two loading conditions included 1) deadweight loading on $7 y$ and 2) a deadweight plus 2 psi internal pressure loading (inservice condition). Figures 13 and 14 illustrate the resultant edge forces and moments for each loading condition, respectively. 


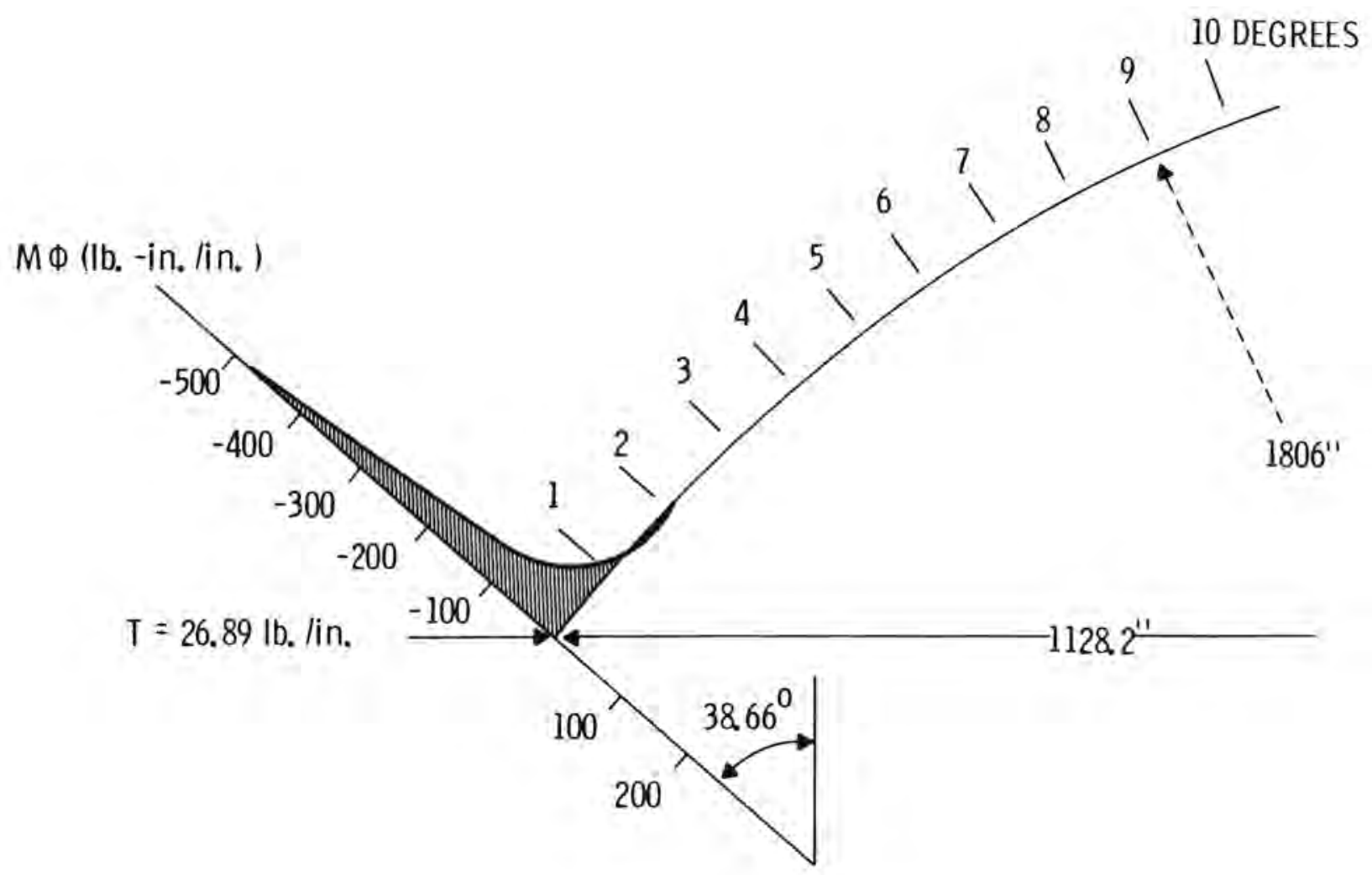

FIGURE 13. Bending Moment and Resultant Edge Force at Dome/Wa11 Junction Under Dead Weight Loading Only 


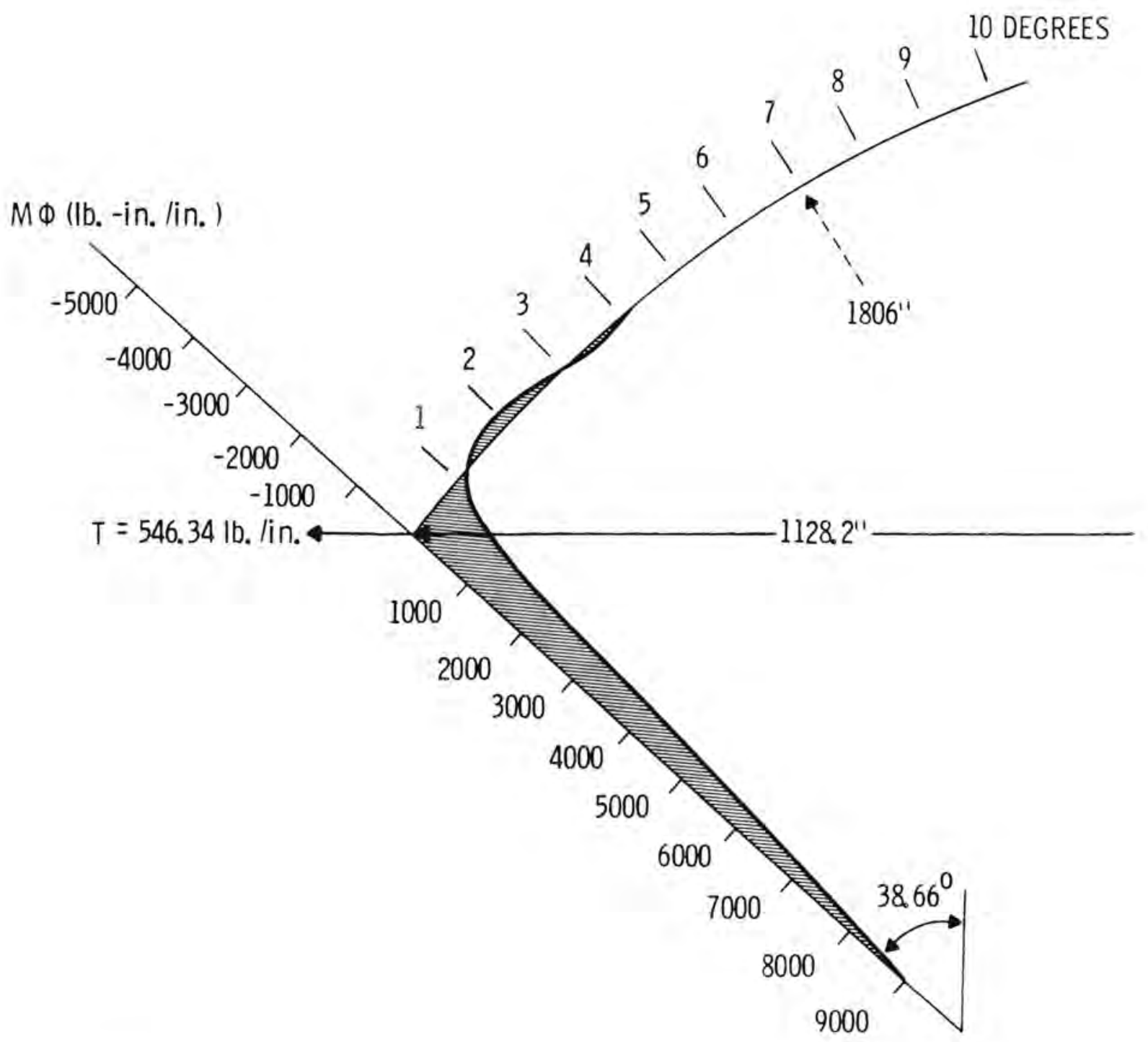

FIGURE 14. Bending Moment and Resultant Edge Force at Dome/Wall Junction Under Dead Weight Plus 2 psi Internal Pressure 
Bending is shown to be large but of a very localized character, and is virtually concentrated in the stiffened edge region. In addition, Figure 15 illustrates equivalent stresses in the dome and adjacent areas as a result of 1,2 and 3 psi net external pressures.

The membrane forces at any point on the dome were calculated by: $(10)$

$$
\begin{array}{ll}
N_{\phi}=-\frac{a q}{1+\cos \phi} & \text { (meridional) } \\
N_{\theta}=a q\left(\frac{1}{1+\cos \phi}-\cos \phi\right) & \text { (hoop) }
\end{array}
$$

where

$$
\begin{aligned}
& a=\text { dome radius } \\
& q=\text { force/unit area } \\
& \phi=\text { included angle }
\end{aligned}
$$

For deadweight loading the meridional membrane stress at $\phi=0$ will be $\sigma_{\phi}=-\mathrm{aq} / 2 \mathrm{t}$ and will increase with increasing $\phi$. The meridional stress for the dome analyzed varied from $-255.73 \mathrm{psi}$ to $-287.20 \mathrm{psi}$. In addition, there is a compressive hoop stress which remains negative until $N_{\theta}$ increases to $51^{\circ} 50^{\prime}$. This is never achieved in the dome under investigation (i.e., maximum included angle $\left.=38.66^{\circ}\right)$. The hoop stresses during deadweight loading varied from $-255.73 \mathrm{psi}$ to $-112.18 \mathrm{psi}$. Under normal operating conditions, with an internal pressure of 2 psi, the dome sees an almost constant meridional and hoop stress throughout the dome. The range is from approximately 6936 psi to 7172 psi. Assuming the bending stresses are localized and self-limiting in nature, the internal pressure would have to increase fivefold before yield stresses are reached. This estimate is ultra-conservative considering no stiffening effects in the dome.

\section{Rollover}

An additional area which is often addressed in storage dynamics is that of rollover and thermal overfill. Rollover is defined as a sudden 


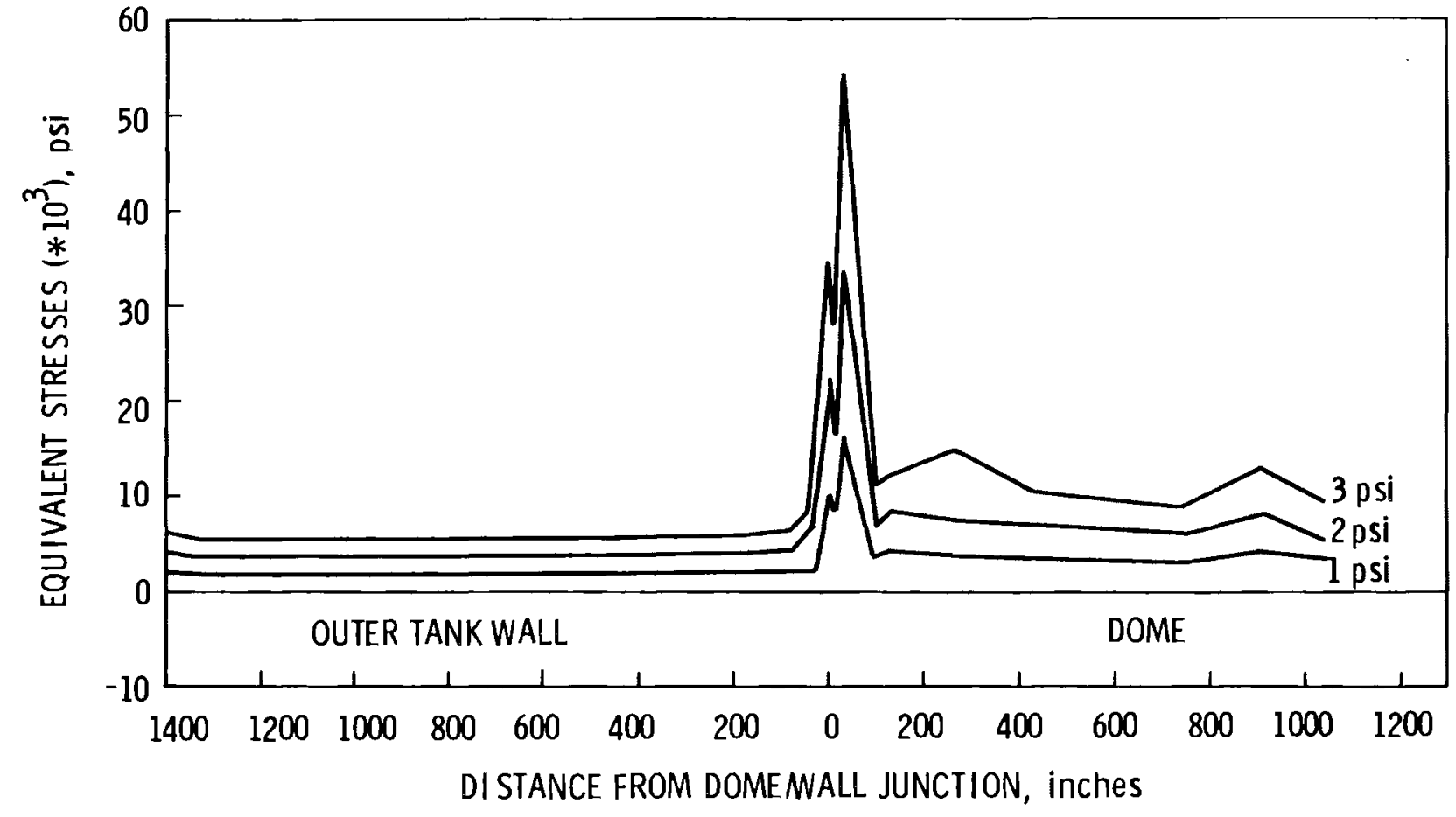

FIGURE 15. Equivalent Stresses at the Dome/Wall Junction for Net External Pressures of 1,2 and 3 psi 
movement of large masses of 1 iquid from the bottom to the top surface of the tank, usualiy as a result of instability caused by density changes. Thermal overfill is defined as a situation where a tank is filled with liquid whose saturation pressure is higher than the maximum operating pressure of the tank. Liquid circulation or top fill of the tank is recommended to combat such occurrences. (11) It has also been suggested that with a Rayleigh number above 1707 , natural circulation within the tank will make stratification impossible. (12) The Rayleigh number is:

$$
R_{a}=\frac{g \alpha \Delta T h_{L N G}^{3}}{\frac{\beta}{\rho} \frac{K}{C_{P}}}
$$

where

$$
\begin{aligned}
g & =\text { gravitational constant } \\
\alpha & =\text { thermal expansion coefficient } \\
\Delta T & =\text { temperature difference between fluid at top and bottom } \\
\mathrm{h}_{\mathrm{LNG}} & =\text { height of } L N G \\
\beta & =\text { kinematic velocity } \\
\mathrm{K} & =\text { thermal conductivity } \\
\rho & =\text { density } \\
C_{\mathrm{P}} & =\text { specific heat }
\end{aligned}
$$

Assuming the following values:

$$
\begin{aligned}
g & =4.17 \times 10^{8} \mathrm{ft} / \mathrm{hr} / \mathrm{hr} \\
\alpha & =0.002222 /{ }^{\circ} \mathrm{F} \\
\Delta T & =15^{\circ} \mathrm{F} \\
h_{L N G} & =114 \mathrm{ft} \\
\beta & =0.0106 \mathrm{sq} \mathrm{ft} / \mathrm{hr} \\
K & =0.11 \mathrm{BTU} / \mathrm{hr} \mathrm{sq} \mathrm{ft}-{ }^{\circ} \mathrm{F} / \mathrm{ft} \\
\rho & =26.71 \mathrm{~b} / \mathrm{cu} \mathrm{ft} \\
C_{P} & =0.82 \mathrm{BUT} / 1 \mathrm{~b}{ }^{\circ} \mathrm{F}
\end{aligned}
$$


The Rayleigh number for the full tank is

$$
R_{a}(f u 11)=7.79 \times 10^{17}
$$

and for the nearly empty tank is

$$
R_{a} \text { (nearly empty) }=2.61 \times 10^{11}
$$

Both of these figures are much greater than what would be required for stratification. In addition, peak shaving plants are less susceptible to such problems because of slow fill and filling liquids of uniform composition. (13) 


\section{REFERENCES}

1. Hashemi, H.T. and H.R. Wesson, "Cut LNG Storage Costs", Hydrocarbon Processing, Vol. 8, 1981, p. 117.

2. West, H.H., J.R. Welker and C.M. Sliepcevich, "Radiation, Heat Flux, and Overpressure in LNG Tanks", DTIC Technical Report AD-754326, 1972, p. 74 .

3. Neil1, D.T., H.T. Hashemi and C.M. Sliepcevich, "Boil-Off Rates and Wal1 Temperatures in Aboveground LNG Storage Tanks", Chemical Engineering Progress, Vol. 64, 1968.

4. Standards for the Production, Storage and Handling of Liquefied Natural Gas, NFPA No. 59A, 1975.

5. Fecht, B.A., "Results in Support of LNG Storage Tank Analysis", Battel le Northwest Laboratories, November 1981.

6. Timoshenko, S.P. and J.M. Gere, Theory of Elastic Stability, McGraw-Hill Book Co., 3rd Edition, New York, 1970, p. 517.

7. Baker, E.H., L. Kovalevsky and F.L. Rish, Structural Analysis of Shells, R.E. Krieger Publishing Co., New York, $198 \overline{1, ~ p p . ~ 253-254 . ~}$

8. Timoshenko, S.P., op cit, p. 495-499.

9. Svensson, N.L., "The Bursting Pressure of Cylindrical and Spherical Vessels", Journal of Applied Mechanics, March 1958.

10. Timoshenko, S.P. and S. Woinowsky-Krieger, Theory of Plates and Shells, McGraw-Hi11 Book Co., New York, 1968, p. $43 \overline{6}$.

11. Maher, J.B. and L.R. Van Gelder, "Rol1-Over and Thermal Overfill in Flat Bottom LNG Tanks".

12. Duffy, A.R., J.E. Sorenson, R.E. Mesloh, and E.L. Smith, "Heat Transfer Characteristics of Belowground LNG Storage", Chemical Engineering Progress, Vol. 63, No. 6 , June 1967, p. 61 .

13. Geist, J.M. and N. Chatterjee, "The Effects of Stratification on Boil-0ff Rates in LNG Tanks", DTIC Technical Report AD-754326, 1972 , p. 50 .

14. Busne11, D., Analysis and User's Manual for BOSOR4, Lockheed Missiles and Space Co., Inc., Sunnyvale, CA, March 1972.

15. De Salvo, G.J. and J.A. Swanson, ANSYS Engineering Analysis User's Manual, Revision 3, Update 67L, Swanson Añalysis Systems, Houston, PA, JuTy 1979. 


\section{SUBSIDENCE}

\section{Discussion}

The foundations for LNG storage tanks are designed and constructed to meet the requirements of the specific site selected. Under the shells a ring wall is often used and installed with such a weight as to counteract the uplift forces due to pressures on the dome. In some cases where differential settling or seismic activity may occur, slab foundations are used. On poor soils, the tank can be decreased in height and increased in diameter to create smaller bearing forces per unit area. However, this tends to decrease the economical advantages present when an optimum height to diameter ratio is used. In other situations, soil conditions may require pile foundations. In all cases soil freezing and subsequent frost heaving must be prevented. This is usually accomplished through the installation of heating coils and use of selected fill. In addition, some foundations of the pile-type allow for circulation of air between the ground and pile caps.

Before in-service operation commences, a hydrostatic proof test is conducted. This establishes tank performance during exposure to a resultant bearing load ranging from 1 to 1.25 times the load at maximum LNG storage capacity. In addition, this test tends to mechanically stress relieve the welded structure. Should settlement occur, whether during proof test or in-service operation, it will most likely fall under one of four categories; uniform settling, tilted settlings, dishing, or differential settling around the tank perimeter. Excessive dishing, and thus possible leakage due to damaged Foamglas, is unlikely if a crowned bottom is used. Differential settling is also unlikely if uniform compaction is initially established. Under these conditions, however, it is possible that elastic buckling could occur during a slow differential settling situation and that reconstruction of the foundation would allow a return to original specifications.

\section{Analyses}

Even slight differential settlement can cause increased loadings imposed on the $\operatorname{tank}(s)$. To investigate these increases stresses, a very simple FEM model utilizing ANSYS ${ }^{(2)}$ was devised. It simulated a 3-D cylindrical 
shell (outer tank), including stiffeners and a concrete ring foundation, which was supported by soil elements. This was accomplished using 3-D rectangular shell and isoparametric solid elements with spring elements modeling soil characteristics. Assuming a soil bearing pressure of 4500 psf, the spring constants were selected to support this pressure with a resultant overall deflection of 0.3 to $0.5 \mathrm{in}$. Subsequent models included varying amounts of circumferential subsidence, subsidence being achieved by decreasing the spring constant, $K$, to 50 percent of its initial value, $K_{0}$. The remainder of the structure was "supported" by spring elements maintaining initial stiffnesses. Three cases were investigated; 10,30 and 60 degrees of total subsidence (i.e., 5, 15 and 30 degrees of the axisymmetric 90 degree model were investigated with spring elements assigned the $1 / 2 \mathrm{~K}_{0}$ values). The final case involved 60 degrees of total subsidence where $K$ was assigned a value of zero (total absence of soil support) through 30 degrees of the model 1 and assigned vaiues to achieve a linear function between $K=0$ and $K=K_{0}$ for the remaining 30 degrees of subsiding soil. Each case was investigated using the 90 degree axisymmetric model and each was exposed to in-service loading conditions.

Figure 16 illustrates the vertical deflection of the foundation as a result of in-service loading conditions on subsidence models for 10,30 and 60 degrees, Results depicting the vertical deformation for the final case (variable K) are illustrated in Figure 17. These deflections were reflected through the height of the tank and slightly intensified toward the top in conjunction with increased radial deflection. In the 60 degree subsidence model the radial displacements varied to a greater degree when progressing circumferentially at designated tank heights.

Stresses in the lower tank were significantly greater between the 10 and 60 degree subsidence model. However, the effects of the subsidence were not great enough to be felt appreciably at higher tank levels. Hoop stresses were consistent between cases and meridional bending stresses were slightly greater for the 60 degree subsidence model. 


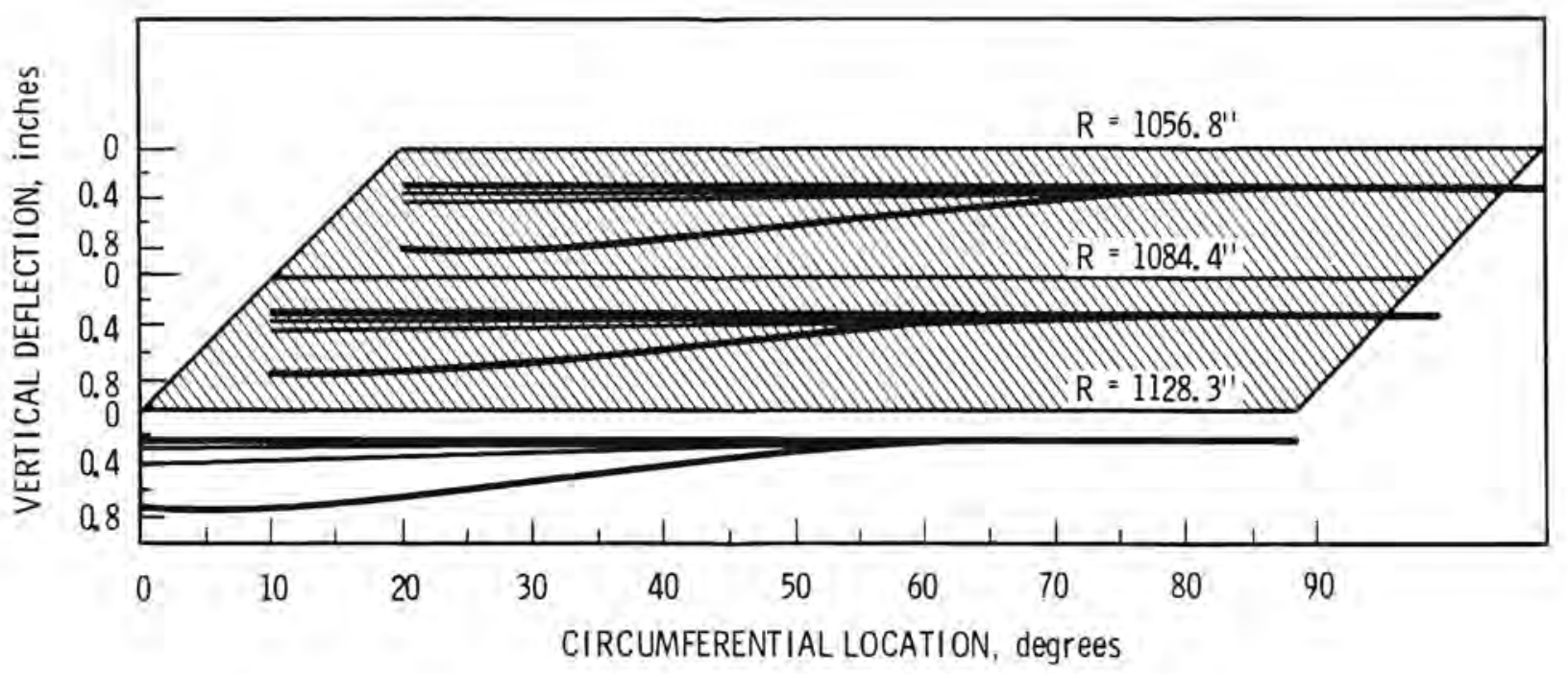

FIGURE 16. Vertical Disp1acement at Foundation Under 10, 30 and 60 Degrees Tota1 Subsidence

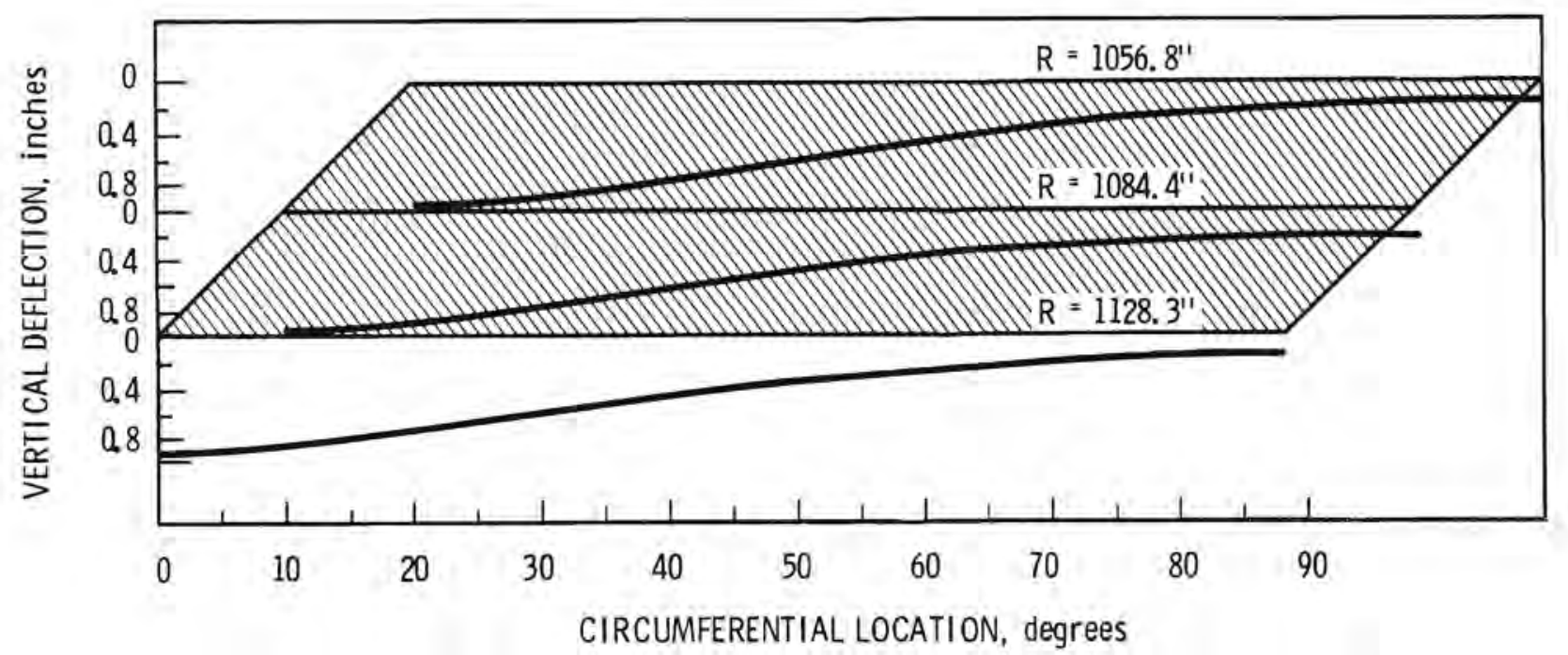

FIGURE 17. Vertical Displacement at Foundation Due to 60 Degrees Subsidence (Varying Soil Stiffness) 
For the most severe case of subsidence, a deformed geometry plot is presented in Figure 18, in addition to the vertical deflection of the foundation shown in Figure 17. Although the vertical deflections did not increase greatly as one progressed meridionally over the tank, the radial deflections, as illustrated in Figure 18, increased significantly (max = 5.78 in.). (1) In addition, probable instability is indicated by what appears to be conditions for circumferential buck 1 ing in the cylinder wall. A major contributing factor to this deflection pattern is the dome weight superimposed on the model simulating worst conditions, perhaps indicative of preliminary tests done before tank pressurization.

To properiy investigate the subsidence scenario a more sophisticated mode1 with soil-foundation interaction would be necessary. Because of the precautions taken in tank construction (e.g., constructing crowned tank bottoms and carefully grading, filling and compacting soil), and because subsidence usually progresses slowly enabling detection and correction of the problem, it was not felt that this area should demand more effort. 


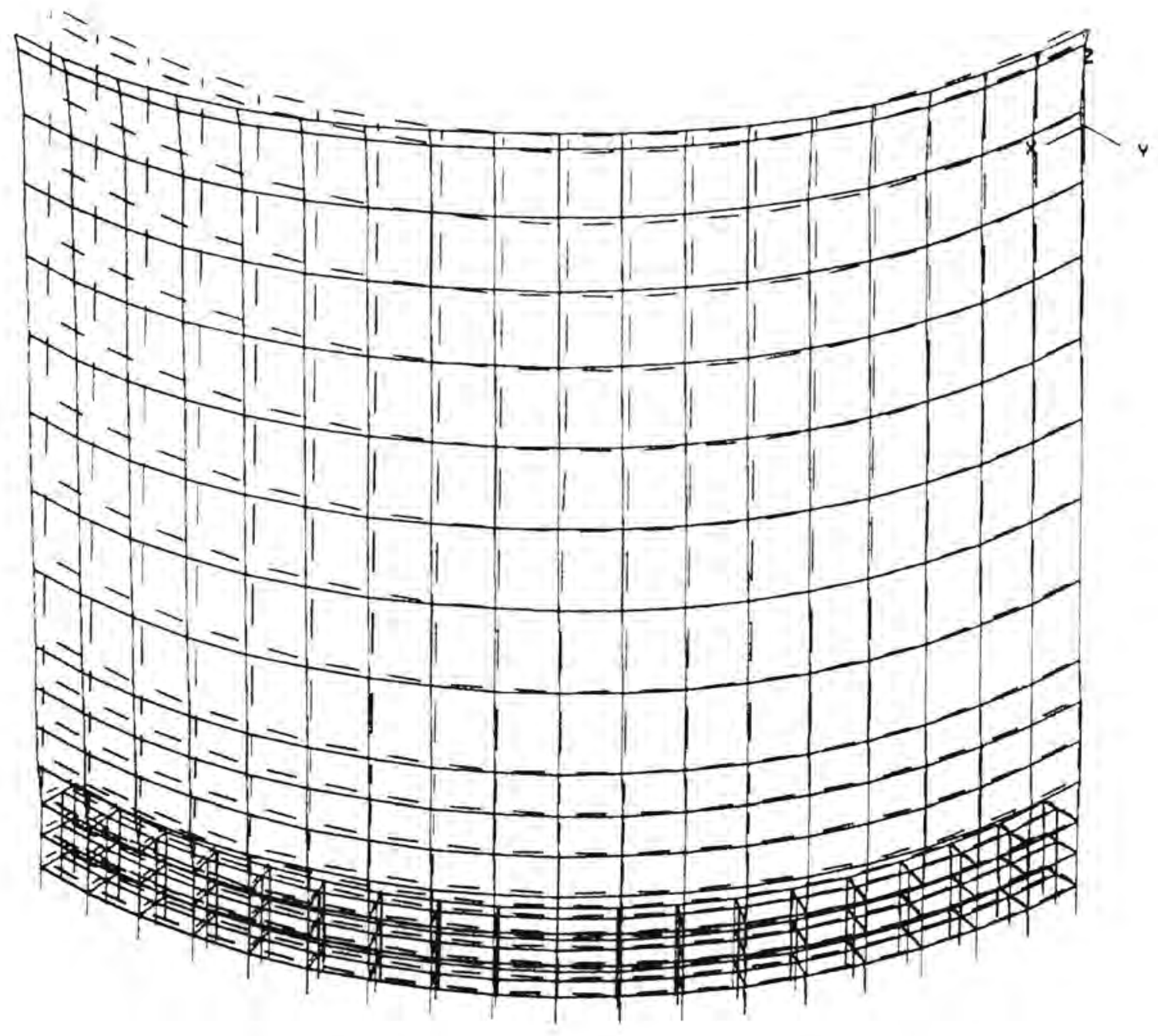

FIGURE 18. FEM Model I1lustrating Displacements in Upper Shel1 Due to Subsidence 


\section{REFERENCES}

1. Fecht, B.A., "Results in Support of LNG Storage Tank Analysis", Battelle Northwest Laboratories, November 1981.

2. De Salvo, G.J. and J.A. Swanson, ANSYS Engineering Analysis User's Manual, Revision 3, Update 67L, Swanson Analysis Systems, Houston, PA, Ju1y 1979. 
TORNADO

Discussion

A tornado is a localized, intense storm of short duration. The destructive forces can be attributed to rotating winds of high speed in conjunction with large decreases in atmospheric pressure. Wind speeds and pressure drops have been estimated at $250 \mathrm{mph}$ and $1.10 \mathrm{psi}{ }^{(1)}$ to $360 \mathrm{mph}$ maximum wind speed and $290 \mathrm{mph}$ rotation speed with a pressure drop of 3.0 psi. (2) The rate of pressure drop is rapid, perhaps up to $2 \mathrm{psi} / \mathrm{sec}$, and the radius of maximum rotational speed can be $150 \mathrm{ft}$ from the tornado center. (2)

Analyses

The probability of a tornado occurrence is often discussed and most certainly considered in the design phase of an LNG facility. A typical method of determining the probability of a tornado striking a specific location in the United States is: $(3)$

$$
P=\frac{2.82 f}{A}
$$

where the constant $2.82=$ mean path area

$$
\begin{aligned}
& f=\text { mean occurrence frequency (see Figure 19) } \\
& A=\text { area of } 1^{\circ} \text { square (see Table 1) }
\end{aligned}
$$

For example, if $P=0.001$ (e.g., latitude $40^{\circ} 30^{\prime}$ at a mean occurrence frequency of 1.2), the mean return period is 1,000 years for the designated location.

\begin{tabular}{|c|c|c|c|c|c|c|}
\hline & & & & & & \\
\hline \multicolumn{2}{|r|}{$25^{\circ} 30^{\prime}$} & $30^{\circ} 30^{\prime}$ & $35^{\circ} 30^{\prime}$ & $40^{\circ} 30^{\circ}$ & $45^{\circ} 30^{\prime}$ & $50^{\circ} 30^{\prime}$ \\
\hline rea & 4300 & 4109 & 3887 & 3634 & 3354 & 2983 \\
\hline
\end{tabular}

TABLE 1. Area of $1^{\circ}$ Square (Square Miles) $)^{(4)}$

Latitude of Middle of Square 


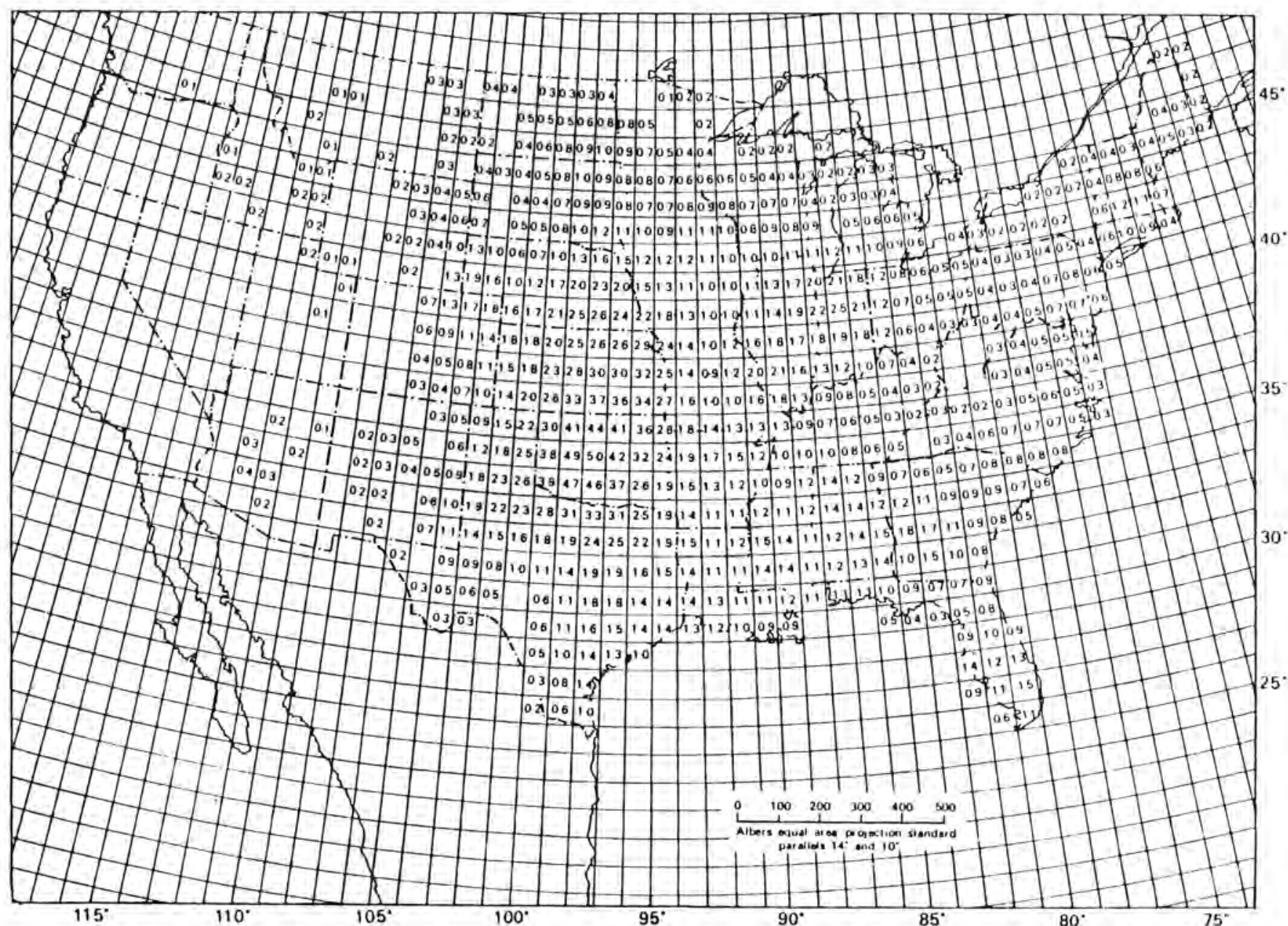

FIGURE 19. Mean Annual Frequency of Tornadoes, U.S.A., 1953-62 (4) 
The total horizontal wind velocity selected as an average maximum for this analysis was $311 \mathrm{mph}$ with a pressure drop of $2.2 \mathrm{psi}$. The wind velocity is transformed into an effective external pressure over the cylinder incorporating appropriate size and shape coefficients. The assumptions adopted for this procedure are included in ANSI Standard A58.1-1972. (5) Supplementary assumptions to this standard include a gust factor of unity, constant velocity pressure with height, a rotational velocity distribution based on the Rankine Vortex, and the maximum velocity pressure intensity, $q_{\max }$, descriptive of the maximum velocity at the tornado radius. (6) The equivalent external pressure is given as:

$$
P_{a}=q_{\max } C_{s} C_{p}
$$

where

$$
\begin{aligned}
a_{\max } & =0.002558 v^{2}, \text { maximum velocity pressure } \\
C_{s} & =0.71, \text { size coefficient from Figure } 20(2) \\
C_{p} & =\text { pressure coefficient }(2) \\
V & =\text { maximum horizontal wind velocity. }
\end{aligned}
$$

These values are given in Table 2 as a function of circumferential location, with the representative configuration of pressure equivalents for a smooth circular cylinder under surface loading conditions given in Figure 21.

Utilizing ANSYS, (9) a two dimensional axisymmetric structure under nonaxisymmetric loading conditions was developed. This was possible through the use of a special class of axisymmetric elements called harmonic elements. The specific element used was an axisymmetric biaxial shell with membrane and bending capabilities. The loading procedure was developed by specifying a Fourier series where each term in the series was defined as a separate load step. A post processor was used to scale and sum results at various circumferential locations. Using a Fourier series generator, the series solution for the tornado conditions specified was as follows. 


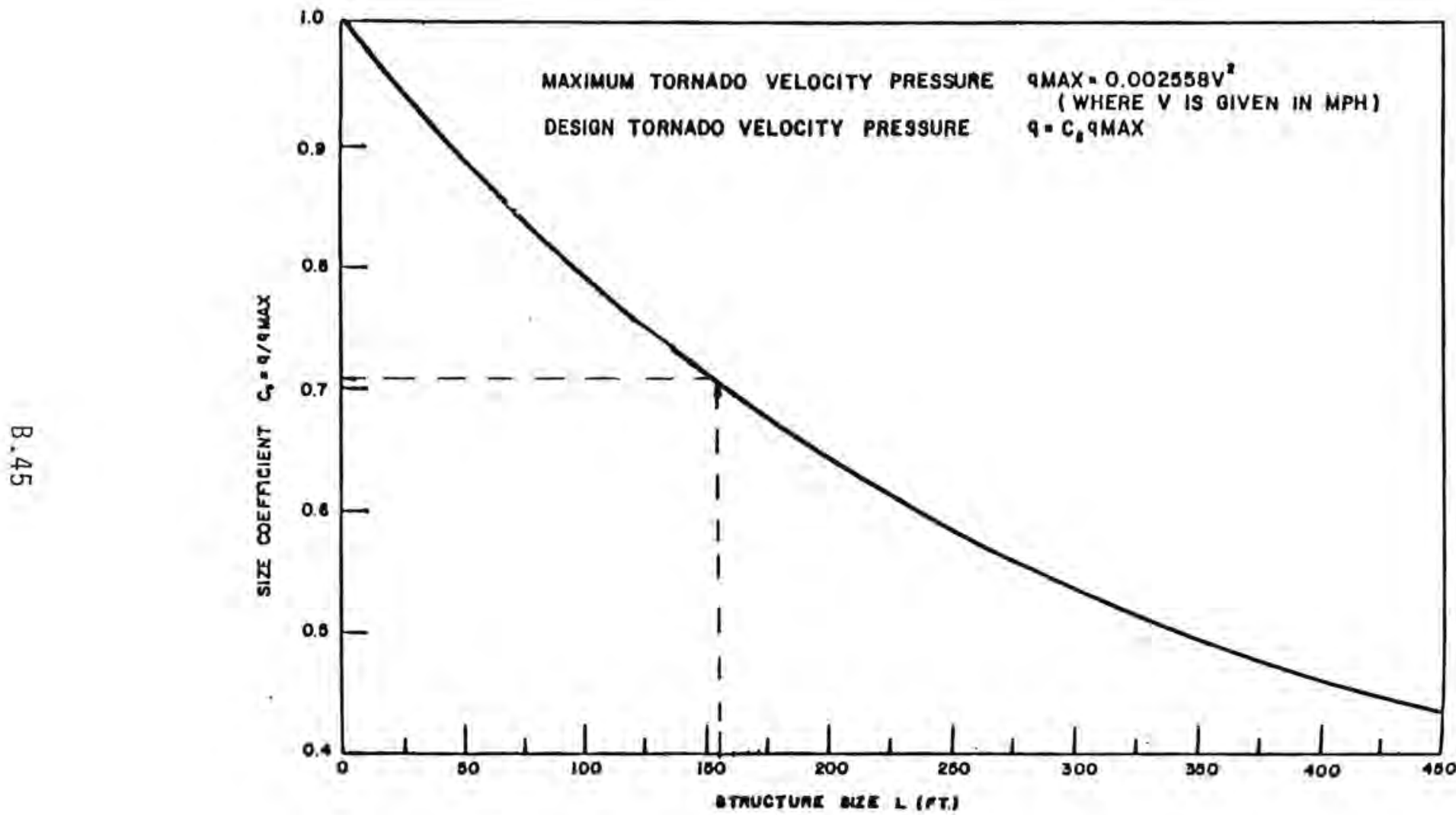

FIGURE 20. Structure Size Effect on Tornado Pressure ${ }^{(6)}$ 
TABLE 2. Size and Pressure Coefficients with CaTculated Values of Equivalent

External Pressure

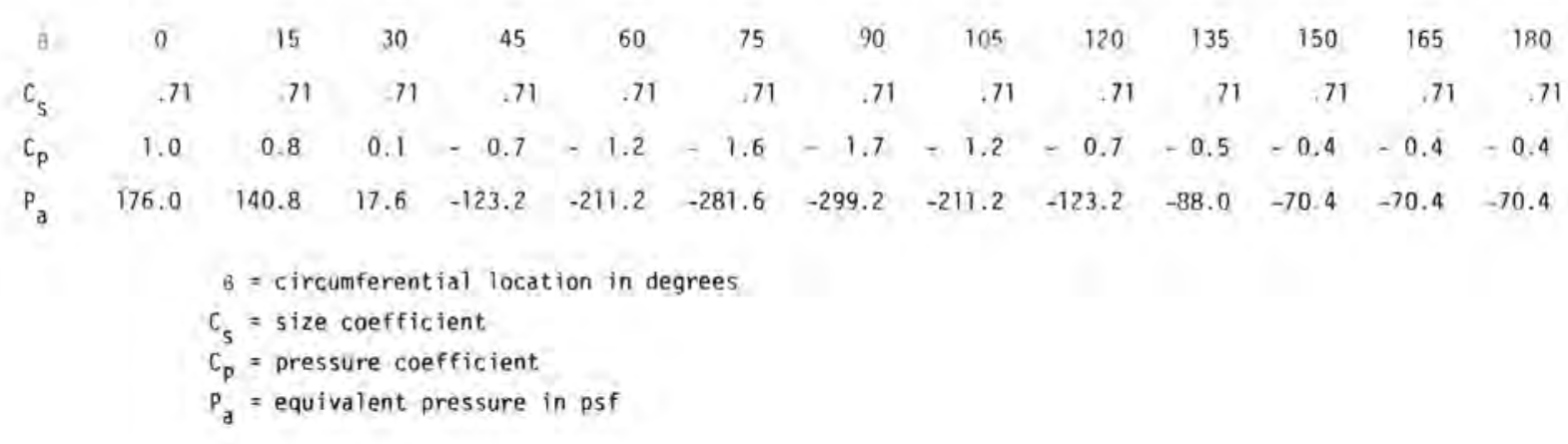

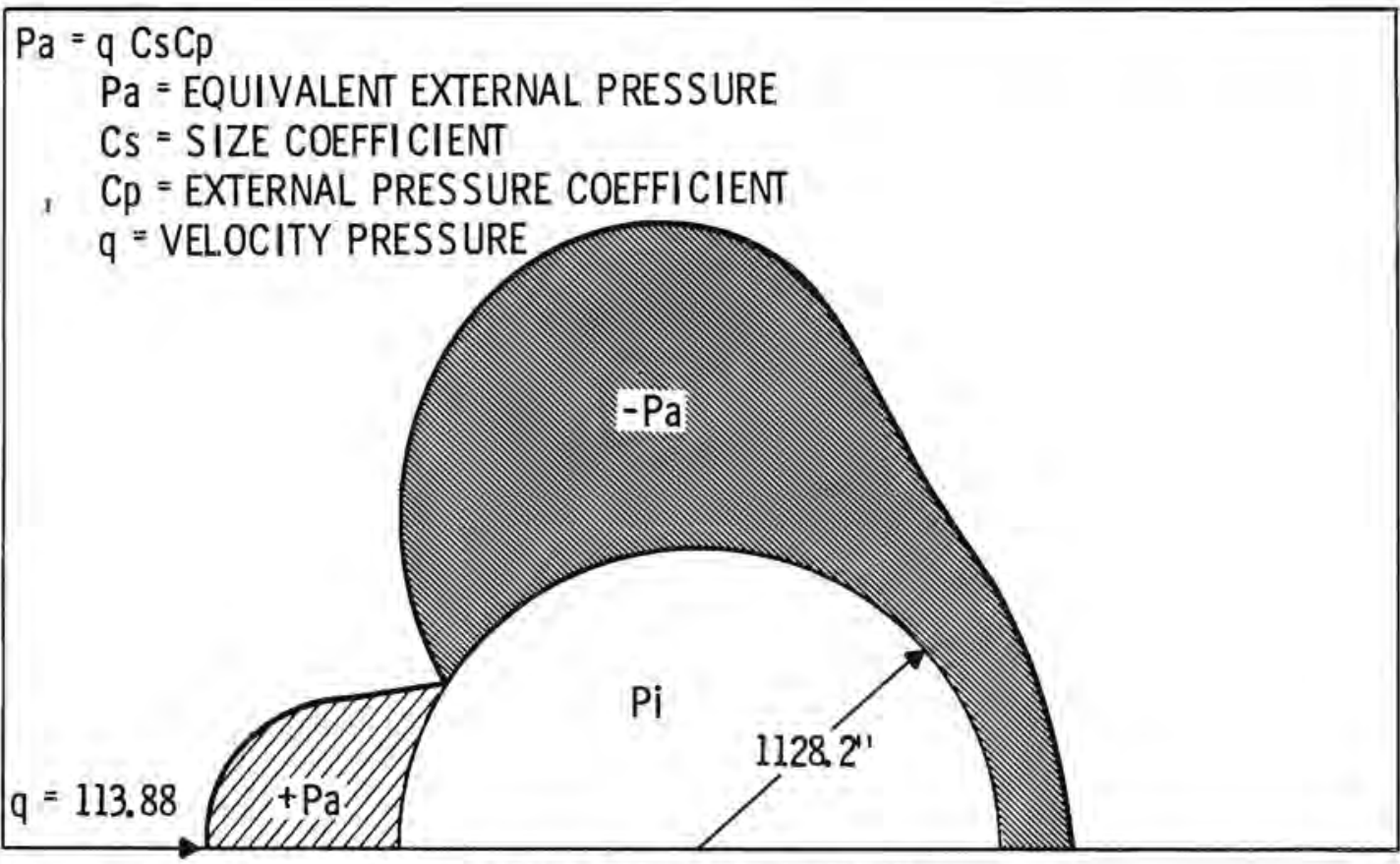

(EQUIVALENT VELOCITY PRESSURE FOR HORIZONTAL

WIND VELOCITY OF $311 \mathrm{mph}$ )

FIGURE 21. Equivalent External Pressure on Cylinder Due to Tornado Winds (4) 


$$
\text { If } \begin{aligned}
y= & f(t), \text { then } \\
y= & -0.7354+0.3658 \cos t+1.1366 \cos 2 t+0.5046 \cos 3 t \\
& -0.0608 \cos 4 t+0.0176 \cos 5 t+0.0808 \cos 6 t-0.0104 \cos 7 t \\
& -0.0608 \cos 8 t-0.0163 \cos 9 t
\end{aligned}
$$

where

$t=$ circumferential location in degrees.

Figure 22 illustrates loading conditions associated with selected terms and Figure 23 illustrates the series solution when a 10 term series is used. This accommodated the values from Table 2 very well. The values in this table represent the equivalent external tornado pressures at circumferential increments of 5 degrees.

The NRC Standard Review Plan, Section $3.32^{(7)}$ suggests a method for combining the effects of tornado induced loads. Excluding missile loads, it provides for a total load equal to either a total wind load, a total differential pressure or a total wind load plus a 50 percent differential pressure. This procedure was followed when investigating tank responses to selected tornado conditions.

Meridional and hoop membrane stresses, meridional bending stresses and equivalent von Mises stresses were determined for seven circumferential locations at 18 different meridional heights from the bottom of the cylinder to the top of the dome. Each of the selected loading conditions were superimposed on the in-service loads (e.g., internal tank pressure, deadweight of structure, etc.).

Under conditions of wind loading only, the highest equivalent stresses (17,000 psi) existed at a $0^{\circ}$ circumferential location (windward side) and at a point on the dome within 5 in. from the dome-wall junction. Yielding, however, was not attained and the high equivalent stresses were due largely to the high localized bending stresses. Under conditions of isolated maximum pressure differential (pressure drop of 2.2 psi), stresses could be expected to be uniform about the tank. Bending stresses exceeded yielding at the dome-wall junction causing the equivalent stresses to also exceed yield. The strain, however, remained under . $2 \%$ and the area of concern 


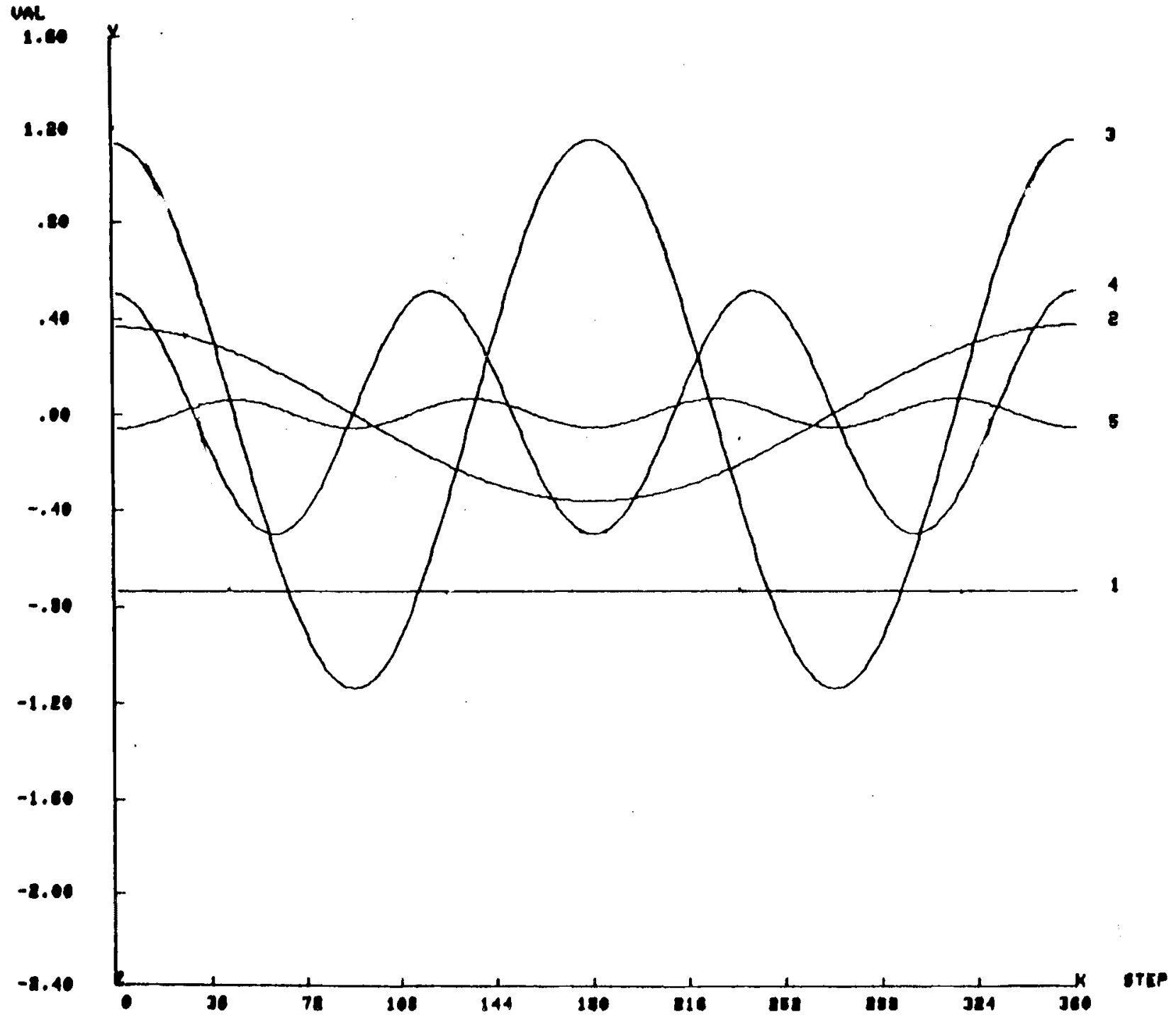

FIGURE 22. First Five Terms in Fourier Series Used as Load Steps in FEM 


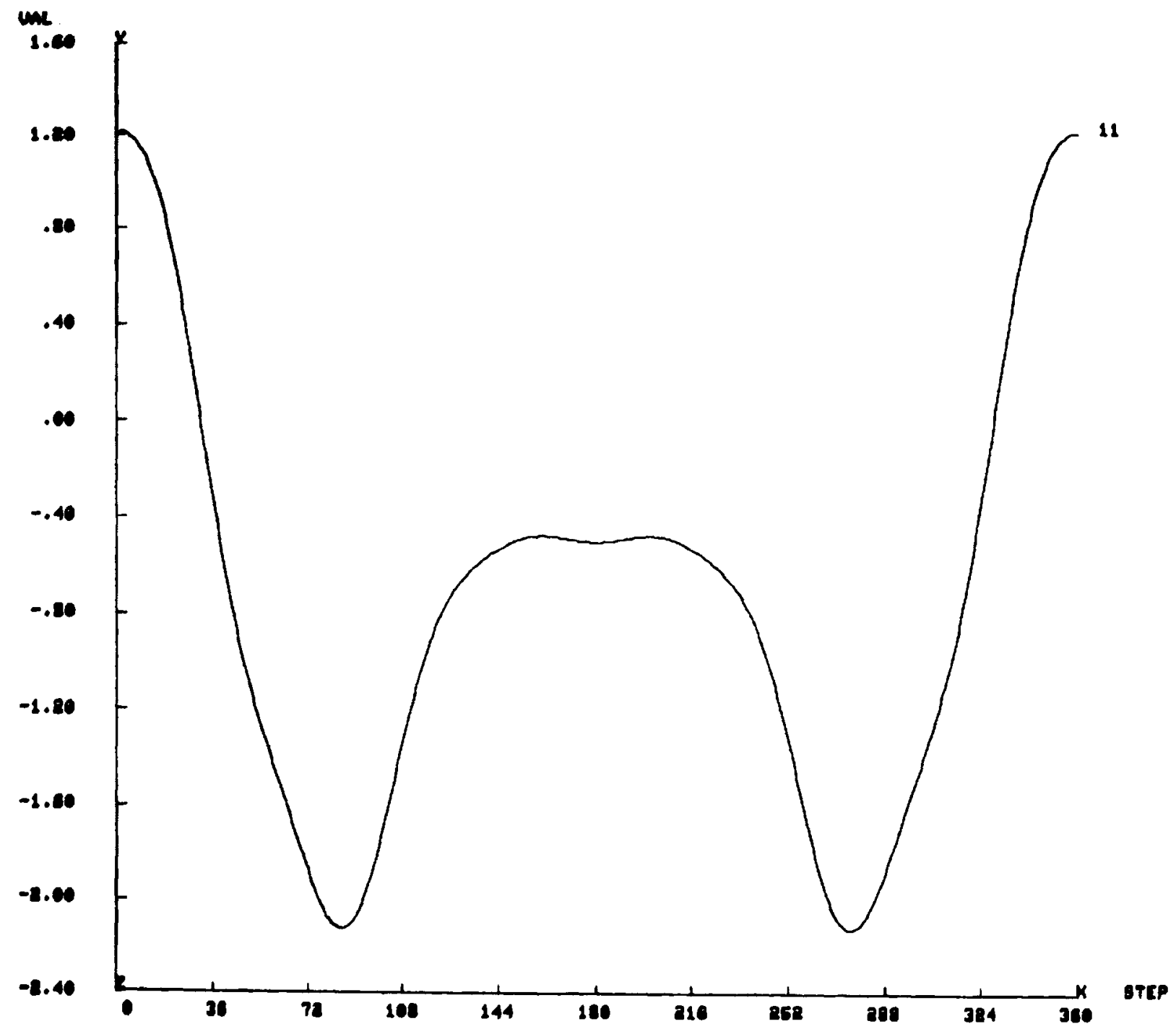

FIGURE 23. Scaled and Summed Terms in Fourier Series Used to Approximate Equivalent External Pressure During Tornado Wind Loading 
was restricted to a region from the junction that was within $4 \%$ of the tank height. Figure 24 illustrates the equivalent stresses present at this junction under conditions of 1,2 and 3 psi net external pressure. Under conditions of wind loading plus 50\% pressure drop, yielding occurred consistently at circumferential locations of $0,30,60,90$ and 120 degrees with respect to equivalent stresses. In this scenario both meridional bending stresses and hoop stresses exceeded yield in the dome as well as dome-wall junction. However, it should be noted that the internal framing, a significant structural support, was not included in the model. In addition, the highest strains were on the order of .5\% which would preclude catastrophic failure. Several things should be considered at this point. Although possịble, failure at the dome-wall junction is not likely from a single occurrence of overpressurization. A more plausible scenario to investigate might be fatigue failure due to pressure cycling. It is also important to consider the location of the excessive stresses. This scenario indicates that occurrence is usually a local phenomena occurring at the dome-wall junction or a phenomena which is restricted to the dome. Under such adverse tornado conditions, failure in the dome may take the form of gross yielding without any danger of spillage of the tank contents. Failure of the dome, if it should occur, would relieve the pressure buildup, and while problems of vaporizing LNG would exist, a catastrophic tank failure would be avoided. 


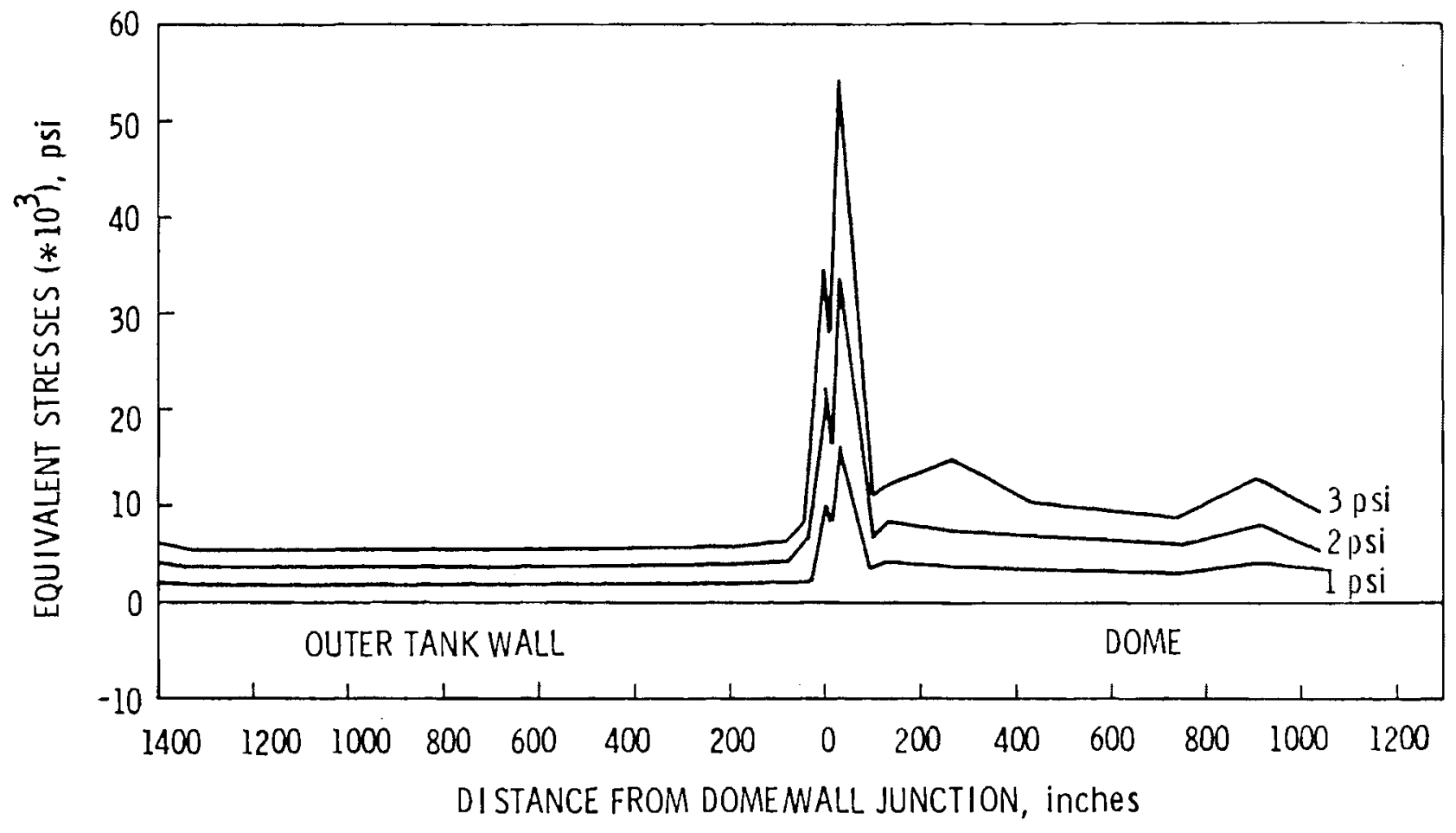

FIGURE 24. Equivalent Stresses at the Dome/Wall Junction for Net External Pressures of 1,2 and 3 psi 


\section{REFERENCES}

1. AGA Project IU-2-1, "A Report on LNG Safety Research", Vol. 1, Arthur D. Little, Inc., Cambridge, Mass, Jan. 1971, p. 41.

2. U.S. Nuclear Regulatory Commission Regulatory Guide 1.76, "Design Basis Tornado for Nuclear Power Plants", April 1974.

3. Thom, H.C.S., "Tornado Probabilities", Monthly Weather Review, Oct.-Dec. 1963, pp. 730-736.

4. Sachs, Peter, Wind Forces in Engineering, 2nd Edition, Pergamon Press, New York, 1978, pp. 49-51.

5. ANSI A58.1, "Building Code Requirements for Maximum Design Loads in Buildings and Other Structures", 1972.

6. Sun, C.N., E.G. Burdette, N.H.L. Perry, "Tornado Wind Forces on Structures", Structural Design of Nuclear Plant Facilities, Vol. 1-A, Nuclear Structures and Materials Committee, ASCE, New York, Dec. 1975, pp. 430-431.

7. U.S. Nuclear Regulatory Commission Standard Review Plan, Section 3.3.2, "Tornado Loadings", 1975.

8. Fecht, B.A., "Results in Support of LNG Storage Tank Analysis", Battelle Northwest Laboratories, November 1981.

9. De Salvo, G.J. and J.A. Swanson, ANSYS Engineering Analys is User's Manual, Revision 3, Update 67L, Swanson Analysis Systems, Houston, PA, JuTy 1979. 
IMPACT

Discussion

This scenario is restricted to the examination of the most common type of missile impact, that resulting from objects transported by commercially available weapons or those hurled by tornado winds. The damage possible is dependent on the missile velocity, flight path, mass and manner of projection (i.e., whether it rotates, tumbles, etc.). Because of their extremely high velocities, bullets are investigated initially, followed by the investigation of other potential penetrators such as telephone poles, pipes, and autos. Generally these higher mass "missiles" are not of great concern since their velocities are quite low and their energy is transmitted over a large area of ductile material. The tank could well buckle but not likely result in a failure associated with large releases of LNG.

The possibility of an airplane impacting an LNG tank was not considered in this report. Calculations based on the number of fatal crashes, the area of the U.S. and the area of a typical LNG tank yield an expected number of airplane crashes at any random site as $5 \times 10^{-11}$ per hour. For LNG sites located near major airports, the risk is greater and should perhaps be investigated. (1)

Most of the formulas developed to date to calculate penetration or perforation of steel targets are empirical in nature. In addition, the results obtained from such calculations are not always in agreement. This occurs, in part, because of the simplifying assumptions made. Typical assumptions, and those which are also incorporated here, include a normal incidence at impact, a ductile failure of the target and a nondeforming projectile. 
Analyses

Missile Impact - Bullet

Figure 25 illustrates results of a test sequence where various stee 1 plates were perforated by soft conically-nosed bullets having initial velocities between $2500 \mathrm{ft} / \mathrm{sec}$ and $2600 \mathrm{ft} / \mathrm{sec}$. Bullet diameters, lengths and weights were $0.256 \mathrm{in.}, 1.36 \mathrm{in}$. and 0.02 pounds, respectively. Assuming normal incidence to occur near ground level when firing from ground level, one would expect a terminal velocity of approximately $500 \mathrm{ft} / \mathrm{sec}$ after penetrating the $0.5625 \mathrm{in}$. outer tank wal1. This terminal velocity would be reduced while travelling through the perlite and, due to reduced velocity and bullet deformation, would not possess a velocity great enough to perforate the inner tank wall (.795 in.) as suggested by Figure 25.

An energy procedure outlined by Goldsmith ${ }^{(2)}$ enables one to compute the residual velocity of a penetrator by calculating the mechanical work done:

$$
W=w_{s t}+w_{D}
$$

where

$$
\begin{aligned}
W_{S t} & =\text { static work of plastic deformation } \\
W_{D} & =\text { dynamic work }
\end{aligned}
$$

The relationship for $W_{S t}$ and $W_{D}$ are derived, with the resulting work equation for an ogive configuration being:

$$
W=\pi h_{0} R\left[1.86 \rho\left(\frac{V_{1} R}{L}\right)^{2}+\frac{1}{2} \sigma_{y}\right]
$$

where

$$
\begin{aligned}
h_{0} & =\text { plate thickness } \\
R & =\text { penetrator radius } \\
\rho & =\text { penetrator density } \\
V_{1} & =\text { striking velocity } \\
L & =\text { penetrator nose length } \\
\sigma_{y} & =\text { yield strength of target }
\end{aligned}
$$




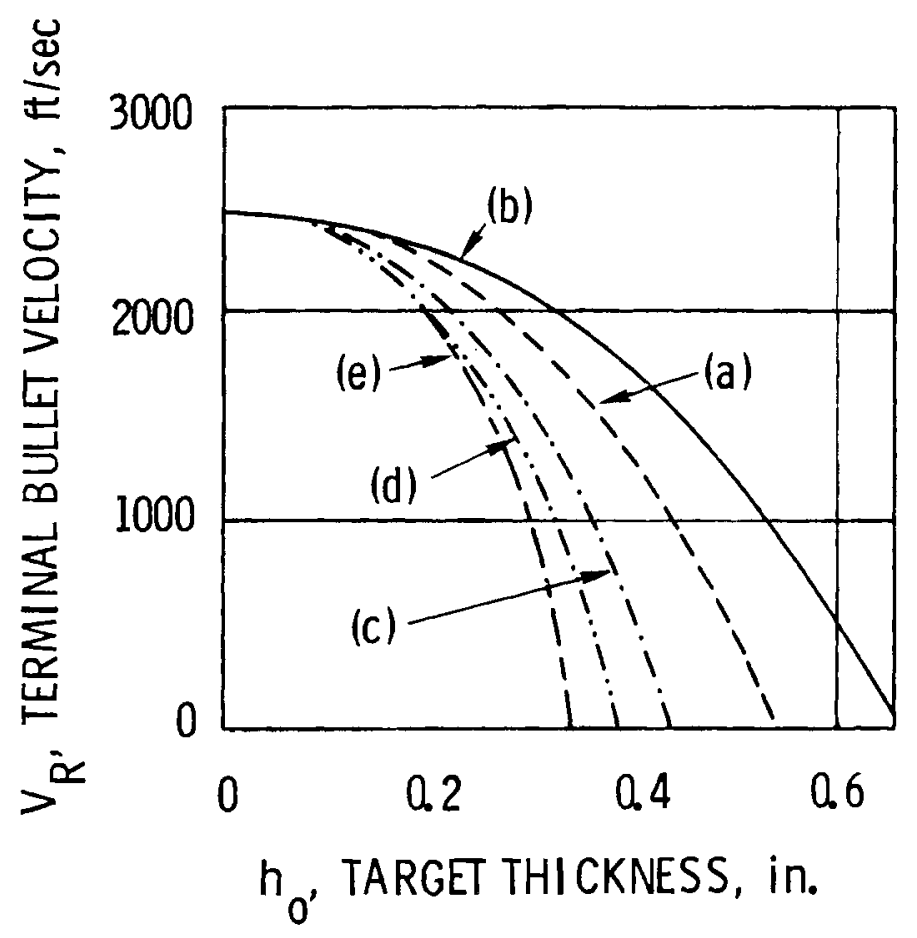

FIGURE 25. Terminal Velocity of Soft, Conically-Nosed Bullets After Perforating Metallic Targets (2), (a) Single Plate of Mild Steel, (b) Laminated Plate of Same Thickness of (a), Laminations $1 \mathrm{~mm}$ Thick, (c) One Plate of Alloy Steel and Thickness $h_{0}$, (d) Two Plates of Alloy Steel, Each of $t=1 / 2 h_{0}, 2.54 \mathrm{in}$. Apart, (e) Two Plates of Alloy Steel, Each of $\mathrm{t}=1 / 2 \mathrm{~h}_{0}, 7.9 \mathrm{in}$. Apart. 
Assuming a .30 caliber bullet traveling at $3000 \mathrm{ft} / \mathrm{sec}$ with a weight of between 150 and 180 grains, and a plate thickness of 0.5625 in., the mechanical work done is approximately $11,3001 \mathrm{~b}$ in. This yields a residual bullet velocity of approximately $2580 \mathrm{ft} / \mathrm{sec}$.

Using a similar procedure and identical specifications, the residual velocity for a conical nose configuration is approximately $2760 \mathrm{ft} / \mathrm{sec}$. The mechanical work done was calculated from: ${ }^{(2)}$

$$
W=\pi h_{0} R\left[\rho\left(\frac{V_{1} R}{L}\right)^{2}+\frac{1}{2} \sigma_{y}\right]
$$

A momentum procedure, which appears to produce results correlating better with experimental results for penetrators with higher velocities, is given for an ogive nose configuration. (2)

$$
[\Delta V]_{f}=V_{1}-V_{f} \approx \frac{\pi \rho h_{0} R^{2}}{m} V_{1} \sin \alpha
$$

where

$$
\begin{aligned}
& m=\text { mass of penetrator } \\
& \alpha=\frac{1}{2} \text { included angle at penetrator nose. }
\end{aligned}
$$

The calculated residual velocity of the penetrator was approximately $2480 \mathrm{ft} / \mathrm{sec}$. It is important to note that in addition to the simplifying assumptions made, frictional heating effects, energy in elastic and plastic waves and possible cracks are also neglected and may not be insignificant. (2)

The BRL (Ballistic Research Laboratories) formula for calculating the velocity needed to perforate steel plate is given as: $(3)$

$$
\mathrm{T}^{3 / 2}=\frac{0.5 M V^{2}}{17,400 \mathrm{~K}^{2} \mathrm{D}^{3 / 2}}
$$

where

$$
\begin{aligned}
& T=\text { plate thickness } \\
& M=\text { missile mass } \\
& D=\text { missile diameter } \\
& K=\text { constant depending on grade of steel, usually } \approx 1 \\
& V=\text { initial penetrator velocity } \\
& B .56
\end{aligned}
$$


Solving for $V$ :

$$
V=\sqrt{\frac{17,400 T^{3 / 2} \cdot K^{2} \cdot D^{3 / 2}}{0.5 M}}
$$

and using the identical bullet and target specifications as previously defined, the minimum velocity needed to perforate steel plate, 0.5625 in. thick, is approximately $1773 \mathrm{ft} / \mathrm{sec}$.

Perhaps the critical question is whether these penetrators will perforate the inner tank wall. To shed some light on the energy losses through perlite, two relationships are presented. These relationships allow estimates of residual velocities of bullets traveling through dry and wet sand and in the second case adapt an equation for calculating residual velocities of bullets passing through water.

Figure 26 illustrates the relationship between target thickness and residual bullet velocity for a bullet traveling through sand. (2) Kimsey (4) provides a formula for calculating residual velocities of penetrators traveling through a water medium. The equation was altered to reflect densities and drag coefficients that might more closely simulate a perlite medium. The equation appears as: ${ }^{(4)}$

$$
\frac{V_{R}}{V_{S}}=e^{-\left(\frac{C_{D} P_{W} t}{2 \rho_{P} L \cos \theta}\right)}
$$

where

$$
\begin{aligned}
V_{R} & =\text { residual penetrator velocity } \\
V_{S} & =\text { striking velocity } \\
C_{D} & =\text { drag coefficient } \\
P_{W} & =\text { density of medium } \\
\rho_{P} & =\text { penetrator density } \\
t & =\text { distance between exit and extrance of medium } \\
\theta & =\text { angle of obliquity } \\
L & =\text { penetrator length }
\end{aligned}
$$




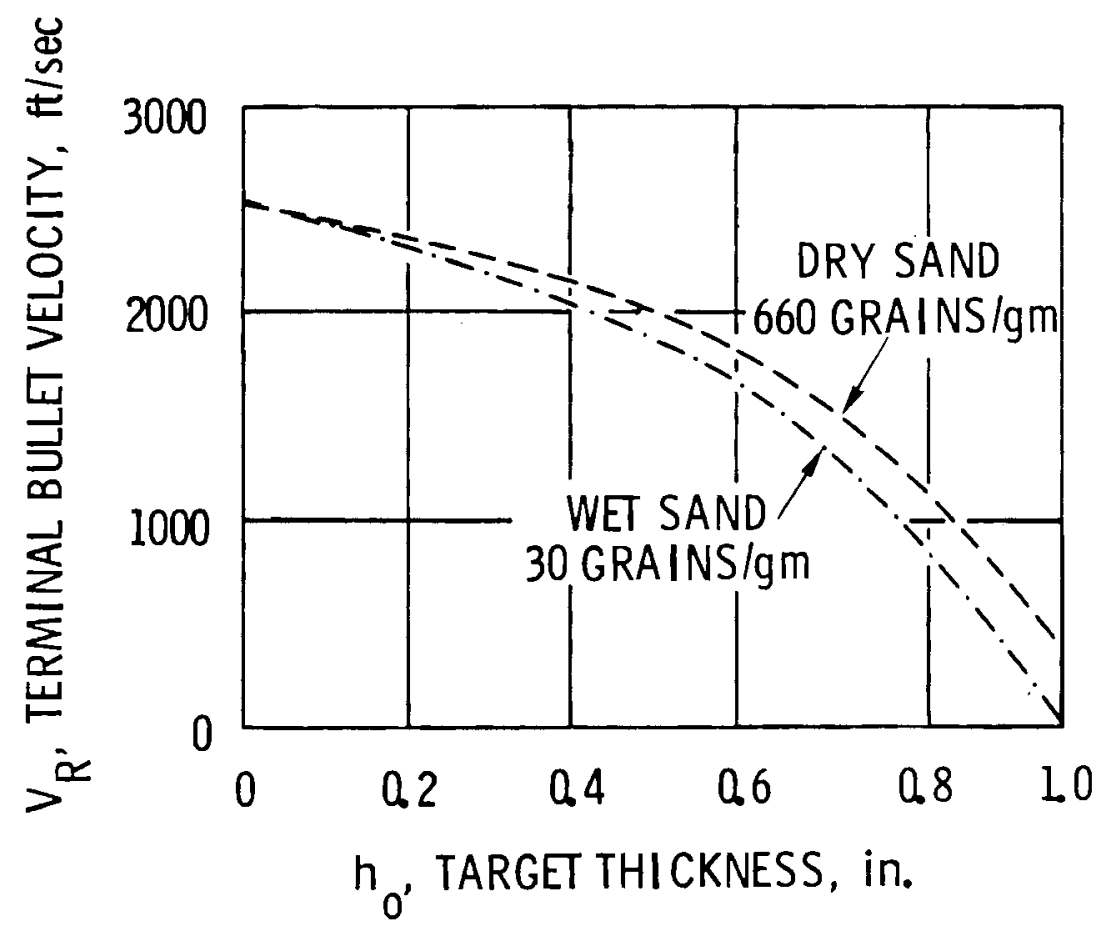

FIGURE 26. Terminal Velocity of Soft, Conically-Nosed Bullets After Perforating Non-Metallic Targets (2) 
At a striking velocity of $2500 \mathrm{ft} / \mathrm{sec}$, the residual velocity is approximately $1600 \mathrm{ft} / \mathrm{sec}$. According to the BRL formula, however, the minimum velocity required to perforate the inner tank at a thickness of 0.795 inches is over $2000 \mathrm{ft} / \mathrm{sec}$.

In experiments where .50 caliber tracer bullets were fired into single wa11 9\% Nickel steel tanks, perforation occurred but no ignition resulted. In performing similar experiments on double-wall tanks, the .50 caliber armor-piercing bullets passed through the outer tank and four feet of insulation to merely dent the inner tank. (1) However, it becomes evident that through utilizing the appropriate weapon, the inner tank could be penetrated. This does not assume a large immediate hazard since there is no combustible mixture locally present and there is no evidence to assume a propagating crack would result.

\section{Missile Impact - Tornado Generated}

Peak tornado missile velocities are determined by Lee ${ }^{(5)}$ assuming the missile travels with respect to the circular tornado vortex path and that it accelerates as long as it remains with the maximum tangential wind speed. The ejection velocity is given as: (5)

$$
\begin{aligned}
& \dot{x}^{4}\left(1-\frac{c_{1}}{2}\right)^{2}+\dot{x}^{3}\left[2 c_{1} v_{m}\left(1-\frac{c_{1}}{2}\right)\right]+\dot{x}^{2}\left[c_{1}^{2} v_{m}^{2}-2 \rho_{a} v_{m}^{2}\right. \\
& \left.\left(1-\frac{c_{1}}{2}\right) c_{4}-\frac{c_{3}^{2} v_{r}^{2}}{4}\right]+\dot{x}\left[-2 c_{1} \rho_{a} v_{m}^{3} c_{4}+\frac{c_{3}^{2} v_{r}^{2} v_{m}}{2}\right]+ \\
& \rho_{a}^{2} v_{m}^{4} c_{4}-\frac{c_{3}^{2}}{4} v_{r}^{2}\left(v_{m}^{2}+v_{r}^{2}\right)=0 .
\end{aligned}
$$


where

$$
\begin{aligned}
& K_{1}=\frac{C_{L} A_{p}}{W} \\
& K_{2}=\frac{C_{d} A_{p}}{W} \\
& C_{1}=R_{a} g K_{1} \\
& C_{2}=R_{g} K_{1} \\
& C_{3}=R \rho_{a} g K_{2} \\
& C_{4}=\frac{1}{\rho_{m}}+\frac{C_{2}}{2}
\end{aligned}
$$

and

$$
\begin{aligned}
& C_{L}=1 \text { ift coefficient } \\
& C_{d}=\text { drag coefficient } \\
& \rho_{m}=\text { mass of missile } \\
& \rho_{a}=\text { mass density of air } \\
& R=\text { radius of funnel cloud surface } \\
& V_{m}=\text { maximum tangential wind speed } \\
& V_{r}=\text { radial wind speed } \\
& A_{p}=\text { projected missile area } \\
& W=\text { weight of missile }
\end{aligned}
$$

The peak tornado missile velocity is given by the equation of motion assuming linear path accelerations:

$$
\dot{x}=\frac{C_{d} A_{p}}{W} \frac{\rho_{a} g\left(V_{m}-\dot{x}\right)^{2}}{2}
$$

The solution of this differential equation is found as: (6)

$$
\frac{V_{m}}{V_{m}-\dot{x}}-\ln \frac{V_{m}}{V_{m}-\dot{x}}=\frac{C_{d} A_{p}}{W} \frac{\rho_{a} g x}{2}
$$


Table 4 gives perforation thicknesses due to the impact of certain velocities for the DW metal tank. The missiles were assumed to strike the target normal to the surface and with their axes parallel to the line of flight.

The outer wall of the metal DW tank varies in thickness as a linear function of tank height. The thicker end is at the bottom with the wall thinning out at the top. For the tank being studied the thicknesses are:

$$
\begin{aligned}
T_{\text {metal, wall }} & =.5625 \text { inch at the bottom } \\
& =.50 \text { inch at the top } \\
T_{\text {metal, roof }} & =.25 \text { inch }
\end{aligned}
$$

The tank walls consist of an outer wall, a thick layer of insulation (perlite) and an inner tank wall which contains the LNG. Perforation thickness calculations were make for perforation of the outer wall only. Sufficient information was not available to calculate the reduction in velocity due to perlite insulation and whether existence of this material would prevent perforation of the inner tank.

From the results, it appears that objects hurled by tornado winds will not perforate the outer wall of the metal tank. Penetration with tornado hurled missiles is possible on the roof but at such heights it is unlikely for above-ground tanks.

Objects hurled by rotating machinery or some pressurized system have enough momentum to perforate the outer tank walls. And from the calculated thicknesses it seems likely that these objects may perforate the inner tarik. wall also. 
TABLE 4. Summary of Effects on DW Metal Tank by Postulated Missiles.

\begin{tabular}{|c|c|c|c|c|c|c|}
\hline \multicolumn{2}{|r|}{ MISS ILE OBJECT } & \multicolumn{2}{|c|}{$\begin{array}{l}\text { VELOCITY } \\
\text { (ft./sec.) } \\
\text { (lb.) }\end{array}$} & $\begin{array}{l}\text { DIAMETER: } \\
\text { (in) }\end{array}$ & $\begin{array}{l}\text { AREA } \\
\left(\mathrm{in}^{2}\right)\end{array}$ & $\begin{array}{c}\text { PERFORATION THICKNESS } \\
\text { (inches) }\end{array}$ \\
\hline & $1^{\prime \prime} \emptyset \times 3^{\prime}$ Steel $\operatorname{Rod}^{(2)}$ & 200 & 8.05 & 3.0 & .785 & 0.4 \\
\hline & $3^{\prime \prime} \emptyset \mathrm{SCH} 40$ Pipe $-15^{\prime}$ long ${ }^{(2)}$ & 130 & 114 & 3.5 & 7.07 & 0.4 \\
\hline 3) & 6" $\emptyset \mathrm{SCH} 40$ Pipe - 15' long ${ }^{(2)}$ & 155 & 285 & 6.63 & 28.3 & 0.5 \\
\hline 4) & $12^{\prime \prime} \emptyset \mathrm{SCH} 40$ Pipe - 15' long ${ }^{(2)}$ & 75 & 800 & 12.75 & 113 & 0.2 \\
\hline & 8" $\emptyset$ slug (solid cylinder) & 800 & 213 & 8.0 & 50.3 & 0.8 \\
\hline 6) & 8" sphere & 262 & 75 & 8.0 & 50.3 & 0.35 \\
\hline & $25.6 " \varnothing$ sphere & 200 & 2500 & 25.6 & 514.7 & 0.8 \\
\hline 8) & Nozzle & 670 & 250 & 9.03 & 64 & 2.4 \\
\hline 9) & Structural column & 220 & 36000 & 9.8 & 75 & 1.1 \\
\hline Iü) & Small fragment & 900 & 20 & 2.8 & 6 & 2.1 \\
\hline 11) & Large Fragment & 750 & 100 & 1.6 & 2 & 0.7 \\
\hline 12) & Cover plate & 300 & 850 & 11.3 & 100 & 1.5 \\
\hline 13) & Valve & 420 & 500 & 1.5 & 1.7 & 12.5 \\
\hline 14) & Valve & 500 & 300 & 1.3 & 1.3 & 12.8 \\
\hline 15) & Pipe & 180 & 200 & 4.5 & 16 & 0.7 \\
\hline
\end{tabular}

1) Thickness that a given missile will just perforate

2) Objects that are tornado incuded 


\section{REFERENCES}

1. AGA Project IU-2-1, "A Report on LNG Safety Research", Vol. 1, Arthur D. Little, Inc., Cambridge, Mass., January 1971, pp. 44-45, 28-29.

2. Goldsmith, Werner, Impact: The Theory and Physical Behavior of Colliding Solids, Edward Arnold Publishing, Ltd., London, 1960, pp. 240-248, 296-307.

3. Gwaltney, R.C., "Missile Generation and Protection in Light-Water Cooled Power Reactor Plants", Nuclear Safety Information Center, Oak Ridge National Lab, Oak Ridge, TN, 1968, p. 34.

4. Kimsey, K.D., "Numerical Simulation of Hydrodynamic Ram", U.S. Army Ballistic Research Lab, Aberdeen Proving Ground, MD, pp. 100-102.

5. Lee, A.J.H., "A General Study of Tornado Generated Missiles", Structural Design of Nuclear Plant Facilities, Vol. II, ASCE, New York, 1974.

6. Miller, D.R. and W.A. Williams, "Tornado Protection for the Spent Fuel Storage Pool", APED-5696 Class I, General Electric, San Jose, CA, Nov. 1968. 
$\underline{\text { FIRE }}$

Discussion

If the outer tank is exposed to a heat source simulating fire conditions, several points of concern arise. For instance, the yield strength of the outer metal tank wall decreases with increasing temperatures while the thermal conductivity of the insulation material increases.

From information provided by Preload Company, ${ }^{(1)}$ the outer surface wal1 temperatures at equilibrium were determined where the radiation heat influx was $4755 \mathrm{BTU} / \mathrm{sq} \mathrm{ft}-\mathrm{hr}$. To further support this analysis the heat flux radiation rate on the tank due to an adjacent tank fire was determined. In a separate analysis the error function or Gauss' error integral was used to determine the temperature history for the outer wall under the conditions established above. A time-temperature history at varying locations through the perlite insulation region was also obtained using the FEM code, ANSYS. And finally, assuming a uniform temperature distribution at specific locations, thermal strains with resulting edge bending stresses and deflections were determined.

\section{Analyses}

\section{Outer Tank Surface Temperature Under Fire Conditions - Steady State}

Assuming steady state conditions at $t=\infty$, the heat flux due to radiation at the outer tank wall surface must equal the heat removed by re-radiation to the surroundings, by convection and by conduction through the walls and insulation. This suggests the following relationship: (1)

$$
Q_{R}=Q_{R R}+Q_{\text {conv }}+Q_{\text {cond }}
$$

where

$$
\begin{aligned}
Q_{R} & =4755 \text { BTU/sq ft-hr } \\
Q_{R R} & =\sigma \varepsilon\left(T_{E}^{4}-T_{0}^{4}\right) \\
Q_{\text {conv }} & =h\left(T_{E}-T_{A I R}\right)^{4 / 3} \\
Q_{\text {cond }} & =\frac{T_{E}-T_{A I R}}{R_{\text {TOT }}}
\end{aligned}
$$


where

$$
\begin{aligned}
T_{E} & =\text { equilibrium temperature of wall surface at } t=\infty \\
T_{0} & =\text { temperature of surrounding environment } \\
T_{A I R} & =\text { temperature of the air } \\
\sigma & =\text { Stephen-Boltzmann constant, } 0.1713 \times 10^{-8} \\
\varepsilon & =\text { emissivity of steel, } 0.80 \\
h & =\text { convection heat transfer coefficient } \\
R & =\text { thermal resistance, } \frac{t}{k} \\
t & =\text { thickness of conducting material } \\
k & =\text { thermal conductivity }
\end{aligned}
$$

The assumption that a unit surface of the vertical cylinder is exposed to a turbulent boundary layer yields the following equilibrium equation:

$$
\begin{aligned}
4755 \mathrm{BTU} / \mathrm{sq} \mathrm{ft}-\mathrm{hr} & =1.37 \times 10^{-9}\left(T_{E}^{4}-530^{4}\right)+0.19\left(T_{E}-70\right)^{4 / 3} \\
& +\frac{\left(T_{E}-70\right)}{176.44}
\end{aligned}
$$

Solving the equation for the equilibrium temperature yields a wall surface temperature of approximately $810^{\circ} \mathrm{F}$. Although this temperature produces an $8 \%$ decrease in yield strength for carbon steels in general, (2) the outer tank stresses under in-service loading conditions on ly experience stresses up to approximately half of the reduced value.

To further investigate the radiation flux utilized in the previous analysis, the heat flux radiation rate on the tank due to an adjacent fire was determined based on procedures developed by Parker. (3) It should be noted that this procedure is based on experimental evidence from smal 1 fires (e.g., $6 \mathrm{ft}$ and $20 \mathrm{ft}$ diameters) under varying conditions (i.e., wind speed and direction, temperature, R.H, pp $\mathrm{H}_{2} \mathrm{O}$ ). Figure 27 illustrates dimensions relative to flame height and angle and respective distances between tanks. Much of this information was obtained from radiant-interchange configuration factors developed by the National Advisory Committee 


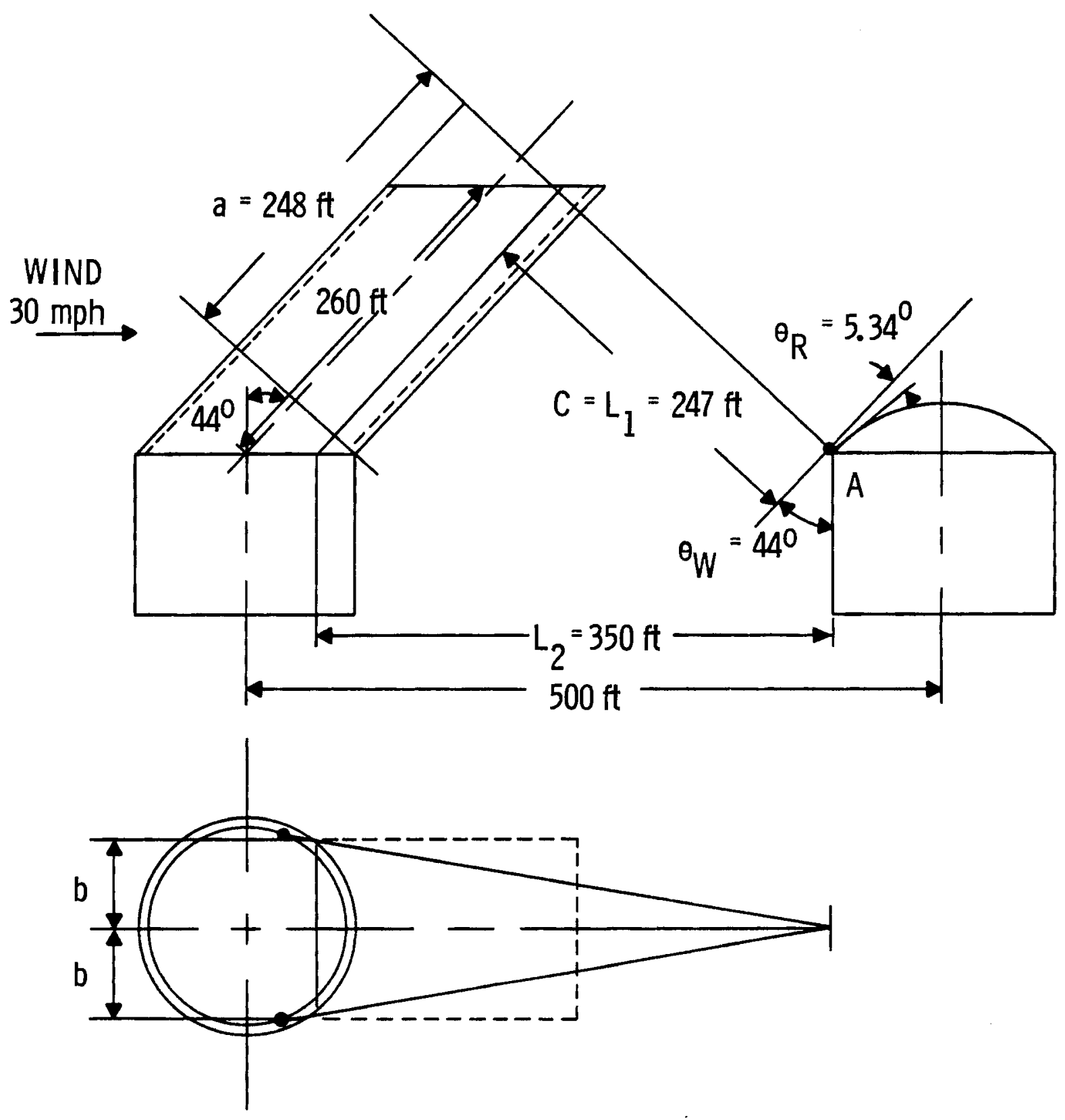

FIGURE 27. Flame and Tank Dimensions Required for Determining Radiation Interception Rate at Point $A$ 
for Aeronautics. (4) Reference 5 presents detailed calculations. The range of values suggested for the radiative flux from an LNG fire is 31,500 to $56,000 \mathrm{BTU} / \mathrm{sq} \mathrm{ft}-\mathrm{hr}$. (3) Through calculating the radiative output:

$$
\begin{aligned}
\dot{Q} & =\pi r^{2} y r(\Delta H) \zeta \\
& =5.022 \times 10^{9} \text { BTU } / \mathrm{hr}
\end{aligned}
$$

the radiative flux for the given tank and fire conditions was:

$$
W=\frac{\dot{Q}}{2 \pi r L}=34,045 \mathrm{BTU} / \mathrm{sq} \mathrm{ft} \mathrm{hr}
$$

which fell within the suggested range.

For the above equations:

$$
\begin{aligned}
r & =\text { tank radius, } 90.3 \mathrm{ft} \\
y & =1 \text { iquid regression rate, } 1.64 \mathrm{ft} / \mathrm{hr} \\
\gamma & =\text { density of liquid } \mathrm{LNG}, 29.3 \mathrm{lb} / \mathrm{ft} \\
\Delta \mathrm{H} & =\text { heat of combustion, } 20,400 \mathrm{BTU} / 1 \mathrm{~b} \\
\zeta & =\text { fraction of total combustion energy } \\
\mathrm{L} & =\text { calculated flame length }
\end{aligned}
$$

The radiative heat intercept rate at the point designated in Figure 27 was determined by: ${ }^{(3)}$

$$
Q=\varepsilon \tau F W \cos \theta
$$

where

$$
\begin{aligned}
E= & \text { absorptivity of wall, } 0.8 \\
\tau= & \text { transmissibility of air at } 70^{\circ} \mathrm{F} \text { and } 80 \% \mathrm{RH}(0.51 \text { for partial } \\
& \text { pressure of } \mathrm{H}_{2} \mathrm{O} \text { in air }=0.020 \text { ata), mean beam length = } \\
& 294 \mathrm{ft} \text { (see Ref. } 4 \text { ) } \\
\mathrm{F}= & \text { view factor, } 0.05270 \text { (see Ref. 4) } \\
\theta= & \text { intercept angle }
\end{aligned}
$$


The heat intercept rate for the given point on the tank wall was:

$$
Q=34,045(0.8)(0.51)(0.1054) \cos 44=1053 \mathrm{BTU} / \mathrm{hr}-\mathrm{sq} \mathrm{ft}
$$

The heat intercept rate for the given point on the roof was:

$$
Q=34,045(0.8)(0.51)(0.1054) \cos 5.34=1458 \mathrm{BTU} / \mathrm{hr}-\mathrm{sq} \mathrm{ft}
$$

These values are well below the intercept rate used in the analysis to determine tank surface temperature in part 1 . In fact, a heat intercept rate of 2000 BTU's/hr-sq ft would result only in a surface temperature of approximate 1 y $550^{\circ} \mathrm{F}$.

\section{Outer Tank Time-Temperature Profile Under Fire Conditions}

In establishing a time-temperature history for the outer tank wall, several assumptions were made. Among the assumptions was that the cylinder was a semi-infinite solid body at an initial uniform temperature and was subsequently exposed to a sudden surface heat source of $810^{\circ} \mathrm{F}$ (calculated in previous section). The plate was considered to be thermally thin having an insufficient internal thermal resistance to support a temperature gradient. Insulated surfaces, an infinite surface heat transfer coefficient and no convection paths were also assumed. The transient temperature distribution for this idealized semi-infinite body is: ${ }^{(6)}$

$$
\frac{T-T_{i}}{T_{f}-T_{i}}=\left[\operatorname{erfc}\left(\frac{x}{2 \sqrt{\alpha t}}\right)-\exp \left(\frac{x h}{K}+\frac{\alpha t}{(K / h)^{2}}\right) \operatorname{erfc}\left(\frac{x}{2 \sqrt{\alpha t}}+\frac{\sqrt{\alpha t}}{(K / h)}\right)\right]
$$

where

$$
\text { erfc } \equiv 1-\operatorname{erf}(w) \text {, the complementary error function }
$$

and

$$
\begin{aligned}
& \text { erf }(w)=\frac{2}{\sqrt{\pi}} \int_{0}^{w} e^{-u^{2}} d u \text {, the Gauss error integral } \\
& T_{i}=\text { initial uniform temperature } \\
& T_{f}=\text { final temperature } \\
& h=\text { surface heat transfer coefficient }
\end{aligned}
$$


Noticing that as $h$ approaches infinity, the transient temperature distribution for an idealized semi-infinite body, initially at $T_{j}$, and undergoing a step change in surface temperature from $T_{i}$ to $T_{f}$, can be expressed as:

$$
\frac{T-T_{i}}{T_{f}-T_{i}}=1-\operatorname{erf}\left(\frac{x}{2 \sqrt{\alpha t}}\right)
$$

To obtain the penetration distance as a function of time, one only need note that the error function approaches one as the argument approaches three (see Table 5 ). In this case the depth $x$ is obtained where $T=T_{j}$, the point at which the temperature still remains at the initial uniform value.

If one sets the argument equal to three, the penetration distance $X$ is found at any point in time for a material of specific thermal diffusivity.

$$
\begin{aligned}
& 3=\left(\frac{x}{2 \sqrt{a t}}\right) \\
& x=6 \sqrt{a t}
\end{aligned}
$$

where

$$
\begin{aligned}
& x=\text { distance from heat source, penetration depth } \\
& \alpha=\text { thermal diffusivity } \\
& t=\text { time }
\end{aligned}
$$

For example, if the outer tank has a thermal diffusivity of 70.56 sq $i n . / h r$, the penetration depth or the extreme location where $T$ remains at $T_{j}$ after one hour of exposure is $13.7 \mathrm{in.}$ Figure 28 illustrates penetration distance versus time for the outer cylinder for any set of initial temperature conditions. 
TABLE 5. Values of Guass' Error Integral ${ }^{(6)}$

\begin{tabular}{|c|c|c|c|c|c|}
\hline$W$ & erf w & $w$ & erf $w$ & W & erf $w$ \\
\hline 0.00 & 0.0000 & 0.4 & 0.4284 & 1.3 & 0.9340 \\
\hline 0.01 & 0.0113 & 0.5 & 0.5205 & 1.4 & 0.9523 \\
\hline 0.02 & 0.0226 & 0.6 & 0.6039 & 1.5 & 0.9661 \\
\hline 0.04 & 0.0451 & 0.7 & 0.6778 & 1.6 & 0.9763 \\
\hline 0.06 & 0.0676 & 0.8 & 0.7421 & 1.8 & 0.9891 \\
\hline 0.08 & 0.0901 & 0.9 & 0.7969 & 2.0 & 0.9953 \\
\hline 0.10 & 0.1125 & 1.0 & 0.8427 & 2.2 & 0.9981 \\
\hline 0.20 & 0.2227 & 1.1 & 0.8802 & 2.5 & 0.9996 \\
\hline 0.30 & 0.3286 & 1.2 & 0.9103 & 3.0 & 1.0000 \\
\hline
\end{tabular}

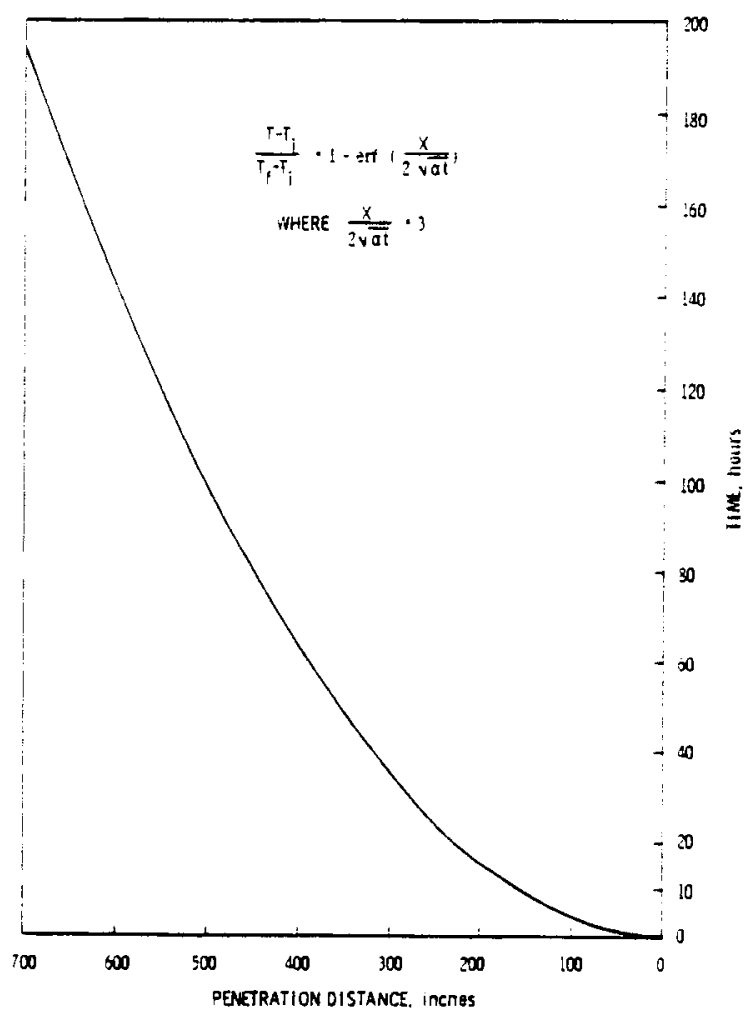

FIGURE 28. Temperature Penetration Distance Versus Time 
Using the same error function procedure, Figure 29 illustrates the temperature history for tank surface locations after an applied point heat source of $810^{\circ} \mathrm{F}$. These locations are simply distances from the applied heat source. Obviously, a fire condition presents a much different thermal loading situation than would be represented by a point source. However, this figure illustrates the local effect of such a sudden increase in temperature. Reference 5 presents detailed calculations.

Still assuming a step change in temperature from $T_{i}$ to $T_{f}$ a simplified means of determining extreme thermal strains is:

$$
\varepsilon_{T}=\alpha(\Delta T)
$$

and applied to the outer tank:

$$
\varepsilon_{T}=\frac{6.5 \times 10^{-6}}{\mathrm{~F}}\left(740^{\circ} \mathrm{F}\right)=4.8 \times 10^{-3} \mathrm{in.} / \mathrm{in} \text {. }
$$

where

$$
\begin{aligned}
\alpha & =\text { thermal expansion } \\
\Delta T & =\text { temperature differential } \\
\varepsilon_{T} & =\text { thermal strain }
\end{aligned}
$$

It is important to note that instantaneous large temperature changes such as imposed here do not occur under typical fire conditions. Even under conditions where one would hypothesize these severe conditions over the entire tank, the resulting stresses are only critical as local bending stresses at the tank bottom. For example, the free radial expansion of the cylinder is: $(7)$

$$
\delta=a \alpha(\Delta T)=1128.3 \times 4.8 \times 10^{-3}=5.42 \text { in. }
$$

If a fixed end is imposed, a moment and shear force result.

$$
\begin{aligned}
& M_{1}=2 a \alpha(\Delta T) \beta^{2} D \\
& Q_{1}=4 a \alpha(\Delta T) \beta^{3} D
\end{aligned}
$$




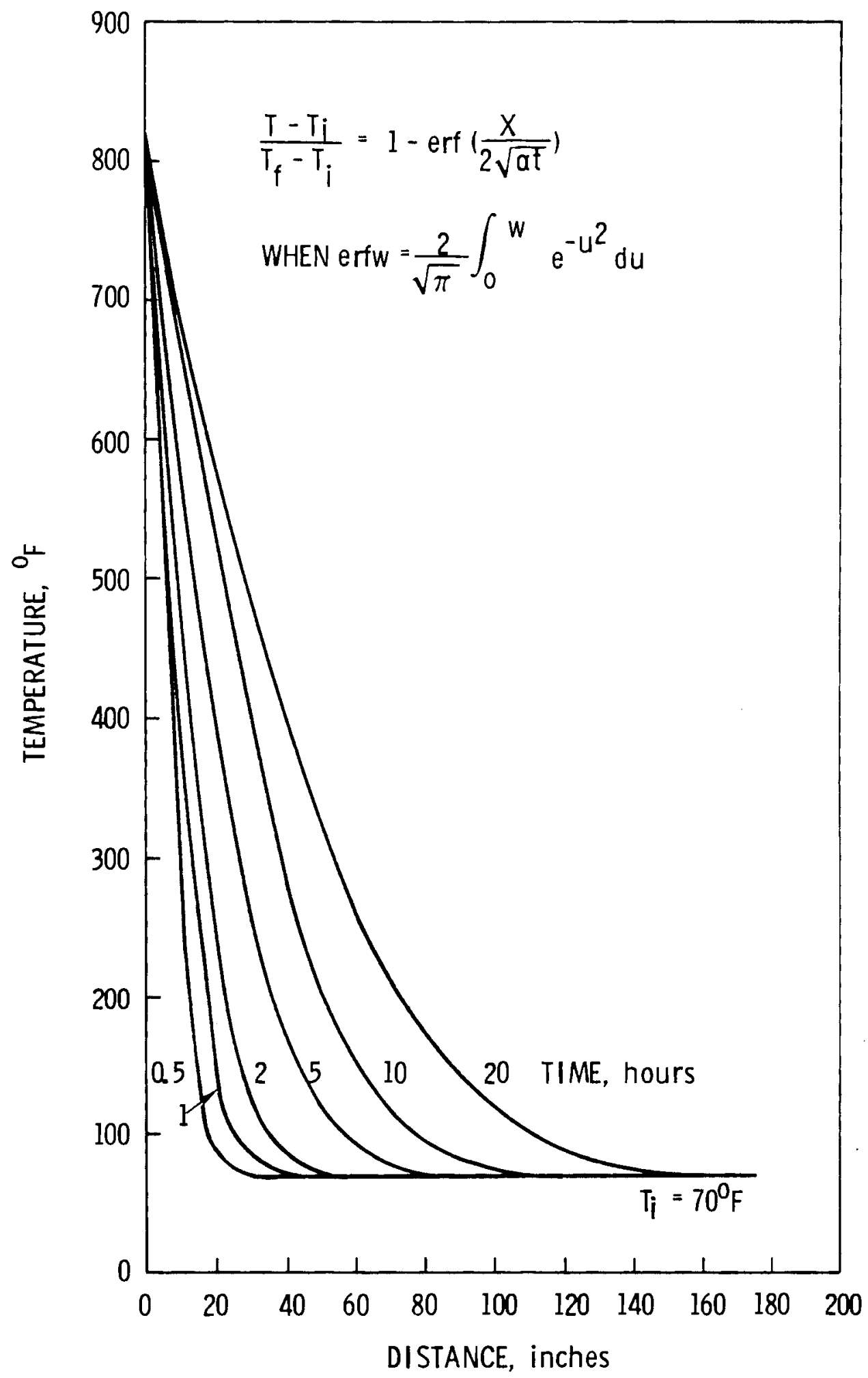

FIGURE 29. Temperature-Time History for Semi-Infinite Solid Under Selected Conditions 
The deflection and moment equations providing stresses at any point along the shell are:

$$
\begin{aligned}
W & =-a \alpha(\Delta T)\left[f_{3}(\beta x)-2 f_{4}(\beta x)\right]-a \alpha(\Delta T) \\
M x & =2 a \alpha \beta^{2} D(\Delta T)\left[f_{1}(\beta x)-f_{2}(\beta x)\right]
\end{aligned}
$$

where

$$
\begin{aligned}
& a=c y l \text { inder radius } \\
& \beta^{4}=\frac{3\left(1-v^{2}\right)}{a^{2} t^{2}} \\
& D=\frac{E t^{3}}{12\left(1-v^{2}\right)} \\
& t=c y l \text { inder thickness } \\
& f 1(\beta x)=e^{-\beta x}(\cos \beta x+\sin \beta x) \\
& f 2(\beta x)=e^{-\beta x} \sin \beta x \\
& f 3(\beta x)=e^{-\beta x}(\cos \beta x-\sin \beta x) \\
& f 4(\beta x)=e^{-\beta x} \cos \beta x
\end{aligned}
$$

The calculated results for specific tank locations are presented in Table 6 for a height up to $250 \mathrm{in}$. It should be noted that these calculations represent rigidly fixed tank bottom boundary conditions and that even these calculations indicate the stresses exceeding yield are within $1 \%$ strain and are very localized. Even if yielding were to occur, failure in the sense of impending endangerment (e.g., vapor or liquid LNG release) would not likely follow. 
TABLE 6. Radial Deflections and Bending Moment at Specified Tank Heights for Cylinder Under Specific Fire Conditions

\begin{tabular}{|c|c|c|}
\hline $\begin{array}{c}\text { Tank } \\
\text { Height }\end{array}$ & Deflection & Moment \\
\hline 0.00000 & -10.85328 & 13962.58919 \\
\hline 10.00000 & -3.51792 & 7344.91186 \\
\hline 20.00000 & -1.45228 & 2668.40361 \\
\hline 30.00000 & -1.93686 & 146.10449 \\
\hline 40.00000 & -3.19513 & -813.12829 \\
\hline 50.00000 & -4.34335 & -908.41771 \\
\hline 60.00000 & -5.09547 & -661.11146 \\
\hline 70.00000 & -5.47073 & -366.39817 \\
\hline 80.00000 & -5.59302 & -145.94135 \\
\hline 90.00000 & -5.58571 & -20.78560 \\
\hline 100.00000 & -5.53371 & 31.01071 \\
\hline 110.00000 & -5.48165 & 40.15714 \\
\hline 120.00000 & -5.44572 & 31.01259 \\
\hline $130: 00000$ & -5.42679 & 18.07773 \\
\hline 140.00000 & -5.41988 & 7.78251 \\
\hline 150.00000 & -5.41947 & 1.63776 \\
\hline 160.00000 & -5.42155 & -1.09678 \\
\hline 170.00000 & -5.42388 & -1.74731 \\
\hline 180.00000 & -5.42558 & -1.44092 \\
\hline 190.00000 & -5.42653 & -.88267 \\
\hline 200.00000 & -5.42691 & -.40676 \\
\hline 210.00000 & -5.42696 & -.10806 \\
\hline 220.00000 & -5.42688 & .03369 \\
\hline 230.00000 & -5.42678 & .07460 \\
\hline 240.00000 & -5.42670 & .06628 \\
\hline 250.00000 & -5.42665 & .04270 \\
\hline
\end{tabular}




\section{Insulation Time-Temperature Profile Under Fire Conditions}

With the assumptions that the inner and outer tank walls would respond to increased temperatures as thermally thin plates, thus acting as capacitive heat sinks, and that the internal thermal resistance would be concentrated in the insulation region which has a conducting path length 50 times greater than either tank wall, a simplified insulation model was defined. The purpose of this model was to obtain a time-temperature profile in the radial direction. The insulation was modeled as a series of 2-D conducting elements which allowed temperature as the single degree of freedom at each node. A thermal analysis option available through the finite element code, ANSYS, (8) was utilized. It allowed temperature dependent thermal property input and provided resulting heat flow rates and nodal temperatures during steady state and transient analyses.

Figure 30 illustrates the time-temperature profile through the insulation as a result of a sudden $810^{\circ} \mathrm{F}$ temperature exposure to the outer edge $(x=0 \mathrm{in.}$.). It was assumed that this edge temperature remained constant through the transient run. In addition, the analysis assumed an infinitely large body of 7 iquid $L N G$ which remained at $-260^{\circ} \mathrm{F}$ providing a constant temperature at $x=44$ in. This transient analysis provides temperature data at various locations through the insulation thickness as a function of time, and appears to indicate that approximately 15 hours elapse under the stated conditions and assumptions before a point $4 \mathrm{in}$. from the inside edge ( $x=44 \mathrm{in}$.) would begin to increase in temperature. 


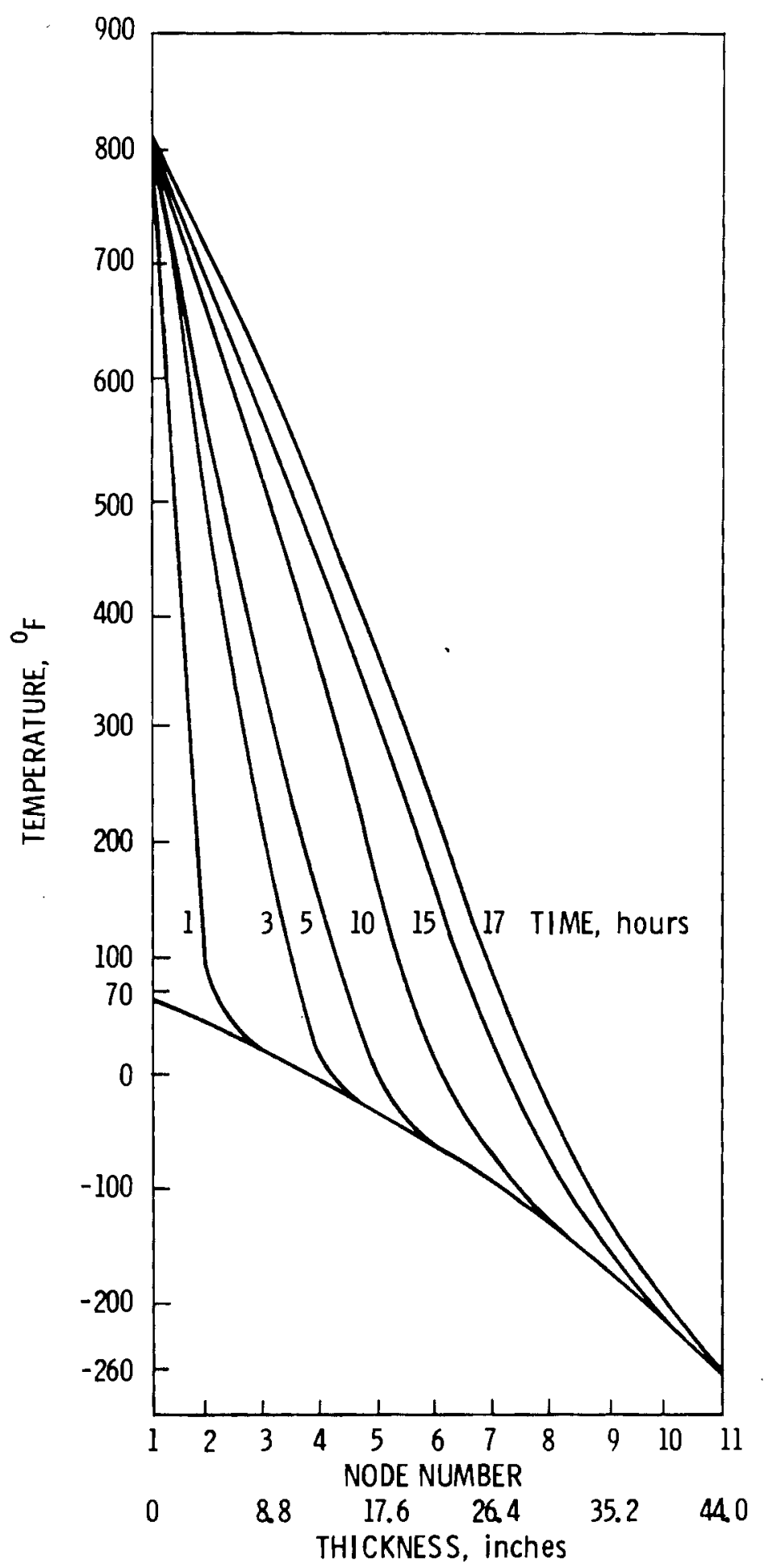

FIGURE 30. Temperature-Time Profile for Perlite Insulation Located Between Tanks 


\section{REFERENCES}

1. Marchaj, T.J., personal communication, The Preload Company, Inc., Garden City, NY.

2. Metals Handbook - 9th Edition, Vol. 1, "Properties Selection: Irons and Steels", ASM Handbook Committee, Metals Park, OH, 1978, p. 651.

3. Parker, R.0., "Radiation From LNG Fires", Final Report on AGA Project IS-109-1, Feb. 1977.

4. Hamilton, D.C. and W.R. Morgan, "Radiant Interchange Configuration Factors", Technical Note 2836, National Advisory Committee for Aeronautics, Purdue University, 1952.

5. Fecht, B.A., "Results in Support of LNG Storage Tank Analysis", Battelle Northwest Laboratories, November 1981.

6. Rohsenow, W.M. and Harry Choi, Heat, Mass and Momentum Transfer, Prentice Hall Publishers, Englewood Cliffs, NJ, 1961, p. 121.

7. Ugural, A.C., Stresses in Plates and Shells, McGraw-Hill Book Co., New York, 1981, p. 263-266.

8. De Salvo, G.J. and J.A. Swanson, ANSYS Engineering Analysis User's Manual, Revision 3, Update 67L, Swanson Analys is Systems, Houston, PA, July 1979. 


\section{EARTHQUAKE}

\section{Discussion}

Seismic zones have been thoroughly investigated during the 20th century with seismic activity being identified and associated with the earth's elevation gradients. (1) The associated wave has been found to vary and to essentially propagate at speeds directly associated with properties of the transmitting mediums. Two wave types tend to predominate from a fault; the longitudinal waves generally having a higher velocity and smaller amplitude than the transverse waves. In addition, these wave types can generate surface waves of the Rayleigh and Love type. In general, the amplitude of these waves tend to decrease over the propagation distance coupled with a gradual increase in period. In addition, the waves having shorter periods tend to decay more rapidly as one moves from the earthquake epicenter than those having longer periods. This explains the evidence of waves of longer period at points distant from the epicenter. (1)

There have been several attempts to more accurately identify geographic zones associated with a high probability of seismic activity. A typical seismic risk map is shown in Figure 31. It is based on modified Mercalli intensities indicative of known seismic activity and strain release patterns as associated with seismic influenced geologic phenomena. (2) There have been methods used to define intensity levels designated for nuclear power plants and associated with each of these seismic zones. One such example illustrated in Table 7 is that designated by Housner ${ }^{(4)}$ for the OBE (Operating Basis Earthquake) and DBE (Design Basis Earthquake).

TABLE 7. Suggested Earthquake Input (4)

\begin{tabular}{|c|c|c|}
\hline $\begin{array}{l}\text { Se ismic } \\
\text { Zone }\end{array}$ & $\begin{array}{l}\text { Intensity of } \mathrm{OBE} \\
\text { Intensity of ET Centro }\end{array}$ & Intensity of El Centro \\
\hline 3 & 1.0 & 2.0 to 3.0 \\
\hline 2 & 0.5 & 1.0 to 2.0 \\
\hline 1 & 0.25 & 0.5 to 0.75 \\
\hline
\end{tabular}




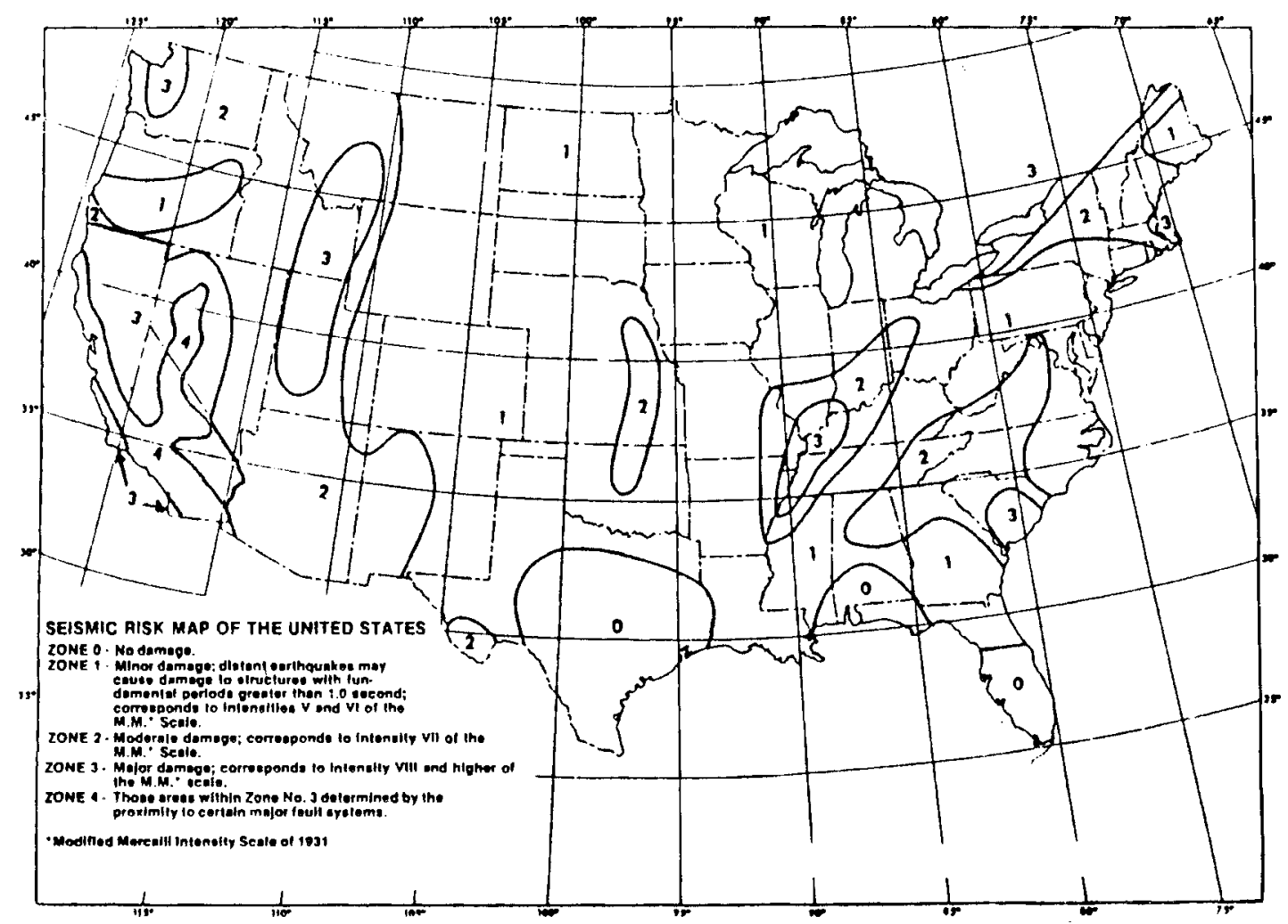

FIGURE 31. Seismic Risk Map of U.S. (3) 
The OBE stipulates a ground motion which could occur during the functional life of the tank. It is most logically correlated with a previous historical event in close proximity to the tank. The plant should function without incident during and following an earthquake of this intensity. The DBE is a maximum potential earthquake where the intensity is as great as would be expected at any future time. The plant should be designed for a safe shutdown in the event of an earthquake of this intensity. (2)

Further work in the area of probability has established the expected number of earthquakes in a selected location during $Y$ years of magnitude greater than $M$. For California this relationship is: (1)

$$
E N=\frac{Y}{370}\left(8 x^{2}-4.69 x^{3}+7.52 x^{4}\right)
$$

where

$$
x=8.7-M
$$

For example, the expected number of earthquake occurrences of magnitude greater than 6 occurring within a 1000 square mile area in 100 years is .66 or one occurrence every 151 years.

Wozniak and Mitche $11^{(5)}$ summarize and categorize the damage which has been done to flat bottom welded steel storage tanks during major earthquake occurrences. Four categories are included. Buckling has occurred at the tank bottom resulting in the "elephant foot" configuration. This has usually been found in unanchored tanks having 10 to 100 foot diameters, and has been caused by meridional compressive stresses resulting from large overturning moments. Sloshing of the liquid has damaged internal roof supports and upper portions of the tank shel1. Differential movements between the tanks and connecting systems (e.g., piping), and failure of the supporting ground have caused damage in isolated instances.

\section{Analyses}

Several approximate methods of determining the response of cylindrical tanks containing liquids have been suggested. A widely used procedure developed by Housner was utilized, (1) followed by suggested alterations to 
to that method. In the procedures followed it was assumed that the 2 tanks act independently of one another and that the analysis was directed at the primary liquid containment barrier.

\section{Dynamic Tank Response Due to Horizontal Seismic Forces}

Housner's procedure assumes an infinitely rigid system when the tank is anchored to a rigid foundation in densely compacted soil. It also assumes the tank under these conditions will acquire the ground accelerations present. The approximate method developed by Housner models tank behavior due to impulsive and convective forces. The impulsive force is that force associated with the shell weight and that portion of the liquid contents that acts as a rigid mass fixed to the shell wall. If one assumes this total mass moves as a rigid body, the mass then exerts a horizontal force proportion to the acceleration seen at the tank bottom. The convective force contributes the dynamic pressures to the system as if it were a mass attached to the shell wall by spring elements. Again, assuming rigid body motion of the tank, the height of the sloshing liquid and the force exerted on the walls is proportional to the amplitude of the oscillating mass induced by ground accelerations. Figure 32 illustrates the impulsive and convective forces along with the associated moment arms. Resulting moments are calculated, with the bending moment on a plane near the tank bottom and the overturning moment on the tank both found, depending on whether the dynamic fluid pressures on the bottom are excluded or included, respectively.

Using the average velocity and acceleration spectral curves of Figures 33 and 34 , a ground acceleration of . $33 \mathrm{~g}$ was utilized in the above procedure. An impulsive force of $1.86 \times 10^{7} 1$ bs resulted in a maximum bending moment of $9.55 \times 10^{7} 1 \mathrm{~b}$-in. and overturning moment of $1.67 \times 10^{10} 1 \mathrm{~b}$-in. The convective force was $1.48 \times 10^{6}$ lbs with a maximum bending moment of $1.31 \times 10^{9} 1 \mathrm{~b}$-in. and an overturning moment of $1.48 \times 10^{9} 1 \mathrm{~b}$-in. The resulting maximum bending moment at the tank bottom was $1.09 \times 10^{10} 1 \mathrm{~b}$-in. with a total overturning moment of $1.82 \times 10^{10} 1 \mathrm{~b}$-in. The maximum shear 


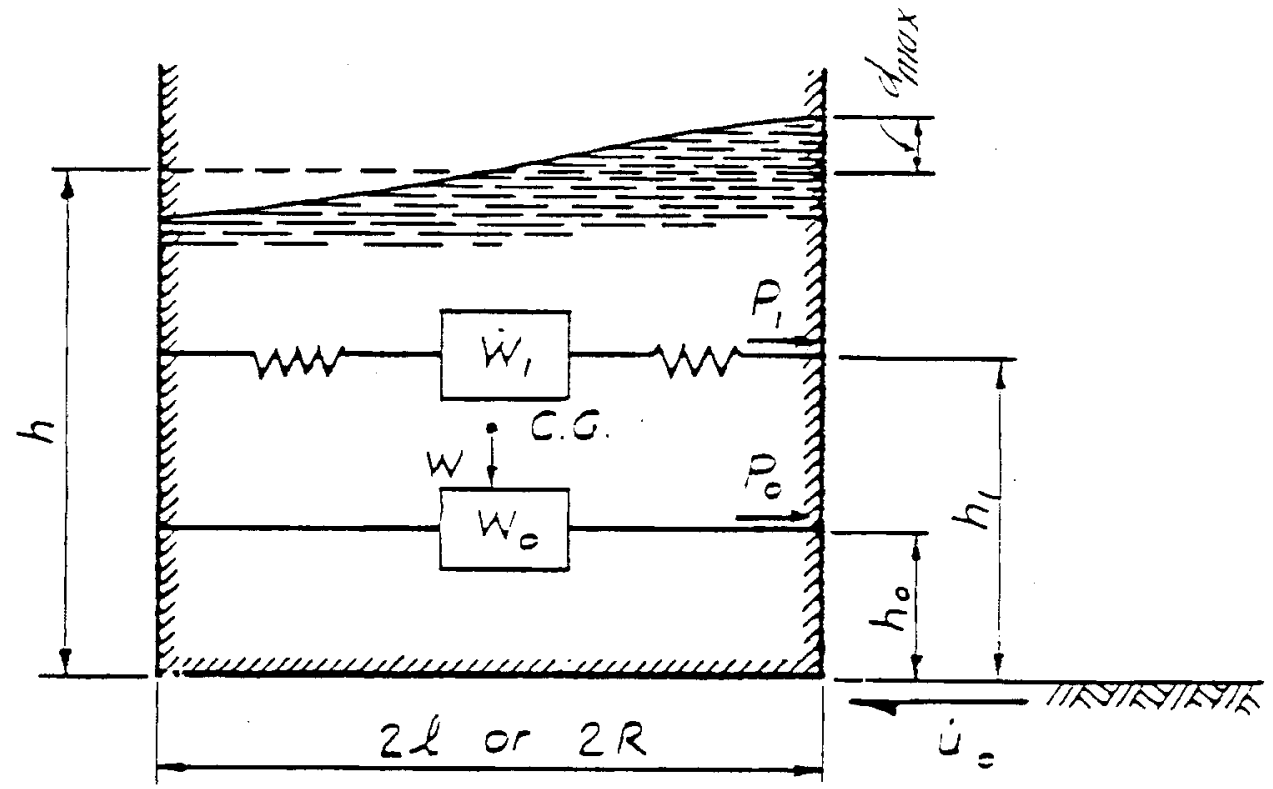

FIGURE 32. Model I1lustrating Impulsive and Convective Forces in a Fluid Container Supported on the Ground (1)

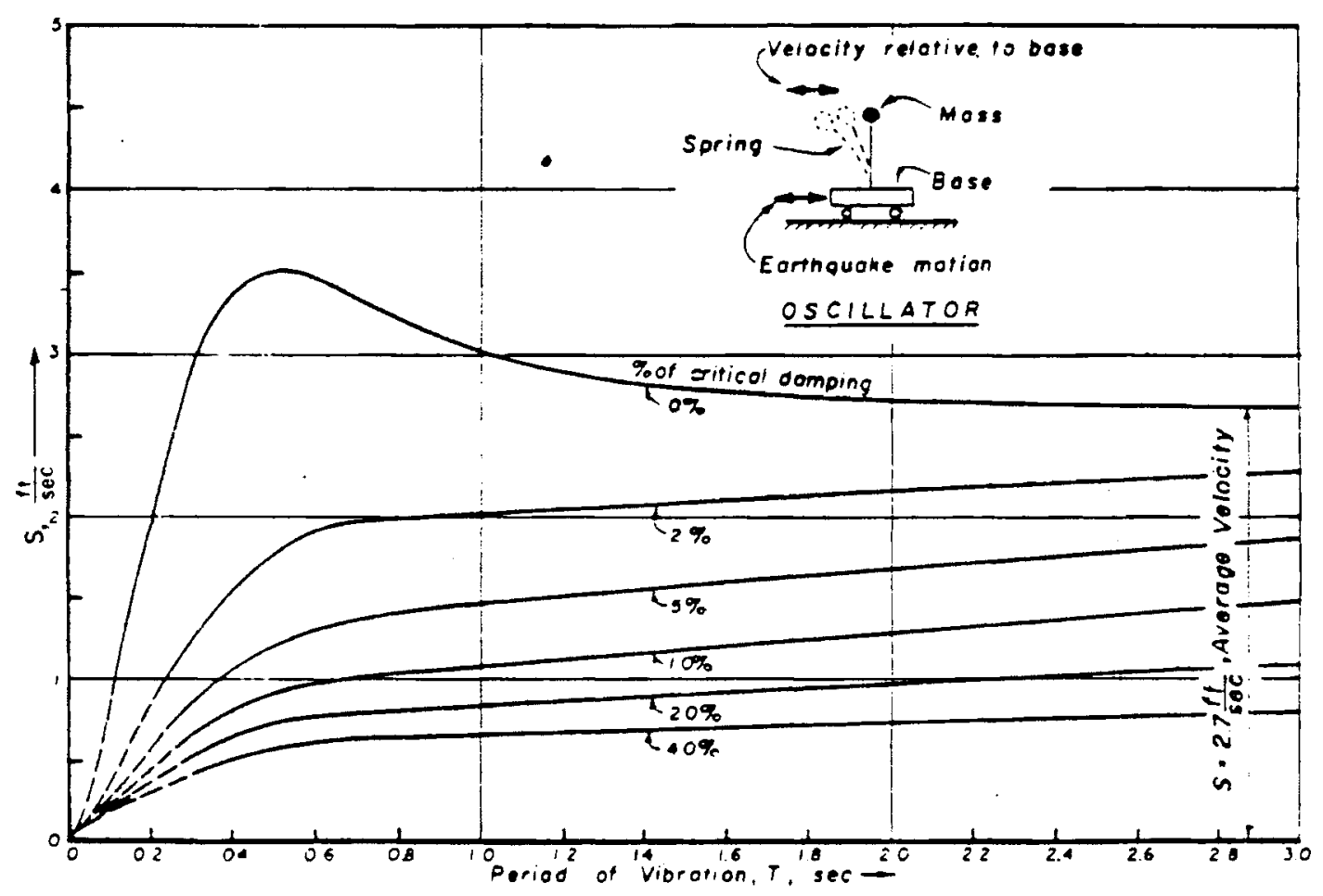

FIGURE 33. Average Velocity Spectrum at El Centro, CA, 1940 (1) 


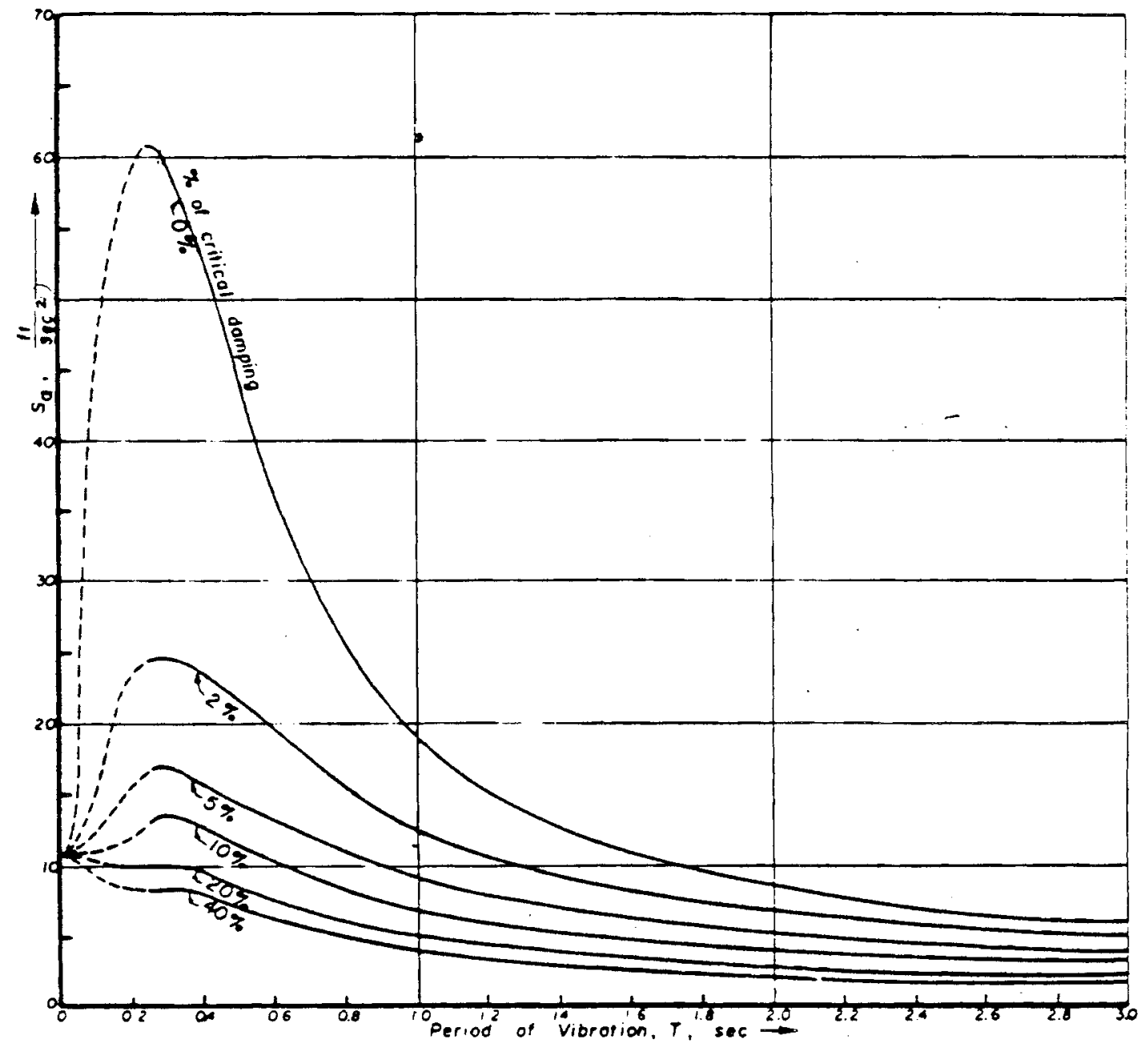

FIGURE 34. Average Acceleration Spectrum at El Centro, CA, 1940 (1) 
at the tank base was $2.01 \times 10^{7}$ bs. This corresponds to a seismic coefficient of approximately .30 . Detailed procedures are included in Ref. 6 .

A variation to Housner's procedure incorporates modifications by Veletsos, (7) where an attempt to describe the response of the flexible tank is made. A procedure is outlined by Wozniak ${ }^{(5)}$ where the design overturning moment at the bottom of the tank is:

$$
M=Z I\left(C_{1} w_{S} x_{S}+c_{1} w_{r} H_{t}+c_{1} w_{1} x_{1}+c_{2} w_{2} x_{2}\right)
$$

This procedure follows Housner closely, with $W_{S}, W_{r}, W_{1}$ and $w_{2}$ corresponding to the shell weight, roof weight and weight of effective mass of tank contents to determine the impulsive and convective forces, respectively. The $H$ values are corresponding heights. With few exceptions, these values are identical to those used in the previous analysis. $C_{1}$ and $c_{2}$ are lateral force coefficients, $Z$ is a seismic zone coefficient and $I$ is a facility factor depending on whether the facility must be functional after the earthquake or not. The maximum amplified ground motion represented by $C_{1}$ was 0.24 . (5) $c_{2}, 0.0258$, was found from the period of the first sloshing mode and the site amplification factor, which varied from 1.0 to 1.5 for stiff to soft soils, respectively. Assuming a maximum seismic zone coefficient of 1.0 and a maximum facility factor of 1.5 , the design overturning moment at the bottom of the tank is $1.11 \times 10^{10} 1 \mathrm{~b}$-in. The Housner results are within this design figure by approximately two percent. This overturning moment is resisted by the anchor system and, in fact, the anchor straps can withstand an additional 38\% increase in overturning moment before the anchor straps reach maximum tensile strength. The fluid sloshes with a period of 7.83 seconds and displaces vertically to a height of $1.81 \mathrm{ft}$ based on a corrected version of the Housner procedure: ${ }^{(5)}$

$$
d=1.124 \mathrm{ZIC} \mathrm{C}_{2} \mathrm{~T}^{2} \tanh (4.77 \sqrt{\mathrm{H} / \mathrm{D}})
$$

where $T$ is the period of the first sloshing mode of the contained liquid. 
The maximum longitudinal compressive force at the tank bottom in a tank with no uplift and the increased hoop tension at selected heights were calculated from the following relationships: ${ }^{(5)}$

$$
b=w_{t}+\frac{4 M}{\pi D^{2}}
$$

where

$\mathrm{b}=$ maximum longitudinal compressive force, $1 \mathrm{bs} / \mathrm{ft}$ of shell circumference

$w_{t}=$ tank shel1 weight, $1 \mathrm{bs} / \mathrm{ft}$

$M=$ overturning moment at tank shell bottom, ft-lbs

$D=$ tank diameter, $\mathrm{ft}$

$P_{E}=P_{1}+P_{2}$

where

$$
\begin{aligned}
P_{E} & =\text { increased hoop tension per inch of she } 11 \text { height } \\
P_{1} & =\text { tension due to impulsive force } \\
& =4.5 \mathrm{ZIC} \mathrm{C}_{1} \text { G D H }\left[\frac{Y}{H}-\frac{1}{2}\left(\frac{Y}{H}\right)^{2}\right] \tanh \left(0.866 \frac{\mathrm{D}}{\mathrm{H}}\right) \\
P_{2} & =\text { tension due to convective force } \\
& =0.975 \mathrm{ZI} \mathrm{C} \mathrm{CDD}_{2} \frac{\cosh \left(3.68 \frac{\mathrm{H}-Y}{\mathrm{D}}\right)}{\cosh \left(3.68 \frac{\mathrm{H}}{\mathrm{D}}\right)}
\end{aligned}
$$

where $Y$ is the distance between the 1 iquid surface and the point of analysis.

The maximum longitudinal compressive force at the tank bottom, assuming no $1 \mathrm{ift}$ off, is approximately $436 \mathrm{kips} / \mathrm{ft}$ of circumference, a longitudinal compressive stress of about $45 \mathrm{ksi}$.

The increased hoop tension at the tank bottom, assuming a full tank, was about $4500 \mathrm{lbs} / \mathrm{in}$. of shell height. At a point half way to the liquid surface the tensile force was about $3400 \mathrm{lbs} / \mathrm{in}$. Superimposing the resultant stress values on the tensile hoop stresses obtained under hydrostatic conditions, hoop stresses did not exceed approximately 38,000 psi. 
Veletsos also presents a procedure for calculating the circular natural frequency for empty tanks acting as cantilever flexural beams, cantilever shear beams, independent rings undergoing ovalling motion, and for tanks with very small values of liquid height to tank radius, as cantilevered strips. Assuming the tank to act as a cantilevered flexural beam, the frequency was $92.12 \mathrm{cps}$. For the cantilevered shear beam, results produced a frequency of $93.80 \mathrm{cps}$ and for Dunkerley's approach, (7) a tank frequency of 79.9 cps was calculated. Assuming a uniform cantilevered flexural beam for the liquid tank system, the natural frequency for the fluid filled tank was $34.81 \mathrm{cps}$. The period corresponds very nearly to the maximum values of velocity and acceleration on the response spectra presented in Figures 33 and 34 .

\section{Stresses at Floor-Wall Junction at Various Seismic Intensities}

To address the concern of inclusion of vertical seismic forces, a procedure was adopted to calculate stresses at the tank-floor joint when considering the combined effect of $100 \%$ vertical seismic forces with $40 \%$ horizontal seismic forces. (8) This procedure, as outlined in the overfill scenario, was implemented combining the effects of vertical and horizontal ground motions corresponding to $.1, .2$ and $.33 \mathrm{~g}^{\prime} \mathrm{s}$. The values are compared with the static condition results. These results are contained in Table 8 with the complete calculations given in Reference 6 .

This procedure assumed an unanchored tank with a resultant uplift associated with each seismic intensity. It has been suggested that uplift be limited to approximately 6 to 7 percent of the tank radius for many flat bottom storage tanks. (5) The seismic intensities in the present analysis showed an approximate $2 \%$ uplift of the bottom plate running perpendicular to the tank wal1. One would expect this problem to vanish with the installation of anchor strap systems used to prevent uplift. It is, however, possible that local yielding might occur near the tank bottom assuming a specified minimum yield strength of 75,000 psi for A353 plate steel. (9) Evidence for this is provided in Table 8 when examining the resultant stresses near the tank bottom for a seismic event of $.33 \mathrm{~g}$ 's. None of the stresses obtained indicated possible failure beyond yielding under the given conditions. 
TABLE 8. Results of Static and Seismic Loadings

Overturning moment, $\mathrm{M}_{\mathrm{OV}}$

Vertical load due to $\mathrm{M}_{\mathrm{OV}}$

Total vertical load $\left(G+.4 G_{V}\right)$

Impulsive pressure at tank,

$$
P_{i m p}
$$

Oscillating pressure at tank

$$
\text { bottom, } P_{\text {osc }}
$$

$\underset{\infty}{\infty} \underset{\infty}{\infty}$ Pressure, $P+.4\left(P_{i m p}+P_{o s c}\right)$

Equivalent density

$$
\frac{P+.4\left(P_{i m p}+P_{0 S C}\right)}{H}
$$

Bending stresses in floor at floor-wall junction

Bending stresses in wall at floor-wall junction due to $M_{0}$

Shear stress at floor

Sum of hoop tensile stresses 15" above floor plate

Resultant stresses 15" above floor plate

\begin{tabular}{|c|c|c|c|}
\hline Static & $.1 \mathrm{~g}$ & $.2 \mathrm{~g}$ & $.33 g$ \\
\hline-- & $3.135 \times 10^{9} 1 \mathrm{~b}$-in. & $6.270 \times 10^{9} 1 \mathrm{~b}$-in. & $1.032 \times 10^{10} 1 b-$ in \\
\hline-- & 849.13 1b/in. & $1698.36 \mathrm{lb} / \mathrm{in}$. & 2302.62 lb/in. \\
\hline 180.15 1b/in. & 519.80 1b/in. & 859.49 1b/in. & 1301.20 1b/in. \\
\hline
\end{tabular}

Bending stresses in floor plate at floor-wall junction

\section{$3.536 \mathrm{psi}$}

5.836 psi

.304 psi

.501 psi

$23.23 \mathrm{psi}$

$27.61 \mathrm{psi}$

$31.98 \mathrm{psi}$

37.605 psi

.01696 lb/in. $.^{3} \quad .020151 b /$ in. $^{3} \quad .02334$ lb/in. ${ }^{3} \quad .02745$ lb/in. ${ }^{3}$

$\begin{array}{rrrr}33,707 \text { psi } & 36,952 \text { psi } & 39,383 \text { psi } & 42,461 \text { psi } \\ 45,394 \text { psi } & 56,258 \text { psi } & 66,188 \mathrm{psi} & 78,972 \text { psi } \\ 600 \text { psi } & 724 \text { psi } & 843 \mathrm{psi} & 998 \text { psi } \\ 30,332 \text { psi } & 44,463 \text { psi } & 52,615 \text { psi } & 63,782 \text { psi } \\ \ldots & 45,207 \text { psi } & 61,280 \text { psi } & 76,244 \text { psi }\end{array}$

26,798 psi

$36,952 \mathrm{psi}$

$39.383 \mathrm{psi}$

42,461 psi 


\section{REFERENCES}

1. Nuclear Reactors and Earthquakes, TID 7024 by Lockheed Aircraft Corp., and Holmes Narver, Inc., for AEC-Division of Nuclear Development, August 1963, pp. 1-51, 183-195.

2. Anderson, T.L. and L.M. Finch, "Seismic Design of Nuclear Power Plants", Vol. 1, Battelle Northwest Laboratories, Richlland, WA, Feb. 1972.

3. Uniform Building Code, 3rd printing, International Conference of Building officials, Whittier, CA, 1976, p. 149.

4. Housner, G.W., "Design of Nuclear Reactors Against Earthquakes", Proceedings of 2nd World Conference on Earthquake Engineering, Vol. II, 1960.

5. Wozniak, R.S. and W.W. Mitche11, "Basis of Seismic Design Provisions for Welded Steel 011 Storage Tanks", presented at API Refining, 43rd Midyear Meeting, Toronto, Ontario, May 1978.

6. Fecht, B.A., "Results in Support of LNG Storage Tank Analysis", Battelle Northwest Laboratories, November 1981.

7. Veletsos, A.S. and J.Y. Yang, "Dynamics of Fixed-Base Liquid Storage Tanks", proceedings of U.S.-Japan Seminar on Earthquake Engineering Research with Emphasis on Lifeline Systems, November 1976.

8. Marchaj, T.J., "Importance of Vertical Acceleration in the Design of Liquid Containing Tanks", proceedings of the 2nd U.S. National Conference on Earthquake Engineering, Stanford, CA, August 1979.

9. API 620 Standard, Appendix Q: Recommended Rules for Design and Construction of Large, Welded, Low Pressure Storage Tanks, API, Washington, D.C., 1974, p. 107. 


\section{CRACK PROPAGATION}

\section{Discussion}

Catastrophic failure due to brittle fracture does not often occur, and in fact, in over 20 years of in-service experience using $9 \% \mathrm{Ni}$ in LNG storage tanks, there has been no record of catastrophic brittle fracture of the primary containment vessel. (1) However, through history there have been large structures that have failed in this manner, thus, the continued investigation that parallels the growth of the field of fracture mechanics. Many factors can contribute to the brittle fracture of a structure (temperatures, material toughness, exposure to fatigue, geometric configuration, etc.) but the three primary variables are identified as flaw size, material toughness, and the stress field. (2) Both primary and secondary tanks are investigated using developed interrelationships among these variables. In addition, some experimental results are presented along with crack existence probability calculations.

\section{Analyses}

\section{Crack Existence Probability}

When investigating possible crack locations, welds are very suspect. It is common to find pores or slag inclusions which can act as local stress raisers. In addition, one can expect lower toughness values and high residual stresses in the deposit or heat affected zone. (3)

There is considerable interest in determining the probable existence of such a crack. In the relationship utilized, (4) this probability is dependent on the weld volume, which in this case includes the heat affected zone (two weld thicknesses wide). Circumferential welds are also the center of attention because they usually see higher stresses and because resultant failure for this configuration may be more serious. The volume of this circumferential weld is:

$$
V=\pi D_{i} h(2 h)=2 \pi D_{i} h^{2}
$$

where

$$
\begin{aligned}
D_{i} & =\text { inside tank diameter } \\
h & =\text { wall thickness }
\end{aligned}
$$


Assuming that the number of cracks in the given volume is Poisson distributed, the probability of $\mathrm{N}$ cracks occuring is: ${ }^{(4)}$

$$
P(N)=\left(V_{P_{V}^{*}}\right)^{N} \frac{e^{-V_{P_{V}^{*}}}}{N !}
$$

and the probability of a crack occurring is one minus the probability of no crack occurrence: ${ }^{(4)}$

$$
p *=1-e^{-V_{P}^{*}}
$$

where

$$
\begin{aligned}
V= & \text { weld volume } \\
N= & \text { number of cracks } \\
P_{V}^{\star}= & \text { frequency of cracks per unit volume with a conservative } \\
& \text { estimate given as } 10^{-4} / \mathrm{in.}^{3}
\end{aligned}
$$

Figure 35 presents results for a weld volume corresponding to one circumferential weld in the lower, outer tank where the probability of having a crack is 0.201 . If one assumes this procedure can be applied to the entire outer shell wall with a weld volume in the neighborhood of $73,000 \mathrm{cu}$ in., the second curve in Figure 35 is produced. The probability of an occurrence of a crack in this case is 0.999 . To completely define the initial crack distribution, however, several other relationships such as depth, aspect ratio, area and length distributions should be investigated.

\section{Inner Tank}

Fracture toughness test results are illustrated in Figure 36 and indicate that quenched and tempered $9 \% \mathrm{Ni}$ steel is on the upper toughness she lf at LNG temperatures. Other results indicating that $9 \% \mathrm{Ni}$ steel is on the upper toughness shelf at LNG temperatures is the apparent inability to propagate cracks in the laboratory at these temperatures. (5) Strict standards must be maintained to assure that such properties are preserved during tank 


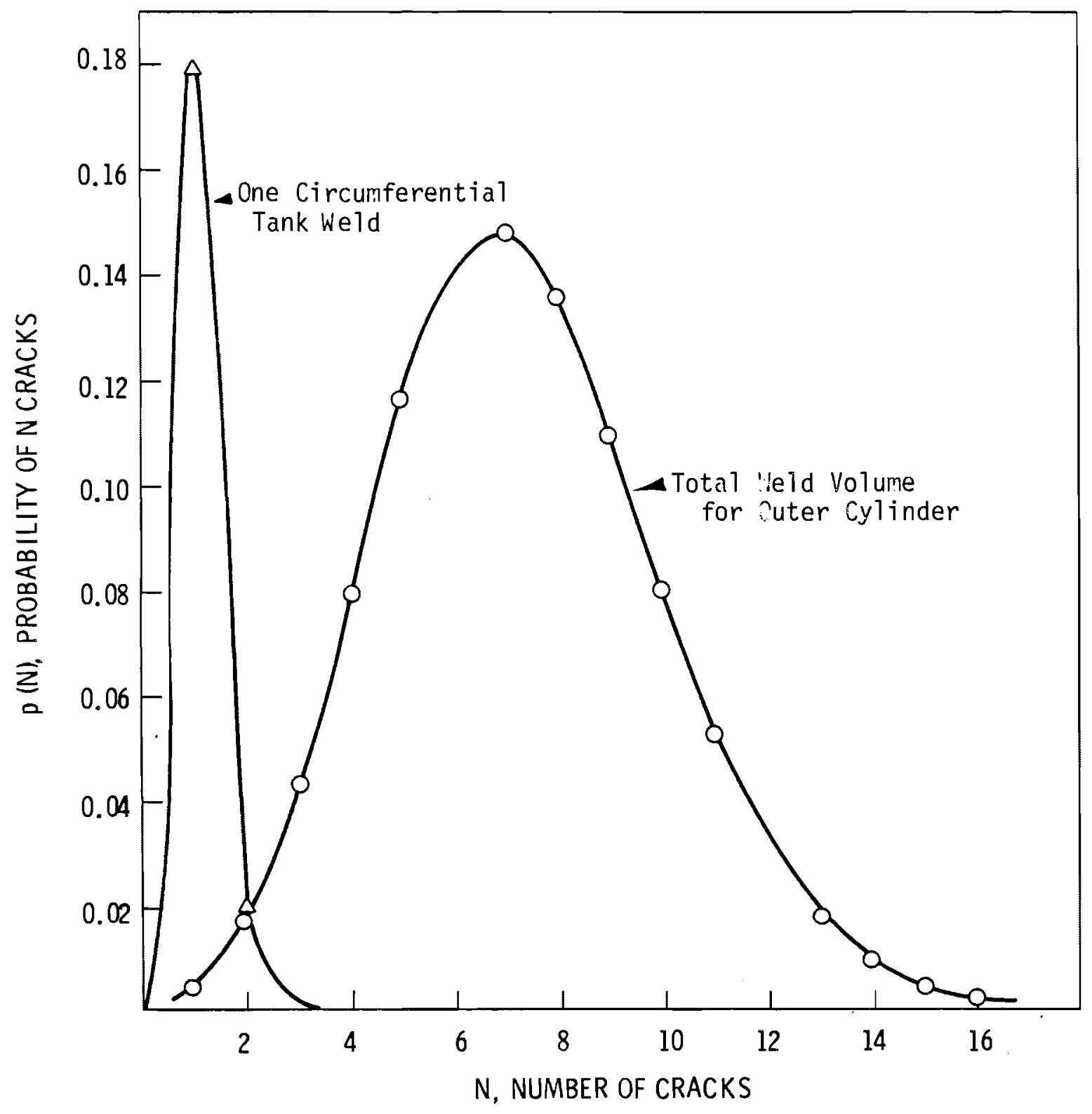

FIGURE 35. Probability of Having N Cracks as a Function of Weld Volume 


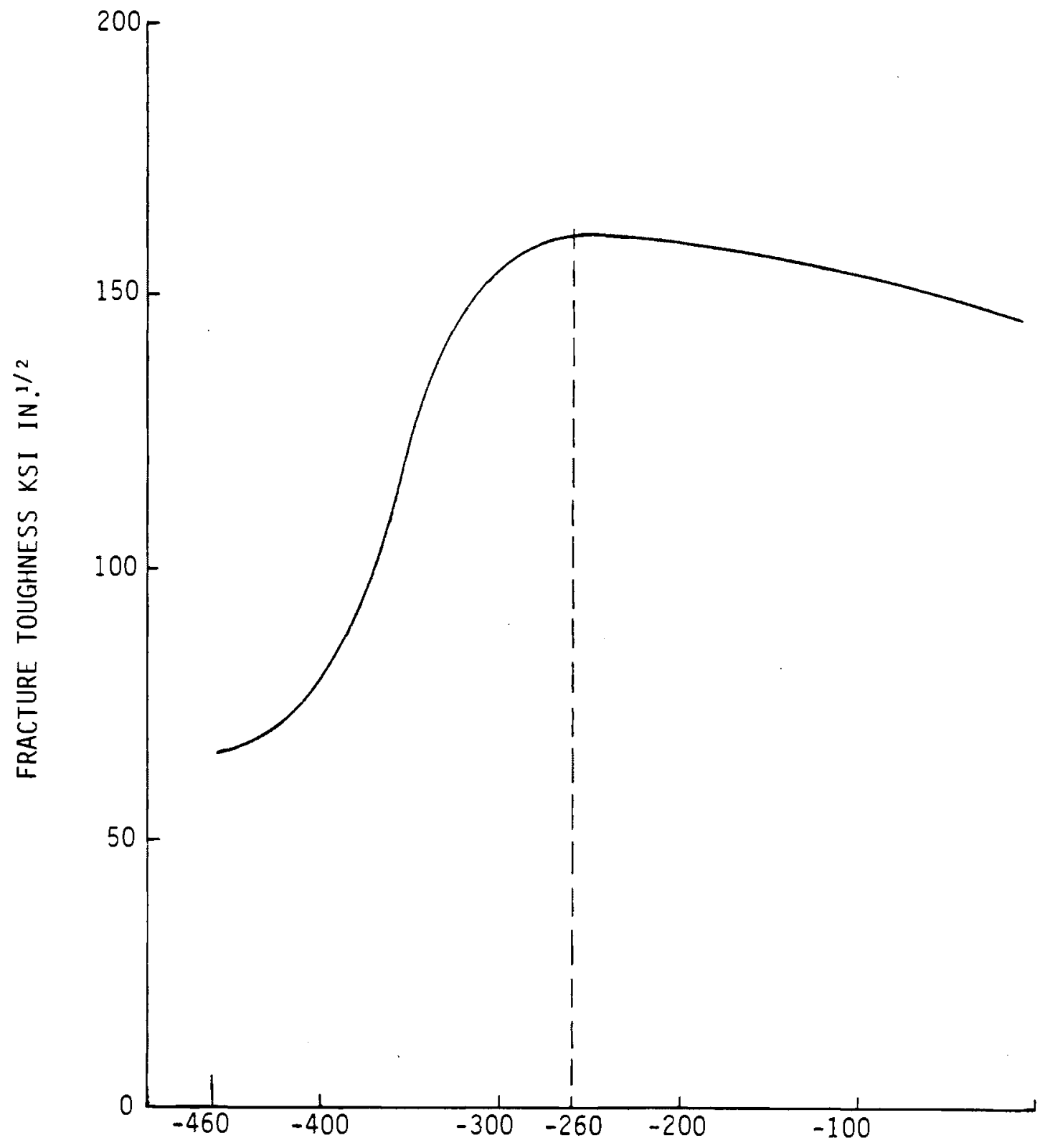

FIGURE 36. Temperature Dependence of $K_{I C}$ Estimates for the Quenched and Tempered 9 NI Steel (6) 
fabrication. Quenched and tempered rather than double normalized and tempered plates along with restricted amounts of severe forming and $f l$ ame burning of the plate edges allow for preservation of these high toughness values. (1) In addition, API 620 standards require Charpy $V$ notch impact tests at design temperatures for the weld material as well as the heat affected zones. Using the lower bound fracture toughness data derived from information up to $1975^{(7)}$ fracture mechanics relationships were used to plot crack length versus applied stress. This was done for a through thickness flaw in an infinite flat plate (Figure 37) and modified for application to the curved shell configuration in the inner cylinder (Figure 38). This figure was developed for a cylinder of $195 \mathrm{ft}$ in diameter with a maximum thickness of .97 in. Figure 38 yields a uniform stress field for the cylinder if entered with a corresponding crack length value from the cylinder. The membrane stress is calculated as: (1)

$$
\sigma_{m}=\sigma_{c} \frac{1.5 \sqrt{R t}}{\ell+1.5 \sqrt{R t}}
$$

where

$$
\begin{aligned}
R & =\text { radius } \\
t & =\text { thickness } \\
\ell & =\text { crack length } \\
\sigma_{C} & =\frac{P R\left(\ell_{C}+1.5 \sqrt{R t}\right)}{t 1.5 \sqrt{R t}}
\end{aligned}
$$

This results because the uniform stress field acts over a length including that which carries the load transferred from the interrupted crack length. The toughnesses given were estimated as being lower bound figures. It should be noted that the quality of these alloy steels improve over the years, resulting in higher toughness values, and most likely higher than the values presented here. There is additional evidence that thinner plates ( $1 / 2$ in.) exhibit fracture toughness levels on the upper shelf at LNG temperatures as well and experimental results have shown that unstable crack growth does not develop down to temperatures reaching $-297^{\circ} \mathrm{F}$. (5) 


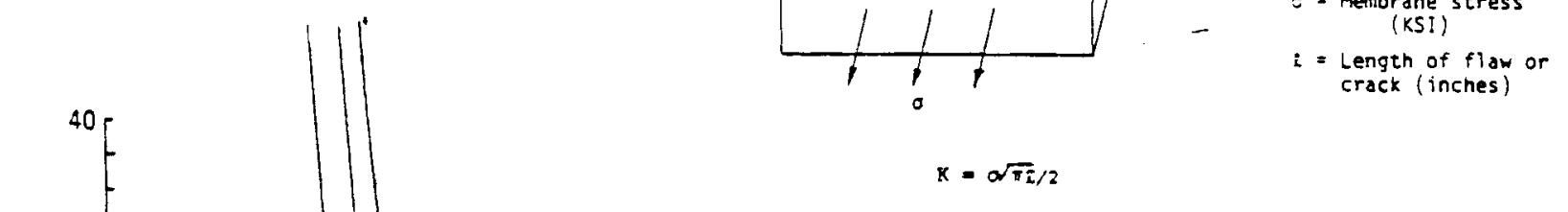

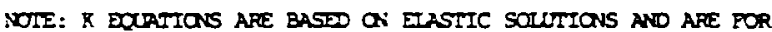
DEFITIE AND SEMI-DFPCLTE GOOMELFY (i.e. vithout gecorric (finite vidth) corrections).

here:

$k$ = Fracture toughness

$\approx$ = Membrane stress (KS!)

Length of flay or crack (inches)

CRITICAL FLAW SIZES

FOR INFINITE FLAT PLATE

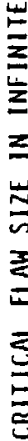

20

"

$\pi$

烈

? ?

1) where:

$\mathcal{L}=$ Lenoth of flaw or crack in plate (inches)

$K_{c}=$ static initiation fracture zoughness

0 Direct memorane stress(KSI)

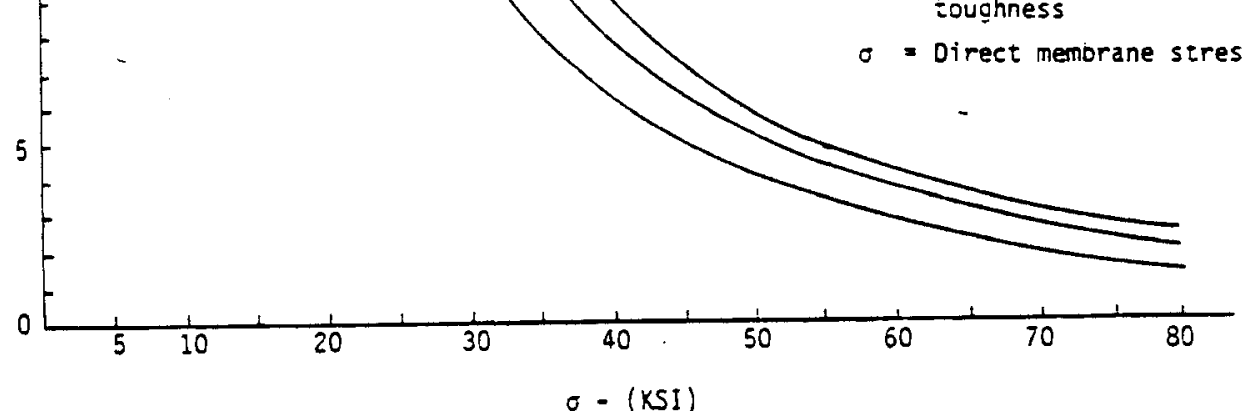

FIGURE 37. Critical Flaw Size Versus Stress for Plate Shown Above ( $9 \% \mathrm{Ni}$ Steel) (1)

B. 95 


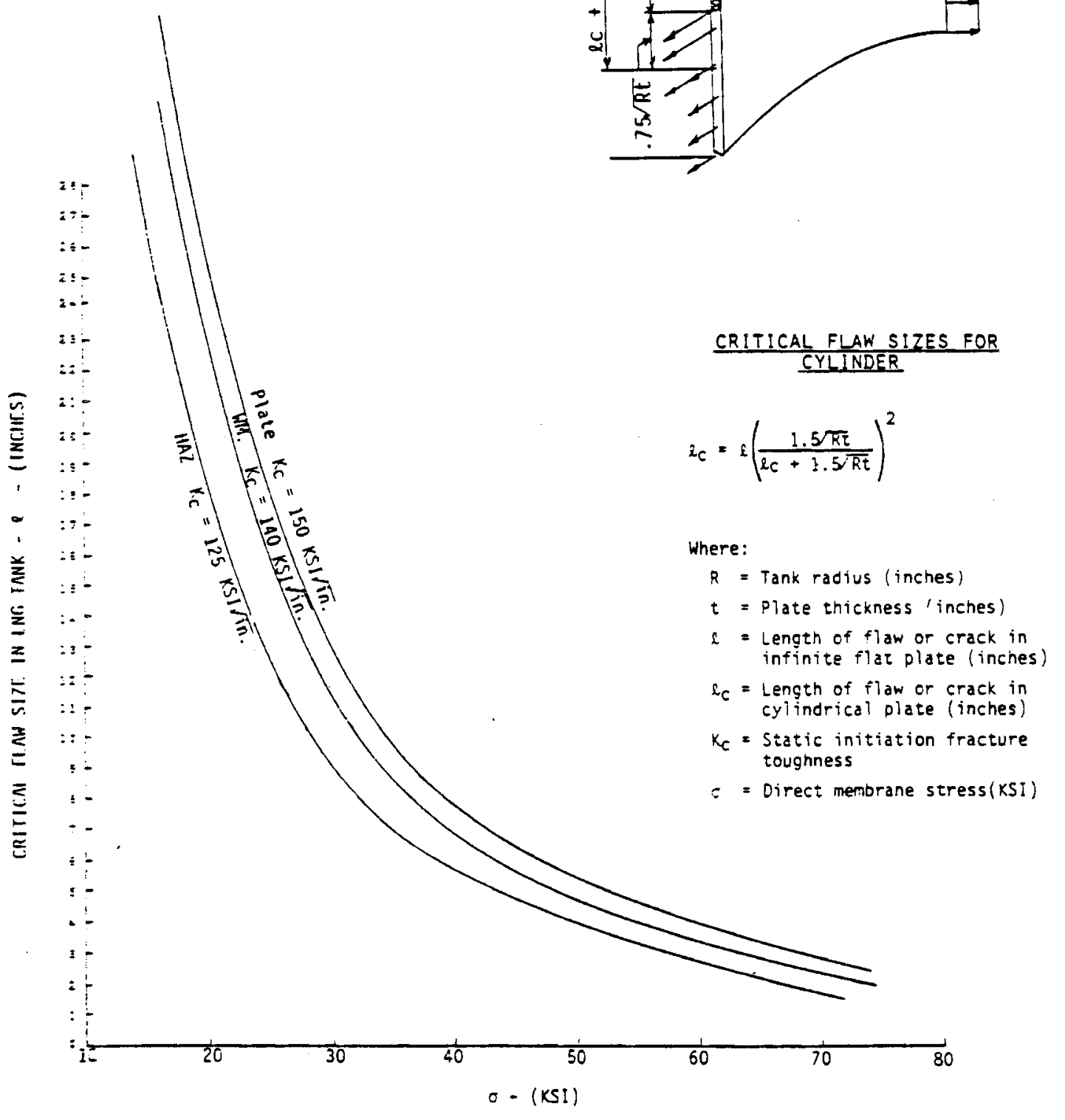

FIGURE 38. Critical Flaw Size Versus Stress for $9 \% \mathrm{Ni}$ Steel Cylinders (1)

B. 96 
There is also considerable interest in crack arrest capabilities of $9 \% \mathrm{Ni}$ steel. Perhaps the best example of such an occurrence is when a crack propagates from an area of low toughness (e.g., weld material or heat affected zone) into an area of higher toughness (e.g., steel plate). Table 9 presents crack arrest fracture toughness data for several specimens tested at temperatures below LNG storage temperatures. The estimate for crack arrest fracture toughness at LNG temperatures is approximately $225 \mathrm{ksi} \sqrt{\mathrm{in} .}$ in $1 \mathrm{in}$. specimens and approximately $280 \mathrm{ksi} \sqrt{\mathrm{in} .}$ in $1 / 2 \mathrm{in.}$ specimens with higher predictions proposed for materials manufactured after 1970. ${ }^{(5)}$

\section{Outer Tank}

There is little question as to whether or not unstable brittle fracture will occur if the cryogenic fluid comes in contact with the outer tank. Most pressure vessel steels of compositions similar to A131 show that at LNG storage temperatures one is well into the lower toughness shelf. $(8,2)$ Assuming

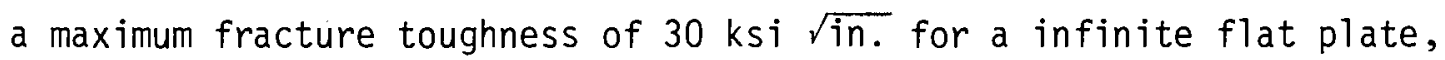
Figure 39 results. Fracture is indeed likely at these temperatures and will propagate until it reaches a reduced stress state or higher toughness value.

TABLE 9. Crack Initiation and Arrest was Produced in the Selected (Early 1970's) 9\% Ni Steel Plate at Temperatures Below LNG Temperature (5)

\begin{tabular}{|c|c|c|c|c|c|}
\hline $\begin{array}{l}\text { est } \\
0 .\end{array}$ & $\begin{array}{l}\text { Thickness } \\
\text { In. (mm) }\end{array}$ & $\begin{array}{c}\text { Test } \\
\text { Temperature } \\
{ }^{\circ} \mathrm{F}\left({ }^{\circ} \mathrm{C}\right) \\
\end{array}$ & $\begin{array}{c}\text { Test } \\
\text { Specimen }\end{array}$ & $\begin{array}{c}k_{i} \\
k s i \sqrt{i n .} \\
\text { (MP } a \sqrt{i n .}) \\
\end{array}$ & $\begin{array}{c}k_{a} \\
\text { ksi } \sqrt{i n .} \\
\text { (MP a } \sqrt{i n .}) \\
\end{array}$ \\
\hline A & $1(25)$ & $-320(-196)$ & TDCB & $K_{c}=125(138)$ & $105(116)$ \\
\hline $3 \mathrm{~A}$ & $1(25)$ & $-320(-196)$ & $\mathrm{CCA}$ & $218(240)$ & $129(142)$ \\
\hline 7 & $1(25)$ & $-297(-183)$ & TDCB & $K_{C}=209(230)$ & $173(191)$ \\
\hline 22 & $1(25)$ & $-297(-183)$ & $\mathrm{CCA}$ & $218(240)$ & $169(186)$ \\
\hline 2 & $1 / 2(12.7)$ & $-320(-196)$ & CCA & $218(240)$ & $149(164)$ \\
\hline
\end{tabular}




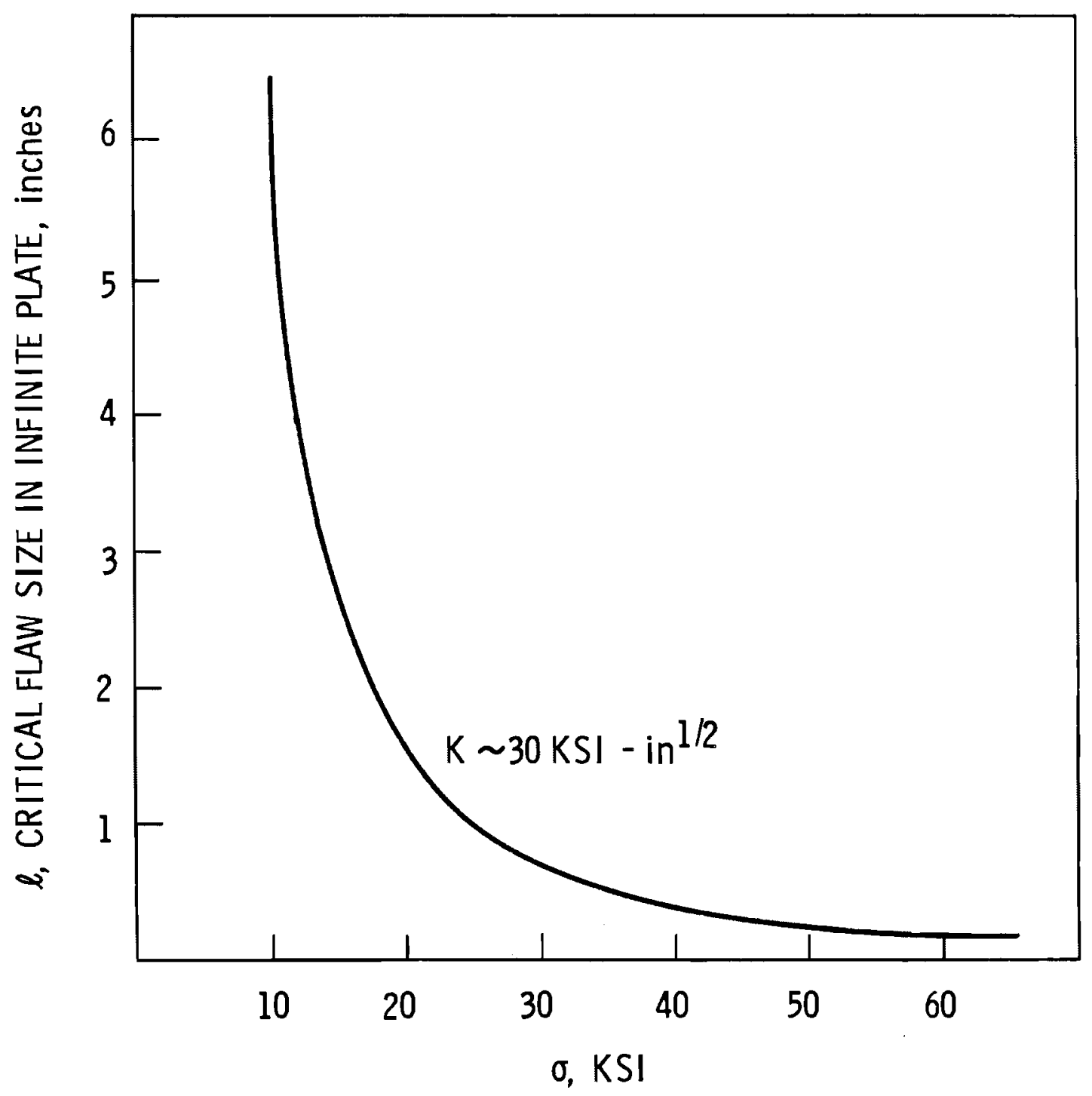

FIGURE 39. Critical Flaw Size for Infinite Plate (Outer Tank) 


\section{REFERENCES}

1. Clark, C., E. Upitis, R. Bruscato, "Refrigerated Storage of Liquefied Gas - A Success Story", presented at IGT Symposium on LNG Storage, Chicago, IL, January 1980.

2. Rolfe, S.T. and J.M. Barsom, Fracture and Fatigue Control in Structures Applications to Fracture Mechanics, Prentice-Ha11, Inc., Englewood, NJ, 1977.

3. A.G.A. Project IU-2-1, "A Report on LNG Safety Research", Vol. 1, Arthur D. Little, Inc., Cambridge, Mass., January 1971, pp. 24-25.

4. Harris, D.O., E.Y. Lim and D.D. Dedhia, "Probability of Pipe Fracture in the Primary Coolant Loop of a PWR Plant", Vo1. 5: Probabilistic Fracture Mechanics Analysis, Lawrence Livermore Laboratory, June 1981 , pp. 43-45.

5. Bruscato, R.M., "The Measurement of Crack Arrest Fracture Toughness in Welded 9\% Nickel Steels Used on Cryogenic Storage Tanks", Chicago Bridge and Iron, Co., CBT 5384, January 1981.

6. Tobler, R.L., R.P. Mikesell and R.P. Reed, "Cryogenic Effects on the Fracture Mechanic Parameters of Ferritic Nickel Alloy Steels", Fracture Mechanics, ASTM Standard Testing Procedure 677.

7. Pense, A.W. and R.D. Stout, "Fracture Toughness and Related Characteristics of Cryogenic Nickel Steels", Welding Research Council Bulletin \#205, May 1975.

8. Server, W.L., and W. 01dfield, "Nuclear Pressure Vessel Steel Data Base", Fracture Control Corp., Goleta, CA, EPRI NP-922, December 1978. 


\section{B.2. SPECIFIC SCENARIOS - PRESTRESSED CONCRETE TANKS}

TORNADO

Discussion

Criteria for tornado wind loading on prestressed concrete LNG storage tanks is investigated. The design basis tornado for nuclear power plants located in Region I defined in U.S. Nuclear Regulatory Commission Regulatory Guide 1.76, "Design Basis Tornado for Nuclear Power Plans," $(5)$ is used.

Designing structures to resist wind loading is a very complex engineering problem. Currently, NFPA $59 A^{(8)}$ does not specifically consider wind pressure in its standards, but references the wind design requirements in API 620.

The reactor safety study has considered designs for areas where tornados are prevalent and has established a "design basis tornado" for the contiguous U.S. divided into three tornado intensity regions, Figure 40 . The corresponding tornado winds are given below:

\begin{tabular}{|c|c|c|c|c|}
\hline Region & $\begin{array}{l}\text { Maximum } \\
\text { Speed } V_{\max } \\
\text { (mph) }\end{array}$ & $\begin{array}{l}\text { Rotational } \\
\text { Speed V } \\
\text { (mph) }\end{array}$ & $\begin{array}{c}\text { Translational } \\
\text { Speed } V_{\text {tr }} \\
(\mathrm{mph})\end{array}$ & $\begin{array}{l}\text { Radius of Maximum } \\
\text { Rotational Wind } \\
\text { Speed } R_{m} \\
(\mathrm{ft} .)\end{array}$ \\
\hline $\begin{array}{l}\text { I } \\
\text { I I } \\
\text { I I I }\end{array}$ & $\begin{array}{l}360 \\
300 \\
240\end{array}$ & $\begin{array}{l}290 \\
240 \\
190\end{array}$ & $\begin{array}{l}70 \\
60 \\
50\end{array}$ & $\begin{array}{l}150 \\
150 \\
150\end{array}$ \\
\hline
\end{tabular}

In addition, the regional pressure drops and pressure drop rates are:

\begin{tabular}{|c|c|c|}
\hline Region & $\begin{array}{l}\text { Total Pressure Drop } \\
\text { (psi) }\end{array}$ & $\begin{array}{r}\text { Rate of Pre } \\
\text { (psi / se }\end{array}$ \\
\hline $\begin{array}{l}\text { I } \\
\text { II } \\
\text { III }\end{array}$ & $\begin{array}{l}3.0 \\
2.25 \\
1.5\end{array}$ & $\begin{array}{l}2.0 \\
1.2 \\
0.6\end{array}$ \\
\hline
\end{tabular}




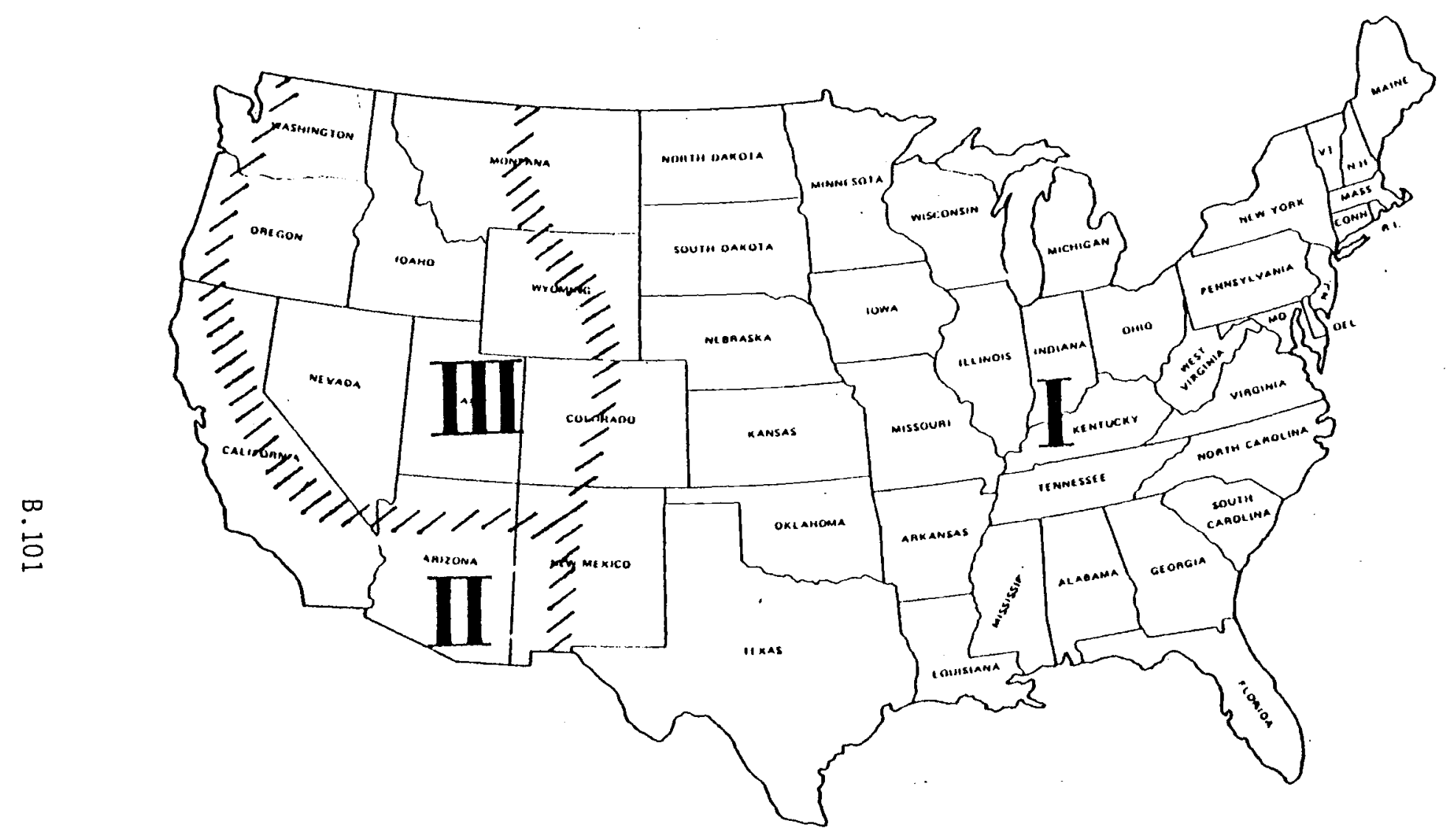

FIGURE 40. Tornado Intensity Regions $(5)$ 
The design basis tornado for nuclear power plants located in Region I assumes internal winds at $360 \mathrm{mph}$, a translational velocity of $70 \mathrm{mph}$, and a maximum pressure differential of 3 psi. The design tornado is more severe than $99 \%$ of a 11 tornados and it is estimated that the probability of a damaging tornado striking a reactor site is at $5 \times 10^{-6}$ per year.

Presently, LNG tanks are not required to be designed to withstand a direct hit by a tornado. It is possible, however, to estimate the ability of a particular type of tank to withstand a tornado. Damage to the tank is of much less concern than a failure leading to the release of $L N G$ from the tank.

\section{Analyses}

The criteria outlined in ANSI A58.1-1972 (6), excluding paragraph 6.3, were used for transforming the tornado wind velocity into an effective pressure applied to exposed surfaces of structures. Supplement to the ANSI Standard were the following assumptions used in Reference 3 :

- Gust factor taken as unity.

- Distribution of rotational velocity governed by Rankine Vortex.

- Velocity pressure assumed constant with height.

- Maximum velocity pressure intensity, $q_{\max }$, applies at radius of tornado funnel at which maximum velocity occurs.

The design wind loading per unit area on the LNG tank due to the horizontal velocity may be calculated from:

$$
p=q_{\max } C_{s} c_{p}
$$

where the maximum velocity pressure, $q_{\max }$, is 332 psf for a total horizontal velocity of $360 \mathrm{mph}$ and $C_{s}, C_{p}$ are the size and pressure coefficients, respectively.

The most distinct difference between ordinary wind and tornado wind load computations is application of the size coefficient, $c_{s}$. There is a certain location, relative to the radius of maximum rotational speed, for a structure with size $L$, which gives the maximum total pressure on the structure. The average (design) pressure is obtained by maximizing this

$$
\text { B. } 102
$$


total pressure expression and dividing by the structure size, L. Figure 41 shows the results of this computation.

The pressure due to wind may be different for various portions of a structure, hence, different pressure coefficients, $C_{p}$ are devised for design purposes. The pressure coefficients are related to the structures external shape and its orientation with respect to the direction of wind movement. The pressure effect due to a rotating tornado wind is assumed, for simplicity, to be the same as that due to an ordinary wind with a straight course of movement. Local wind pressure coefficients for the aboveground and underground concrete LNG storage tank are given in Figures 42 and 43 , respectively.

NRC Standard Review Plan Section 3.3.2 provides an acceptable method of combining the effects of tornado-induced loads as follows:

$$
\begin{aligned}
& W_{T}=W_{W} \\
& W_{T}=W_{P} \\
& W_{T}=W_{W}+0.5 W_{P}
\end{aligned}
$$

where,

$$
\begin{aligned}
& W_{T}=\text { total tornado load } \\
& W_{W}=\text { tornado wind load } \\
& W_{P}=\text { tornado differential pressure load }
\end{aligned}
$$

The most adverse of the combinations for each particular structure was used and combined with the dead load, Figures 44,45 and 46.

Maximum wind speeds in a typical tornado are estimated at 200-250 mph, considerably in excess of normal wind design loads for LNG storage tanks. The internal pressure differential exerted on the tank could increase up to 1 psi in a period of a few minutes during passage of a tornado over an LNG tank. This pressure change could lead to an overpressurization failure depending on the design and operating pressures of the tank. 


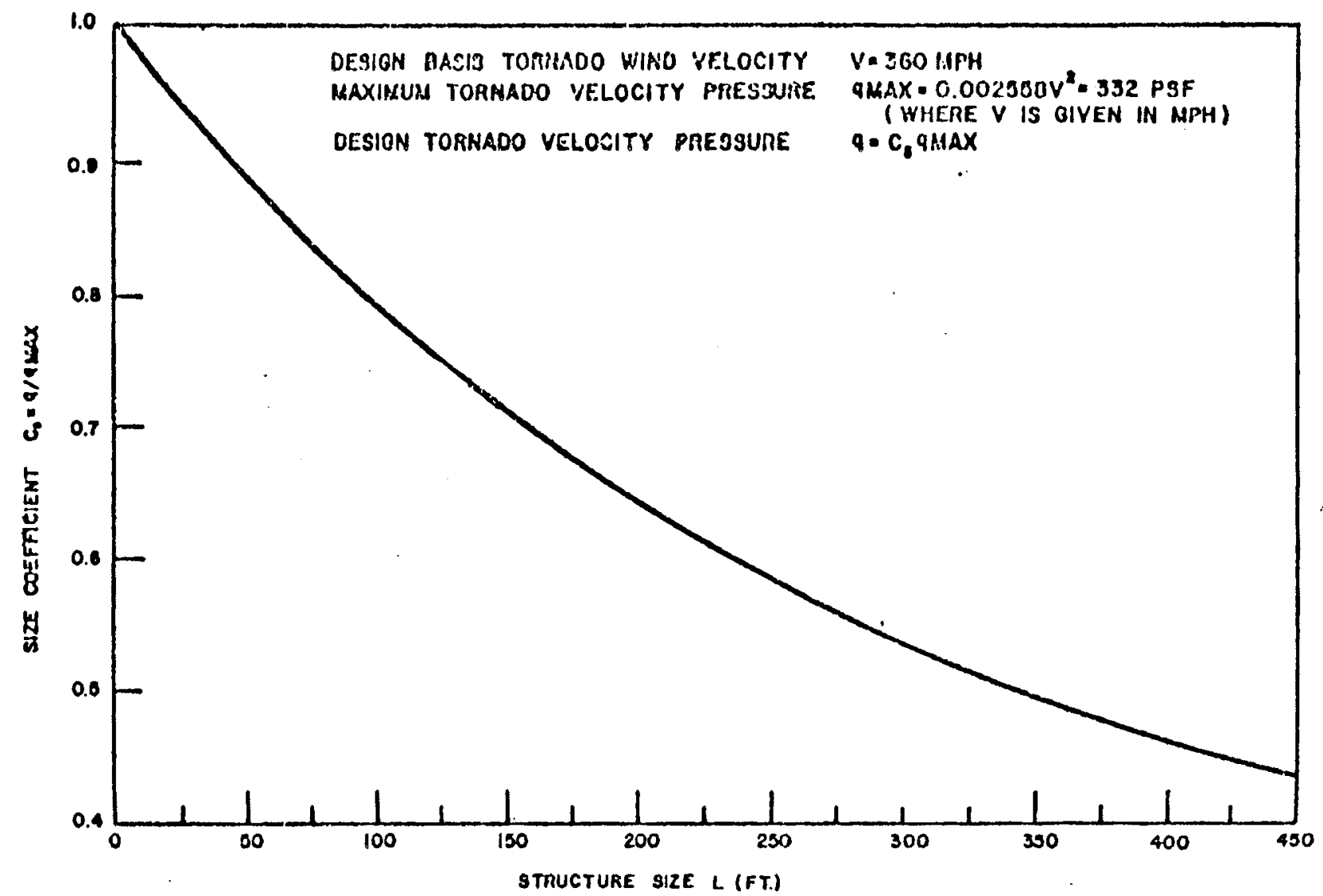

FIGURE 41. Structure Size Effect on Tornado Pressure ${ }^{(3)}$ 


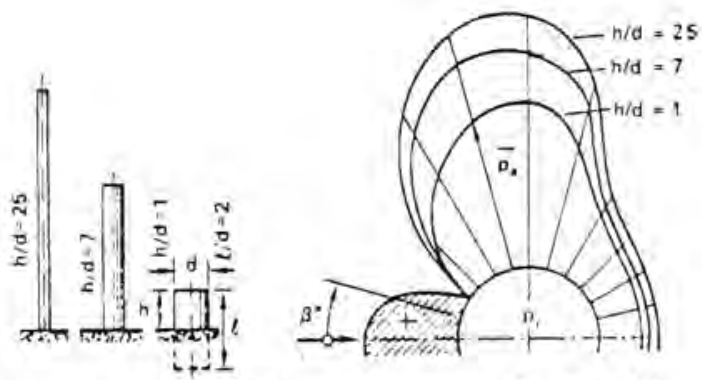

Stack operaling $C_{p, 1}=+0.1 ; \quad$ slack closed $C_{0,1}=-0.8$.

\begin{tabular}{c|c|c|c|c|c|c|c|c|c|c|c|c|c|c|c}
\hline h/di & $1 / d$ & $\beta=$ & $0^{\circ}$ & $15^{\circ}$ & $30^{\circ}$ & $45^{\circ}$ & $60^{\circ}$ & $75^{\circ}$ & $90^{\circ}$ & $105^{\circ}$ & $120^{\circ}$ & $135^{\circ}$ & $150^{\circ}$ & $165^{\circ}$ & $180^{\circ}$ \\
\hline 25 & 50 & $C_{p, a}=$ & +1.0 & +0.8 & +0.1 & -0.9 & -1.9 & -2.5 & -2.6 & -1.9 & -0.9 & -0.7 & -0.6 & -0.6 & -0.6 \\
7 & 14 & $C_{p, a}=$ & +1.0 & +0.8 & +0.1 & -0.8 & -1.7 & -2.2 & -2.2 & -1.7 & -0.8 & -0.6 & -0.5 & -0.5 & -0.5 \\
1 & 2 & $C_{p, a}=$ & +1.0 & 10.8 & +0.1 & -0.7 & -1.2 & -1.6 & -1.7 & -1.2 & -0.7 & -0.5 & -0.4 & -0.4 & -0.4 \\
\multicolumn{2}{l}{ Spheres } & $C_{p, a}=$ & +1.0 & +0.9 & +0.5 & -0.1 & -0.7 & -1.1 & -1.2 & -1.0 & -0.6 & -0.2 & +0.1 & +0.3 & +0.4 \\
\hline
\end{tabular}

FIGURE 42. Wind Pressure Coefficients, Above Ground Tank (2)

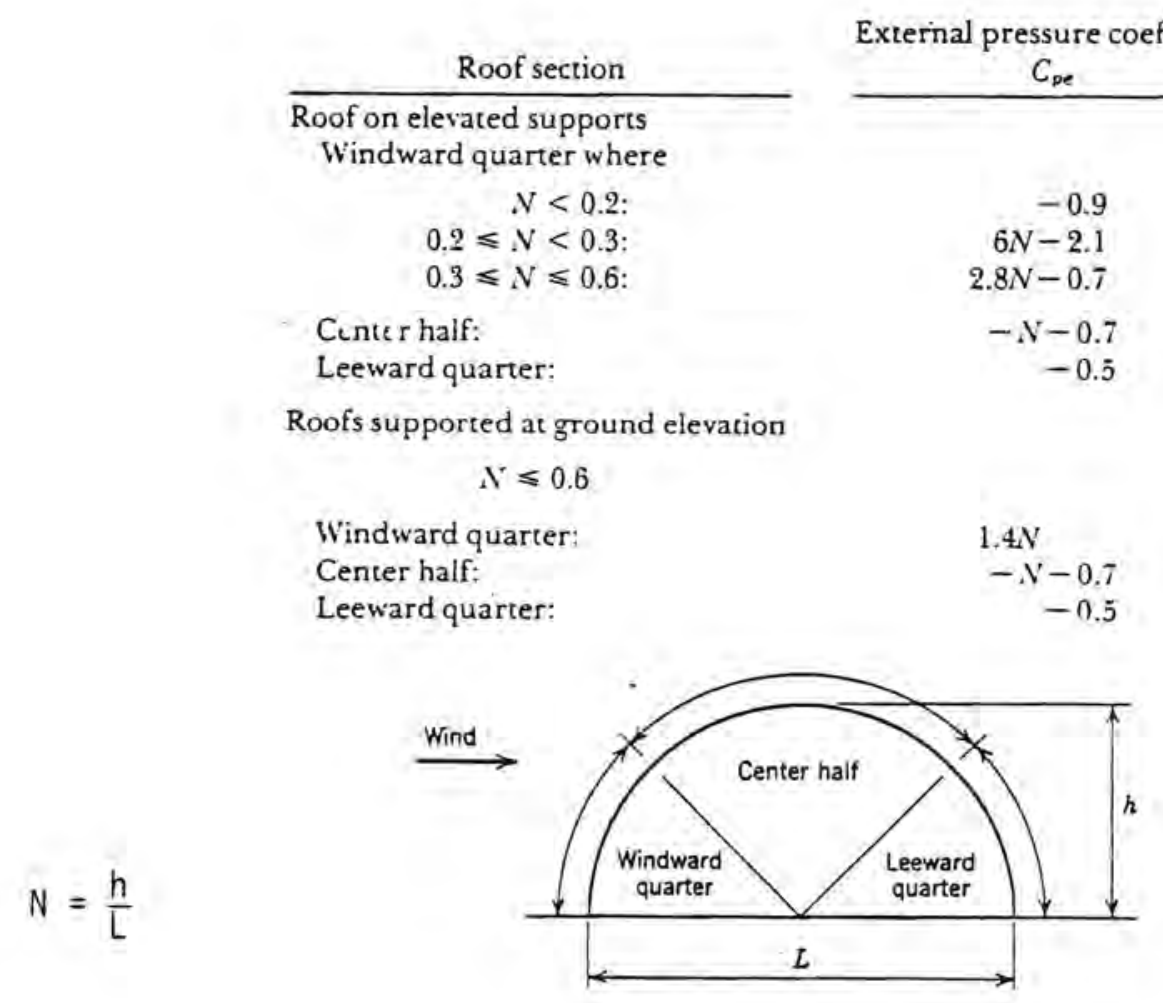

FIGURE 43. Wind Pressure Coefficients, Below Ground Tank(1) 


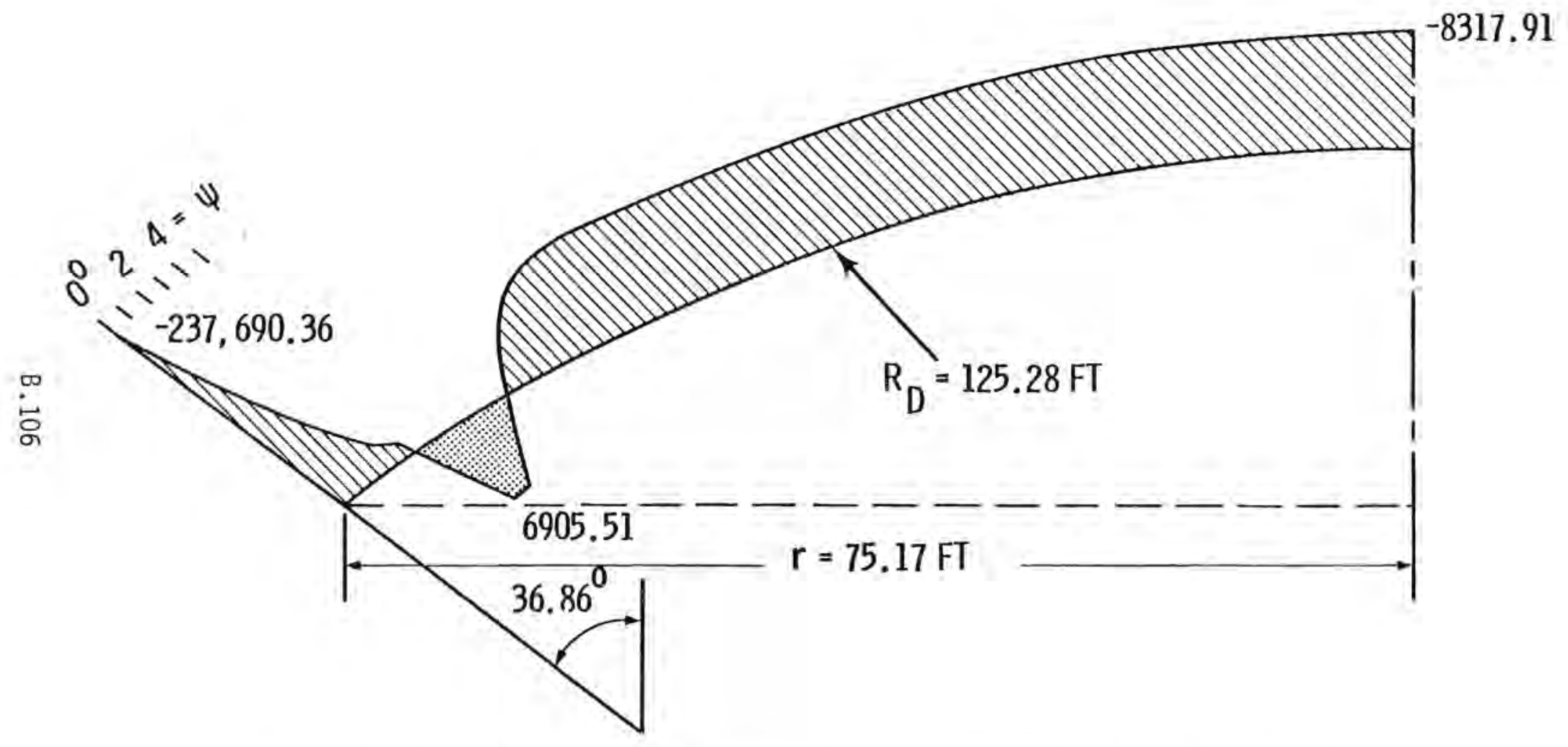

FIgURE 44. $N_{\theta}(1 \mathrm{~b} . / \mathrm{ft}$.$) - Effect of Wind +\mathrm{DL}, \theta=0^{\circ}$ Above Ground Tank 


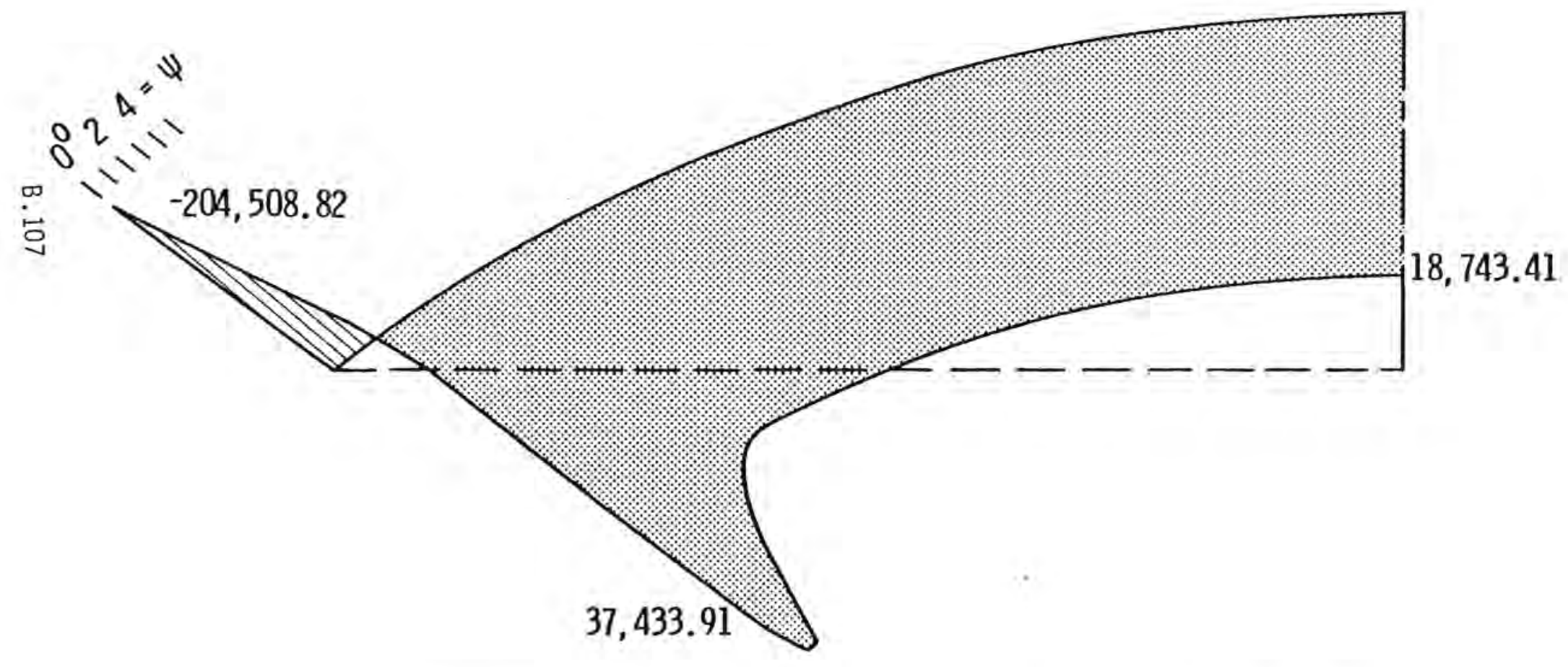

FIGURE 45. N $N_{\theta}$ (1b./ft.) - Effect of 3.0 psi Pressure Drop + DL, Both Tanks 


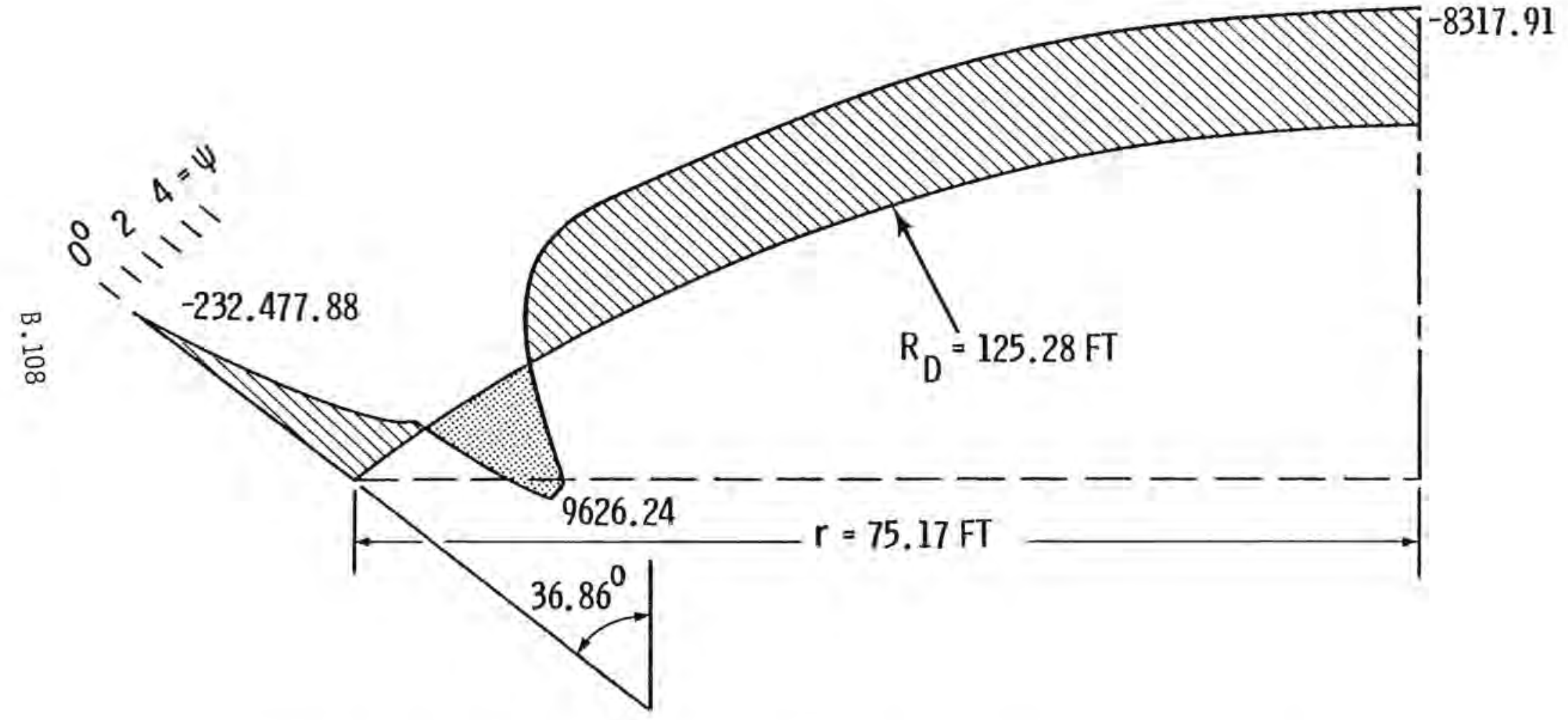

FIGURE 46. $N_{\theta}$ (1b./ft.) - Effect of Wind $+D L, \theta=180^{\circ}$, Underground Tank 
The allowable stresses for concrete were calculated from ACI $318^{(4)}$ except as noted in Table 10. (7) An allowable axial and flexural compression stress of 2250 psi and an allowable tensile stress of 424 psi was obtained.

In considering the compression case for the concrete dome, the most adverse of combinations of loads was the effect of wind plus dead load at $\theta=0^{\circ}$, Figure 44 , and $\theta=180^{\circ}$, Figure 46, for the above and underground tank, respectively. The resulting membrane force, $N_{\theta}=-237,690.361 \mathrm{~b} . / \mathrm{ft}$., for the aboveground tank divided by the ring depth produced a compressive stress equal to 1378.76 psi, well below the allowable stress of 2250 psi. A compressive stress of 1348.52 psi was obtained for the underground tank.

The load combination of the 3.0 psi pressure drop plus dead load, Figure 45 , lead to the most adverse condition for both the above and underground tank in investigating the tensile stresses in the dome. The resulting tensile stress of $389.94 \mathrm{psi}$ is under the allowable tensile stress of 424 psi.

The prestressed concrete tanks used in this scenario would be able to withstand a direct hit by a tornado and thus prevent the release of LNG from the tank. 
TABLE 10. Allowable Stresses $(7)$

\begin{tabular}{|c|c|c|c|c|}
\hline \multirow[t]{2}{*}{ Description } & \multicolumn{2}{|c|}{ Concrete } & \multicolumn{2}{|c|}{ Shotcrete } \\
\hline & $\begin{array}{l}\text { Temporary } \\
\text { Stresses, } \\
\quad \text { fci }\end{array}$ & $\begin{array}{l}\text { Stresses at } \\
\text { Design Loads, } \\
\text { fc }\end{array}$ & $\begin{array}{l}\text { Temporary } \\
\text { Stresses, } \\
\quad \text { fgi }\end{array}$ & $\begin{array}{l}\text { Stresses at } \\
\text { Design Loads, } \\
\text { fg }\end{array}$ \\
\hline Axial compression & $0.55 f^{\prime} \mathrm{ci}$ & $0.45 \mathrm{fc}^{\prime}$ & $\begin{array}{l}0.45 f^{\prime} \mathrm{gi} \\
\text { but not more than } \\
1600+40 \mathrm{t}_{\mathrm{c}} \text { psi } \\
\left(112+1.12 \mathrm{t}_{\mathrm{c}}\right. \\
\left.\mathrm{kgf} / \mathrm{cm}^{2}\right)^{\mathrm{b}}\end{array}$ & $0.38 \mathrm{fg}^{\prime}$ \\
\hline Axial tension & 0 & 0 & 0 & 0 \\
\hline Flexural compression & $0.60 f^{\prime} \mathrm{ci}$ & $0.45 \mathrm{fc}^{\prime}$ & $0.45 f^{\prime} g i$ & $0.38 \mathrm{fg}^{\prime}$ \\
\hline $\begin{array}{l}\text { Fluxural tension, in zones } \\
\text { with no auxiliary re- } \\
\text { inforcement }\end{array}$ & 0 & 0 & 0 & 0 \\
\hline $\begin{array}{l}\text { Fluxural tension in zones } \\
\text { with auxiliary rein- } \\
\text { forcement and no dia- } \\
\text { phragmg }\end{array}$ & $\begin{array}{c}250 \mathrm{psi} \\
\left(17.6 \mathrm{kgf} / \mathrm{cm}^{2}\right)\end{array}$ & $\begin{array}{c}200 \mathrm{psi} \\
\left(14.1 \mathrm{kgf} / \mathrm{cm}^{2}\right)\end{array}$ & $\begin{array}{c}250 \mathrm{psi} \\
(17.6 \mathrm{kgf} / \mathrm{cm} 2)\end{array}$ & $\left(14.1 \mathrm{kgf} / \mathrm{cm}^{2}\right)$ \\
\hline $\begin{array}{l}\text { Flexural tension in zones } \\
\text { with auxiliary rein- } \\
\text { forcing and diaphragm }\end{array}$ & $\mathrm{c}$ & c & $\mathrm{C}$ & $\mathrm{c}$ \\
\hline $\begin{array}{l}\text { Shear, diagonal tension } \\
\text { and bearing }\end{array}$ & & $d$ & & $d$ \\
\hline Bond & & e & & $e, f$ \\
\hline
\end{tabular}

NOTES:
b. Before creep and shrinkage losses.
b. For $>4 \mathrm{in.}(10 \mathrm{~cm})$; for $t_{c}$ less than 4 in., use fgt $=1500 \mathrm{psi}\left(105.5 \mathrm{kgt} / \mathrm{cm}^{2}\right)$; for dome ring, use $0.45 f^{\top} g \bar{i}$.

c. Assume 100 percent of tensile force taken by reinforcing steel and or diaphragm.

d. See Table 1002(a), ACI 318-77.

e. See Chapter 13, ACI 313-63.

f. See Chapter 13, ACI 316-63. Consider vertically fluted steel diaphragm bond equivalent to plain bars.

g. Auxiliary reinforcement is provided for entire flexural tension force. 


\section{REFERENCES}

1. Timber Construction Manual, Second Edition, American Institute of Timer Construction, Englewood, Colorado, Copyright 1974, pp. 3-21.

2. Simiu, Emil, and Scanlan, Robert H., Wind Effects on Structures: An Introduction to Wind Engineering, John Wiley and Sons, New York, Copyright 1978.

3. Sun, C.N., Burdette, and Perry, N.H.L., "Tornado Wind Forces On Structures."

4. American Concrete Institute Building Code Requirements, ACI 318-77, American Concrete Institute, Detroit, Michigan.

5. U.S. Nuclear Regulatory Commission Regulatory Guide 1.76, "Design Basis Tornado for Nuclear Power Plants," April 1974.

6. ANSI A58.1-1972, "Building Code Requirements for Minimum Design Loads in Building and Other Structures."

7. Jorgensen, Ib Falk, "Design and Construction of Circular Prestressed Concrete Structures," ACI Journa1, September 1970, pp. 657-672.

8. Standard for the Production Storage and Handling of Liquefied Natural Gas (LNG), NFPA 59A-1979.

9. Recommended Rules for Design and Construction of Large, Welded, LowPressure Storage Tanks, API Standard 620, American Petroleum Institute, July 1973. 


\section{MISSILE IMPACT}

\section{Discussion}

In this study only site generated missiles have been investigated. Aircraft impact or military type missiles were not considered due to their remote probability of occurrence.

Missiles may be generated by an event that is not related to plant operations or by a failure of plant equipment. Debris transported by tornado winds and falling objects generated by activities near the site are the most common type in the first category. The second type of missile usually results from forces released accidentally from pressurized systems or rotating machinery.

Missile parameters required for impact analysis include deformation characteristics, geometry, mass, trajectory and velocity. Depending on the geography of the site and the type of plant, postulated missiles and their properties may vary.

A structure that provides missile protection is usually referred to as a target. The energy of the missile is absorbed by local damage at the location of impact. The extent or severity of local damage depends on missile characteristics, target material properties and structural response. The prediction of local damage in the impact area includes estimating the depth of penetration, minimum thickness to prevent perforation, and minimum thickness to preclude spalling.

\section{Analyses}

In analyzing the effects of missile impact, the following formulas are probably best known and most widely used: (3)

1. The Ahman and Whitney Formula

2. The Army Corps of Engineers Formula

3. The Ballistic Research Laboratory Formula

4. The Modified National Defense Research Committee Formula

5. The Modified Petry Formula, Variations I and II 
In spite of their wide spread use, these formulas may give highty different results in some instances, with a difference factor of 16 or higher not uncommon (2). A11 of the formulas listed suffer 1 imitations in the range of available test data. This is especially true in the velocity range below $1000 \mathrm{ft} . / \mathrm{sec}$., since missiles of interest to industry fall in the range of $100-600 \mathrm{ft} . / \mathrm{sec}$.

The Modified National Defense Research Conmittee (NDRC) Formula is recommended from the review of available literature (2) for nondeformable missiles and the range of velocities encountered in the industry. This has the best correlation with available data and will be compared with the Modified Petry Formula.

A11 of the formulas above assume that the missile strikes the target normal to the surface and that the axis of the missile is parallel to the line of flight.

A summary of the effects on the tank by the postulated missiles are listed in Table 11.

Based on recommendations outlined in the NRC guide description of some postulated missiles and their impact velocities can be obtained from the references $(1,2)$. Missiles such as planks and utility poles are termed "soft" missiles since they deform upon impact. They cannot be investigated by the formulas listed, which are for essentially "hard" nondeformable missiles. However, these "soft" missiles present little danger in terms of local damage or structural response even at velocities in the range of $500 \mathrm{ft} . / \mathrm{sec}$. (2).

In addition to the missiles recommended by NRC, other postulated missiles were investigated based on the likelihood of being a falling object generated by activities near the site, transported by tornado winds, or released accidentally from pressurized systems or rotating machinery. 
TABLE 11. Summary of Effects on Concrete Tank by Postualted Missiles

\begin{tabular}{|c|c|c|c|c|c|c|}
\hline & MISSILE OBJECT & $\begin{array}{l}\text { VELOCITY } \\
\text { (ft./sec.) }\end{array}$ & $\begin{array}{l}\text { WE IGHT } \\
\text { (1b.) }\end{array}$ & $\begin{array}{l}\text { DIAMETER } \\
\text { (in.) }\end{array}$ & $\begin{array}{l}\text { AREA } \\
\left(\text { in }^{2}\right)\end{array}$ & $\begin{array}{c}\text { PERFORATION THICKNESS } \\
\text { (inches) }\end{array}$ \\
\hline$\therefore$ & $1^{\prime \prime} \varnothing \times 3^{\prime}$ Steel $\operatorname{Rod}^{(2)}$ & 200 & 8.05 & 3.0 & .785 & 3.7 \\
\hline & $3^{\prime \prime} \emptyset \times \mathrm{SCH} 40$ Pipe $-15^{\prime}$ long $(2)$ & 130 & 114 & 3.5 & 7.07 & 7.0 \\
\hline 3) & 6" $\varnothing \mathrm{SCH} 40$ Pipe - 15 1ong ${ }^{(2)}$ & 155 & 285 & 6.63 & 28.3 & 11.0 \\
\hline & $12^{\prime \prime} \emptyset \mathrm{SCH} 40$ Pipe - 15' long (2) & 75 & 800 & 12.75 & 113 & 8.2 \\
\hline 5) & 8" $\varnothing$ slug (solid cylinder) & 800 & 213 & 8.0 & 50.3 & 15.5 \\
\hline 6) & 8" shpere & 262 & 75 & 8.0 & 50.3 & 10.3 \\
\hline 7) & $25.6^{\prime \prime} \emptyset$ sphere & 200 & 2500 & 25.6 & 514.7 & 30.0 \\
\hline o) & Nozzle & 670 & 250 & 9.03 & 64 & 27.3 \\
\hline 9) & Structural Column & 220 & 36000 & 9.8 & 75 & 60 \\
\hline 10) & Small fragment & 900 & 20 & 2.8 & 6 & 13. \\
\hline 11) & Large Fragment & 750 & 100 & 1.6 & 2 & 18.9 \\
\hline 12) & Cover plate & 300 & 850 & 11.3 & 100 & 25.8 \\
\hline 13) & Valve & 420 & 500 & 1.5 & 1.7 & 24.9 \\
\hline 14) & Valve & 500 & 300 & 1.3 & 1.3 & 23.6 \\
\hline 15) & Pipe & 180 & 200 & 4.5 & 16 & 11.1 \\
\hline
\end{tabular}

1) Thickness that a given missile will just perforate

2) Object that are tornado induced

3) The exterior concrete wall of the prestressed concrete tank consists of a 16-inch layer of concrete, a 3/16-inch carbon steel tank liner and 2-inches of shotcrete. The roof consists of 8-inches of concrete with the 3/16-inch liner. The carbon steel liner is equivilent to 7 thicknesses of concrete and the shotcrete is similar to concrete. Therefore the effective thicknesses which the hurled missile would need to impact are: $T($ concrete, wa11) $=(16+3 / 16(7)+2)$ inches $=19.3124$ inches $T($ concrete, roof $)=(8+3 / 16(7))$ inches $=11.5$ inches 
Summarized in Table 11 are the effects of the postulated missiles on the tank. A missile shape factor of 0.72 (flat nosed bodies) or 0.84 (blunt nosed bodies) was used and all other required missile parameters are listed in Table 11. The missiles were assumed to strike the target normal to the surface and with their axes parallel to the line of flight.

The perforation thickness for the postulated missiles are provided, indicating the thickness that the given missile will just pass through. Perforation velocities for both the wall and roof are also listed.

For the above ground concrete LNG storage tank it is shown that $40 \%$ of the postulated missiles pose a potential hazard to the tank's wall; i.e., the perforation thickness is greater than the transformed wall thickness (16 in. concrete, $3 / 16$ in. P liner and 2 in. P.M.). For the transformed roof thickness (8 in. concrete and $3 / 16$ in. $P_{L}$ ) $60 \%$ of the postulated missiles would penetrate through the roof. Only the first seven (7) missiles were considered for the roof due to its relative height above the ground and the probability of occurrence for each respective missile.

In investigating the underground concrete LNG storage tank all fifteen (15) postulated missiles were considered for the roof. It is shown in this case that $80 \%$ of the postulated missiles would penetrate the roof upon impact.

It may be concluded that the above ground concrete tank has less inherent danger for failure from missile impact based on its relative. orientation than the underground tank. 


\section{REFERENCES}

1. DePineress, 0.G., "Site Information for Nuclear Projects," Structural Design of Nuclear Plant Facilities, ASCE, 1975.

2. Kennedy, R.P., "A Review of Procedures for the Analysis and Design of Concrete Structures to Resist Impact Effects", Nuclear Engineering and Design 37, North-Holland Publishing Co., $19 \overline{76 .}$

3. Personal communication with Preload Technology, Inc., Garden City, New York, July 10, 1981. 


\section{FIRE}

\section{Discussion}

The effects of fire on the LNG storage tank were considered. Part one of the two phase study investigated the temperature distribution in the wall due to a flux radiation of $4755 \mathrm{Btu} / \mathrm{ft}^{2} \mathrm{~h}(6)$. The heat flux radiation rate on the tank due to a fire in an adjacent tank was determined in Part Two.

Concrete used in prestressed work is often mechanically compacted, dense in texture, subjected to higher compressive stresses, and possesses higher strength than concrete used in other work. The sensitivity of high tensile steel to temperature can be compared with that of mild steel bars. Results on the strength of high tensile wires and strands under high temperature show that, up to about $300^{\circ} \mathrm{F}$, there is a slight increase in strength. From $300^{\circ} \mathrm{F}$ tensile strength reduces to a value of about $50 \%$ at $750^{\circ} \mathrm{F}$. Since the ultimate strength of a prestressed member in bending is proportional to the ultimate strength of steel, the 1 imit of $750^{\circ} \mathrm{F}$ in the steel may be considered as the point of impending failure, provided that a full live load is on the structure.

Many tests on the fire resistance of prestressed concrete have been conducted both in the United States and elsewhere. Results of these tests have shown that the fire resistance of prestressed concrete depends on several factors:

1. The principal factor is the clear cover of concrete which protects the stee1. Many tests have shown that prestressed concrete with an adequate concrete cover can readily withstand standard fires lasting up to 4 hours.

2. The shape of the element may appreciably affect the fire resistance.

3. The cross-sectional size of the element is another factor, since with increased size its heat absorption capacity increases.

4. The positioning of tendons away from the exposed surfaces will increase the fire resistance. 
5. Amount of end restraint for the element may appreciably affect its fire resistance.

A major potential hazard of an LNG facility is a fire and its consequences. Gas fires generaliy fall into two categories: a low-pressure type where the flame is localized and high-pressure type in which a burning gas jet may impinge on other equipment. A high velocity gas jet could be produced by a crack in a gas treatment vessel or a failure in gas piping. If such a jet ignites, the length of the burning jet depends primarily on the size of the opening. The flame jet length (feet) for methane is about 16 times the hole diameter (inches). Rapid heating and secondary failure may occur if such a jet impinges on other equipment and the exposures are not cooled with water. This type of gas fire poses less of a hazard than the low pressure type and was not analyzed further.

A large LNG pool fire is normally a low-pressure type with the fire about three times higher than its base dimension. Objects around the fire absorb the radiated heat from the visible burning zone. The thermal radiation intensity can be estimated as a function of location and distance from the fire for a specified size burning LNG pool and known weather conditions. Failure of steel structures, machinery, fatality or serious burns to people from doses of thermal radiation have been fairly well defined. This combination of information, along with specific site details, allows hazard severity estimates to be made.

Some of the safety concerns in the transportation and storage of LNG were highlighted in a report issued on July 31 , 1978, by the General Accounting Office entitled, "Liquefied Energy Gases". Foremost among these concerns were: (1) the protection of persons and property near an LNG facility from thermal radiation (heat) caused by ignition of a major spill of LNG, (2) protection of persons and property near an LNG facility from dispersion and delayed ignition of a natural gas cloud arising from a major spill of LNG, and (3) reduction of the potential for a catastrophic spil1 of LNG. 
The study of the effect of fire on the tank consists of two parts and will focus on points (1) and (3) above. Part One of the study will investigate the temperature distribution in the wall due to a flux radiation, $Q$, of $4755 \mathrm{Btu} / \mathrm{ft}^{2} \mathrm{~h}(6)$. The basic assumption for this analysis considers the roof to no longer be intact and the fire to be concentrated within the tank's boundaries. The heat flux radiation rate on the tank due to a fire in an adjacent tank $525 \mathrm{ft}$. (C.L.-C.L.) away will be determined in Part Two of the study. The clear distance between tanks is well above the minimum clear distances specified by NFPA 59A-1979 (1) and 1isted below:

Minimum Clear Distances

\begin{tabular}{|c|c|c|}
\hline Water Capacity Per Container & $\begin{array}{l}\text { From Container } \\
\text { To Property } \\
\text { Line Which } \\
\text { May Be } \\
\text { Built Upon }\end{array}$ & $\begin{array}{l}\text { Between } \\
\text { Any Two } \\
\text { Adjacent } \\
\text { Containers }\end{array}$ \\
\hline Less than 125 gal $(473 \mathrm{~L})$ * & None & None \\
\hline 125 to $250 \mathrm{gal}(473$ to $946 \mathrm{~L})$ & $10 \mathrm{ft} .(3 \mathrm{~m})$ & None \\
\hline 251 to $500 \mathrm{gal}(950$ to $1892 \mathrm{~L})$ & $10 \mathrm{ft} .(3 \mathrm{~m})$ & $3 \mathrm{ft} .(1 \mathrm{~m})$ \\
\hline 501 to $2,000 \mathrm{gal}\left(1.9\right.$ to $\left.7.6 \mathrm{~m}^{3}\right)$ & $25 \mathrm{ft} .(7.6 \mathrm{~m})$ & $3 \mathrm{ft} .(1 \mathrm{~m})$ \\
\hline 2,001 to $30,000 \mathrm{gal}\left(7.6+\right.$ to $\left.113 \mathrm{~m}^{3}\right)$ & $50 \mathrm{ft} .(15 \mathrm{~m})$ & $5 \mathrm{ft} .(1.5 \mathrm{~m})$ \\
\hline 30,001 to $70,000 \mathrm{gal}\left(113+\right.$ to $\left.265 \mathrm{~m}^{3}\right)$ & $75 \mathrm{ft} .(23 \mathrm{~m})$ & $10 \mathrm{ft} .(3 \mathrm{~m})$ \\
\hline Above $70,000 \mathrm{gal}\left(265 \mathrm{~m}^{3}\right)$ & $\begin{array}{l}0.7 \text { times the con- } \\
\text { tainer diameter but } \\
\text { not less than } 100 \mathrm{ft} \\
(30 \mathrm{~m}) .\end{array}$ & $\begin{array}{l}1 / 4 \text { of sum of diam- } \\
\text { eters of the two } \\
\text { adjacent containers } \\
\text { but not less than } \\
25 \mathrm{ft} .(7.6 \mathrm{~m})\end{array}$ \\
\hline \multicolumn{3}{|c|}{$\begin{array}{l}\text { *If the aggregate water capacity of a multicontainer installation is } 501 \text { gal } \\
\left(1.9 \mathrm{~m}^{3}\right) \text { or greater, the minimum distance shall comply with the appropriate } \\
\text { portion of this table, applying the aggregate capacity rather than the capacity } \\
\text { per container. If more than one installation is made, each installation shall } \\
\text { be separated from another installation by at least } 25 \mathrm{ft} \text {. ( } 7.6 \mathrm{~m} \text { ). Do not } \\
\text { apply the minimum distances between adjacent containers to such installations. }\end{array}$} \\
\hline
\end{tabular}

Some state codes, however, are double the NFPA $59 \mathrm{~A}$ requirements and probably reflect an increasing concern about LNG hazards. 
Analysis

In investigating the temperature distribution in the tank wall from a fire within the tank's boundaries, it was assumed that the temperature of the surroundings and the air were $40^{\circ} \mathrm{F}$ and $86^{\circ} \mathrm{F}$, respectively. The methodology proposed by H. S. Carslow and J. C. Jaeger ( 2 ) was adopted where the temperature distribution profile was just the temperature rise, $v$, minus the surface temperature, $v_{s}$.

As the tank wall is exposed to a fire radiation of $Q=4755 \mathrm{Btu} / \mathrm{ft}^{2} \mathrm{~h}$ (6) it will warm up at the surface to the following temperature vs. time (Figure 47):

$\begin{array}{ll}366^{\circ} \mathrm{F} & \text { After one hour } \\ 460^{\circ} \mathrm{F} & \text { After two hours } \\ 512^{\circ} \mathrm{F} & \text { After three hours } \\ 543^{\circ} \mathrm{F} & \text { After four hours } \\ 566^{\circ} \mathrm{F} & \text { After five hours }\end{array}$

At the beginning of the zone of the prestressing wires, the temperature of the wall $1.0 \mathrm{in}$. below the surface will be:

$\begin{array}{ll}275^{\circ} \mathrm{F} & \text { After one hour } \\ 375^{\circ} \mathrm{F} & \text { After two hours } \\ 435^{\circ} \mathrm{F} & \text { After three hours } \\ 475^{\circ} \mathrm{F} & \text { After four hours } \\ 495^{\circ} \mathrm{F} & \text { After five hours }\end{array}$

The temperatures computed above indicate that the tank's wal1 will not be in danger of collapse until well after a four (4) hour duration from the initiation of the fire. Further, the prestressing wires will be at temperatures sufficiently below the critical temperature of $608^{\circ} \mathrm{F}\left(320^{\circ} \mathrm{C}\right)$ for typical stresses in wires specified in FIP/CEB Recommendations for the Design of Re inforced and Prestressed Concrete Structural Members for Fire Resistance. 


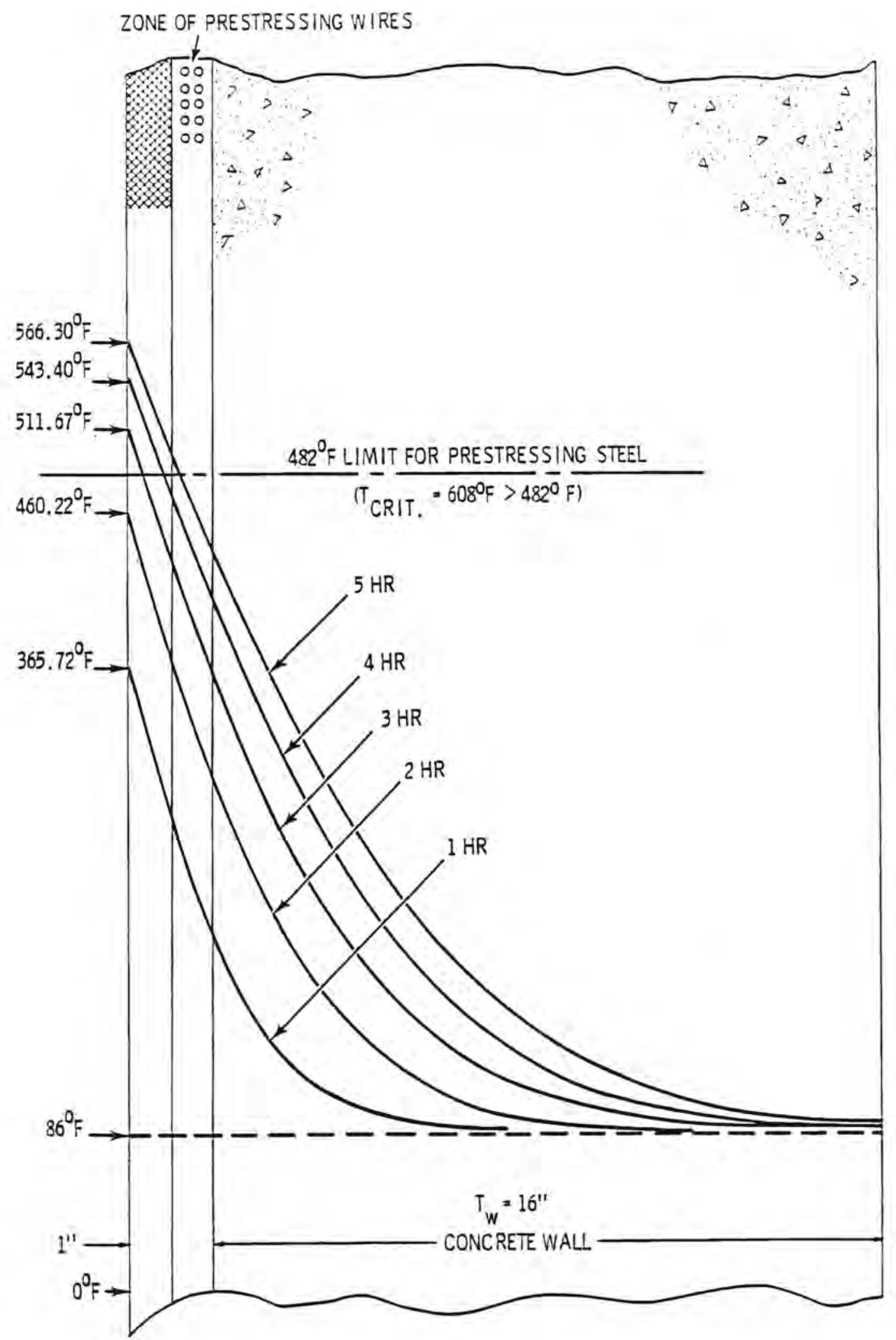

FIGURE 47. Temperature Distribution in the Wal1, $\mathrm{Q}=4755 \mathrm{Btu} / \mathrm{ft} .{ }^{2} \mathrm{~h}(6)$ B. 121 
When the face of the inside wall is covered by insulation the equilibrium temperature, $T_{E}$, will increase by $31^{\circ} \mathrm{F}$. This in turn would raise the surface temperature of the wall, but no significant change in the temperature distribution through the wal1 would occur.

The heat interception rate on the wall or roof of an adjacent tank was computed as outlined in the references $(3,5)$. In the analysis it was assumed that there was a wind velocity of $30 \mathrm{mph}$, an air temperature of $70^{\circ} \mathrm{F}$ at a relative humidity of $80 \%$ and the tanks separated by a distance of $525 \mathrm{ft}$. (C.L.-C.L.). The radiation power, W, of the flame was calculated to be $40,000 \mathrm{Btu} / \mathrm{ft}^{2} \mathrm{~h}$. This value is below the emissive power for LNG fires $\left(45,000 \mathrm{Btu} / \mathrm{ft}^{2} \mathrm{~h}\right)$ as noted in the work by $\operatorname{Raj}(4)$.

The radiation interception rate, Q, from an inclined flame at the top of the $150.33 \mathrm{ft}$. diameter tank to a point downwind from the fire, Figure 48, will be $986 \mathrm{Btu} / \mathrm{ft}^{2} \mathrm{~h}$ at the wall of the other tank (point "A"-wa11) and $1253 \mathrm{Btu} / \mathrm{ft}^{2} \mathrm{~h}$ at the roof (point "A"-roof). If an underground tank was located downwind instead, the radiation interception rate would reduce to $961 \mathrm{Btu} / \mathrm{ft} .^{2} \mathrm{~h}$ (point "B"-roof).

As a further check on the clear distance spacing, the tanks were placed $250 \mathrm{ft}$. apart (0.S.-0.S.). These results indicated an $11 \%$ and $24 \%$ increase in the radiation interception rate for the wa 11 and roof, respectively, due to the $33 \%$ decrease in clear distance. In spite of this relative increase, the heat interception rate, $Q$, would remain well below the flux radiation of $Q=4755 \mathrm{Btu} / \mathrm{ft} .{ }^{2} \mathrm{~h}$ used in Part One of the study. It may then be concluded that a concrete LNG tank would be able to withstand the radiation effects from an inclined flame (30 mph wind) due to a fire in an adjacent tank. 

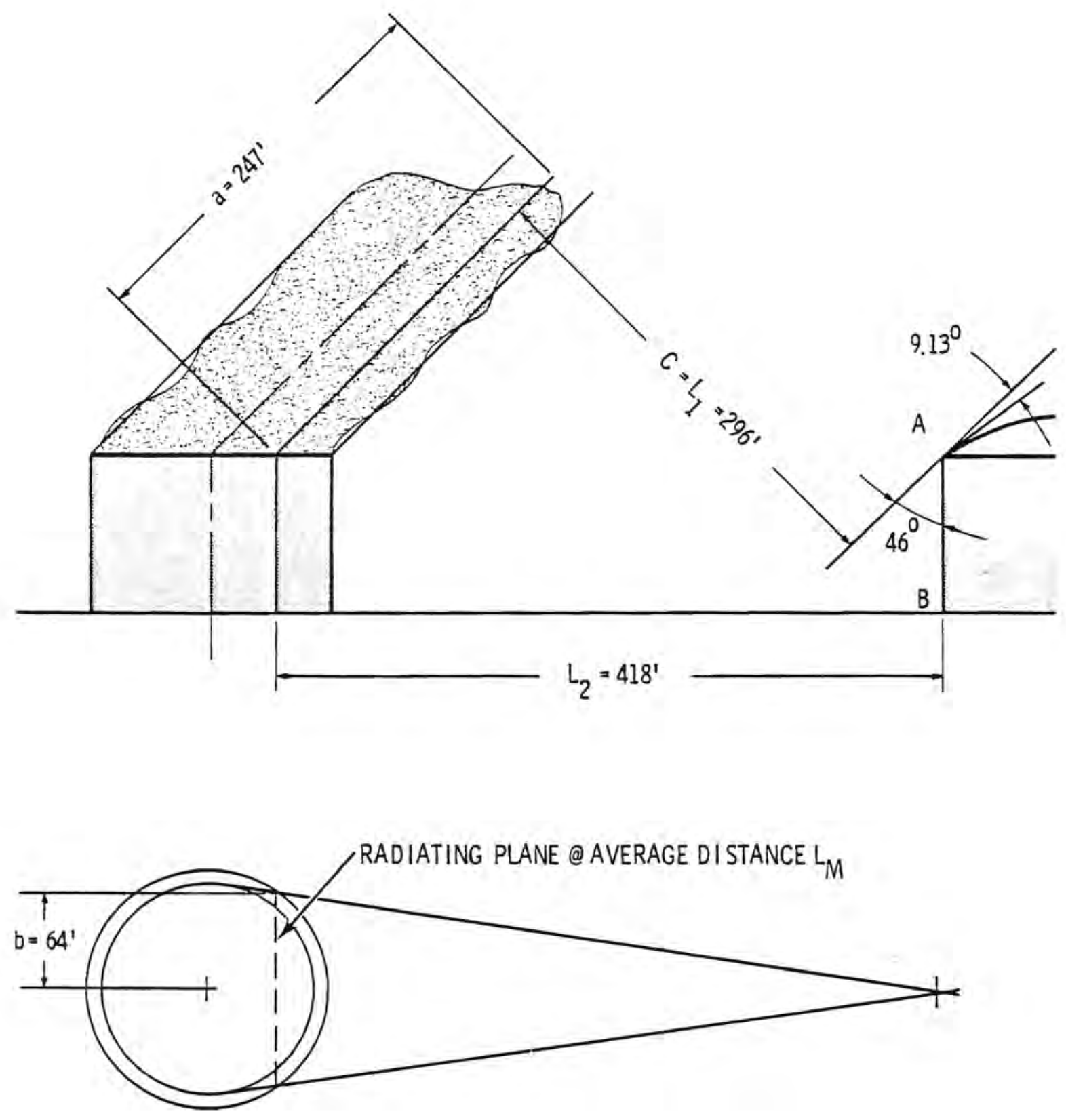

FIGURE 48. Heat Interception Rate 


\section{REFERENCES}

1. Standards for the Production, Storage and Handling of Liquefied Natural Gas (LNG), NFPA 59A-1979.

2. Carslow, H.S. and Jaeger, J.C., "Conduction of heat in Solids, "Oxford, The Clarendon Press, 1959.

3. Parker, Robert 0., "Final Report on American Gas Association Project IS 109-1 Radiation From LNG Fires", February 1977.

4. Raj, Phani, P.K., "Calculations of Thermal Radiation Hazards From LNG Fires - A Review of the State-of-the-Art", Presented at the AGA Transmission Conference, St. Louis, MO, May 1977.

5. Hamilton, D.C. and Morgan, W.R., "Radiant-Interchange Configuration Factors", National Advisory Committee for Aeronautics, Technical Note 2836, December 1952.

6. Personal communication with Preload Technology, Inc., Garden City, NY, July 10, 1981. 
SEISMIC

Discussion

The effects of a seismic load on prestressed concrete LNG storage containers were considered.

In the designing of stationary LNG storage containers NFPA 59A (4) requires that seismic loads be considered. The Uniform Building Code (UBC) and the procedures described in Chapter 6, "Dynamic Pressure on Fluid Containers," of Nuclear Reactors and Earthquakes, TID-7024 (1) are referenced by NFPA 59A as the basis for the seismic design of above ground storage tanks. The UBC only considers lateral accelerations which might occur during an earthquake. It is reasoned that the vertical component of ground vibration may be neglected due to the considerable excess of strength in the vertical direction allowed by the safety factors used in design. The Uniform Building Code uses a seismic probability map of the United States, Figure 49, in conjunction with the formula below to determine a design basis lateral force that a building or structure must be able to withstand. The design basis lateral force, $F$, is given by:

$$
F=Z C_{p} W_{p}
$$

where,

$$
\begin{aligned}
W_{p}= & \text { the weight of the tank and contents } \\
C_{p}= & 0.12, \text { for tanks resting on the gound } \\
Z= & \text { numerical coefficient determined by the seismic } \\
& \text { zone map. } Z \text { equals } 3 / 16,3 / 8,3 / 4 \text { and } 1 \text { for } \\
& \text { Zones } 1,2,3 \text { and } 4, \text { respectively. The value } Z \\
& \text { to be used in Zone } 0 \text { is not given by the UBC. }
\end{aligned}
$$

Seismic design techniques for 1iquid-containing cylindrical tanks are generally based on the work of Housner (1). As cited in Reference 1, it was assumed in his studies that there was a perfect 1 iquid in a rigid tank subjected to a horizontal earthquake exitation applied to the tank. 


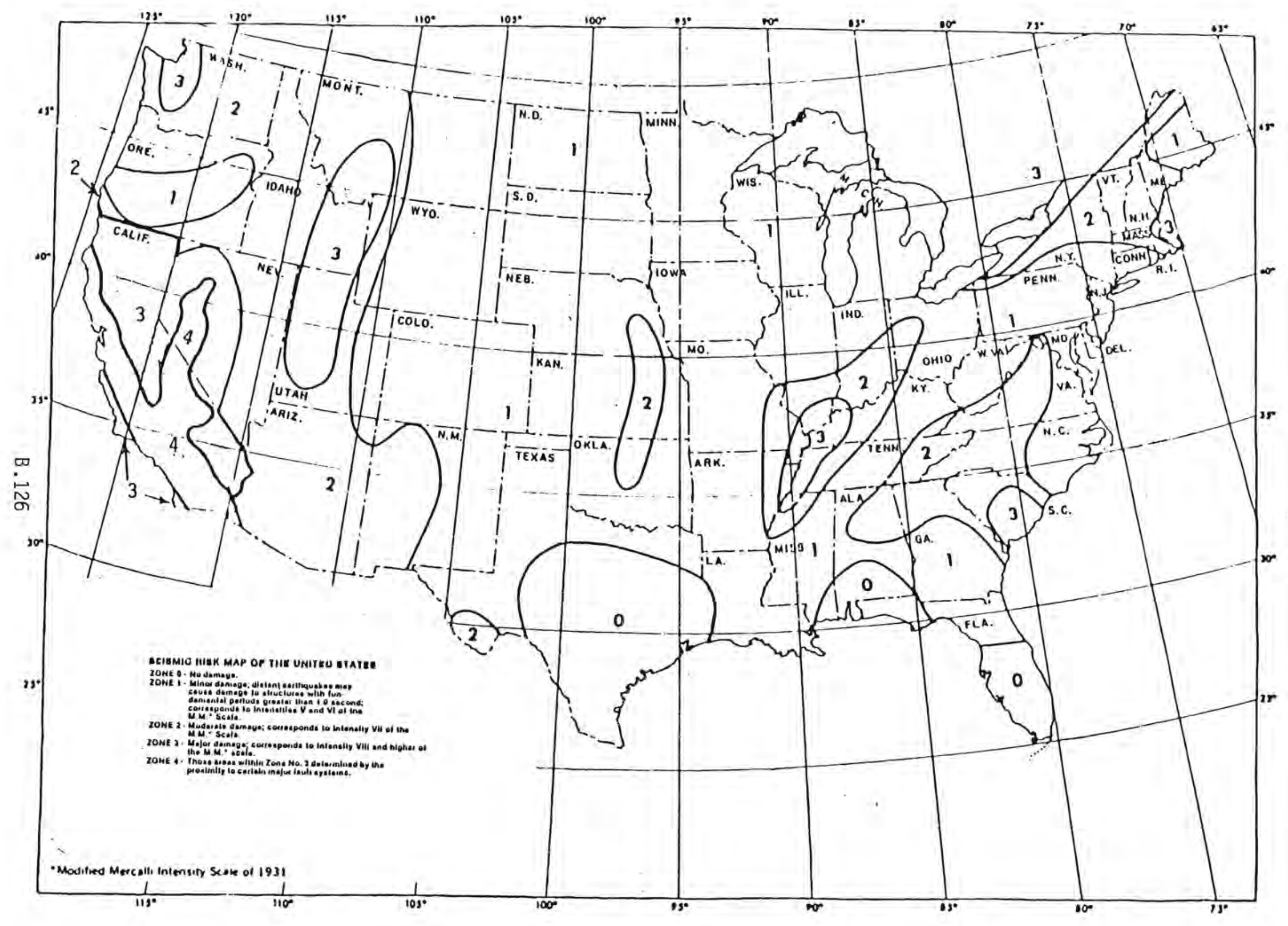

FIGURE 49. Seismic Risk Map of the United States (3) 
It was further assumed that the tank did not deform when the 1 iquid responded in a sloshing mode. The possibility of response of the liquidcontaining tank to the horizontal earthquake excitation was taken into account only for the oscillating part of the Tiquid, Figure 50. The impulse part of the liquid was considered as a mass rigidly attached to the rigid mass of the tank wall, affected by the ground motion and the magnitude of horizontal acceleration.

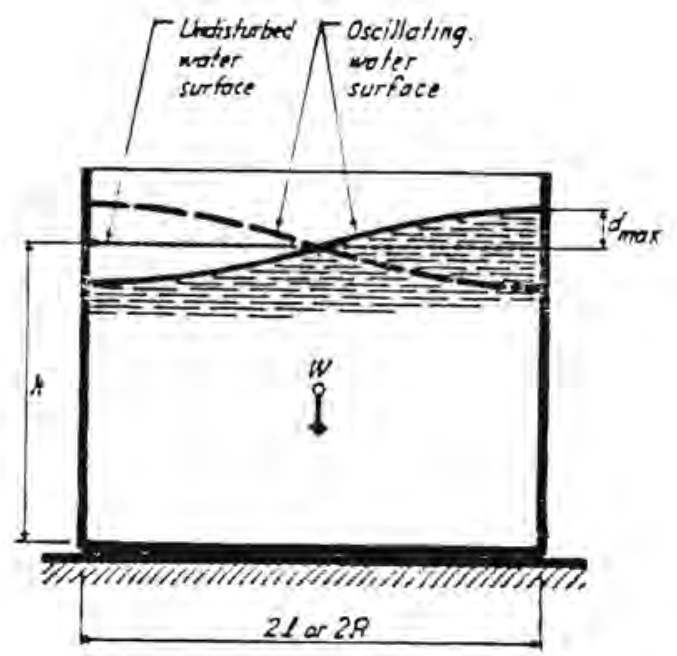

FIGURE 50. Fluid Motion in Tank (1)

Procedures to compute the dynamic forces from both parts of the Tiquid, their locations, overturning moment of the tank and liquid pressure distribution exerted on the wa11 due to horizontal acceleration in rigid tanks are presented in Reference 1.

For the seismic design of LNG inground storage tanks, the seismiccoefficient method is suggested in Recommended Practice for LNG Inground Storage, Japan Gas Association (2). In the seismic-coefficient method, the structure is designed under a loading condition in which the inertia force acts upon the structure statically as an external force. The safety of LNG inground storage tanks which have been designed by the seismiccoefficient method have been confirmed from the results of the model system 
vibration tests, dynamic analysis, and earthquake observations (2). A recommended method for the seismic design of underground LNG storage tanks in the United States has not appeared in the 1iterature to date,

\section{Anatysis}

Strong-motion earthquake acceleration records with respect to time have been obtained for a number of earthquakes. Among the more intense strong motion earthquakes recorded so far is that of the El Centro, California earthquake of May 18, 1940. The recorded accelerogram, in the north-south component of horizontal motion, is shown in Figure 51.

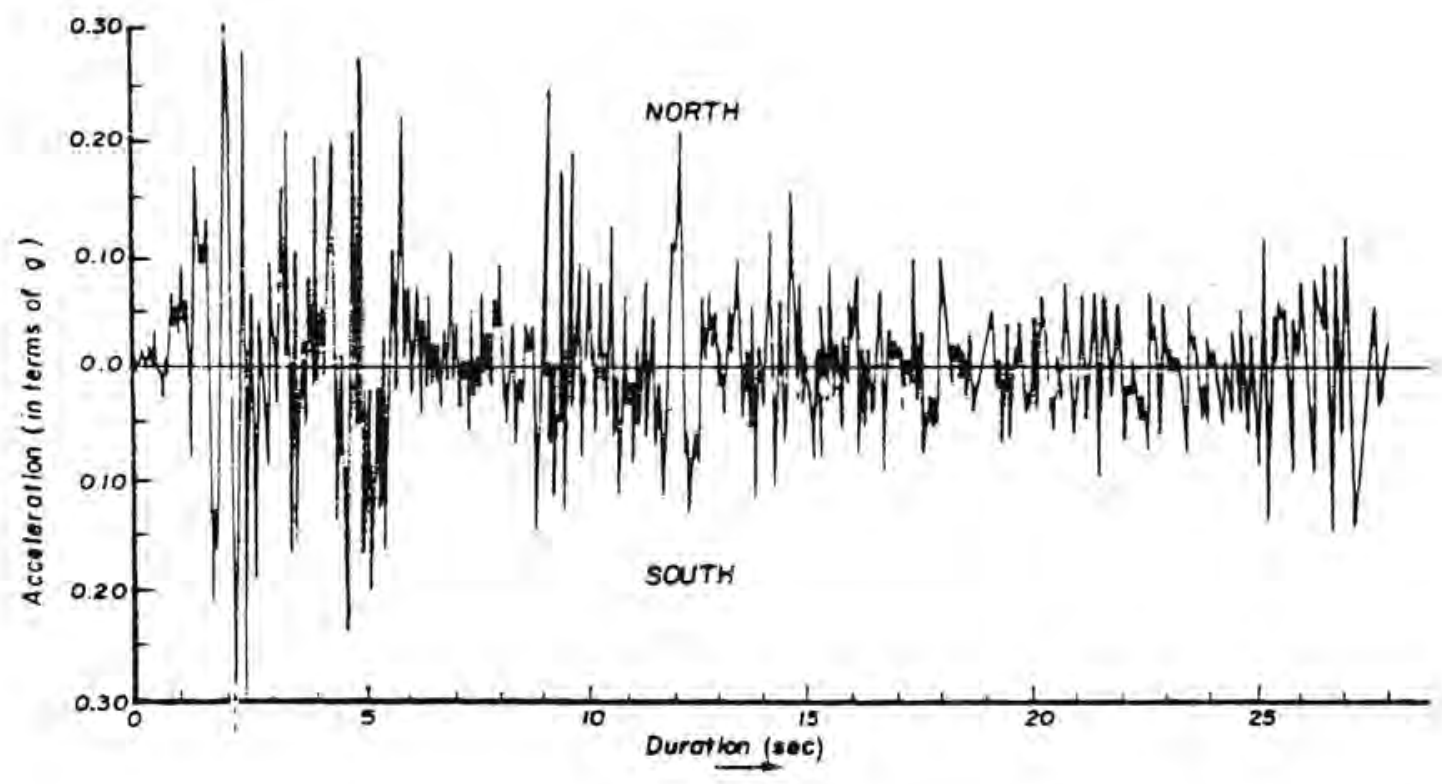

FIGURE 51. Accelerograph Record of El Centro, California, Earthquake, May 18, 1940 (1).

For this earthquake, the maximum ground acceleration was $0.33 \mathrm{~g}$, the largest acceleration recorded in the United States to date. This acceleration is generally considered the upper bound, hence, was used in the equations of Housner in analyzing the seismic effects on a 1iquidcontaining above ground cylindrical tank. 
The seismic-coefficient method used for inground storage tanks is similar to the method recommended in the UBC, except the earth pressure on the structure during an earthquake is also considered. The value of the design seismic coefficient, $K_{H}$, is given by the following formula (2):

$$
K_{H}=\alpha_{1} \cdot \alpha_{2} \cdot \alpha_{3} \cdot K_{0}
$$

where,

$$
\begin{aligned}
K_{H}= & \text { horizontal design seismic coefficient of soil beneath } \\
& \text { the ground surface } \\
K_{0}= & \text { standard horizontal seismic coefficient, } K_{0}=0.15 \\
\alpha_{1}= & \text { seismic zone factor } \\
\alpha_{2}= & \text { soil condition factor } \\
\alpha_{3}= & 1.0-\frac{Z}{H}\left(1.0-\frac{1}{\alpha_{2}}\right), \text { depth factor, where } Z \text { is the } \\
& \text { distance from the ground surface and } H \text { is the depth } \\
& \text { to base bed from ground surface }
\end{aligned}
$$

The seismic zone factor, $\alpha_{1}$, is determined from a seismic risk map as shown in Figure 52. The factors for Zones $A, B$ and $C$ are $1.0,0.85$ and 0.7 , respectively.

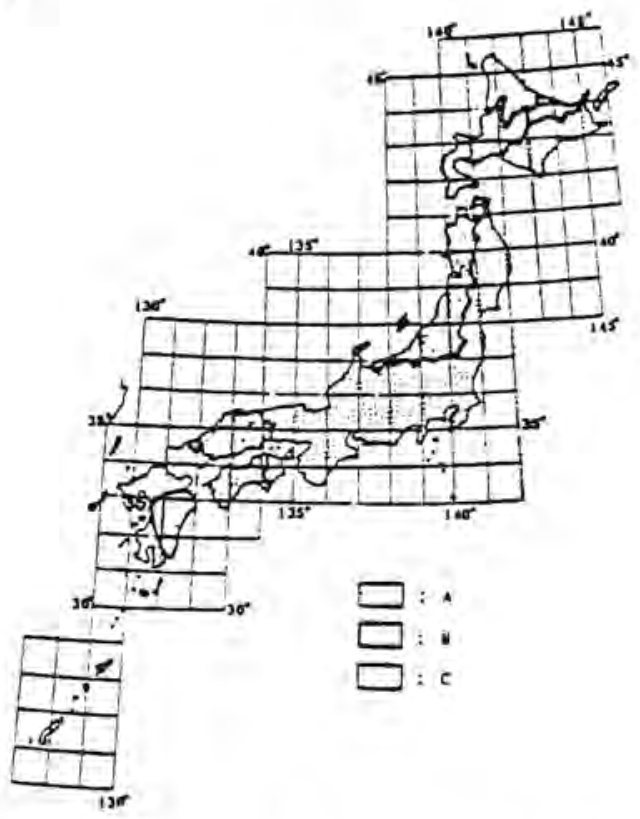

FIGURE 52. Seismic Zoning Map (2)

$$
\text { B. } 129
$$


The soil condition factor, $\alpha_{2}$, is determined according to the ground conditions above the base bed. These respective factors for each classification class are given below:

\begin{tabular}{|c|c|c|}
\hline Classification & Ground Condition & Soil Condition Factor \\
\hline Class 1 & $\begin{array}{l}\text { Diluviat layer with depth less } \\
\text { than } 10 \text { meters above base bed. }\end{array}$ & 1.4 \\
\hline \multirow[t]{2}{*}{ Class 2} & $\begin{array}{l}\text { Diluvial layer with depth greater } \\
\text { than } 10 \text { meters above base bed. }\end{array}$ & 1.6 \\
\hline & $\begin{array}{l}\text { Alluvial layer with depth less } \\
\text { than } 10 \text { meters above the dilu- } \\
\text { vial layer. }\end{array}$ & \\
\hline Class 3 & $\begin{array}{l}\text { Alluvial layer with depth less } \\
\text { than } 25 \text { meters, which has soft } \\
\text { layer with depth less than } 5 \\
\text { meters. }\end{array}$ & 1.8 \\
\hline Class 4 & Other than the above. & 2.0 \\
\hline
\end{tabular}

The earth pressure during an earthquake takes the form of an eccentric earth from both sides of the side wall, Figure 53. This earth pressure during an earthquake is given by (2):

$$
\Delta P_{E}=P_{E A}-P_{A}
$$

where,

$$
\begin{aligned}
& \Delta P_{E}=\text { earth pressure during earthquake } \\
& P_{E A}=\text { active earth pressure during earthquake } \\
& P_{A}=\text { active earth pressure at normal condition }
\end{aligned}
$$




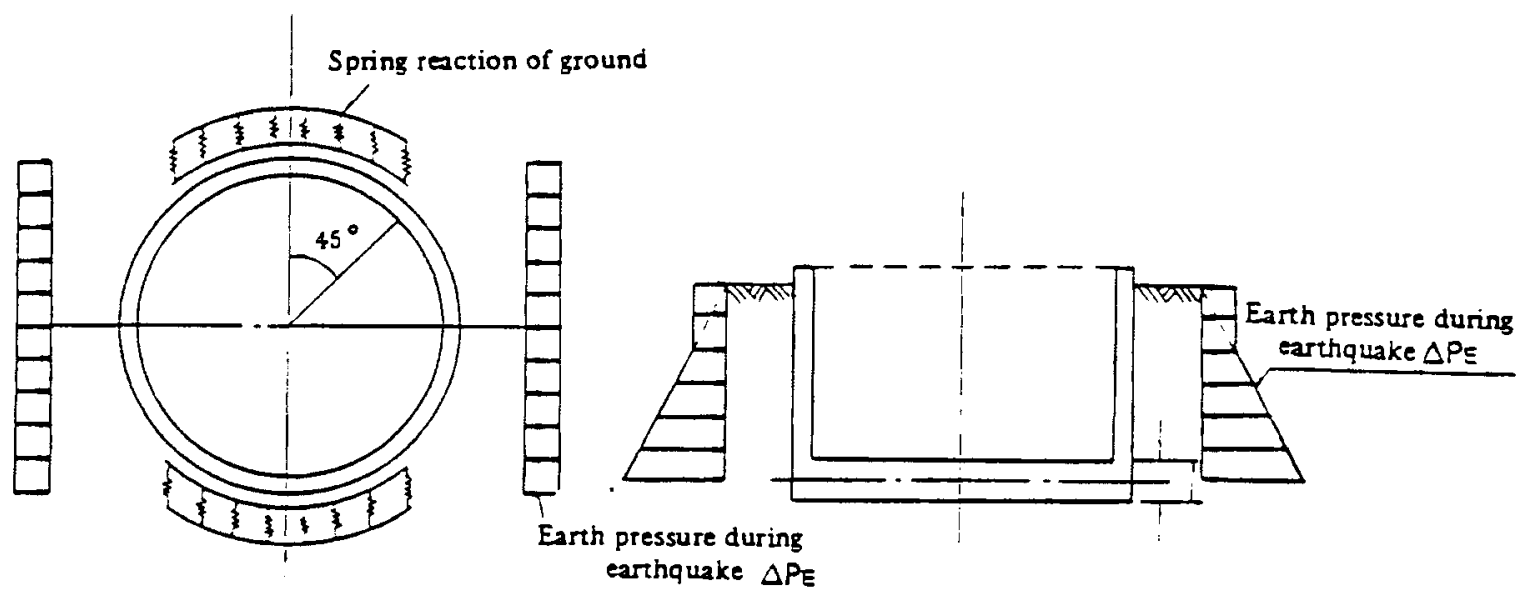

FIGURE 53. Loading Pattern of Earth Pressure During Earthquake (2)

The active earth pressure during an earthquake and normal condition for both sandy and cohesive soils may be calculated from the equations cited in Reference 2.

Time-dependent vibratory motions are set up in a shell whenever it is disturbed from a position of stable equilibrium. With regard to the roof of the LNG storage tank, the bending stress in the shell plate due to a horizontal seismic force is low due to its comparatively flat shape and light weight. The first seven (7) natural frequencies for an assumed clamped shell are shown in Table 12 and were obtained using the finite different energy code, BOSOR.

LNG tanks are designed to withstand earthquake accelerations appropriate for their locations. Each area of the country is divided into earthquake zones of similar frequency and severity of historically recorded earthquakes. For the most hazardous seismic zone, building codes incorporate requirements for lateral accelerations up to $0.1 \mathrm{~g}$, based on a full tank (5). The maximum ground acceleration of $0.33 \mathrm{~g}$ from the EI Centro, CA, earthquake was used in the analysis instead, since this represents the largest acceleration recorded in the United States. 
TABLE 12. Natural Frequencies (cps) - Clamped Spherical Shel1

\begin{tabular}{|c|c|c|c|c|c|c|c|}
\hline $\mathrm{n} / \mathrm{m}$ & 1 & 2 & 3 & 4 & 5 & 6 & 7 \\
\hline 0 & 4.70802 & 13.4904 & 14.1611 & 15.4232 & 17.8099 & 21.5083 & 26.4791 \\
\hline 1 & 6.23746 & 13.7470 & 14.6042 & 16.3180 & 17.3177 & 19.4939 & 23.8366 \\
\hline 2 & 12.3612 & 14.0572 & 15.3146 & 17.7023 & 21.4046 & 26.3799 & 32.4255 \\
\hline
\end{tabular}

岕

Where $n$ and $m$ are the circumferential wave number and natural frequency number, respectively. 
A total impulsive force of $15,547 \mathrm{~K}$ was induced on the above ground storage tank from this ground acceleration, resulting in a maximum bending moment of $524,723 \mathrm{~K}-\mathrm{ft}$. on a section just above the base and a maximum overturning moment of $892,380 \mathrm{~K}-\mathrm{ft}$. A maximum bending moment of $59,164 \mathrm{~K}-\mathrm{ft}$. on the tank wall and a maximum overturning moment of $66,060 \mathrm{k}-\mathrm{ft}$. resulted from a maximum convective force of $1006 \mathrm{~K}$ acting on the tank wall. This force causes the fluid to oscillate with a period of $6.32 \mathrm{sec}$. The LNG surface rose $3.45 \mathrm{ft}$. above its undisturbed level from this excitation. The total bending moment on the tank is $583,887 \mathrm{k}-\mathrm{ft}$., the total overturning moment is $958,440 \mathrm{k}-\mathrm{ft}$., and the maximum horizontal shear at the base is $16,554 \mathrm{~K}$. This shear translates to a seismic coefficient of $0.26 \mathrm{~g}$ due to the total effect of the weight of the tank and LNG liquid.

Generally, tanks need not be anchored when the required resistance to overturning can be provided by the tank shell and internal contents. The total weight of the tank and contents, $63,931 \mathrm{~K}$, is easily able to withstand the maximum overturning moment of $958,440 \mathrm{~K}-\mathrm{ft}$. In addition a $60 \%$ margin of safety is provided.

A more conservative estimate of the effect of the maximum overturning moment on the tank would be to disallow the vertical liquid load. It is assumed that the prestressing wires develop full tension load before any liquid can develop any effective downward ballast. The vertical prestressing in the tank's wall would adequately provide resistance to the maximum overturning moment.

ACI 318-77 (7) does not deal directly with the shear strength provided by the concrete for circular prestressed members. Considering the tank as a wall section and ignoring the effects of prestressing, it was determined that the No. 3 stirrups, spaced at $18 \mathrm{in.}$, provided a safety factor of 7.5 against the total maximum horizontal shear of $16,554 \mathrm{k}$. 
Due to the many variables in the seismic-coefficient method for inground storage tanks, it is difficult to equate the equations to current United States methodology. It may be concluded, however, that inground tanks have less adverse effects from seismic loads due to the buffer effect of the surrounding soil, Figure 53. For long durations of ground excitation voids would start to develop between the tank and surrounding soil, and the condition for the above ground tank would be approached. Additional research is needed in this area.

A knowledge of the free-vibration characteristics of thin elastic shells is important both to our general understanding of the fundamentals of the behavior of a shell and to the industrial application of shell structures. Due to its comparatively flat shape and light weight, the roof of the LNG storage tank poses little problem from a horizontal seismic force. Table 12 shows the first seven (7) natural frequencies for the she11, assumed clamped, under free vibration. The natural period of vibration of $0.21 \mathrm{sec}$. is within the range of 0.10 to 0.25 seconds, typical natural periods of vibration for storage tanks (6).

It may be concluded that the basic design configuration for both the above and below ground prestressed concrete LNG storage tank would be able to withstand a maximum ground acceleration of $0.33 \mathrm{~g}$. 


\section{REFERENCES}

1. Lockheed Aircraft Corporation and Holmes and Narver, Inc., Nuclear Reactors and Earthquakes, Chapter 6 and Appendix F, ERDA TID 7024, pp. 183-195 and 367-390, August 1963.

2. Recommended Practice for LNG Inground Storage, Japan Gas Association, Committee on LNG Inground Storage, March 1979.

3. Uniform Building Code, International Conference of Building Officials, Copyright 1976, pp. 132-150.

4. Standard for the Production, Storage and Handling of Liquefied Natural Gas (LNG), NFPA 59A, 1979.

5. Allan, D., et al., "Technology and Current Practices for Processing, Transferring and Storing Liquefied Natural Gas", PB-241048, Arthur D. Little, Inc., Cambridge, MA, December 1974.

6. Wozniak, R.S. and Mitchel1, W.W., "Basis of Seismic Design Provisions for Welded Steel 0il Storage Tanks".

7. Building Code Requirements for Reinforced Concrete, (ACI 318-77), American Concrete Institute, Detroit, MI. 


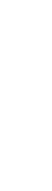


No. of

Copies

10 J. M. Cece (EP-323)

Office of Environmental Protection, Safety and

Emergency Preparedness

U.S. Department of Energy

Wash ington, D.C. 20545

10 H. F. Walter (EP-35)

Office Of Environmental

Protection, Safety and

Emergency Preparedness

U.S. Department of Energy

Washington, D.C. 20545

12 DOE Technical Information Center

P. J. Anderson

Institute of Gas Technology

3424 South State Street

Chicago, IL 60616

S. Ata 11 ah

Gas Research Institute

8600 West Bryn Mawr Avenue

Chicago, IL 60631

L. E. Be 11

Western LNG Terminal Associates

700 South Flower Street

Suite 3300

Los Angeles, CA 90017

C. P. Buck ley

Boston Gas Company

One Beacon Street

Boston, MA 02108

A. M. Clarke

Algonqu in Gas Transmission Company

1284 Soldiers Field Road

Boston, MA 02135
No. of

Copies

W. E. Coe, Jr.

Southern Energy Company

P.0. Box 1367

Savannah, GA 31402

R. I. Cole

American Gas Association

1515 Wi lson Boulevard

Arlington, VA 22209

R. Danielson

Bay State Gas Company

120 Royal1 Street

Canton, MA 02021

W. Dennis

Office of Pipeline Safety Regulations

4007 th Street, S.W.

Wash ington, D.C. 20590

E. Drake

Arthur D. Little, Inc.

Acorn Park

Cambridge, MA 02140

J. P. Frazier

Natural Gas Pipeline Company of America

122 South Michigan Avenue

Chicago, IL 60603

S. Fujinami

Tankage Designing Section

Kawasaki Heavy Industries, LTD

118, Futatsuzuka, Noda-shi,

Chiba 278, JAPAN

W. Geiger

Battelle-Inst itute e.V.

Am Roemerhof 35

6000 Frankfurt am Ma in 90

FEDERAL REPUBLIC OF GERMANY 
No. of

Copies

R. C. Reid

Department of Chemical

Engineering

Massachusetts Institute

of Technology

Cambridge, MA 02139

M. I. Rudnicki

Aerojet Energy Conversion Company

P.0. Box 13222

Sacramento, CA 95813

H. P. Schorr

Brook lyn Un ion Gas Company

195 Montague Street

Brook lyn, NY 11201

J. D. Shefford

British Gas Corporation

59 Bryanston Street

Marble Arch

London W1A2AZ, ENGLAND

J. K. Speckha 1s

Columbia LNG Corporation

20 Montchan in Road

Wilmington, DE 19807

H. Stevens

Northwet Pipeline Corporation

P.0. Box 30

Umati11a, OR 97882

R. Tatge

CV Internationa 1, Incorporated 2741 Toledo Street, Suite 208

Torrance, CA 90503

J. R. Welker

Applied Technology Corporation

P.0. Box FF

Norman, OK 73070
No. of

Copies

S. J. Wiersma

Gas Research Institute

8600 West Bryn Mawr Avenue

Chicago, IL 60631

W. W. Wilson

San Diego Gas and Electric Company

P.0. Box 1831

San Diego, CA 92112

ONSITE

DOE Rich land Operations

H. E. Ransom

26 Pac ific Northwest Laboratory

W. J. Bair

H. J. Bomelburg

C. A. Counts

W. E. Dav is

J. G. DeSteese (10)

B. A. Fecht

T. E. Gates

G. D. Morr

K. 0. Nelson

P. J. Pelto

R. E. Rhoads

L. D. Williams

Technical Information (4)

Publishing Coordination 
Technical Report Documentation Page

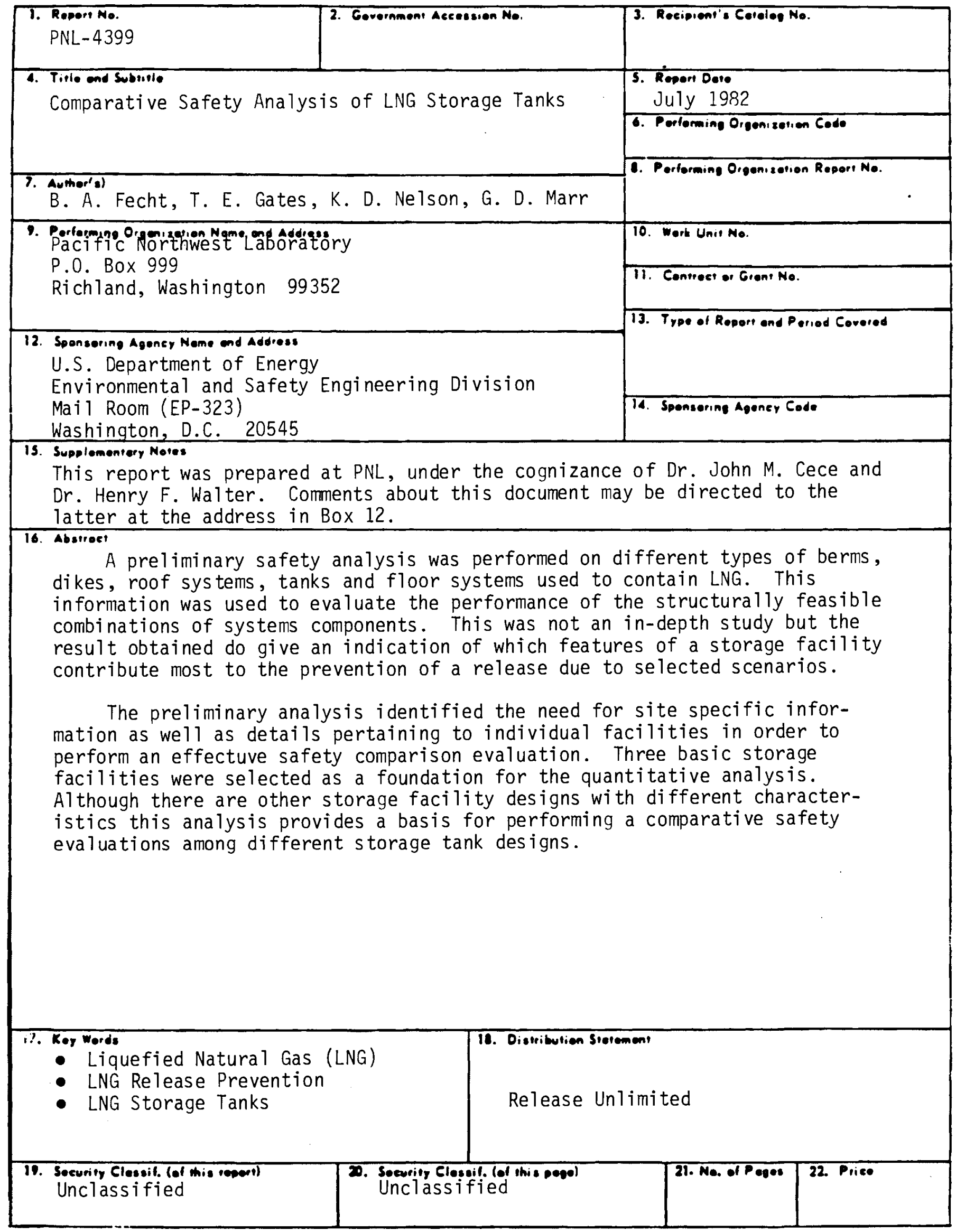




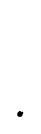

